Compaction of Ceramic Microspheres, Spherical Molybdenum Powder and Other Materials to $3 \mathrm{GPa}$

S. R. Carlson, B. P. Bonner, F. J. Ryerson, M. M. Hart

March 6, 2006 
This document was prepared as an account of work sponsored by an agency of the United States Government. Neither the United States Government nor the University of California nor any of their employees, makes any warranty, express or implied, or assumes any legal liability or responsibility for the accuracy, completeness, or usefulness of any information, apparatus, product, or process disclosed, or represents that its use would not infringe privately owned rights. Reference herein to any specific commercial product, process, or service by trade name, trademark, manufacturer, or otherwise, does not necessarily constitute or imply its endorsement, recommendation, or favoring by the United States Government or the University of California. The views and opinions of authors expressed herein do not necessarily state or reflect those of the United States Government or the University of California, and shall not be used for advertising or product endorsement purposes.

This work was performed under the auspices of the U.S. Department of Energy by University of California, Lawrence Livermore National Laboratory under Contract W-7405-Eng-48. 


\section{List of Figures}

Fig. 1. Grain densities of test materials

Fig. 2. SEM photographs of untested aluminum powder

Fig. 3. SEM photographs of untested glassy carbon spheres

Fig. 4. SEM photographs of untested ceramic microspheres

Fig. 5. SEM photographs of untested copper powder

Fig. 6. SEM photographs of untested molybdenum powder

Fig. 7. SEM photograph of untested Ottawa sand

Fig. 8. SEM photographs of untested silicon carbide powder

Fig. 9. SEM photographs of untested titanium powder

Fig. 10. Jacketed specimen prepared for hydrostatic testing

Fig. 11. Original foam cylinder with core removed

Fig. 12. Two views of the foam specimen prior to jacketing

Fig. 13. Pressure-displacement curves for Isopar $\mathrm{H}$

Fig. 14. Friction correction for the liquid medium press

Fig. 15. Pressure vs. displacement for Nickel Standard \#1

Fig. 16. Friction correction for solid medium press

Fig. 17. Kawakita model fits for ceramic microspheres and molybdenum powder

Fig. 18. Aluminum \#3 after hydrostatic compression to $0.9 \mathrm{GPa}$

Fig. 19. Carbon \#3 after hydrostatic compression to $0.9 \mathrm{GPa}$

Fig. 20. Ceramic \#3 after hydrostatic compression to $0.9 \mathrm{GPa}$

Fig. 21. Copper \#3 after hydrostatic compression to $0.9 \mathrm{GPa}$

Fig. 22. Foam specimen after hydrostatic compression 
Fig. 23. Molybdenum \#3 after hydrostatic compression to $0.9 \mathrm{GPa}$

Fig. 24. Ottawa Sand \#2 after hydrostatic compression to $0.9 \mathrm{GPa}$

Fig. 25. Silicon Carbide \#5 after hydrostatic compression to $0.9 \mathrm{GPa}$

Fig. 26. Titanium \#3 after hydrostatic compression to $0.9 \mathrm{GPa}$

Fig. 27. Grain densities and initial and final bulk densities for the test materials

Fig. 28. Initial and final porosities for the test materials

Fig. 29. Hydrostatic pressure versus specific volume for aluminum powder to $1 \mathrm{GPa}$

Fig. 30. Hydrostatic pressure versus specific volume for glassy carbon spheres to $1 \mathrm{GPa}$

Fig. 31. Hydrostatic pressure versus specific volume for ceramic microspheres to $1 \mathrm{GPa}$

Fig. 32. Hydrostatic pressure versus specific volume for copper powder to $1 \mathrm{GPa}$

Fig. 33. Hydrostatic pressure versus specific volume for epoxy foam to $30 \mathrm{MPa}$

Fig. 34. Hydrostatic pressure versus specific volume for molybdenum powder to $1 \mathrm{GPa}$

Fig. 35. Hydrostatic pressure versus specific volume for Ottawa sand to $1 \mathrm{GPa}$

Fig. 36. Hydrostatic pressure versus specific volume for silicon carbide powder to $1 \mathrm{GPa}$

Fig. 37. Hydrostatic pressure versus specific volume for titanium powder to $1 \mathrm{GPa}$

Fig. 38. Bulk modulus for glassy carbon spheres

Fig. 39. Bulk modulus for ceramic microspheres

Fig. 40. Bulk modulus for molybdenum powder

Fig. 41. Bulk modulus for silicon carbide powder

Fig. 42. Bulk modulus for titanium powder

Fig. 43. Energy expended per unit volume in hydrostatic compression to $1 \mathrm{GPa}$

Fig. 44. Energy expended per gram of material in hydrostatic compression to $1 \mathrm{GPa}$

Fig. 45. Energy expended per unit volume versus yield strength for metallic powders 
Fig. 46. Energy expended per unit volume and relative porosity change to $1 \mathrm{GPa}$

Fig. 47. Energy expended per gram and relative porosity to $1 \mathrm{GPa}$

Fig. 48. Crushing strength of hollow ceramic microspheres

Fig. 49. Pressure vs. specific volume for ceramic microspheres to $3 \mathrm{GPa}$

Fig. 50. Pressure vs. specific volume for molybdenum specimen \#6 to $3 \mathrm{GPa}$

Fig. 51. Pressure vs. specific volume for molybdenum specimen \#7 to $3 \mathrm{GPa}$

Fig. 52. Pressure vs. relative volume for ceramic microspheres and molybdenum powder

Fig. 53. Bulk modulus versus pressure for ceramic microspheres

Fig. 54. Bulk modulus versus pressure for molybdenum powder

Fig. 55. Bulk modulus versus relative density for ceramic microspheres

Fig. 56. Bulk modulus versus relative density for molybdenum powder

Fig. 57. Porosity versus pressure for aluminum powder

Fig. 58. Porosity versus pressure for glassy carbon spheres

Fig. 59. Porosity versus pressure for ceramic microspheres

Fig. 60. Porosity versus pressure for copper powder

Fig. 61. Porosity versus pressure for molybdenum powder

Fig. 62. Porosity versus pressure for Ottawa sand

Fig. 63. Porosity versus pressure for silicon carbide powder

Fig. 64. Porosity versus pressure for titanium powder

Fig. 65. Pressure-volume curve from the exponential curve fit for aluminum powder

Fig. 66. Pressure-volume curve from the exponential curve fit for glassy carbon spheres

Fig. 67. Pressure-volume curve from the exponential curve fit for ceramic microspheres

Fig. 68. Pressure-volume curve from the exponential curve fit for copper powder 
Fig. 69. Pressure-volume curve from the exponential curve fit for molybdenum powder

Fig. 70. Pressure-volume curve from the exponential curve fit for Ottawa sand

Fig. 71. Pressure-volume curve from the exponential curve fit for silicon carbide powder

Fig. 72. Pressure-volume curve from the exponential curve fit for titanium powder

Fig. 73. Merge pressures predicted by the exponential model fit for each material

Fig. 74. Total energy expended per gram of material predicted by the exponential model

Fig. 75. Exponential model pressure-volume curve and molybdenum $\# 7$ data

Fig. 76. Numerical curve fit through molybdenum \#7 porosity data

Fig. 77. Second order model pressure-volume curve and molybdenum \#7 data

Fig. 78. Numerical curve fit through ceramic AlSP\#1 porosity data

Fig. 79. Second order model pressure-volume curve and ceramic AlSP\#1 data

Fig. 80. Numerical curve fit through selected aluminum powder porosity data

Fig. 81. Second order model pressure-volume curve and aluminum powder data

Fig. 82. Heckel plot for ceramic microsphere specimen AlSP \#1.

Fig. 83. Heckel plot for molybdenum specimen \#6.

Fig. 84. Heckel plot for molybdenum specimen \#7.

Fig. 85. Heckel plot for aluminum specimen $\# 2$.

Fig. 86. Heckel plot for glassy carbon spheres.

Fig. 87. Heckel plot for silicon carbide powder.

Fig. 88. Heckel plot for titanium powder. 


\section{List of Tables}

Table 1. Starting materials

Table 2. Starting material grain densities

Table 3. Initial mass, volume, bulk density and porosity for hydrostatic test specimens

Table 4. Initial mass, volume, bulk density and porosity for solid medium specimens

Table 5. Data reduction table for solid medium tests

Table 6. Energy expended in compaction

Table 7. Exponential model parameters

Table 8. Model estimates of merge pressure and total expended energy

Table A1. Mass of solid medium specimen assembly components

Table A2. Curve-fitting parameters for the liquid medium press friction correction

Table A3. Curve-fitting parameters for the solid medium press friction correction

Table A4. Kawakita regression fit coefficients and model parameters

Table A5. Aluminum powder results

Table A6. Glassy carbon results

Table A7. Ceramic microsphere results

Table A8. Copper powder results

Table A9. Foam results

Table A10. Molybdenum powder results

Table A11. Ottawa Sand results

Table A12. Silicon Carbide powder results

Table A13. Titanium powder results 


\title{
Compaction of Ceramic Microspheres, Spherical Molybdenum Powder and Other Materials to 3 GPa
}

\author{
Steven R. Carlson, Brian P. Bonner, Fredrick J. Ryerson and Mark M. Hart \\ Lawrence Livermore National Laboratory \\ Livermore, California 94551
}

\begin{abstract}
Pressure-volume relationships were measured at room temperature for eight granular materials and one specimen of epoxy foam. The granular materials included hollow ceramic microspheres, spherical molybdenum powder, Ottawa sand, aluminum, copper, titanium and silicon carbide powders and glassy carbon spheres. Measurements were made to $0.9 \mathrm{GPa}$ in a liquid medium press for all of the granular materials and to $3 \mathrm{GPa}$ in a solid medium press for the ceramic microspheres and molybdenum powder. A single specimen of epoxy foam was compressed to $30 \mathrm{MPa}$ in the liquid medium press. Bulk moduli were calculated as a function of pressure for the ceramic microspheres, the molybdenum powder and three other granular materials. The energy expended in compacting the granular materials was determined by numerically integrating pressurevolume curves. More energy was expended per unit volume in compacting the molybdenum powder to $1 \mathrm{GPa}$ than for the other materials, but compaction of the ceramic microspheres required more energy per gram due to their very low initial density. The merge pressure, the pressure at which all porosity is removed, was estimated for each material by plotting porosity against pressure on a semi-log plot. The pressure-volume curves were then extrapolated to the predicted merge pressures and numerically integrated to estimate the energy required to reach full density for each material. The results suggest that the glassy carbon spheres and the ceramic microspheres would require more energy than the other materials to attain full density.
\end{abstract}

\section{Introduction}

This report describes quasi-static, pressure-volume measurements on eight granular materials, including both metallic and non-metallic powders, and one epoxy foam specimen. All of the granular materials were compressed to $0.9 \mathrm{GPa}$ in a hydrostatic, liquid medium press. Spherical molybdenum powder and ceramic microspheres, being of special interest, were also compressed to $3 \mathrm{GPa}$ in a solid medium press. Most of the experimental techniques and data reduction procedures in this study were pioneered by Bridgman (1964) and were employed in earlier work at LLNL on fractured earth materials (Stephens and Lilley, 1966), alluvium (Heard and Stephens, 1970) and powders (Weed, 1984). In addition, we have used a sensitive helium pycnometer to measure recovered specimen volumes in a series of cycles to progressively higher pressures. An empirical relationship from the materials science literature due to Kawakita and Ludde (1970) was used to fit smooth curves to the pressure-volume data from the pycnometer measurements. The 1-GPa hydrostatic results are discussed in section 3.1, and the 3-GPa solid medium results are discussed in section 3.2. Materials that retain significant 
porosity at $3 \mathrm{GPa}$ may absorb considerably more energy at higher pressures. We used an empirical approach to estimate the energy required to compact each granular material to its merge pressure, as discussed in section 3.3. A second relationship from the materials science literature due to Heckel (1961a,b) provides a basis for a discussion of some of the powder compaction results in section 3.4.

\section{Methods}

\subsection{Material Descriptions}

The materials selected for study consist of four spherical metal powders: aluminum, copper, molybdenum and titanium, four non-metallic granular materials: natural quartz sand, hollow ceramic microspheres, glassy carbon spheres, angular silicon carbide powder and one epoxy foam. Most of the powders were purchased from commercial sources (Table 1). The ceramic microspheres, and some of the other powders, were probably created by the spray-dry process. A description of the spray-dry fabrication process is given in Lukasiewicz (1989) and observations of the internal structure of spray-dried powders are presented in Uematsu et al. (1990). Particle sizes range from 1014 microns for the aluminum powder to 200-400 microns for the glassy carbon spheres. Powder densities range from $0.68 \mathrm{~g} / \mathrm{cm}^{3}$ for intact hollow ceramic microspheres to 10.22 $\mathrm{g} / \mathrm{cm}^{3}$ for molybdenum (Table 2). Powder densities were supplied by the manufacturers for most materials, and were also calculated by weighing out small quantities of loose powders and measuring their volumes in a helium pycnometer. The measured densities agree closely with the manufacturer's values for most materials, but slightly underestimate the manufacturer's values for glassy carbon, molybdenum and copper (Figure 1). Small pockets of air trapped in the pore space between particles may have led to measured volumes that are slightly too large for these materials.

The granular materials were examined with a scanning electron microscope (SEM) as part of the pre-test characterization. SEM photographs of each material at magnifications between 40x and 1000x are given in Figures 2-9. Aluminum powder was the finest-sized material studied, with many particles below $10 \mu \mathrm{m}$ in diameter (Figure 2). The aluminum powder is less uniform in size than the other metal powders, and many of the smaller aluminum particles adhere to larger particles or form agglomerates. The aluminum particles are well-rounded, but a fraction are oblong rather than spherical in shape. The glassy carbon spheres (Figure 3) and Ottawa sand were the coarsest materials studied. The glassy carbon spheres are highly spherical and, although a few small spheres can be seen, relatively uniform in size. The ceramic microspheres (Figure 4) are also highly spherical and relatively uniform in size. They were imaged in both their original condition and after being manually crushed between two platens. The microsphere walls vary somewhat in thickness, but most appear to be 2-5 microns thick. Small pores exist within the microsphere walls, as can be seen in the lower image. Many of the copper particles are spherical, but others are irregular in shape (Figure 5). Surface features of one of the spherical copper grains are captured in Figure 5b. The molybdenum powder particles are well-rounded, though somewhat variable in shape, with highly porous walls composed of many small fragments (Figure 6). The rough surface texture of the 
molybdenum particles contrasts strongly with the smooth surface features of the copper particles. Ottawa sand, a natural material, is more variable in size and shape than most of the powders (Figure 7). Although the sand grains are not very spherical, the edges are often rounded. The silicon carbide particles are highly angular (Figure 8 ) in contrast to most of the other materials. The silicon carbide particles resemble Ottawa sand, but are smaller and more uniform in size and the particle edges are sharper. The titanium particles are mostly highly spherical and range between 20 and $100 \mu \mathrm{m}$ in size (Figure 9). The particle surfaces are smooth, similar to copper.

\subsection{Specimen Preparation}

\subsubsection{Hydrostatic Test Specimens}

Twenty-nine specimens, each approximately $36 \mathrm{~cm}^{3}$ in volume, were prepared for hydrostatic testing. The mass, initial volume, bulk density and porosity of each sample are given in Table 3 . Bulk density was calculated by dividing mass by volume, and porosity was found as one minus the ratio of the bulk and grain densities. The manufacturer's values of grain density were used, where available, in calculating porosity. A grain density of $2.606 \mathrm{~g} / \mathrm{cm}^{3}$, obtained from measurements on crushed ceramic particles, was used to compute porosity for the ceramic microspheres. Despite molybdenum's high grain density of $10.22 \mathrm{~g} / \mathrm{cm}^{3}$, the molybdenum specimens have bulk densities of only $3.6 \mathrm{~g} / \mathrm{cm}^{3}$, so that the calculated initial porosities are high, about $65 \%$. Only the hollow ceramic microspheres and the epoxy foam have higher initial porosities. The high molybdenum powder porosity is due in part to the highly porous structure of the individual molybdenum spheres, as seen in Figure 6.

The powder specimens were prepared inside cylindrical indium jackets. Indium was chosen as the jacketing material because its low strength allows the jackets to accommodate very large deformations without leaking and with minimal intrusion into the specimen. Preliminary tests were made with copper jackets of various designs, but leaks were consistently encountered, as the copper was unable to accommodate the large strains. The specimen jackets were fabricated from solid indium. Each indium jacket consisted of a thin-walled tube sealed at each end with a cup-shaped end cap. The inner diameter of the indium tubes was $25.4 \mathrm{~mm}$. The jackets were approximately $90 \mathrm{~mm}$ long, about $2 \mathrm{~mm}$ thick, and were typically fabricated from about $57 \mathrm{~g}$ of indium. The relatively thick jacket walls were found to be useful in preventing leaks. The end caps were $25 \mathrm{~mm}$ in diameter and about $15 \mathrm{~mm}$ in length. Each was fabricated from about $8 \mathrm{~g}$ of indium. The lower end cap was inserted into the tubing with the concave side facing outward and was soldered in place.

The indium jacket was then weighed on a Sartorius model 1773 mass balance and placed inside a brass support ring to protect the soft jacket walls from indentation. The powder specimens were filled in stages. Approximately $7 \mathrm{ml}$ of powder was poured into the container in each stage, and the container was then vibrated at low intensity for five to six minutes on a Fritsch Analysette 3 sieve shaker. The process was repeated four or five times, as required, to fill the container. The brass support ring was removed, and the full 
specimen was weighed. The container weight, which was typically about $65 \mathrm{~g}$, was subtracted to yield the powder mass. The second end cap was then inserted into the tube and soldered in place to seal the jacket. The sealed specimen was weighed and then placed in the helium pycnometer to determine the initial specimen volume and to check for possible air leaks. If no leaks were found, the specimen was ready for hydrostatic testing. A fully prepared specimen is shown in Figure 10.

The single foam specimen was prepared by carefully coring a one-inch diameter cylinder from a roughly cylindrical foam sample (Figure 11). The finished core was slightly larger than the typical powder specimen, but weighed less than six grams. Photographs of the foam core show its highly porous structure, and two particularly large voids can be seen in the upper image (Figure 12). The initial porosity of the foam specimen was calculated to be $88.5 \%$. The foam specimen was encased in an indium jacket similar to those used for the powder specimens.

\subsubsection{Solid Medium Test Specimens}

The solid medium specimens were prepared in cylindrical tin canisters, $12.7 \mathrm{~mm}$ in outer diameter and $30.5 \mathrm{~mm}$ in length. The canister walls were $0.5 \mathrm{~mm}$ thick and the base was $1.3 \mathrm{~mm}$ thick. The canisters were filled with powder in five stages with a vibration interval after each partial fill, similar to the larger liquid medium specimens. Seven molybdenum specimens and one ceramic microsphere specimen were prepared and tested. A thin disk of indium was placed on top of the powder in four molybdenum specimens and in the ceramic microsphere specimen. The soft indium disks allow the loading stress to be applied more uniformly to the powder. A thin tin disk served as the canister lid. The lids were not soldered into place, and some air may vent from the specimens at low pressure before the tin flows sufficiently to form a seal. Two cylinders of high-purity nickel were jacketed in tin canisters in the same manner as the powder specimens to serve as reference standards. The various components were weighed on a sensitive mass balance. The weights are given in Table A1 in the appendix.

Specimen dimensions were measured with a micrometer. The initial powder volumes were calculated from the interior dimensions of the tin canisters after subtracting the thickness $(1.6 \mathrm{~mm})$ of the indium disks. Bulk densities were calculated by dividing powder mass by volume, and porosities were calculated using a grain density of 10.22 $\mathrm{g} / \mathrm{cm}^{3}$ for molybdenum and $2.606 \mathrm{~g} / \mathrm{cm}^{3}$ for the ceramic microspheres (Table 4). The resulting porosities are in very good agreement with the initial porosities calculated for the corresponding liquid medium specimens.

\subsection{Experimental Procedures}

\subsubsection{Hydrostatic Tests}

All of the hydrostatic pressure tests were made in the gray 400-ton press located in Room 1005 of Building 243. The essential elements of the press are a steel reaction frame, a compound die, a piston and a hydraulic ram. The die consists of three concentric 
cylinders of hardened AISI S5 tool steel. The die is $392 \mathrm{~mm}$ (15 in) in length with an outer diameter of $406 \mathrm{~mm}$ ( $16 \mathrm{in})$ and an inner diameter of $38 \mathrm{~mm}$ (1.5 in). The piston assembly consists of an AISI S5 tool steel piston, a mushroom plug, two adaprene washers and two aluminum-bronze sealing rings. The die sits atop a 400 -ton hydraulic ram. Pressure is generated as the hydraulic ram lifts the die against the reaction frame forcing the piston inward.

The specimen container was enclosed in a thin nitrile glove to provide a secondary barrier in the event of a jacket leak. The specimen and a $127 \mathrm{~mm}$ long fused silica rod were then placed in a rubber capsule and lowered into the die. The fused silica rod was used to displace a portion of the fluid volume $(64 \mathrm{ml})$. The confining fluid was a mixture of $99 \%$ Dow Corning Isopar H fluid, which is similar in composition to kerosene, and 1\% DTE24 oil. The small amount of DTE oil provides lubrication for the seals.

The hydraulic ram pressure was read with a Teledyne Tabor model 5427 pressure transducer. An HP model 6235A power supply provided 28 volts DC excitation to the pressure transducer. The piston displacement was read with two Schaevitz model DCEC-2000 linear variable displacement transducers (LVDTs). A \pm 15 volt DC excitation voltage was supplied to the LVDTs by a Schaevitz PSD-4-15-001 power supply. The LVDTs produce a linear $\pm 10 \mathrm{~V}$ DC output signal over a range of $100 \mathrm{~mm}$. The input and output voltages were read by an Agilent model 34970A digital multimeter and an Agilent 34901A 20 channel multiplexer. The voltages were transferred via GPIB to a National Instruments PCI-GPIB card in a PowerMac G4.

The data acquisition program was written with National Instruments LabVIEW 6.0 software. The program reads and displays the input and output voltages at a sampling rate of $1 \mathrm{~Hz}$ and writes the data on the computer hard drive as an ascii text file. Data are recorded over both the loading and unloading portions of the pressure cycle. The data acquisition program also converts the LVDT output voltages to inches of displacement and converts the pressure transducer voltages to ram pressure in psig. The reduction in surface area from the ram to the piston is used to calculate internal pressure in the die. Volume changes are calculated from piston displacements. The small radial expansion of the die with pressure is neglected by the data acquisition software. Tare runs were performed in which all of the items except the test specimen were placed in the vessel.

The powders were compressed to a nominal pressure of $1 \mathrm{GPa}$ over several cycles. After each cycle, the specimen was removed from the pressure vessel. Most of the volume change is not recovered with the release of pressure, and this non-recoverable portion was measured after each pressure cycle with a Quantachrome pycnometer. The pycnometer works by precisely measuring the pressure change that occurs when a known volume of gas is transferred at constant temperature from a reference chamber to a sample chamber containing the test specimen. The volume of the test specimen is then calculated according to Archimedes's principle. The reference pressure was typically 17 psig. Helium gas was used for all volume measurements. 
The powder volumes were calculated by subtracting the volume of the specimen jacket, which is assumed constant, from the measured specimen volumes. The jacket volume was calculated from the jacket mass divided by the density of indium. Bulk densities were calculated for each nominal peak pressure by dividing powder mass by volume. Porosities were calculated assuming that all volume change is due to porosity reduction. The powder volume after each pressure cycle was normalized by the initial powder volume. Specific volume is the inverse of bulk density. Mu is calculated as the ratio of the powder density after a pressure cycle to its initial density minus one.

\subsubsection{Solid Medium Tests}

All of the solid medium compression tests were made in the red 400-ton press located in Room 1005 of Building 243. The press consists of a steel reaction frame, a compound die, a tungsten carbide piston and anvil and two hydraulic rams. The larger, 400-ton hydraulic ram lifts the die and smaller Enerpac ram against the reaction frame to provide a clamping load. The Enerpac ram then drives the piston upward through the die bore to compress the specimen against the anvil. Loading is controlled with a PC-PCS Pressure Control System supplied by Rockland Research Corporation. The pressure control system provides a well-controlled, uniform loading rate.

The hydraulic ram pressure was read with a Sensotec model THE/4256-03 pressure transducer. The pressure transducer provides a 5.0-volt output signal over a 10,000-psig range. A Sola model SDP124-100 power supply provided 28 volts DC excitation to the pressure transducer. The piston displacement was read with two Schaevitz LVDTs, one attached to the ram (model DC-EC-1000) and the other to the frame (model DC-EC-250). A \pm 15 volt DC excitation voltage was supplied to the LVDTs by a Schaevitz PSD-4-15001 power supply. The LVDTs produce a linear $\pm 10 \mathrm{~V}$ DC output signal over a range of $50 \mathrm{~mm}$ and $12.7 \mathrm{~mm}$, respectively. The input and output voltages were read by an Agilent model 34970A digital multimeter and an Agilent 34901A 20-channel multiplexer. The voltages were transferred via GPIB to a National Instruments PCIGPIB card in a PowerMac G4.

The data acquisition program was written with National Instruments LabVIEW 6.0 software and is a modified version of the data acquisition program used with the liquid medium press. The program reads and displays the input and output voltages at a sampling rate of $1 \mathrm{~Hz}$ and writes the data as an ascii text file on the computer hard drive. Data are recorded over both the loading and unloading portions of the pressure cycle. The data acquisition program also converts the LVDT output voltages to inches of displacement and converts the pressure transducer voltages to ram pressure in psig. The reduction in surface area from the ram to the piston is used to calculate internal pressure in the die in kilobars. The small radial expansion of the die with pressure is neglected by the data acquisition program.

At the end of the test, the specimen was carefully pushed out of the die, and its dimensions were measured with a micrometer. The final dimensions provide a check on the data reduction calculations. 


\subsection{Data Reduction}

\subsubsection{Die Bore Expansion}

Pressure is measured in the hydraulic ram and calculated for the die as the ratio of the cross-sectional area of the ram to the die bore. Since the die bore expands diametrically with the rise in internal pressure, the calculated pressures will be slightly higher than the true pressures if no correction is made. We multiplied our calculated pressures by 0.9851 to correct for die bore expansion, based on tabulated correction terms given in Stephens and Lilley (1967).

\subsubsection{Friction Corrections}

A correction for friction is necessary because a portion of every change in ram pressure is required to overcome frictional forces as the piston moves through the die. We used a method for calculating friction corrections described in Bridgman (1964a) in which the friction correction is calculated from the mean value of the loading and unloading pressures at constant displacement. The friction correction for the liquid medium press was determined from compression tests on Isopar $\mathrm{H}$. The pressure-displacement data (Figure 13) show a hysteresis loop in which loading pressures (the blue line) exceed unloading pressures (the red line) at every displacement. The entire hysteresis loop is attributed to friction. Higher ram pressures are measured in the loading portion of the test because extra ram pressure is required to overcome friction as the piston is pushed into the die. Lower ram pressures are measured during unloading because extra fluid pressure in the die is required to overcome friction as the piston is pushed out of the die. The mean curve, shown in green, is the corrected pressure at each displacement, and the friction correction is simply the difference between the observed and mean pressures. A backlash effect occurs as unloading begins that, if ignored, would cause the calculated friction corrections to diminish unrealistically at high pressure (Bridgman, 1964a). The backlash effect is very minor for the liquid medium press, as the loading and unloading curves are nearly parallel at high pressure. Following Grens (1970), we assumed the friction correction to be constant at its maximum value at the highest pressures. The Isopar $\mathrm{H}$ data yield a maximum friction correction of $0.076 \mathrm{GPa}$ for the liquid medium press (Figure 14). A polynomial equation was fit to the friction correction curve for convenience in applying the friction correction to the test data. The curve-fitting parameters are given in Table A2 of the appendix.

Friction corrections for the solid medium press were made in essentially the same way, but the larger backlash effect in the solid medium press data was treated differently. Separate friction corrections were made for the nickel reference standard and the powder specimen tests, using pressure-displacement curves that close, or very nearly close, at zero pressure. Generally, the specimens and the nickel standards have to be taken to the maximum pressure of $3 \mathrm{GPa}$ on at least one previous run before suitable pressuredisplacement curves can be obtained. Data from one molybdenum powder run and two nickel standard runs were selected. Loading and unloading pressures were averaged at 
selected displacements for both materials. The backlash effect is much more evident in the solid media data (Figure 15) and would cause the calculated friction corrections to diminish considerably at high pressure. Bridgman (1964a) removed the backlash artifact by graphically extending the unloading curve. To do so, he first plotted the pressure difference between the loading and unloading curves against pressure. The pressure difference, $\Delta \mathrm{P}$, was seen to increase gradually with pressure over most of the range and then fall sharply as the backlash sets in. Bridgman manually extrapolated the rising portion of the $\Delta \mathrm{P}-\mathrm{P}$ curve to maximum pressure using a graphical technique, and then calculated mean pressure from the extended portion of the unloading curve at high pressures. We used a numerical curve-fitting routine, TableCurve2D, to fit the lower pressure portion of our $\Delta \mathrm{P}-\mathrm{P}$ curves to an equation of the form

$$
\Delta \mathrm{P}=\left(\mathrm{a}_{0}+\mathrm{a}_{1} \mathrm{P}\right) /\left(1+\mathrm{a}_{2} \mathrm{P}+\mathrm{a}_{3} \mathrm{P}^{2}\right)
$$

and then extrapolated to $3 \mathrm{GPa}$. The fitting parameters are given in Table A3 of the appendix. The calculated friction corrections, which are one-half $\Delta \mathrm{P}$ at each pressure, were then subtracted from the nickel standard and powder specimen data separately. The powder specimen friction correction rises monotonically to $0.2 \mathrm{GPa}$ (Figure 16).

\subsubsection{Kawakita Curve Fits and Energy Calculations}

Specimen volumes, obtained from helium pycnometer measurements, were plotted against peak pressure for each of the granular materials, and curves calculated from a powder compaction model due to Kawakita and Ludde (1970) were fit to the data.

Kawakita proposed the following relation between relative volume compaction, $\mathrm{C}$, and hydrostatic pressure, $\mathrm{P}$ :

$$
\mathrm{C}=\left(\mathrm{V}_{0}-\mathrm{V}\right) / \mathrm{V}_{0}=(\mathrm{abP}) /(1+\mathrm{bP})
$$

where $\mathrm{V}_{0}$ is the initial powder volume, $\mathrm{V}$ is volume at pressure or after a pressure cycle, and $\mathrm{a}$ and $\mathrm{b}$ are fitting parameters. The fitting parameters are estimated by rearranging equation (2) as

$$
\mathrm{P} / \mathrm{C}=(1 / \mathrm{a}) \mathrm{P}+1 / \mathrm{ab}
$$

and regressing a straight line through a plot of $\mathrm{P} / \mathrm{C}$ versus pressure. Parameter "a" was identified as the initial specimen porosity by Kawakita and Ludde (1970) and is found from the regression slope. The regression intercept is the room pressure bulk modulus (Hayward, 1974). Linear regression fits for ceramic microspheres and molybdenum powder are shown in Figure 17. The regression slope for molybdenum yields an initial porosity of $63 \%$ in excellent agreement with the $65 \%$ porosity obtained from the pycnometer data. The regression slope for the ceramic microspheres yields an initial porosity of $78 \%$, which is somewhat lower than the $85 \%$ pycnometer value. The fitting parameters were used to calculate pressure-specific volume curves with equation (2). 
The energy expended per gram in compacting each powder was found by numerically integrating the fitted curves to $1 \mathrm{GPa}$. The numerical integration was performed with the "Integrate-Area" macro provided in the Kaleidagraph software package. The energy expended in compressing the molybdenum powder and ceramic microspheres to $3 \mathrm{GPa}$ was found by integrating the pressure-volume curves from the solid medium compression tests using the same macro routine. The area under the pressure-specific volume curves converts as $1 \mathrm{GPa} \mathrm{cm}^{3} / \mathrm{g}$ equals $1 \mathrm{~kJ} / \mathrm{g}$, and the area under the pressure-relative volume curves converts as $1 \mathrm{GPa}$ equals $1 \mathrm{~kJ} / \mathrm{cm}^{3}$.

\subsubsection{Solid Medium Data Reduction}

The data reduction procedure for the solid medium compression tests derives from earlier work at LLNL by Stephens and Lilley (1967) and Weed (1984). The method is to compare the specimen volume to the volume of a gold or nickel reference standard at every pressure. Both metals have well-known pressure-volume relations. The use of a reference standard eliminates corrections for the contraction of the piston, anvil and backing plates and for stretching of the press frame (Stephens and Lilley, 1967). We have modified the data reduction procedure to incorporate the constraint provided by the micrometer measurements of the final specimen dimensions. The data reduction procedure is described with reference to Table 5, which contains data and calculated values for a portion of a molybdenum powder test. The powder specimen data were corrected for friction and die bore expansion before being entered into the table.

The first column is a list of interpolation pressures (in kilobars) representing a portion of the loading cycle. The second column contains specimen displacements (in inches). The displacements have been interpolated to correspond to the pressures in column 1. The LVDTs measure the piston travel, including some motion before the piston makes contact with the specimen. An attempt has been made to pick the point of contact by visual inspection of the pressure-displacement data, but this can be difficult for soft materials. The nickel displacements in column 3 are obtained by interpolation of the nickel standard data set. The data reduction procedure is performed in two passes. On the first pass, the contact pick is assumed to be accurate and the entries in column 4 are set equal to those in column 2. On the second pass the column 4 entries are adjusted by a constant value to bring the calculated final (room pressure) specimen length into agreement with the specimen length measured with a micrometer at the end of the test. The fifth column contains net displacements, i.e.- specimen displacements (column 4) minus nickel standard displacements (column 3). The sixth column is used to remove the small net displacement at zero pressure. Relative volume changes (column 7) are calculated from the zeroed net displacements (column 6), and units are converted from inches to centimeters. The eighth column contains nickel standard volumes calculated from nickel $\mathrm{P}-\Delta \mathrm{V} / \mathrm{V}_{0}$ data of Bridgman (1964b). The powder specimen volumes (column 9) are found by subtracting the relative volume changes (column 7) from the nickel standard volumes (column 8) after a correction is made for the small difference in initial length between the powder specimen and the nickel standard. The tenth column is the specific volume of the specimen, found by dividing the column 9 entries by the powder mass. The eleventh column contains specimen volumes normalized by the specimen's initial 
volume. Column 12 contains $m u$, the ratio of the powder density at pressure to its initial density minus one. In the final column pressures are converted to gigapascals.

The final length of the powder specimen was measured with a micrometer at the end of the compaction test and compared to the final specimen length calculated from the LVDT data. The measured and calculated lengths generally differ. The measured length of molybdenum specimen Mo_fjr_6, for example, was found to $1.9 \mathrm{~mm}$ (0.075 in.) shorter than the final specimen length calculated from the LVDT data. The discrepancy is likely due to the difficulty in accurately picking the point of contact of the piston with the powder specimen. We believe the micrometer measurements are far more accurate than our picks of the piston contact point. Consequently, the column 4 entries were changed to reflect the discrepancy ( 0.075 inches were added to all but the first entry in column 4 for Mo_fjr_6) and a second pass was made through the data reduction procedure, so that the calculated volume at the end of the test agrees with the final specimen volume as measured with the micrometer.

\section{Results}

\subsection{Hydrostatic Tests to 1 GPa}

\subsubsection{Recovered Specimens}

Photographs of the hydrostatic test specimens illustrate the wide range of volume reduction for the different materials (Figures 18-26). The aluminum specimens are unusual in that many small air pockets formed along the sides of the jacket (Figure 18). This observation suggests that porosity reduction in aluminum powder was sufficiently complete to prevent much of the air from migrating upward through the specimen. The glassy carbon specimen (Figure 19) is barely compacted in stark contrast to the ceramic microsphere specimen (Figure 20). The copper specimen is oddly bulged (Figure 21). The foam specimen (Figure 22) underwent a tremendous amount of deformation in compression to $30 \mathrm{MPa}$. The upper image (Figure 22a) shows the foam specimen after a pressure cycle to $5 \mathrm{MPa}$. The specimen retained its cylindrical shape except for two indentations that most likely correspond to the two large voids seen in Figure 12. The foam is sufficiently strong to withstand pressures of $5 \mathrm{MPa}$, but clearly not $8 \mathrm{MPa}$, as evidenced by the highly deformed remnant shown in the middle image (Figure 22b). The final state of the foam specimen, after pressure cycles to 20 and $30 \mathrm{MPa}$, is shown in Figure 22c. The molybdenum specimen (Figure 23) can be considered an intermediate case between glassy carbon and the ceramic microspheres. The Ottawa sand specimen shows relatively little volume reduction (Figure 24). The silicon carbide (Figure 25) and titanium (Figure 26) specimens show intermediate levels of volume reduction.

\subsubsection{Density and Porosity}

Initial and final bulk densities are compared with grain densities for all of the materials in Figure 27. The bulk densities are calculated from pycnometer measurements of specimen volumes after subtracting the volume of the jacket material. Except for Ottawa sand and 
foam, the bulk densities are the average of three or more specimens. The final densities are calculated after hydrostatic compression to approximately $0.9 \mathrm{GPa}$ for the powders and to $0.03 \mathrm{GPa}$ for the foam. The grain densities are calculated from pycnometer measurements of loose powder volumes. Compression to $0.9 \mathrm{GPa}$ resulted in relatively large increases in bulk density for the metallic powders: $\mathrm{Al}, \mathrm{Cu}, \mathrm{Mo}$ and Ti. The metallic powders have relatively low yield strengths, so that the grains deform plastically and fill void spaces at relatively low pressures. The final bulk densities of three metallic powders, $\mathrm{Al}, \mathrm{Cu}$ and $\mathrm{Ti}$, are nearly equal to their respective grain densities, indicating that further compression will result in very little porosity reduction. Except for the ceramic microspheres, the non-metallic powders show fairly small increases in bulk density, partly because of their relatively high yield strengths and partly because these materials are less dense than the metals. The large increase in bulk density for the ceramic microspheres results from their initial hollow structure; much porosity is removed as the hollow spheres are crushed. The foam specimen also shows a relatively large increase in bulk density with compression to $0.03 \mathrm{GPa}$.

Initial and final porosities for the powders and foam, calculated from the bulk and grain densities, are shown in Figure 28. Initial porosities for most materials were around 40\%. Two materials, the hollow ceramic microspheres and the epoxy foam, had initial porosities over $80 \%$. The molybdenum specimens had an initial porosity of $65 \%$ due, in part, to the porous structure of the individual grains. Silicon carbide had a relatively high initial porosity of about $50 \%$, which is likely due in part to its angular grain shape.

Ottawa sand had the lowest initial porosity, about $33 \%$, of the materials studied. The low porosity for Ottawa sand is probably due to its broad grain size distribution. The foam specimen underwent the greatest porosity reduction though only compressed to $0.03 \mathrm{GPa}$. Of the powders, the ceramic microspheres and the molybdenum experienced the largest reductions in porosity in absolute terms, while the ductile metal powders, $\mathrm{Al}, \mathrm{Cu}$ and $\mathrm{Ti}$ underwent large relative reductions in porosity. Final porosities for these three metal powders and for the foam are in single digits. After compression to $0.9 \mathrm{GPa}$, molybdenum powder has about the same porosity as Ottawa sand despite its much larger initial porosity. Three materials: glassy carbon, silicon carbide and crushed ceramic microspheres retain more than $20 \%$ porosity after compression to $0.9 \mathrm{GPa}$. The residual ceramic porosity is about the same as the initial Ottawa sand porosity. Of the materials tested, glassy carbon underwent the least permanent porosity reduction and may have underwent more porosity recovery on unloading than the other materials.

\subsubsection{Pressure-Volume Relationships}

Specific volumes are plotted against peak hydrostatic pressure for each material in Figures 29-37. The volumes were measured at room pressure with a pycnometer after each completed pressure cycle. The pressures have been corrected for friction and die bore expansion. The solid lines in all but the foam plot are Kawakita model fits to the data, as described in Section 2.4.3. The Kawakita model generally provides a very good fit. The fitting coefficients are given in Table A4 of the appendix. The area under the fitted curve provides an estimate of the energy expended in compacting the material. These energy estimates are given in the figures and in column 2 of Table 8 . Most of the 
compaction occurs at low pressures, particularly for the ceramic microspheres (Figure 31) and the ductile metallic powders, aluminum (Figure 29) and copper (Figure 32). The glassy carbon spheres (Figure 30) show the least permanent volume reduction; they are either very stiff or most of the deformation is recovered on unloading. The pressurevolume curve for the foam specimen shows tremendous volume reduction between 5 and $20 \mathrm{MPa}$.

Bulk moduli were estimated from the pressure-volume data for five of the hydrostatically compressed powders. The method employed in calculating bulk moduli is described in Heard and Stephens (1970). The calculated moduli can be quite noisy, particularly for small volume changes. No effort was made to determine a bulk modulus for aluminum, copper, Ottawa sand and the foam specimen because of the scatter in the pressure-volume data for these materials. The bulk moduli show an upward trend with pressure for each of the materials (Figures 38-42). The calculated bulk moduli are generally below $10 \mathrm{GPa}$ at pressures below $0.9 \mathrm{GPa}$, but the glassy carbon spheres (Figure 38) appear to be stiffer than the other materials. The calculated bulk moduli for glassy carbon exceed $10 \mathrm{GPa}$ at pressures above $0.5 \mathrm{GPa}$.

\subsubsection{Energy Expended in Compaction}

The energy expenditures per unit volume and per gram to compact the granular materials to $1 \mathrm{GPa}$ are given in Table 6 and shown in Figures 43-44. Molybdenum and titanium required the most energy per unit volume, followed by silicon carbide; aluminum and the ceramic microspheres required the least (Figure 43). However, compaction of the very light ceramic microspheres required by far the most energy per gram (Figure 44). The energy expended per gram to compact molybdenum, which has a very high grain density, was lower than that of silicon carbide and similar to that of several other materials.

The less ductile metallic powders, molybdenum and titanium, required more energy to compact to $1 \mathrm{GPa}$ than the more ductile copper and aluminum powders. The energy expended per unit volume in compacting the metallic powders to $1 \mathrm{GPa}$ shows a clear upward trend with yield strength (Figure 45). This is as expected, since greater pressures must be applied to the less ductile powders to fill pore space through plastic flow.

The metallic and non-metallic powders fall into two separate groups when expended energy per unit volume is plotted against relative porosity reduction (Figure 46). The metallic powders plot in the right-hand portion of the figure, near full density. Relative porosity reductions for the metal powders range from $75 \%$ for molybdenum to about $95 \%$ for aluminum and copper. The non-metallic powders plot in the left-hand portion of the figure, with relative porosity reductions of $30-60 \%$. The aluminum and copper powders offer little potential for additional energy absorption with compaction to higher pressures. The less-ductile molybdenum and titanium powders require more energy and retain more pore space to $1 \mathrm{GPa}$ than aluminum and copper. Thus, molybdenum and titanium have the potential to absorb additional energy above $1 \mathrm{GPa}$. Porosity reduction in the more brittle non-metallic materials is likely to proceed largely by fragmentation. These materials show lower relative reductions in porosity and intermediate levels of expended 
energy--more than aluminum, but less than molybdenum or titanium. The relatively high levels of residual porosity for the non-metallic materials indicate that they may absorb considerably more energy at higher pressures. Silicon carbide and glassy carbon appear particularly promising as they are further from full density at $1 \mathrm{GPa}$. The energy expended per gram to compact each material to $1 \mathrm{GPa}$ is plotted against relative porosity reduction in Figure 47. The ceramic microspheres, with their very low initial density, require far more energy per gram than the other materials. The non-metallic powders retain a larger portion of their porosity to $1 \mathrm{GPa}$ may potentially require considerably more energy per gram to compact to full density than the metal powders.

The hollow ceramic microspheres have thin, brittle walls, and evidence from the piston displacement data (Figure 48) suggests that an appreciable amount of crush-up may occur at pressures as low as 1.5 to $2.0 \mathrm{MPa}$. The piston displacement records show about 0.5 $\mathrm{cm}$ of displacement with little or no gain in pressure at 1.5-2.0 GPa. Given the vessel bore diameter of $3.8 \mathrm{~cm}$, this displacement translates to a volume loss of $5.7 \mathrm{~cm}^{3}$, about $15 \%$ of the powder volume or about $18 \%$ of the initial pore space.

\subsection{Solid Medium Tests to 3 GPa}

\subsubsection{Pressure-Volume Relationships}

The solid medium specimens are less than one-tenth the volume of the hydrostatic specimens, but are prepared in much the same manner and can be compressed to much higher pressures. A ceramic microsphere specimen, AlSP\#1, was prepared, as described in Section 2.2.2, with an initial bulk density of $0.386 \mathrm{~g} / \mathrm{cm}^{3}$, similar to the hydrostatic specimens. After an initial conditioning run to $0.02 \mathrm{GPa}$, specimen AlSP \#1 was compressed to $3.0 \mathrm{GPa}$ in the solid medium press. The pressures were corrected for friction and die bore expansion and the displacements were converted to volume strains with reference to a solid nickel standard, as described in Section 2.3.2. The displacements from the solid medium compression test were shifted $0.6 \mathrm{~mm}$ (toward greater displacement) to correct for a probable error in picking the point of piston contact with the specimen. The resulting pressure-volume curve is shown as a solid line in Figure 49 along with results from the hydrostatic tests on four ceramic microsphere specimens. The solid medium and hydrostatic test results agree very well. The pressurevolume curve steepens dramatically at or near a specific volume of $0.7 \mathrm{~cm}^{3} / \mathrm{g}$. This value corresponds to a bulk density of $1.43 \mathrm{~g} / \mathrm{cm}^{3}$ or a porosity of $45 \%$. As the initial porosity was $85 \%$, a little over half of the pore space has been lost at quite low pressures. About half of the initial porosity was located within the thin-walled, hollow microspheres. It seems likely that most of this porosity is lost at low pressures, leaving a mass of ceramic shards that much more strongly resist further deformation.

Seven molybdenum specimens were prepared for testing in the solid medium press. The first three were prepared without indium disks; the others were prepared as described in Section 3.2.3. The solid medium molybdenum specimens have initial bulk densities of $3.5 \mathrm{~g} / \mathrm{cm}^{3}$ similar to the hydrostatic specimens, which averaged $3.6 \mathrm{~g} / \mathrm{cm}^{3}$. Data from molybdenum specimen Mo_fjr_03 were used to compute a friction correction for the 
solid medium press. The final two specimens were tested somewhat differently. Specimen Mo_fjr_06 (Molybdenum \#6) was tested in a series of loading/unloading cycles. After an initial conditioning run to $0.05 \mathrm{GPa}$, it was compressed to $0.5 \mathrm{GPa}$, then 1.0 GPa, 2.8 GPa and finally to $3.0 \mathrm{GPa}$ with complete unloading between each compression cycle. Specimen Mo_fjr_07 (Molybdenum \#7), in contrast, was compressed to $3.0 \mathrm{GPa}$ in a single cycle without a conditioning run.

The final lengths of Molybdenum \#6 and \#7 were measured with a micrometer after testing to $3 \mathrm{GPa}$. The final length of Molybdenum \#7 was somewhat difficult to measure because one end was damaged in removing the sealing ring. Despite the damaged end, both specimens were found to be $16.6 \mathrm{~mm}$ (0.654") long. The final lengths obtained with the micrometer are about $10 \%$ shorter than the lengths calculated from the LVDT data. After a calibration check showed that the LVDTs remained with in tolerance, it was concluded that the discrepancies are most likely due to errors in picking the point of contact between the piston and the specimen. Consequently, the displacement data were shifted sufficiently to bring the calculated final specimen lengths into agreement with the micrometer measurements. The Molybdenum \#6 displacements were increased by 1.9 $\mathrm{mm}(0.075$ "), the Molybdenum \#7 displacements were increased by $1.5 \mathrm{~mm}(0.060 ")$ and specimen volumes were recalculated. The resulting pressure-volume curves are shown as solid lines in Figures 50-51. They are in excellent agreement with the pressure-volume data from the earlier hydrostatic tests (open circles).

Solid medium $\mathrm{P}-\mathrm{V} / \mathrm{V}_{0}$ curves for the ceramic microspheres and molybdenum powder are compared in Figure 52. The two molybdenum curves are barely distinguishable. The volume at $3 \mathrm{GPa}$ is about $34 \%$ and the recovered volume is about $36 \%$ of the initial volume for both specimens. The initial molybdenum porosity was $65 \%$, the porosity at 3 $\mathrm{GPa}$ is about $2 \%$ and the recovered porosity is only slightly higher. The areas under the two pressure-volume curves average $0.145 \mathrm{GPa}$ or $145 \mathrm{~J} / \mathrm{cm}^{3}$ of energy $/ \mathrm{cm}^{3}$ expended. The hollow ceramic microspheres show much more compaction than molybdenum powder at low pressures, but the crushed ceramic shards that result form a stiff mass that strongly resists further compaction. Above $0.3 \mathrm{GPa}$, the additional relative volume reduction for the ceramic material is about one-third that of molybdenum. The volume at $3 \mathrm{GPa}$ is about $18 \%$ and the recovered volume is about $23 \%$ of the initial volume. The area under the ceramic $\mathrm{P}-\mathrm{V} / \mathrm{V}_{0}$ curve is $0.06 \mathrm{GPa}$, about $40 \%$ that of molybdenum, but the potential for additional energy absorption remains due to the remnant pore space. The energy results are given in Table 6.

\subsubsection{Bulk Modulus}

Bulk moduli were estimated from the slopes of the pressure-volume curves for the ceramic microspheres and molybdenum powder. The bulk modulus increases with pressure for both materials; both become stiffer as porosity is removed. However, their stiffening behavior differs in that the ceramic microsphere bulk modulus increases at a diminishing rate with pressure (Figure 53), whereas the molybdenum bulk modulus increases at an increasing rate with pressure (Figure 54). The ceramic microsphere stiffening behavior resembles that of Diagonal Line alluvium; its bulk modulus also 
increases at a diminishing rate with pressure (Heard and Stephens, 1970). Such behavior may result if the largest pores are removed early in the compaction process at low pressures. The molybdenum behavior may be due to strain hardening. If deformation causes the solid phase to harden, larger pressure increments may be required to yield additional reductions in volume.

The ceramic microsphere and molybdenum bulk moduli are plotted against the ratio of bulk density to grain density in Figures 55-56. Little change in bulk modulus is seen at low relative densities for either material. The ceramic bulk modulus rises in a nearly linear fashion between relative densities of 0.55 and 0.75 (Figure 55). The molybdenum bulk modulus rises approximately exponentially above a relative density of 0.5 (Figure 56). A dramatic increase in bulk modulus near full densification has also been observed for iron powder (Pavier and Doremus, 1999).

\subsection{Merge Pressure and Energy Estimation}

\subsubsection{Exponential Model}

In section 3.1 we provided estimates of the energy expended in compressing the test powders to $1 \mathrm{GPa}$. The estimates were obtained by fitting a curve, derived from the Kawakita model, through the pressure-volume data and numerically integrating to $1 \mathrm{GPa}$. However, the powders differ widely in the extent to which they are densified at $1 \mathrm{GPa}$, from under $5 \%$ residual porosity for aluminum and copper to over $20 \%$ for glassy carbon, ceramic microspheres and silicon carbide. Thus, several materials may absorb much additional energy at higher pressures, whereas others, such as aluminum and copper, may not.

To estimate the total energy that may potentially be expended in compaction, the pressure-volume curve for each material must be integrated up to the merge pressure, at which all of the available porosity is removed. The Kawakita model, which was used to calculate the fitting curves in Figures 29-37, is unsuitable for estimating merge pressure because full densification is approached asymptotically. However, we found that an exponential relationship provides a good, empirical fit between porosity, expressed as void ratio, and pressure for each powder except aluminum, for which the data are badly scattered. Regression fits for each material are shown in Figures 57-64. Data points plotted as solid circles were included in the regression fits, and data points shown as open circles were omitted. The estimated merge pressures, found as the zero-porosity intercepts, vary over two orders of magnitude, and involve a good deal of extrapolation, particularly for the non-metallic powders. As with any extrapolation, the estimated merge pressures could (probably do) differ considerably from their true values, due to an error in the regression slope, or because the relationship between pressure and porosity is not truly exponential. This approach is strictly empirical, after all. The predicted merge pressures and pressure sensitivities are summarized in Table 8 . A very good fit was obtained for the molybdenum data at porosities between $15 \%$ and $50 \%$ (Figure 61 ). The predicted merge pressure for molybdenum is slightly below the peak pressure reached in the solid medium tests. 
The regression coefficients and the bulk modulus of the solid material were used to calculate specific volume as a function of pressure for each powder. The bulk modulus was used to calculate the increase in density of the solid particles with pressure. The bulk modulus was assumed to be constant, and it was assumed that all pores remain closed during unloading so that the unloading path is linear. After the pressure-volume curves were obtained, the area between the loading and unloading paths was found by numerical integration. The extrapolated pressure-volume curves are shown as solid lines in Figures 65-72, and the experimental data are shown as circles. Estimates of merge pressure and of total expended energy per gram are given in Table 8 and plotted as histograms in Figures 73-74. The estimates for the metal powders are probably too low. If strain hardening or some other mechanism becomes increasingly important near full density, then the pressure-volume curves may steepen more than predicted by the exponential model. The exponential model predicts that more energy will be required per gram to compact the brittle, non-metallic materials: glassy carbon, ceramic microspheres, Ottawa sand and silicon carbide to full density (Figure 74).

The exponential models developed from the hydrostatic data were compared to the solid medium data for molybdenum and the ceramic microspheres. The exponential model predicts a merge pressure of $2.9 \mathrm{GPa}$ for molybdenum, so that the solid medium tests should have attained sufficient pressure to close all of the porosity. Overall, a fairly good fit is obtained between the model curve, shown in blue, and the solid medium data, shown in red (Figure 75). However, the exponential model over-predicts compaction at pressures below $0.5 \mathrm{GPa}$ and over-predicts compaction above $2 \mathrm{GPa}$ in comparison to the data. And the solid medium compression tests surpassed the merge pressure predicted by the exponential model without closing all of the porosity. An effort was made, therefore, to obtain a tighter curve-fit that would also provide a higher estimate for merge pressure.

\subsubsection{Second Order Model}

The Molybdenum \#7 pressure-volume data were imported into TableCurve2D, a commercially available curve-fitting application, and a number of equations were tried. An excellent fit was obtained with the following equation

$$
\Phi=\mathrm{a}_{0}+\mathrm{a}_{1} \cdot \exp \left(-\mathrm{a}_{2} \cdot \mathrm{P}\right)+\mathrm{a}_{3} /\left(1+\mathrm{a}_{4} \cdot \mathrm{P}\right)
$$

where $\Phi$ is porosity expressed as void ratio, $\mathrm{P}$ is pressure, and the $\mathrm{a}_{\mathrm{i}}$ terms are fitting coefficients (Figure 76). Equation (4) is the solution to a second order differential equation of the form

$$
\mathrm{d} \Phi / \mathrm{dP}=\mathrm{k}_{0} \Phi+\mathrm{k}_{1} \Phi^{2}
$$

The five regression coefficients were used to calculate specific volumes as a function of pressure (Figure 77). The second order model predicts a merge pressure of $3.7 \mathrm{GPa}$, higher than the $2.9 \mathrm{GPa}$ predicted by the exponential model, and about $10 \%$ more area under the pressure-volume curve. Our approach is empirical, and is similar to an earlier 
effort by Cooper and Eaton (1962) who used a double exponential equation to model compaction for several ceramic powders.

The pressure and porosity data for ceramic microsphere specimen AlSP\#1 were also imported into TableCurve2D and the same set of equations were fit (Figure 78). The best fit was obtained for an equation having two second order terms

$$
\Phi=\mathrm{a}_{0}+\mathrm{a}_{1} /\left(1+\mathrm{a}_{2} \cdot \mathrm{P}\right)+\mathrm{a}_{3} /\left(1+\mathrm{a}_{4} \cdot \mathrm{P}\right)
$$

which is the solution to

$$
\mathrm{d} \Phi / \mathrm{dP}=\mathrm{k}_{0} \Phi^{2}+\mathrm{k}_{1} \Phi^{2}
$$

The resulting model predicts a merge pressure of 10.6 GPa for the ceramic microspheres, which is much lower than the 57.6 GPa predicted by the exponential model (Figure 79).

The predicted energy for compression to $10.6 \mathrm{GPa}$ is $0.907 \mathrm{~kJ} / \mathrm{g}$, a little less than half the $2.05 \mathrm{~kJ} / \mathrm{g}$ predicted by the exponential model.

The same approach was applied to the aluminum data in an attempt to improve upon the exponential model. Equation (4) was found to give a good fit to a portion of the aluminum data (Figure 80), and the regression coefficients were used to calculate specific volumes as a function of pressure (Figure 81). The data points plotted as open circles in Figure 81 were omitted from the regression analysis. The second order model predicts a merge pressure of $0.74 \mathrm{GPa}$, about twice the $0.35 \mathrm{GPa}$ predicted by the exponential model. The higher merge pressure seems more consistent with the data, though these are badly scattered at low specific volumes. The merge pressures and energies predicted by the exponential and second order models are given in Table 8, along with the energies found by numerically integrating the Kawakita curve fits to the hydrostatic pressurevolume data to $1 \mathrm{GPa}$.

\subsection{Heckel Analysis}

Heckel (1961a,b) analyzed powder compaction by analogy to a first-order chemical reaction in which open pores are the reactant, densification is the end product and pressure replaces time. The reaction rate is proportional to the amount of available reactant. For Heckel's model this is expressed as

$$
\mathrm{dD} / \mathrm{dP}=\mathrm{K}(1-\mathrm{D})
$$

where $\mathrm{D}$ is the relative density, $\mathrm{P}$ is pressure and $\mathrm{K}$ is a proportionality constant. The differential equation is solved as

$$
\ln (1 /(1-\mathrm{D}))=\mathrm{KP}+\mathrm{A}
$$

where A is a constant related to the initial relative density. Heckel (1961a) plotted $\ln (1 /(1-D))$ against pressure for four metal powders and observed a linear relationship 
above pressures of 100-200 MPa. He attributed the non-linear portion of the curves at low pressures to particle rearrangement and the linear portion to plastic deformation. Plots of this type are often called Heckel plots. Heckel (1961b) showed that the proportionality constant, $\mathrm{K}$, is inversely proportional to yield strength for metal powders. Heckel's analysis has been applied to a variety of powder types, and Hersey and Rees (1971) have proposed a method for distinguishing between plastic and brittle deformation mechanisms based on Heckel's analysis. The interpretation of low-pressure, nonlinear portion of the Heckel plot has been controversial. Hewitt et al. (1974) argue that plastic deformation occurs at points of stress concentration in the low-pressure region and that the pressure at which the curve becomes linear corresponds to a transition from local to homogeneous plastic flow. A third, nonlinear region at higher pressures is sometimes observed (e.g., Kurt and Davies, 1996).

The Heckel plot for ceramic microsphere specimen AlSP \#1 (Figure 82) exhibits the first two regions. The curved portion of the Heckel plot exends to about $0.5 \mathrm{GPa}$, and the plot is linear thereafter to $3 \mathrm{GPa}$. A linear regression fit to the data above $1 \mathrm{GPa}$ gives a slope of $0.219 \mathrm{GPa}^{-1}$. The slope corresponds to a yield strength of $1.5 \mathrm{GPa}$, but is probably more properly related to the compressive strength of the ceramic material and friction between the ceramic shards. Although some particle rearrangement may have occurred at low pressures, crushing of hollow microspheres is likely to be the dominant mode of densification below $0.5 \mathrm{GPa}$, corresponding to the curved portion of the Heckel plot.

The two Heckel plots for molybdenum (Figures 83-84) are very similar, and both show three distinct regions. The initial, curved region extends to about $0.5 \mathrm{GPa}$, becoming linear very gradually. The linear region ends at about $2.0 \mathrm{GPa}$ for both specimens, and the plots are concave upwards at the higher pressures. The molybdenum specimens retain about $5 \%$ porosity at the onset of curvature. A linear regression analysis of the data between 1.0 and 2.0 GPa gives slopes of $0.88 \mathrm{GPa}^{-1}$ and $0.95 \mathrm{GPa}^{-1}$ for Molybdenum \#6 and Molybdenum \#7, respectively. These slopes are considerably steeper than that found for the ceramic microspheres. The regression slopes give yield strengths of 350 and $380 \mathrm{MPa}$, which are somewhat below the 415-450 $\mathrm{MPa}$ range given by goodfellow.com for soft molybdenum.

Heckle plots for aluminum, glassy carbon, silicon carbide and titanium (Figures 85-88) differ between the metallic and non-metallic powders. For the metal powders, the curves become linear at quite low pressures, whereas the plots for the non-metallic powders only become linear above $0.5 \mathrm{GPa}$ and may not be linear below $1 \mathrm{GPa}$. The onset of linearity occurs at about $50 \mathrm{MPa}$ for aluminum and $150 \mathrm{MPa}$ for titanium. Linear regression of the data above those pressures gives yield strengths of $36 \mathrm{MPa}$ for aluminum and 160 $\mathrm{MPa}$ for titanium. The transition pressures and the calculated yield strengths are in good agreement with the range of yield strengths provided by goodfellow .com for these metals: 10-35 MPa for aluminum and 140-250 MPa for titanium. 


\section{Summary and Conclusions}

Pressure-volume measurements were made at ambient temperature on eight granular materials to $0.9 \mathrm{GPa}$ in a liquid medium press and on molybdenum powder and ceramic microspheres to $3 \mathrm{GPa}$ in a solid medium press. The materials compact primarily through porosity reduction. A pressure of $1 \mathrm{GPa}$ was sufficient to remove nearly all porosity from the aluminum and copper powders, and most porosity from the titanium and molybdenum powders. The molybdenum powder retains more porosity at $1 \mathrm{GPa}$ than the other metal powders. More than half of the ceramic microsphere porosity is lost by $1 \mathrm{GPa}$, but the crushed ceramic microspheres retain about $23 \%$ porosity to $3 \mathrm{GPa}$. In contrast, the molybdenum powder porosity is reduced to about $2-3 \%$ at $3 \mathrm{GPa}$. The two angular materials, Ottawa sand and silicon carbide powder, retain about half of their initial porosity after compaction to $1 \mathrm{GPa}$. The glassy carbon spheres retain most of their initial porosity or recover it on unloading. The epoxy foam loses nearly all porosity by 20-30 MPa.

The energy expended in compacting the granular materials to 1 GPa was found by numerically integrating curves fit to the pressure-volume data. More energy was expended in compacting molybdenum powder to $1 \mathrm{GPa}$ on a per-unit-volume basis than for any other material. Compaction of the ceramic microspheres to $1 \mathrm{GPa}$ required more energy per gram due to the very low initial density of the ceramic microspheres. The 3 GPa results are similar: more energy per unit volume was expended in compressing molybdenum powder, and more energy per gram was expended in compressing ceramic microspheres. Because the non-metallic powders retain more porosity at $1 \mathrm{GPa}$, they have more potential to absorb additional energy at higher pressures.

Granular materials can absorb energy through porosity reduction up to their merge pressures. To obtain rough estimates of the merge pressures, we plotted porosity against pressure on a log scale for each material and took the zero porosity intercepts to be the merge pressures. We then extrapolated the pressure-volume curves to the merge pressures and numerically integrated to find the areas under the curves. The estimated energies must be treated with caution as they are based on extrapolations, but they suggest that the glassy carbon and the ceramic microspheres have the potential to absorb more energy than the other materials, if they can be compressed to their very high merge pressures.

\section{Acknowledgements}

William Ralph assisted with equipment set-up and also took many of the photographs. Carl Boro fabricated the specimen jackets. Dave Ruddle cored the foam specimen. Chantal Aracne assisted with post-test characterization. Dan Farber and Homer Weed provided useful comments and ideas. Charles Chow provided guidance during the later stages of the effort. 


\section{References}

Bridgman, P. W., 1964a. "The compression of 46 substances to $50,000 \mathrm{~kg} / \mathrm{cm}^{2}$," in Collected Experimental Papers, vol. VI, Harvard University Press, Cambridge, MA, Paper No. 134, pp. 3411-3441.

Bridgman, P. W., 1964b. "Linear compressions to $30,000 \mathrm{~kg} / \mathrm{cm}^{2}$ including relatively incompressible substances," in Collected Experimental Papers, vol. VI, Harvard University Press, Cambridge, MA, Paper No. 168, 3933-3978.

Cooper, A. R., Jr. and L. E. Eaton, 1962. "Compaction behavior of several ceramic powders," J. Am. Ceram. Soc., 45, 97-101.

Grens, J. Z., 1970. "Computer operation of a compressibility testing apparatus," Lawrence Radiation Laboratory, Livermore, CA, UCIR-457, 14 p.

Hayward, A. T. J., 1971. "How to measure the isothermal compressibility of liquids accurately, " J. Phys. D: Appl. Phys., 4, 938-950.

Heard, H. C. and D. R. Stephens, 1970. "Compressibility and strength behavior of Diagonal Line alluvium," Lawrence Radiation Laboratory, Livermore, CA, UCID-15736, $8 \mathrm{p}$.

Heckel. R. W., 1961a. “Density-pressure relationships in powder compaction,” Trans. Metall. Soc. AIME, 221, 671-675.

Heckel, R. W., 1961b. “An analysis of powder compaction phenomena," Trans. Metall. Soc. AIME, 221, 1001-1008.

Hersey, J. A., and J. E. Rees, 1971. "Deformation of particles during briquetting," Nature, 230, 96.

Hewitt, R. L., W. Wallace and M. C. de Malherbe, 1974. "Plastic deformation in metal powder compaction," Powder Metallurgy, 17, 1-12.

Lukasiewicz, S. J., 1989. "Spray-drying ceramic powders," J. Am. Ceram. Soc., 72, 617624.

Kawakita, K. and K. H. Ludde, 1970. "Some considerations on powder compression equations," Powder Technology, 4, 61-68.

Kurt, A. O. and T. J. Davies, 1996. "A study of compaction of metal powders," Ulusal Toz Metalurjisi Konferansi, 16-17 Eylul, Ankara, Turkey, 493-506.

Pavier, E. and P. Doremus, 1999. "Triaxial characterisation of iron powder behaviour," Powder Metallurgy, 42, 345-352. 
Stephens, D. R. and E. M. Lilley, 1966. "Static PV curves of cracked and consolidated earth materials to 40 kilobars," Lawrence Radiation Laboratory, Livermore, CA, UCRL$14711,43 \mathrm{p}$.

Stephens, D. R. and E. M. Lilley, 1967. "Procedure for pressure-volume runs on rocks," Lawrence Radiation Laboratory, Livermore, CA, UCID-15070, 12 p.

Uematsu, K., J.-Y. Kim, M. Miyashita, N. Uchida and K. Saito, 1990. "Direct observation of internal structure in spray-dried alumina granules," J. Am. Ceram. Soc., 73, 2555-2557.

Weed, H. C., 1984. "Pressure-density behavior for $\mathrm{AlN}, \mathrm{Al}_{2} \mathrm{O}_{3}, \mathrm{SiO}_{2}, \mathrm{TiB}_{2}$ and $\mathrm{TiC}$ powders up to $3.5 \mathrm{GPa}$," Lawrence Livermore National Laboratory, Livermore, CA, UCID-20302, $31 \mathrm{p}$. 
Table 1. Starting materials. Information supplied by the manufacturers.

\begin{tabular}{|l|l|l|l|c|l|}
\hline \multicolumn{1}{|c|}{ Material } & \multicolumn{1}{|c|}{ Source } & Stock No. & Lot No. & Size $(\boldsymbol{\mu m})$ & \multicolumn{1}{c|}{ Comment } \\
\hline Aluminum & Alfa Aesar & 41001 & C04M09 & $10-14$ & $\begin{array}{l}\text { Spherical, 98\% } \\
\text { metals basis. }\end{array}$ \\
\hline Carbon & Alfa Aesar & 42130 & K15M10 & $200-400$ & $\begin{array}{l}\text { Glassy spherical, } \\
\text { type 1. }\end{array}$ \\
\hline $\begin{array}{l}\text { Ceramic } \\
\text { Microspheres }\end{array}$ & Zeeland Ind. & W1012 & NA & $63-106$ & $\begin{array}{l}\text { Vacuum baked at } \\
120^{\circ} \text { C for 3 hrs. }\end{array}$ \\
\hline Copper & Alfa Aesar & 43385 & K06L16 & $37-88$ & $\begin{array}{l}\text { Spherical, 99.9\% } \\
\text { metals basis. }\end{array}$ \\
\hline Foam & LLNL & NA & NA & NA & $\begin{array}{l}\text { Single cored } \\
\text { specimen. }\end{array}$ \\
\hline Molybdenum & Alfa Aesar & 41919 & D24L18 & 88 & $\begin{array}{l}\text { Spherical, 99.5\% } \\
\text { metals basis. }\end{array}$ \\
\hline $\begin{array}{l}\text { Ottawa Sand } \\
\text { U.S. Silica }\end{array}$ & F-50 & NA & $\sim 300$ & $\begin{array}{l}\text { Clean, natural quartz } \\
\text { sand }\end{array}$ \\
\hline $\begin{array}{l}\text { Silicon } \\
\text { Carbide }\end{array}$ & LLNL & NA & NA & 50 & Angular grains \\
\hline \begin{tabular}{l} 
Titanium \\
\hline
\end{tabular} & Alfa Aesar & 41545 & F18M19 & $\sim 100$ & $\begin{array}{l}\text { Spherical, 99.9\% } \\
\text { metals basis. }\end{array}$ \\
\hline
\end{tabular}

Table 2. Starting material grain densities

\begin{tabular}{|c|c|c|c|c|c|}
\hline Material & Formula & $\begin{array}{c}\text { Mass } \\
\text { (g) }\end{array}$ & $\begin{array}{c}\text { Volume } \\
\left(\mathrm{cm}^{3}\right)\end{array}$ & $\begin{array}{c}\text { Measured } \\
\text { Density } \\
\left(\mathrm{g} / \mathrm{cm}^{3}\right)\end{array}$ & $\begin{array}{c}\text { Manufacturer's } \\
\text { Density } \\
\left(\mathrm{g} / \mathrm{cm}^{3}\right)\end{array}$ \\
\hline Aluminum & $\mathrm{Al}$ & 5.016 & 1.851 & 2.710 & 2.699 \\
\hline Carbon & $\mathrm{C}$ & 3.211 & 2.426 & 1.324 & 1.450 \\
\hline Intact Ceramic & $\mathrm{NA}$ & 1.333 & 1.960 & 0.680 & NA \\
\hline Crushed Ceramic & $\mathrm{NA}$ & 3.070 & 1.178 & 2.606 & NA \\
\hline Copper & $\mathrm{Cu}$ & 18.823 & 2.121 & 8.76 & 8.940 \\
\hline Foam & NA & 0.8778 & 0.7025 & 1.250 & NA \\
\hline Molybdenum & Mo & 11.08 & 1.103 & 10.049 & 10.220 \\
\hline Ottawa Sand & $\mathrm{SiO} 2$ & 6.514 & 2.479 & 2.627 & 2.650 \\
\hline Silicon Carbide & $\mathrm{SiC}$ & 5.493 & 1.719 & 3.196 & NA \\
\hline Titanium & $\mathrm{Ti}$ & 10.569 & 2.347 & 4.504 & 4.507 \\
\hline
\end{tabular}


Table 3. Initial mass, volume, bulk density and porosity for hydrostatic test specimens

\begin{tabular}{|c|c|c|c|c|}
\hline Specimen & $\begin{array}{c}\text { Powder Mass } \\
\text { (g) }\end{array}$ & $\begin{array}{c}\text { Powder Vol. } \\
\left(\mathrm{cm}^{3}\right)\end{array}$ & $\begin{array}{c}\text { Bulk Density } \\
\left(\mathrm{g} / \mathrm{cm}^{3}\right)\end{array}$ & $\begin{array}{c}\text { Porosity } \\
(\%)\end{array}$ \\
\hline Aluminum \#1 & 59.921 & 36.31 & 1.650 & 38.8 \\
\hline Aluminum \#2 & 60.979 & 36.23 & 1.683 & 37.6 \\
\hline Aluminum \#3 & 59.229 & 36.13 & 1.639 & 39.3 \\
\hline Carbon \#1 & 30.947 & 36.56 & 0.847 & 41.6 \\
\hline Carbon \#2 & 30.867 & 36.39 & 0.848 & 41.5 \\
\hline Carbon \#3 & 31.173 & 36.94 & 0.844 & 41.8 \\
\hline Ceramic \#1 & 13.939 & 36.29 & 0.384 & 85.2 \\
\hline Ceramic \#2 & 14.082 & 36.62 & 0.385 & 85.2 \\
\hline Ceramic\#3 & 14.206 & 37.11 & 0.383 & 85.3 \\
\hline Ceramic \#4 & 13.901 & 36.46 & 0.381 & 85.3 \\
\hline Copper \#1 & 200.779 & 36.62 & 5.483 & 38.7 \\
\hline Copper \#2 & 201.646 & 37.38 & 5.395 & 39.7 \\
\hline Copper \#3 & 193.625 & 35.79 & 5.410 & 39.5 \\
\hline Copper \#4 & 195.436 & 36.08 & 5.416 & 39.4 \\
\hline Copper \#5 & 195.325 & 36.28 & 5.384 & 39.8 \\
\hline Foam \#1 & 5.387 & 37.59 & 0.143 & 88.5 \\
\hline Molybdenum \#1 & 132.913 & 36.98 & 3.594 & 64.8 \\
\hline Molybdenum \#2 & 130.011 & 36.34 & 3.577 & 65.0 \\
\hline Molybdenum \#3 & 130.106 & 36.50 & 3.565 & 65.1 \\
\hline Ottawa Sand \#1 & 63.741 & 35.81 & 1.780 & 32.8 \\
\hline Ottawa Sand \#2 & 62.117 & 35.59 & 1.745 & 34.1 \\
\hline Silicon Carbide \#1 & 61.041 & 36.87 & 1.655 & 48.2 \\
\hline Silicon Carbide \#2 & 61.159 & 36.37 & 1.682 & 47.4 \\
\hline Silicon Carbide \#3 & 60.577 & 36.01 & 1.682 & 47.4 \\
\hline Silicon Carbide \#4 & 60.177 & 36.23 & 1.661 & 48.0 \\
\hline Silicon Carbide \#5 & 60.525 & 36.24 & 1.670 & 47.7 \\
\hline Titanium \#1 & 105.564 & 36.40 & 2.900 & 35.7 \\
\hline Titanium \#2 & 105.299 & 36.38 & 2.895 & 35.8 \\
\hline Titanium \#3 & 105.172 & 36.42 & 2.888 & 35.9 \\
\hline
\end{tabular}

Table 4. Initial mass, volume, bulk density and porosity for solid medium specimens

\begin{tabular}{|c|c|c|c|c|}
\hline Specimen & $\begin{array}{c}\text { Powder Mass } \\
\text { (g) }\end{array}$ & $\begin{array}{c}\text { Powder Vol. } \\
\left(\mathrm{cm}^{3}\right)\end{array}$ & $\begin{array}{l}\text { Bulk Density } \\
\left(\mathrm{g} / \mathrm{cm}^{3}\right)\end{array}$ & $\begin{array}{c}\text { Porosity } \\
(\%)\end{array}$ \\
\hline AlSP_fjr_1 & 1.0503 & 2.723 & 0.386 & 85.1 \\
\hline Mo_fjr_1 & 10.2974 & 2.949 & 3.492 & 65.8 \\
\hline Mo_fjr_2 & 10.3168 & 2.950 & 3.498 & 65.8 \\
\hline Mo_fjr_3 & 10.3415 & 2.950 & 3.506 & 65.7 \\
\hline Mo fjr 4 & 9.7447 & 2.784 & 3.500 & 65.8 \\
\hline Mo_fjr_5 & 9.7520 & 2.782 & 3.505 & 65.7 \\
\hline Mo_fjr_6 & 9.7494 & 2.783 & 3.504 & 65.7 \\
\hline Mo_fjr_7 & 9.7500 & 2.785 & 3.501 & 65.7 \\
\hline
\end{tabular}


Table 5. Data reduction table for solid medium tests

\begin{tabular}{|c|c|c|c|c|c|c|c|c|c|c|c|c|}
\hline 1 & 2 & 3 & 4 & 5 & 6 & 7 & 8 & 9 & 10 & 11 & 12 & 13 \\
\hline $\begin{array}{l}\mathbf{P} \\
(k b)\end{array}$ & $\begin{array}{l}\text { Orig. } \\
\text { D(in) }\end{array}$ & $\begin{array}{l}\text { Nickel } \\
\text { D(in) }\end{array}$ & $\begin{array}{l}\text { Shifted } \\
\text { D(in) }\end{array}$ & $\begin{array}{l}\text { Diff. } \\
\text { D(in) }\end{array}$ & $\begin{array}{l}\text { Zeroed } \\
\text { D(in) }\end{array}$ & $\begin{array}{l}\Delta V \\
\left(\mathrm{~cm}^{3}\right)\end{array}$ & $\begin{array}{l}\mathrm{Ni} \mathrm{V} \\
\left(\mathrm{cm}^{3}\right)\end{array}$ & $\begin{array}{l}\mathrm{V} \\
\left(\mathrm{cm}^{3}\right)\end{array}$ & $\begin{array}{l}\text { Sp. V } \\
\left(\mathrm{cm}^{3} / \mathrm{g}\right)\end{array}$ & V/Vo & Мu & $\begin{array}{l}\text { P } \\
\text { (GPa) }\end{array}$ \\
\hline 0.000 & 0.000018 & 0.00003 & 0.000018 & $-1.21 \mathrm{e}-5$ & 0.0000 & 0.0000 & 2.71440 & 2.8203 & 0.28928 & 1.0000 & 0.0000 & 0.00 \\
\hline 0.025 & 0.000487 & 0.00015 & 0.075487 & 0.075337 & 0.075349 & 0.20453 & 2.71430 & 2.6156 & 0.26829 & 0.92744 & 0.083857 & 0.00250 \\
\hline 0.050 & 0.017207 & 0.00029 & 0.092207 & 0.091917 & 0.091929 & 0.24953 & 2.71420 & 2.5705 & 0.26366 & 0.91145 & 0.10298 & 0.00500 \\
\hline 0.075 & 0.040065 & 0.00040 & 0.115065 & 0.11467 & 0.11468 & 0.31128 & 2.71409 & 2.5087 & 0.25732 & 0.88952 & 0.13032 & 0.00750 \\
\hline 0.100 & 0.057484 & 0.00049 & 0.132484 & 0.13199 & 0.13201 & 0.35831 & 2.71399 & 2.4615 & 0.25248 & 0.87281 & 0.15208 & 0.01000 \\
\hline 0.125 & 0.070230 & 0.00061 & 0.145230 & 0.14462 & 0.14463 & 0.39258 & 2.71389 & 2.4272 & 0.24896 & 0.86062 & 0.16849 & 0.0125 \\
\hline 0.150 & 0.082509 & 0.00071 & 0.157509 & 0.15680 & 0.15681 & 0.42564 & 2.71379 & 2.3940 & 0.24555 & 0.84886 & 0.18477 & 0.0150 \\
\hline 0.175 & 0.093855 & 0.00083 & 0.168855 & 0.16803 & 0.16804 & 0.45612 & 2.71368 & 2.3634 & 0.24242 & 0.83802 & 0.20018 & 0.0175 \\
\hline 0.200 & 0.103890 & 0.00094 & 0.178890 & 0.17795 & 0.17796 & 0.48306 & 2.71358 & 2.3364 & 0.23964 & 0.82843 & 0.21416 & 0.0200 \\
\hline 0.250 & 0.122909 & 0.00123 & 0.197909 & 0.19668 & 0.19669 & 0.53389 & 2.71338 & 2.2853 & 0.23441 & 0.81033 & 0.24144 & 0.0250 \\
\hline 0.300 & 0.141531 & 0.00163 & 0.216531 & 0.21490 & 0.21491 & 0.58336 & 2.71317 & 2.2357 & 0.22932 & 0.79272 & 0.26918 & 0.0300 \\
\hline 0.350 & 0.159520 & 0.00218 & 0.234520 & 0.23234 & 0.23235 & 0.63069 & 2.71297 & 2.1881 & 0.22444 & 0.77586 & 0.29693 & 0.0350 \\
\hline 0.400 & 0.176955 & 0.00287 & 0.251955 & 0.24908 & 0.24910 & 0.67614 & 2.71276 & 2.1425 & 0.21976 & 0.75968 & 0.32474 & 0.0400 \\
\hline 0.450 & 0.194079 & 0.00353 & 0.269079 & 0.26555 & 0.26556 & 0.72083 & 2.71256 & 2.0976 & 0.21515 & 0.74376 & 0.35328 & 0.0450 \\
\hline 0.500 & 0.210341 & 0.00421 & 0.285341 & 0.28113 & 0.28114 & 0.76313 & 2.71235 & 2.0551 & 0.21079 & 0.72869 & 0.38145 & 0.0500 \\
\hline 0.600 & 0.240599 & 0.00605 & 0.315599 & 0.30955 & 0.30956 & 0.84026 & 2.71194 & 1.9775 & 0.20284 & 0.70119 & 0.43600 & 0.0600 \\
\hline 0.700 & 0.268139 & 0.00752 & 0.343139 & 0.33562 & 0.33563 & 0.91103 & 2.71153 & 1.9064 & 0.19554 & 0.67595 & 0.49000 & 0.0700 \\
\hline 0.800 & 0.292190 & 0.00858 & 0.367190 & 0.35861 & 0.35862 & 0.97343 & 2.71113 & 1.8436 & 0.18909 & 0.65368 & 0.54114 & 0.0800 \\
\hline 0.900 & 0.312563 & 0.00942 & 0.387563 & 0.37814 & 0.37815 & 1.0265 & 2.71072 & 1.7901 & 0.18361 & 0.63474 & 0.58749 & 0.0900 \\
\hline 1.000 & 0.330144 & 0.01018 & 0.405144 & 0.39496 & 0.39498 & 1.0721 & 2.71031 & 1.7441 & 0.17889 & 0.61840 & 0.62975 & 0.100 \\
\hline
\end{tabular}


Table 6. Energy expended in compaction

\begin{tabular}{|c|c|c|c|c|}
\hline \multirow[b]{2}{*}{ Material } & \multicolumn{2}{|c|}{ Hydrostatic Data (1 GPa) } & \multicolumn{2}{|c|}{ Solid Medium (3 GPa) } \\
\hline & $\begin{array}{c}\text { Energy } / \mathrm{cm}^{3} \\
\left(\mathrm{~kJ} / \mathrm{cm}^{3}\right)\end{array}$ & $\begin{array}{c}\text { Energy/g } \\
(\mathrm{kJ} / \mathrm{g})\end{array}$ & $\begin{array}{c}\text { Energy } / \mathrm{cm}^{3} \\
\left(\mathrm{~kJ} / \mathrm{cm}^{3}\right)\end{array}$ & $\begin{array}{c}\text { Energy/g } \\
(\mathrm{kJ} / \mathrm{g})\end{array}$ \\
\hline Aluminum & 0.0168 & .0102 & NA & NA \\
\hline Carbon & 0.0448 & .0167 & NA & NA \\
\hline Ceramic & 0.0309 & .0806 & 0.060 & 0.155 \\
\hline Copper & 0.0486 & .00456 & $\mathrm{NA}$ & $\mathrm{NA}$ \\
\hline Molybdenum & 0.0843 & .0236 & 0.145 & 0.0416 \\
\hline Ottawa Sand & 0.0395 & .0226 & NA & NA \\
\hline Silicon Carbide & 0.0585 & .0351 & NA & NA \\
\hline Titanium & 0.0768 & .0265 & NA & NA \\
\hline
\end{tabular}

${ }^{1}$ From Kawakita fits to the hydrostatic pressure-volume data to $1 \mathrm{GPa}$.

Table 7. Exponential model parameters

\begin{tabular}{|l|c|c|c|c|}
\hline Material & $\begin{array}{c}\text { Porosity } \\
\text { Range }\end{array}$ & $\begin{array}{c}\text { Merge } \\
\text { Pressure } \\
(\mathbf{G P a})\end{array}$ & $\begin{array}{c}\text { Pressure } \\
\text { Dependence } \\
\left(\mathbf{G P a}^{-1}\right)\end{array}$ & $\begin{array}{c}\text { Correlation } \\
\text { Coefficient }\end{array}$ \\
\hline Aluminum & $0.0-0.2$ & 0.348 & -12.9 & .917 \\
\hline Carbon & $0.3-0.4$ & 432 & -22.7 & .986 \\
\hline Ceramic & $0.3-0.8$ & 57.6 & -12.5 & .979 \\
\hline Copper & $0.0-0.3$ & 0.927 & -12.6 & .951 \\
\hline Molybdenum & $0.15-0.5$ & 2.88 & -7.39 & .999 \\
\hline Ottawa Sand & $0.16-0.26$ & 32.8 & -20.7 & .943 \\
\hline Silicon Carbide & $0.2-0.4$ & 34.8 & -15.5 & .984 \\
\hline Titanium & $0.05-0.3$ & 1.46 & -10.4 & .999 \\
\hline
\end{tabular}

Table 8. Model estimates of merge pressure and energy expended in compaction

\begin{tabular}{|l|c|c|c|c|}
\hline \multirow{2}{*}{ Material } & \multicolumn{2}{|c|}{ Exponential Model } & \multicolumn{2}{c|}{ Second Order Model } \\
\cline { 2 - 5 } & $\begin{array}{c}\text { Energy } \\
(\mathrm{kJ} / \mathrm{g})\end{array}$ & $\begin{array}{c}\text { Merge Pres. } \\
(\mathrm{GPa})\end{array}$ & $\begin{array}{c}\text { Energy } \\
(\mathrm{kJ} / \mathrm{g})\end{array}$ & $\begin{array}{c}\text { Merge Pres. } \\
(\mathrm{GPa})\end{array}$ \\
\hline Aluminum & 0.0085 & 0.348 & 0.0121 & 0.741 \\
\hline Carbon & 11.5 & 432 & NA & NA \\
\hline Ceramic & 2.05 & 57.6 & 0.907 & 10.6 \\
\hline Copper & 0.00932 & 0.927 & NA & NA \\
\hline Molybdenum & 0.0503 & 2.88 & 0.0547 & 3.70 \\
\hline Ottawa Sand & 0.566 & 32.8 & NA & NA \\
\hline Silicon Carbide & 0.782 & 34.8 & NA & NA \\
\hline Titanium & 0.0351 & 1.46 & NA & NA \\
\hline
\end{tabular}




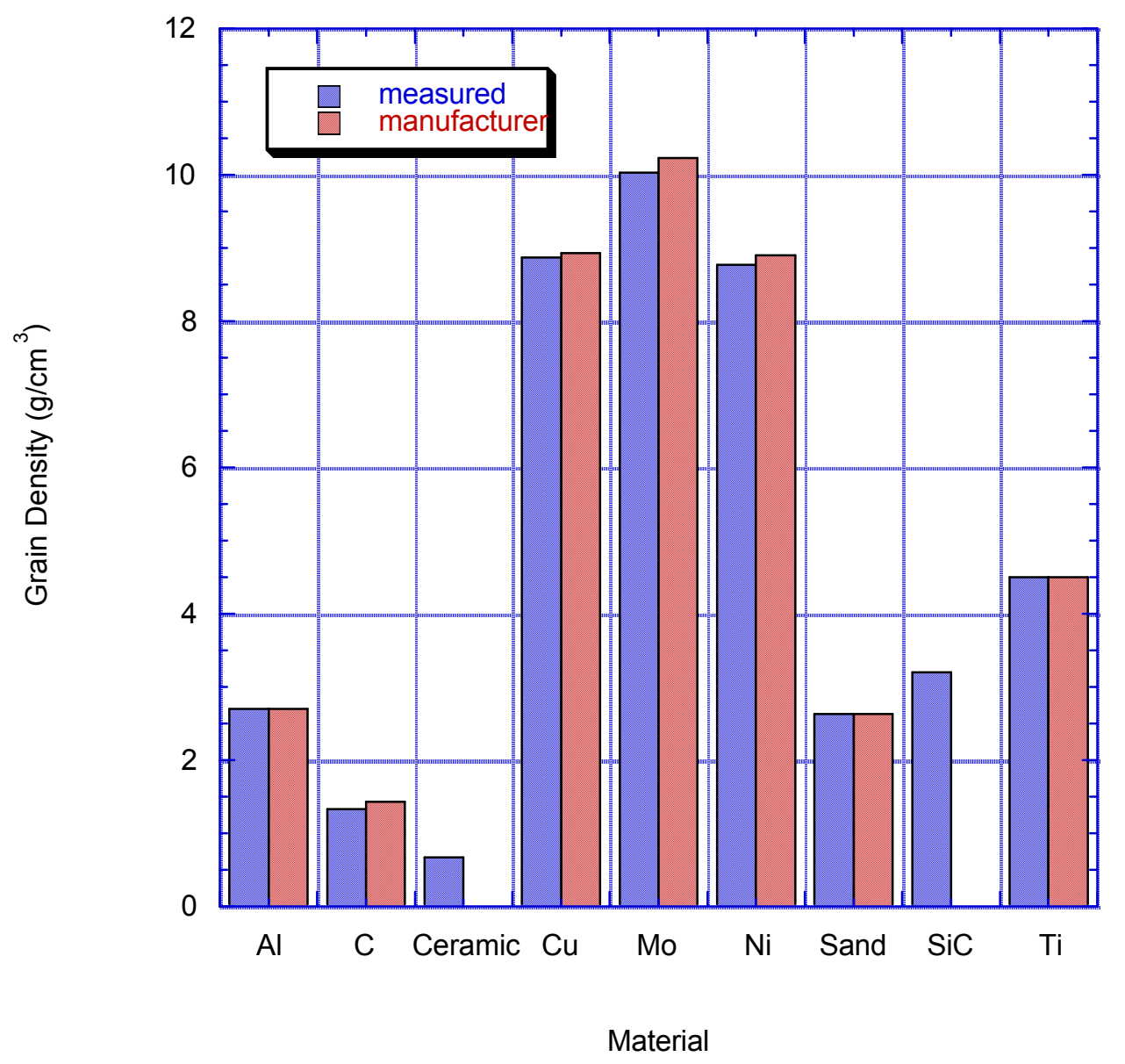

Fig. 1. Grain densities of test materials. 


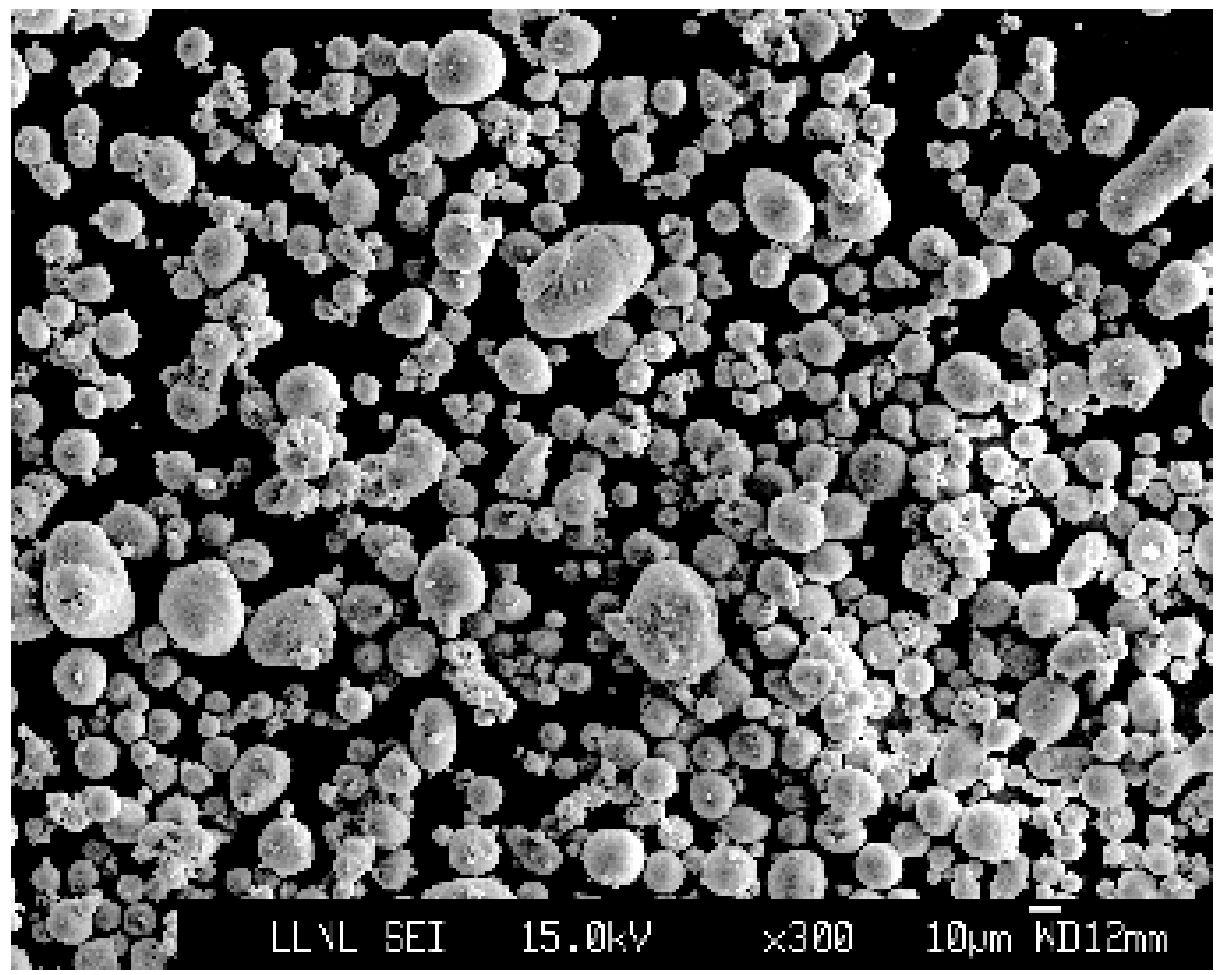

a.

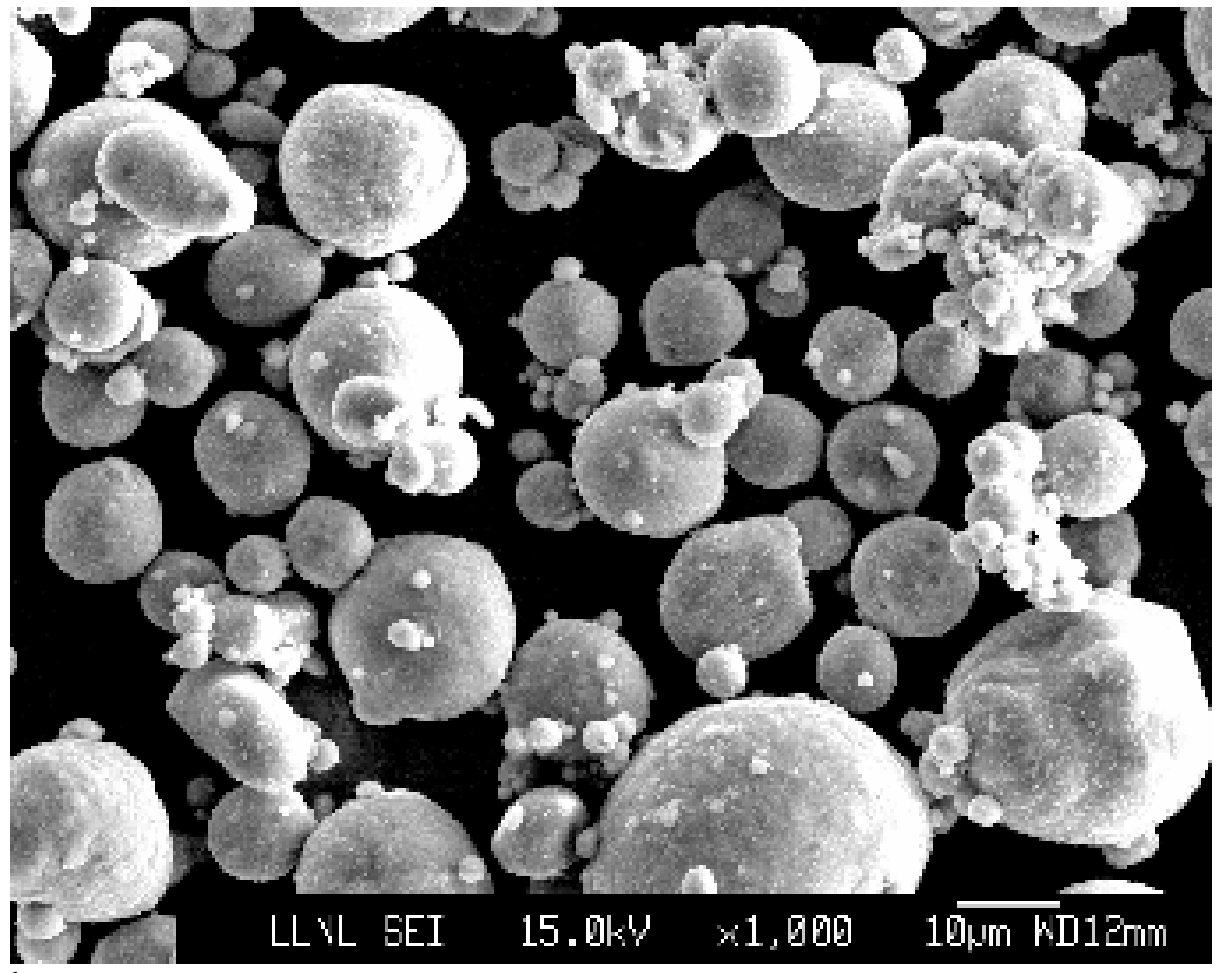

b.

Fig. 2. SEM photographs of untested aluminum powder. Magnification: a) 300x. b) $1000 x$. 


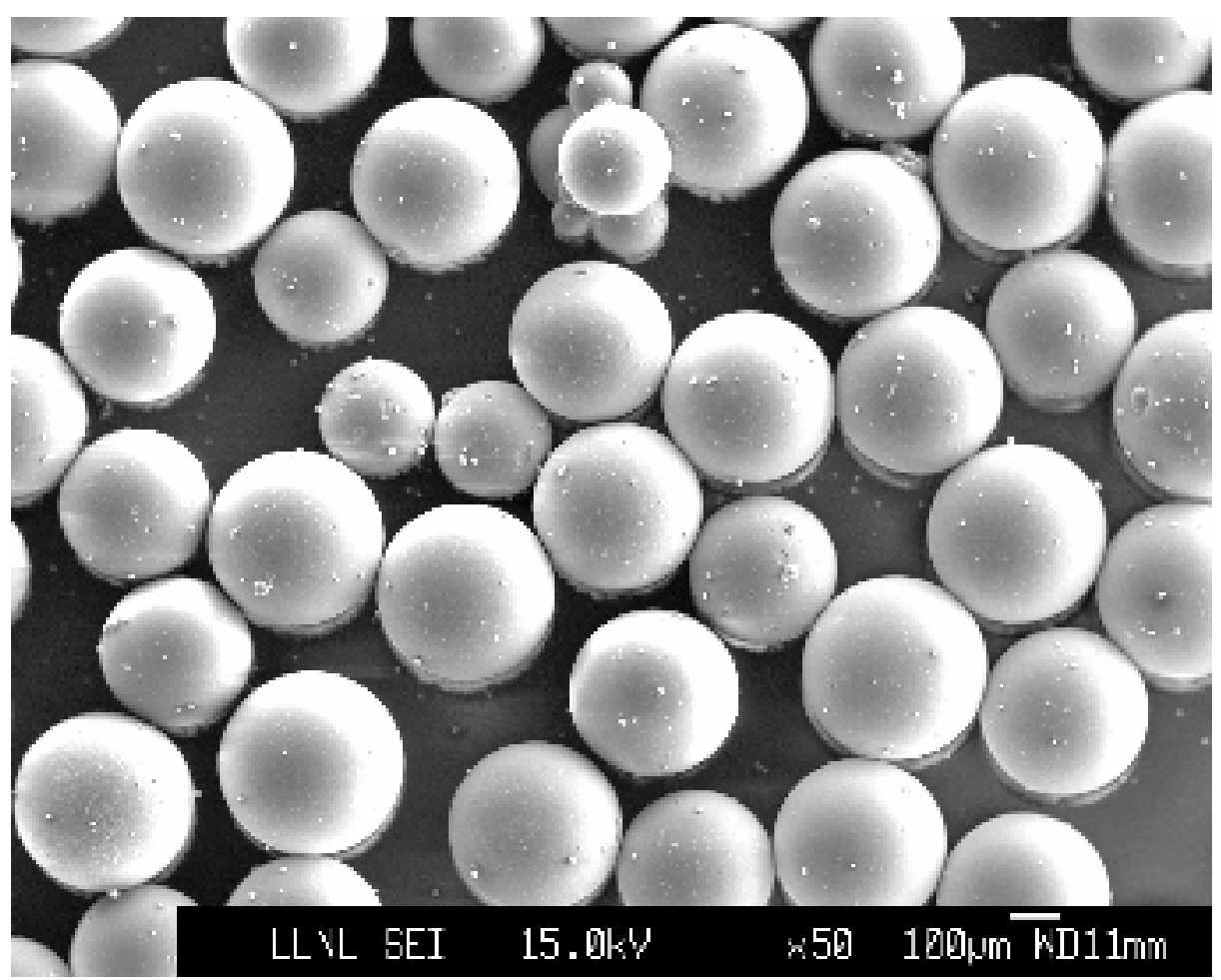

a.

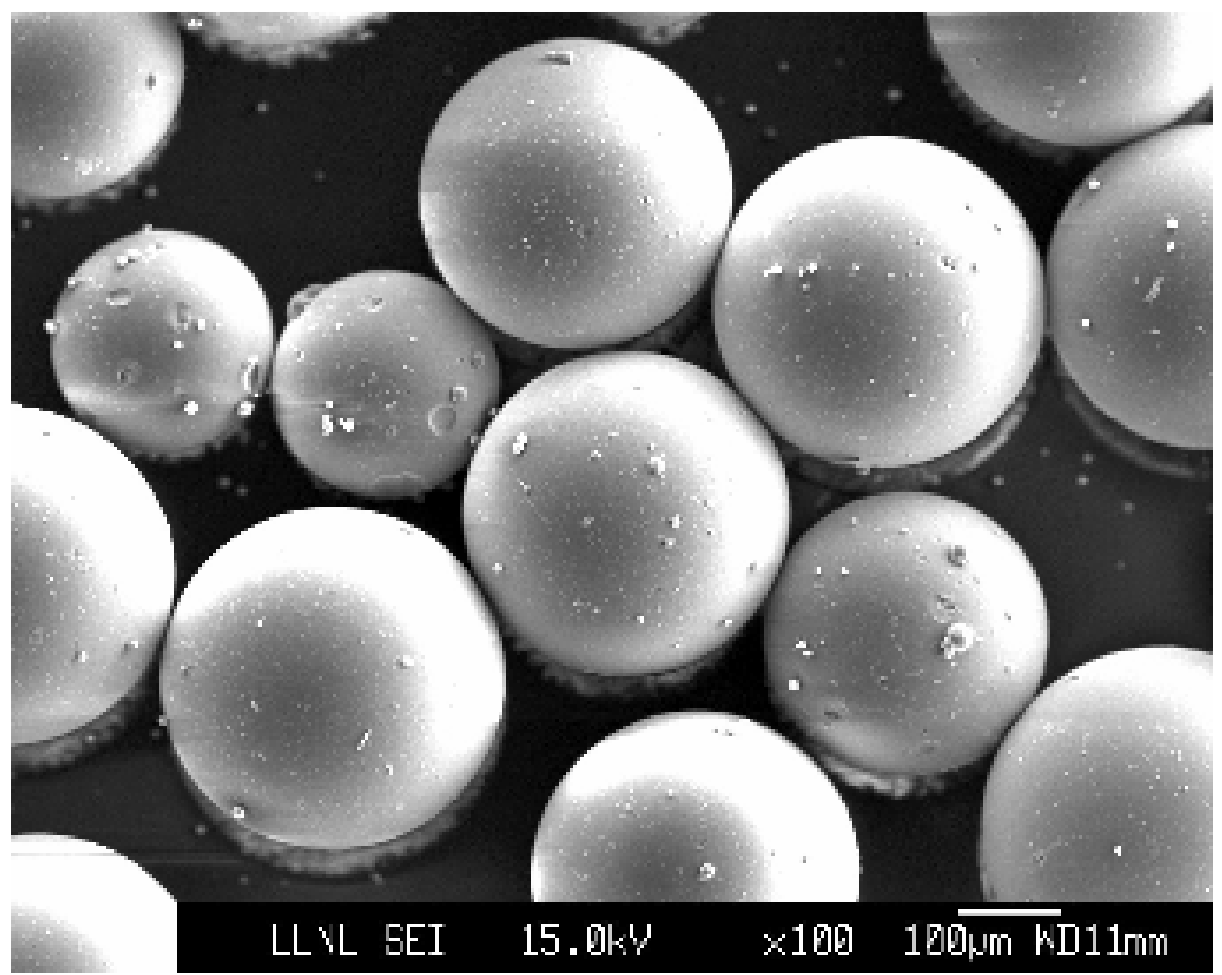

b.

Fig. 3. SEM images of untested glassy carbon powder. Magnification: a.) 50x. b.) 100x. 


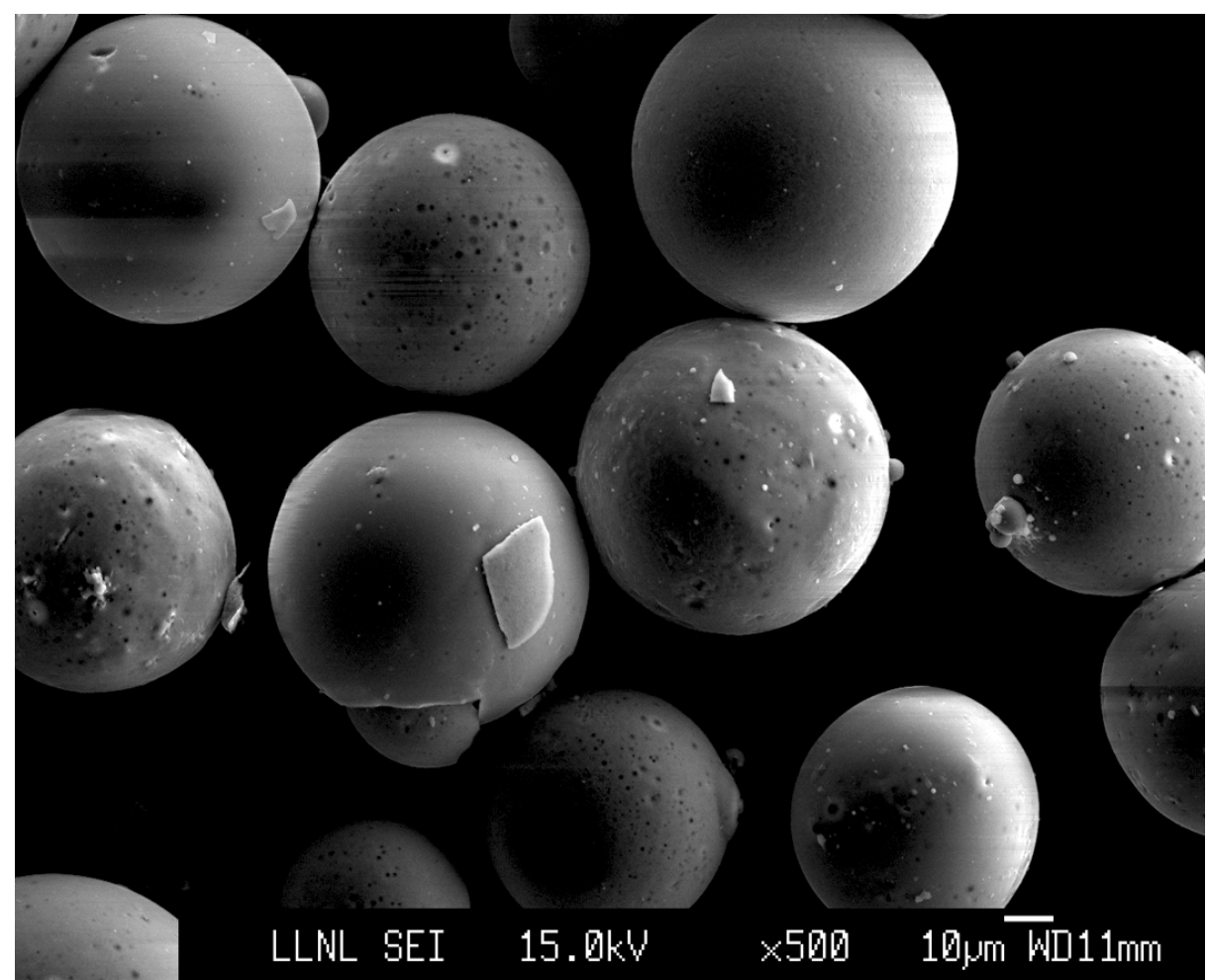

a.

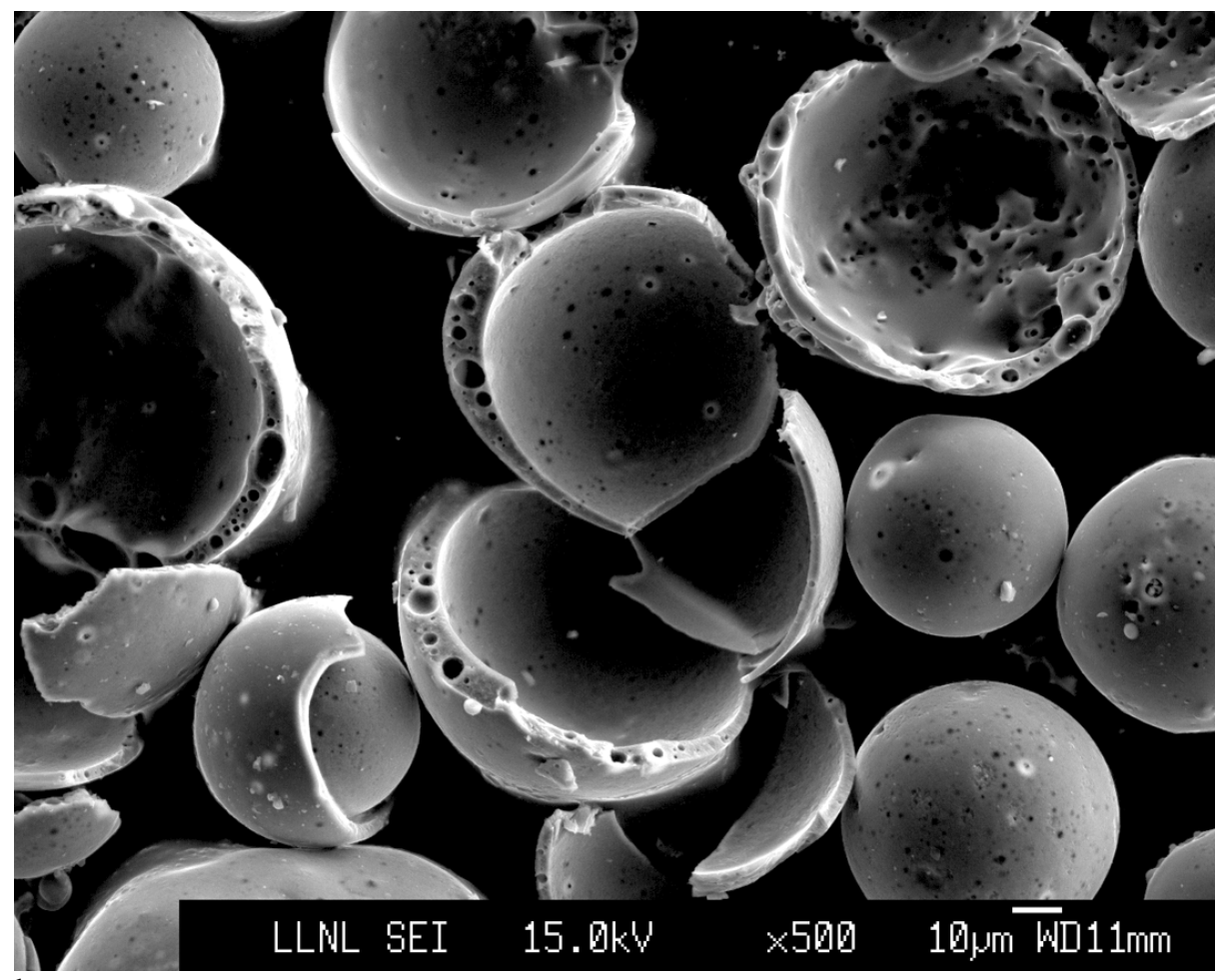

b.

Fig. 4. Untested ceramic microspheres a.) original condition. b.) crushed between platens. Magnification: 500x. 


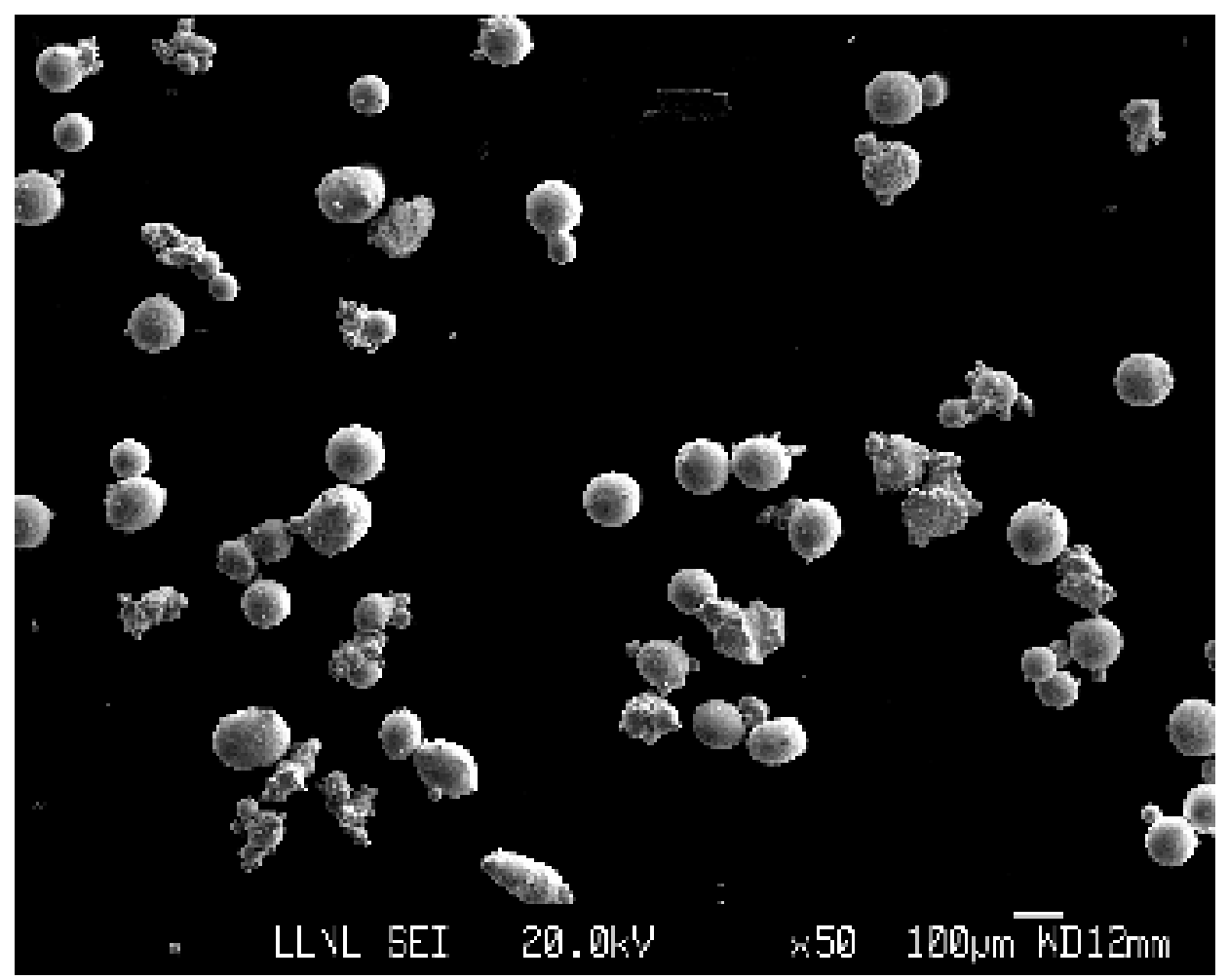

a.

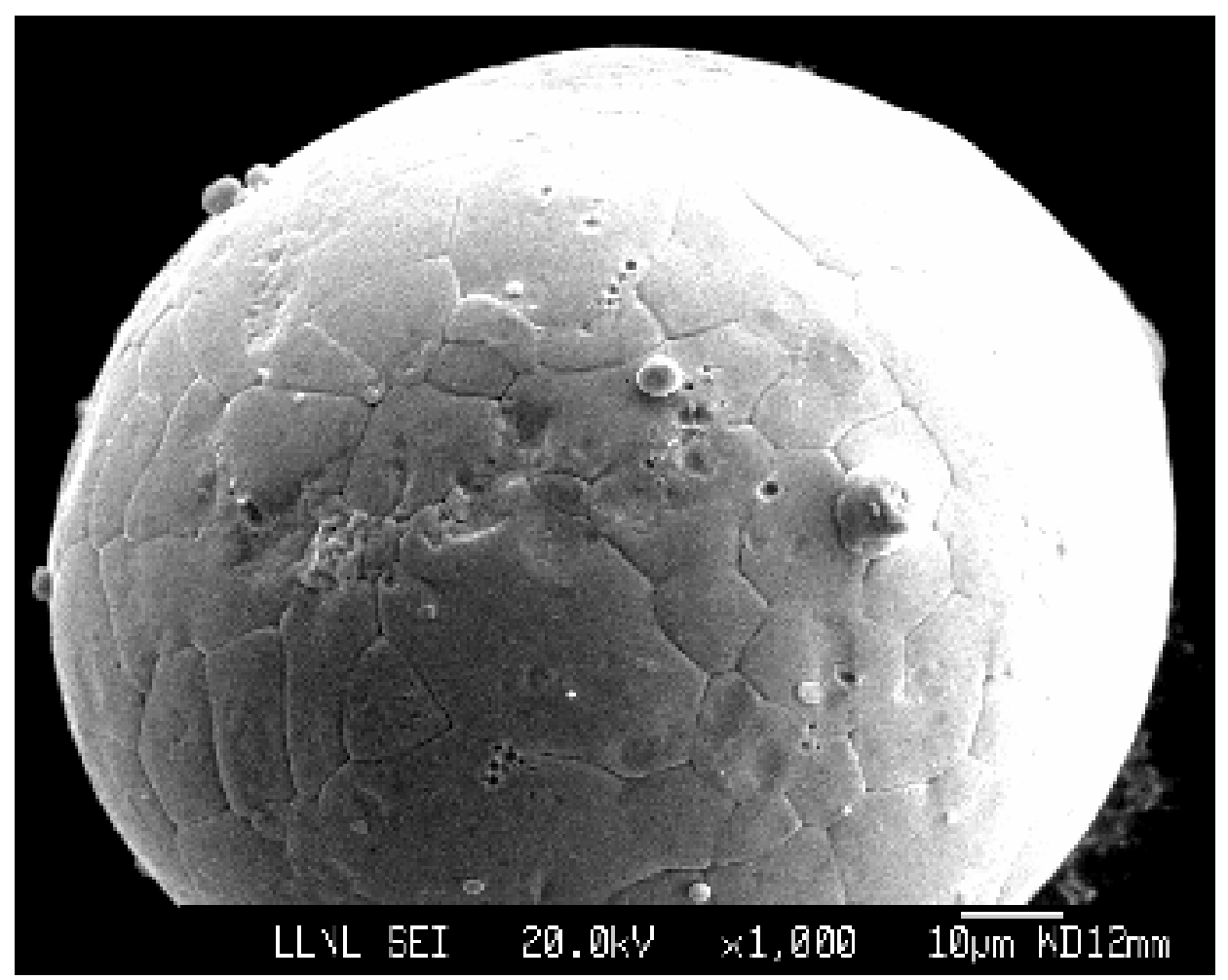

b.

Fig. 5. SEM photographs of untested copper powder. Magnification: a) 50x. b) 1000x. 


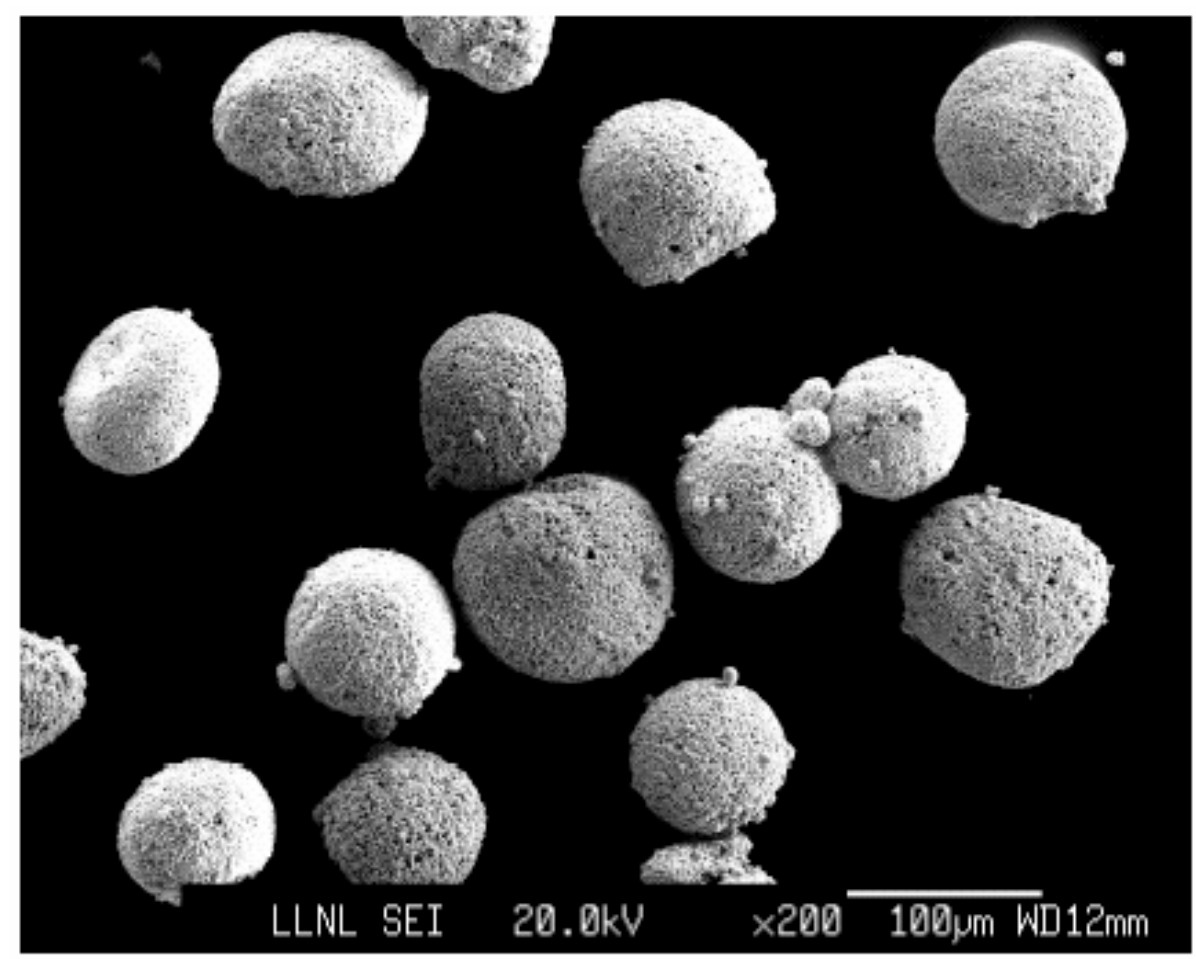

a.

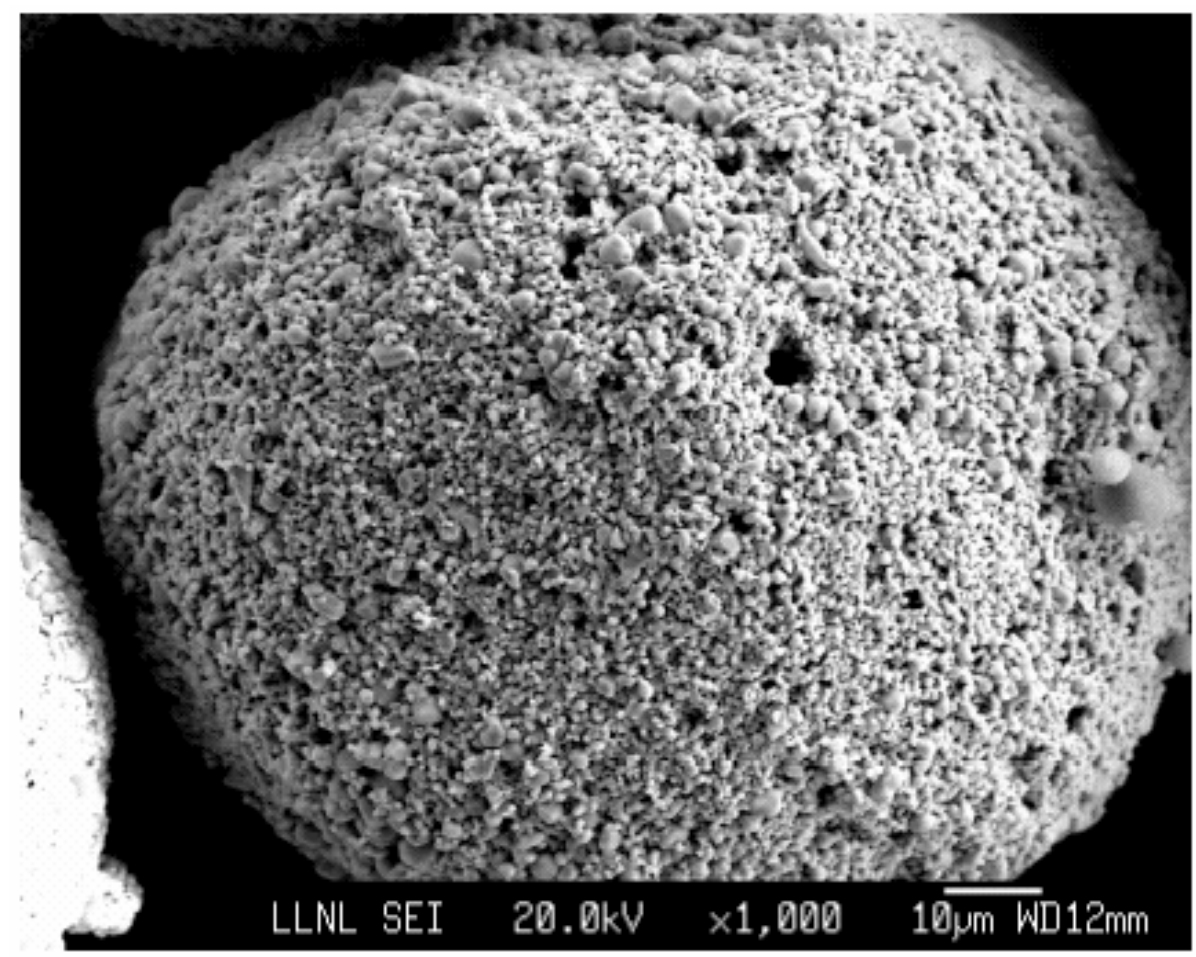

b.

Fig. 6. SEM photographs of untested molybdenum powder. Magnification: a) 200x. b) 1000x 


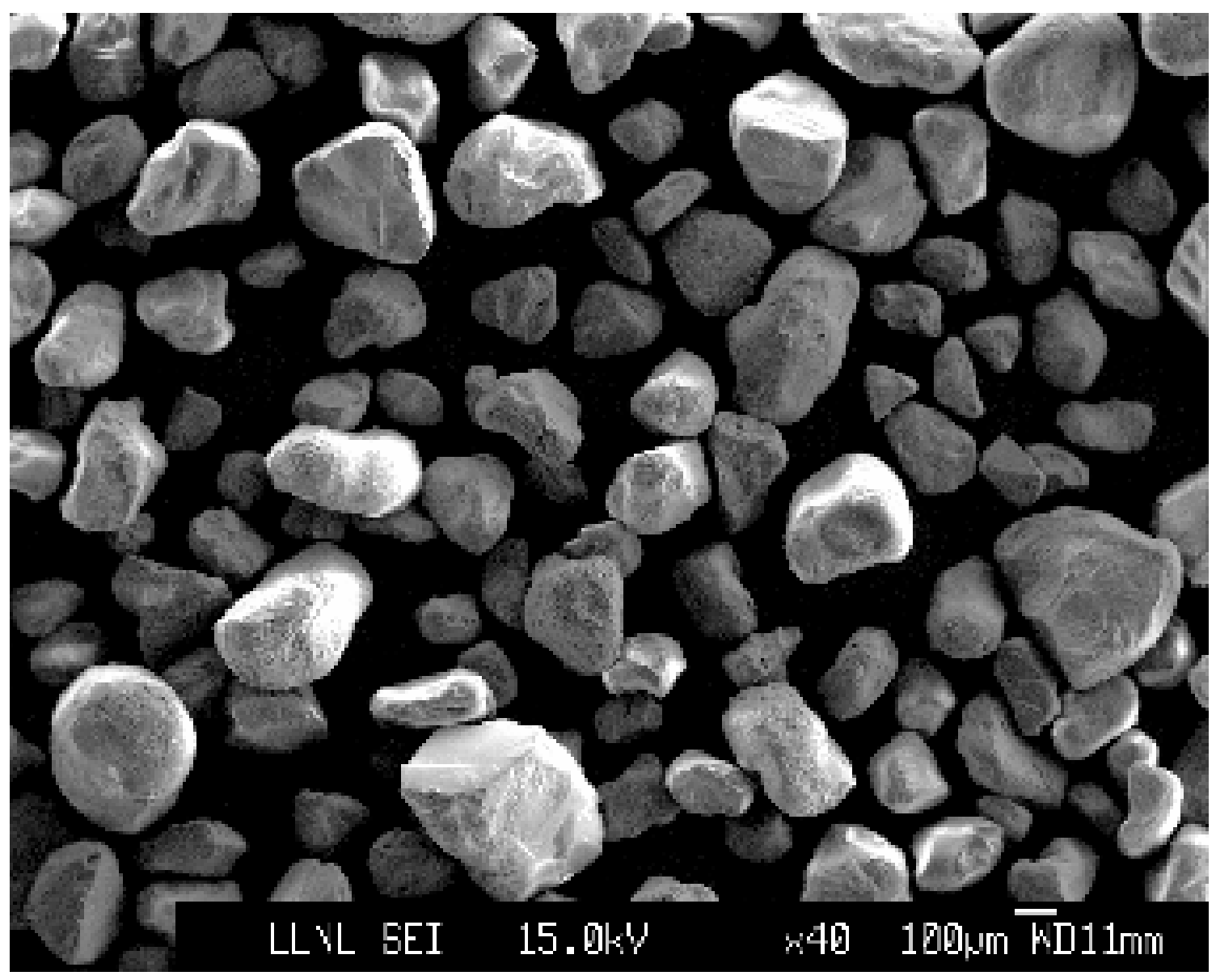

Fig. 7. SEM photograph of untested Ottawa sand. Magnification: 40x. 


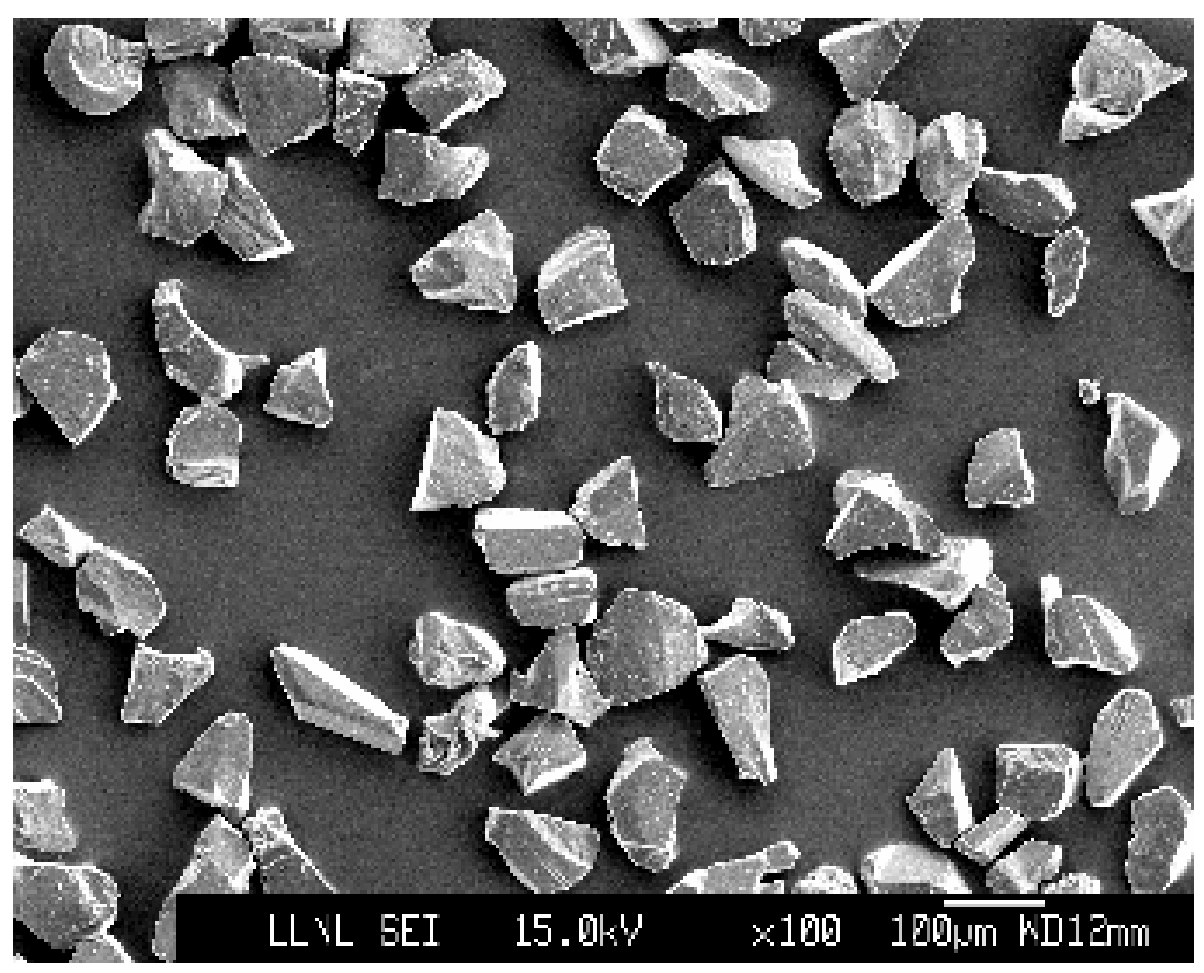

a.

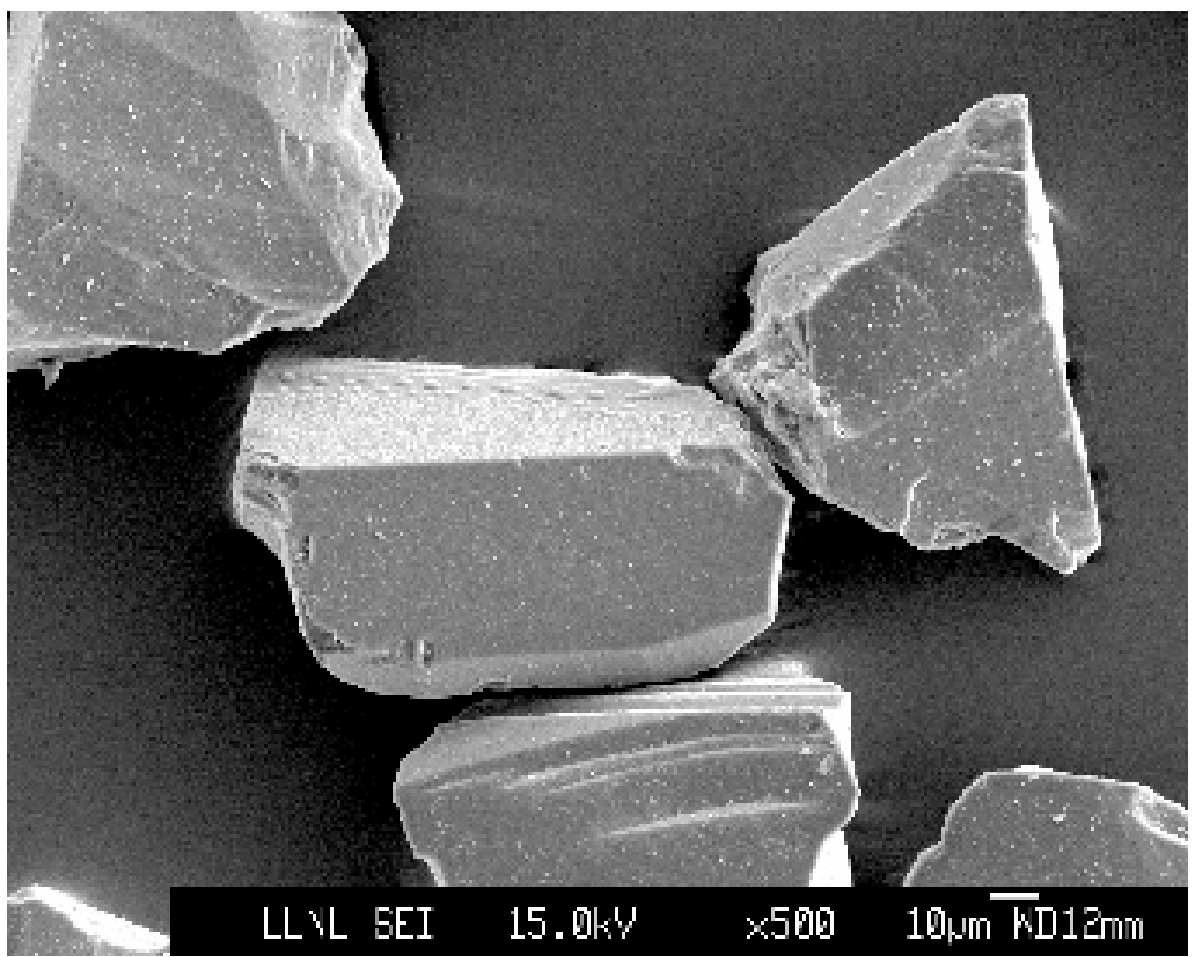

b.

Fig. 8. SEM photographs of untested silicon carbide powder. Magnification: a) 100x. b) $500 x$. 


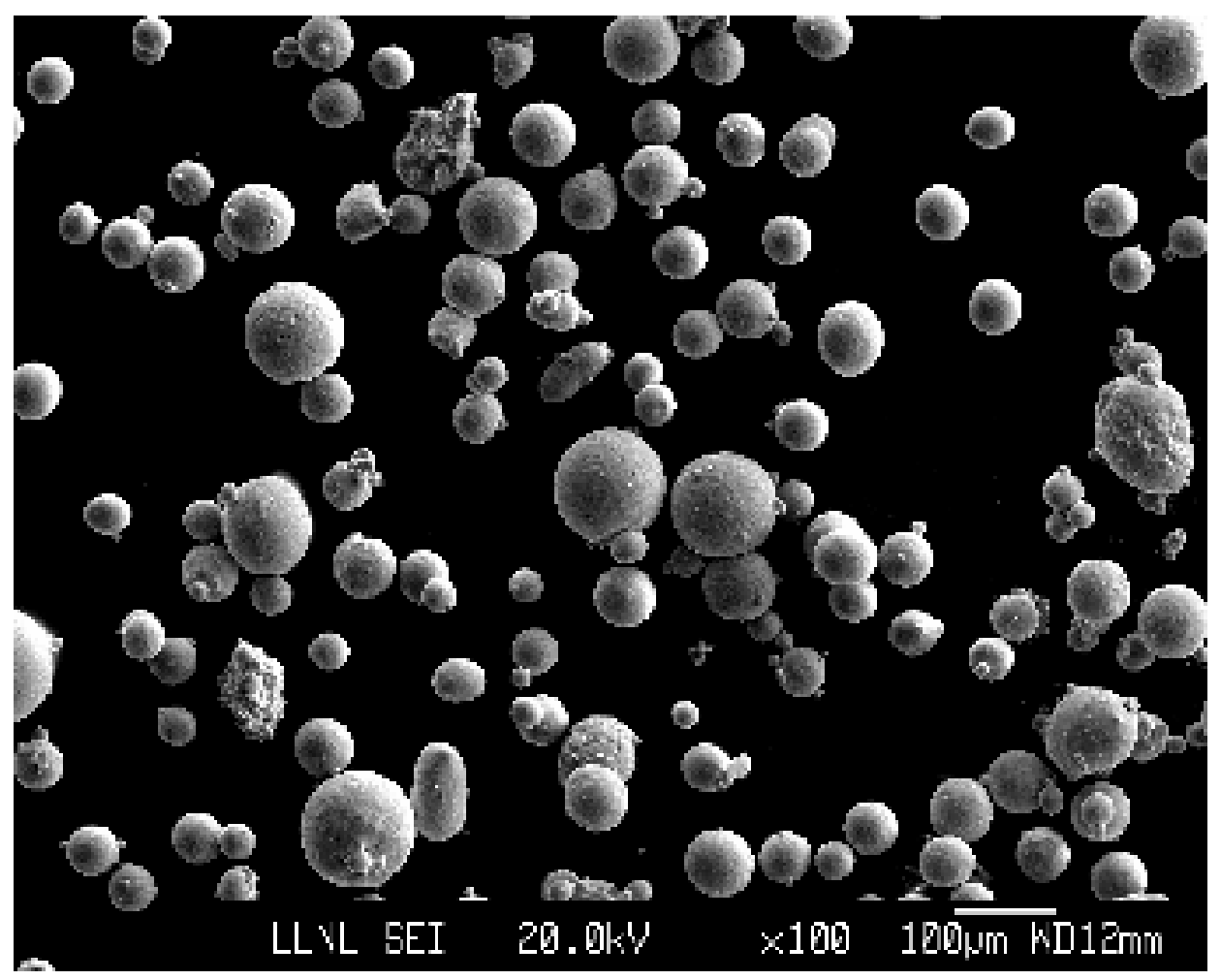

a.

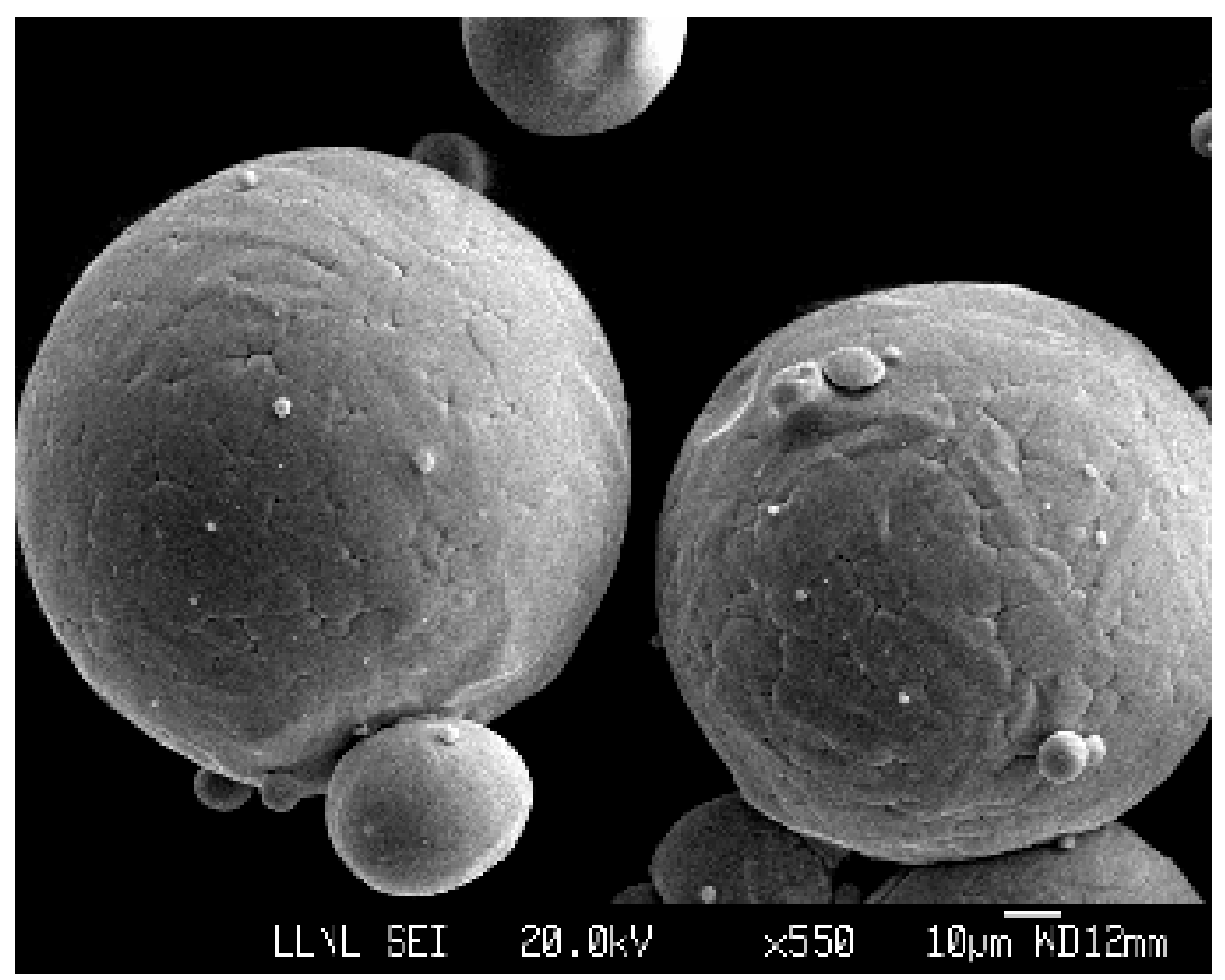

b.

Fig. 9. SEM photographs of untested titanium powder. Magnification: a) 100x. b) 550x. 


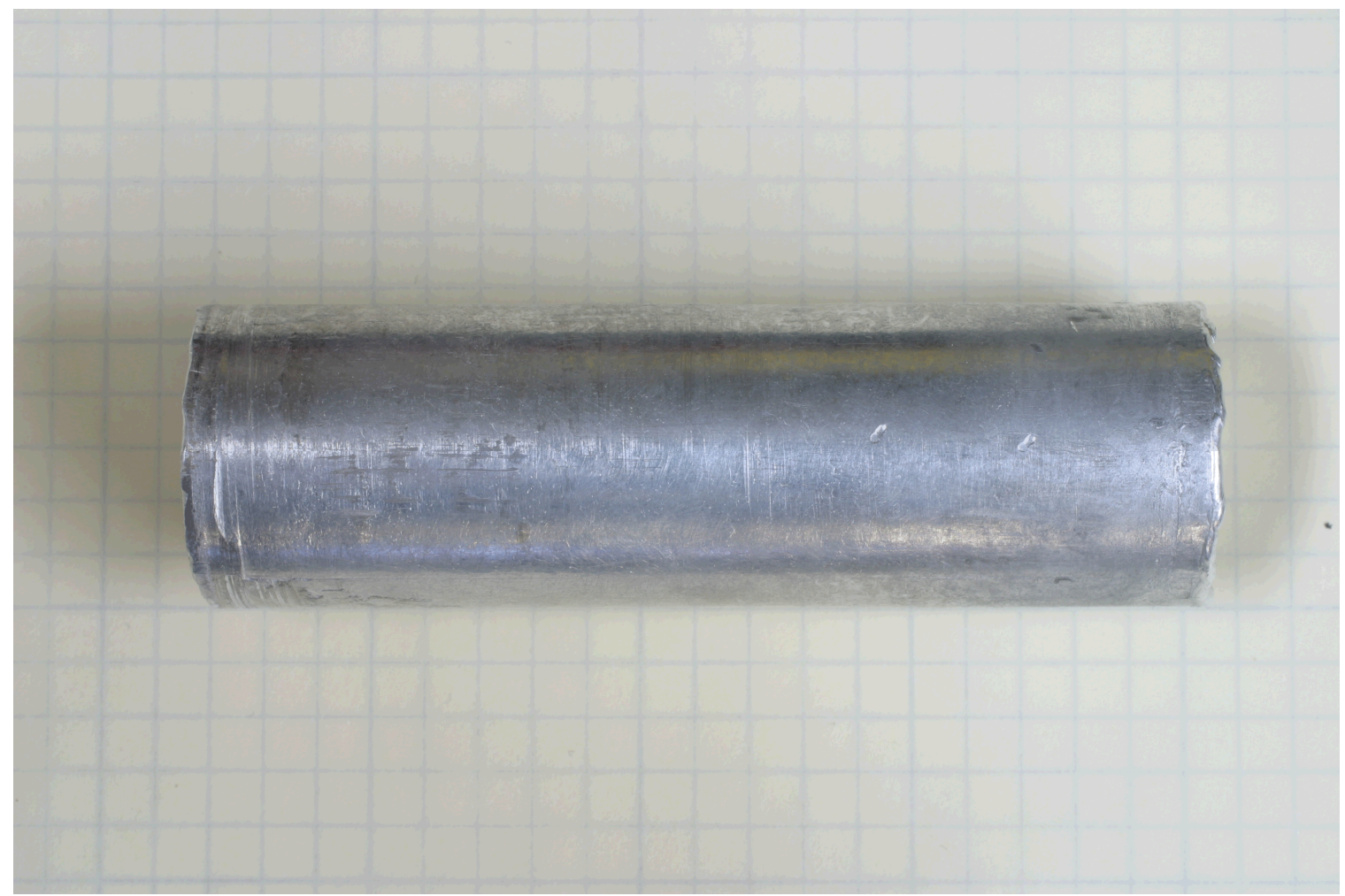

a.

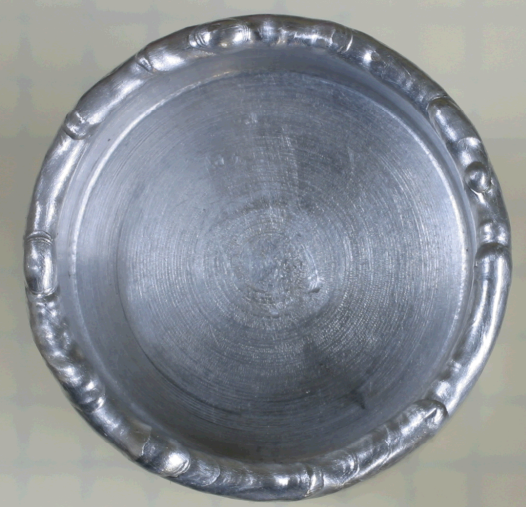

b.

Fig. 10. Jacketed specimen prepared for hydrostatic testing, a.) side view. b.) top view. 


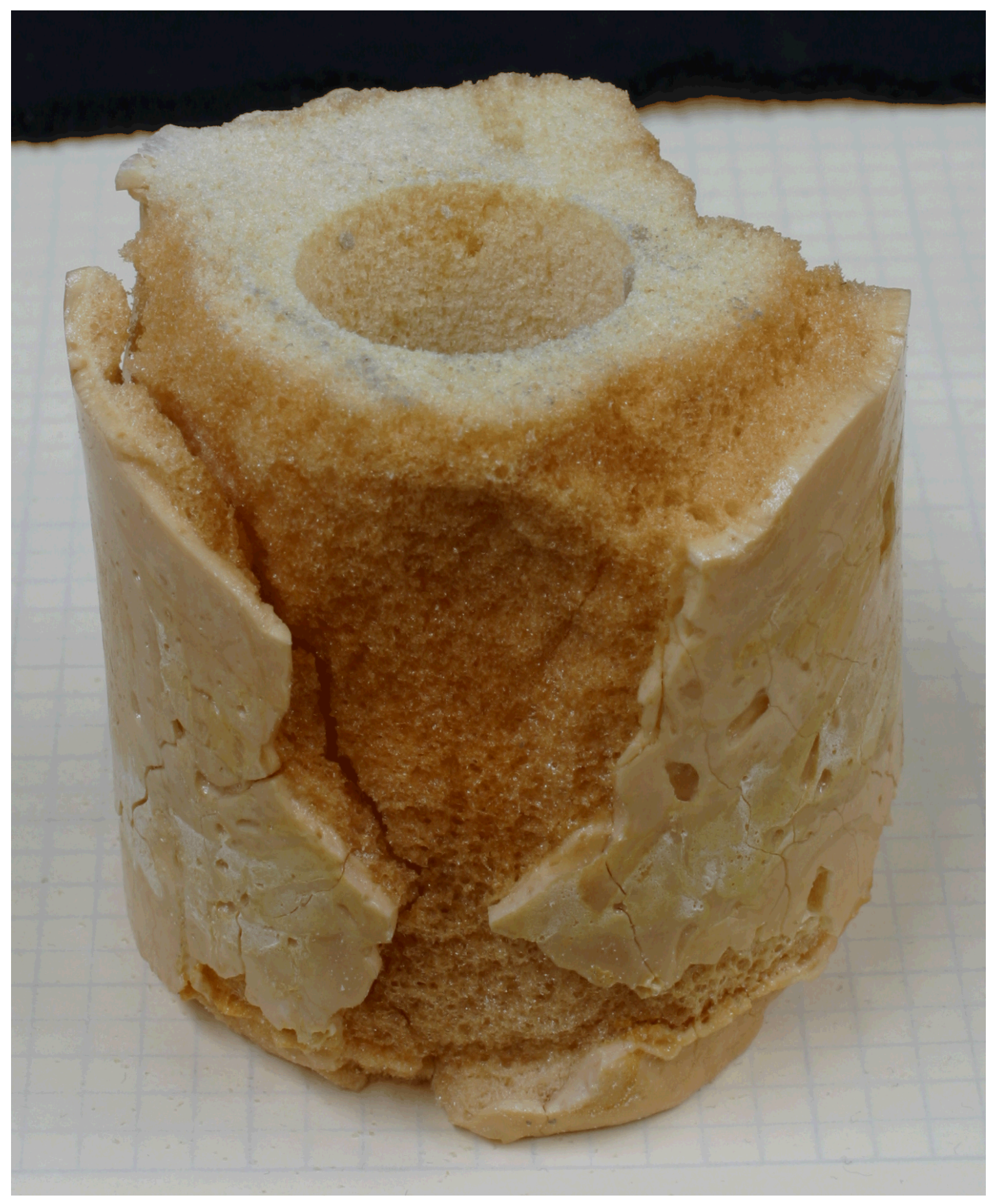

Fig. 11. Original foam cylinder with core removed. 

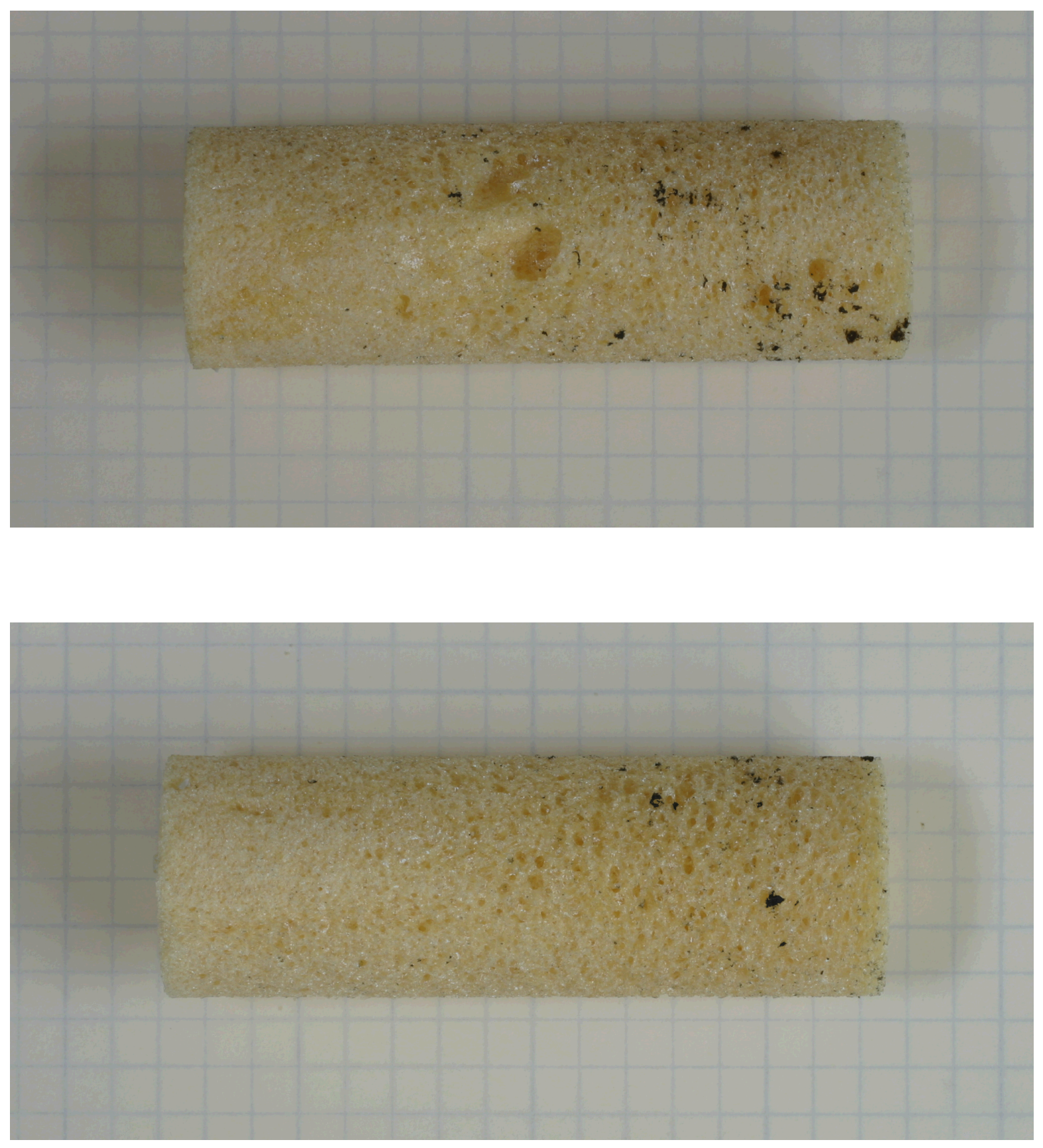

Fig. 12. Two views of the foam specimen prior to jacketing. A few large pores can be seen in the upper image. The background grid is five squares per inch. 


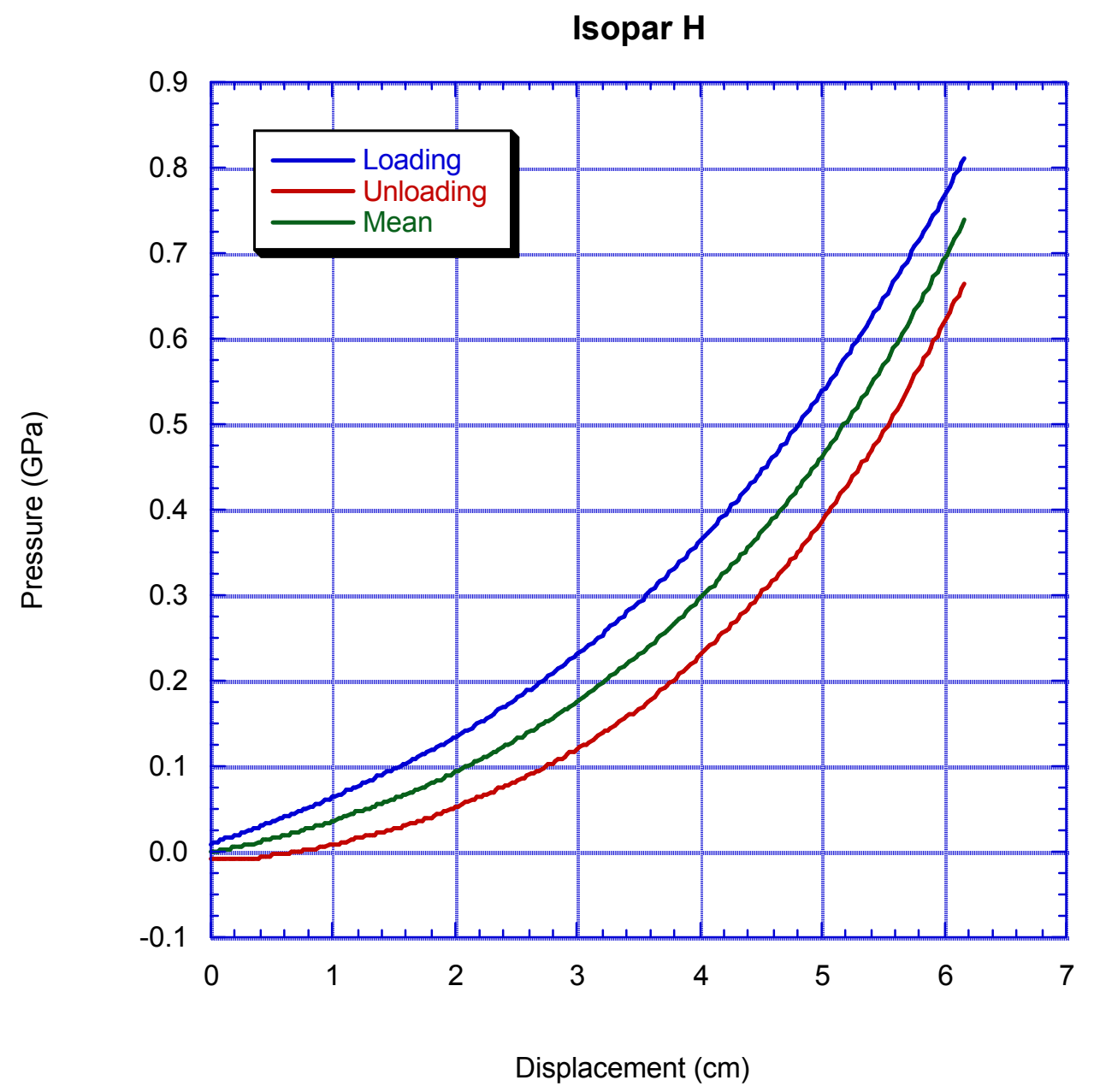

Fig. 13. Pressure-displacement curves for Isopar $\mathrm{H}$ used in friction calculations for the liquid medium press. 


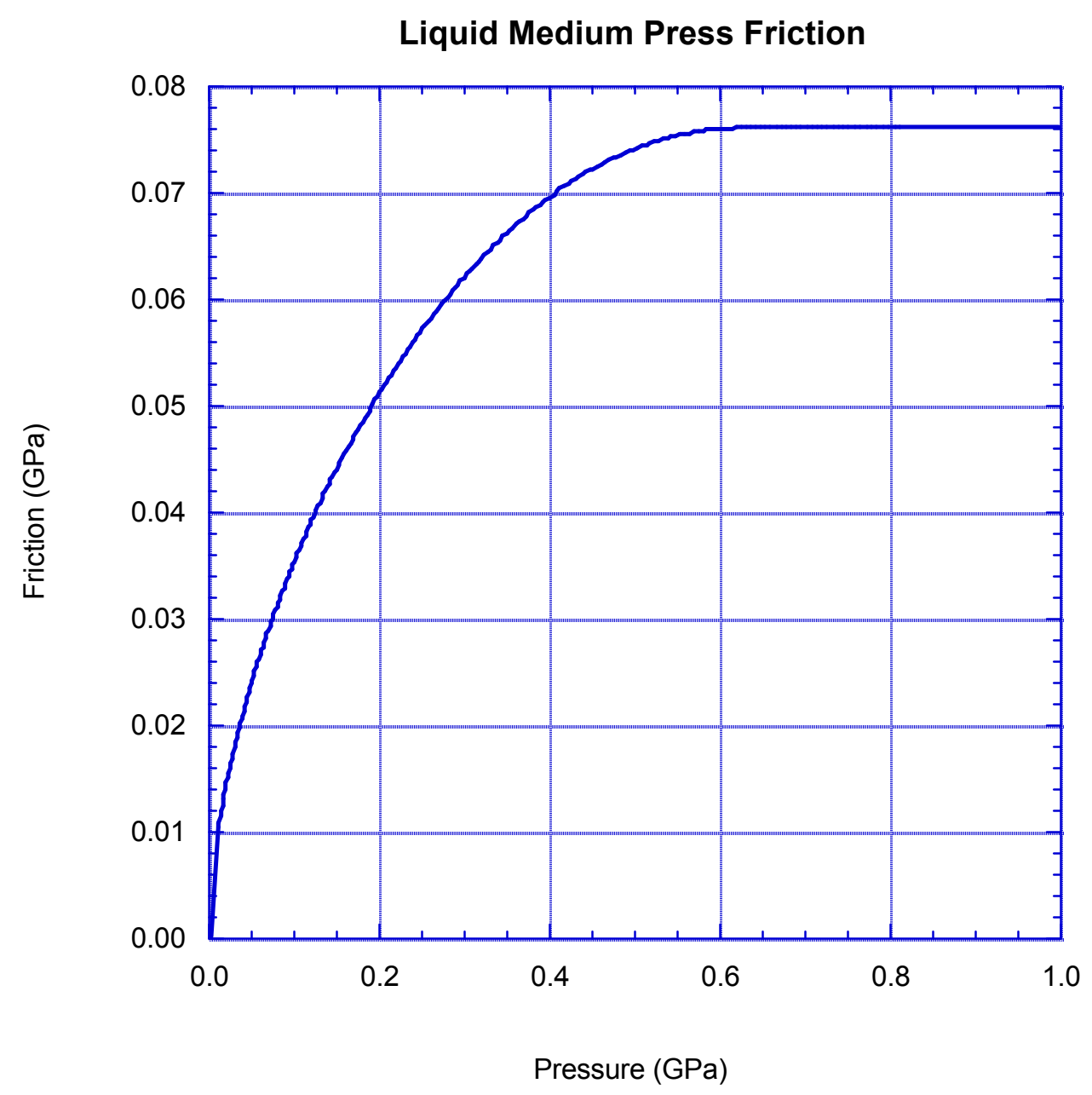

Fig. 14. Friction correction for the liquid medium press obtained from Isopar $\mathrm{H}$ pressuredisplacement data. 


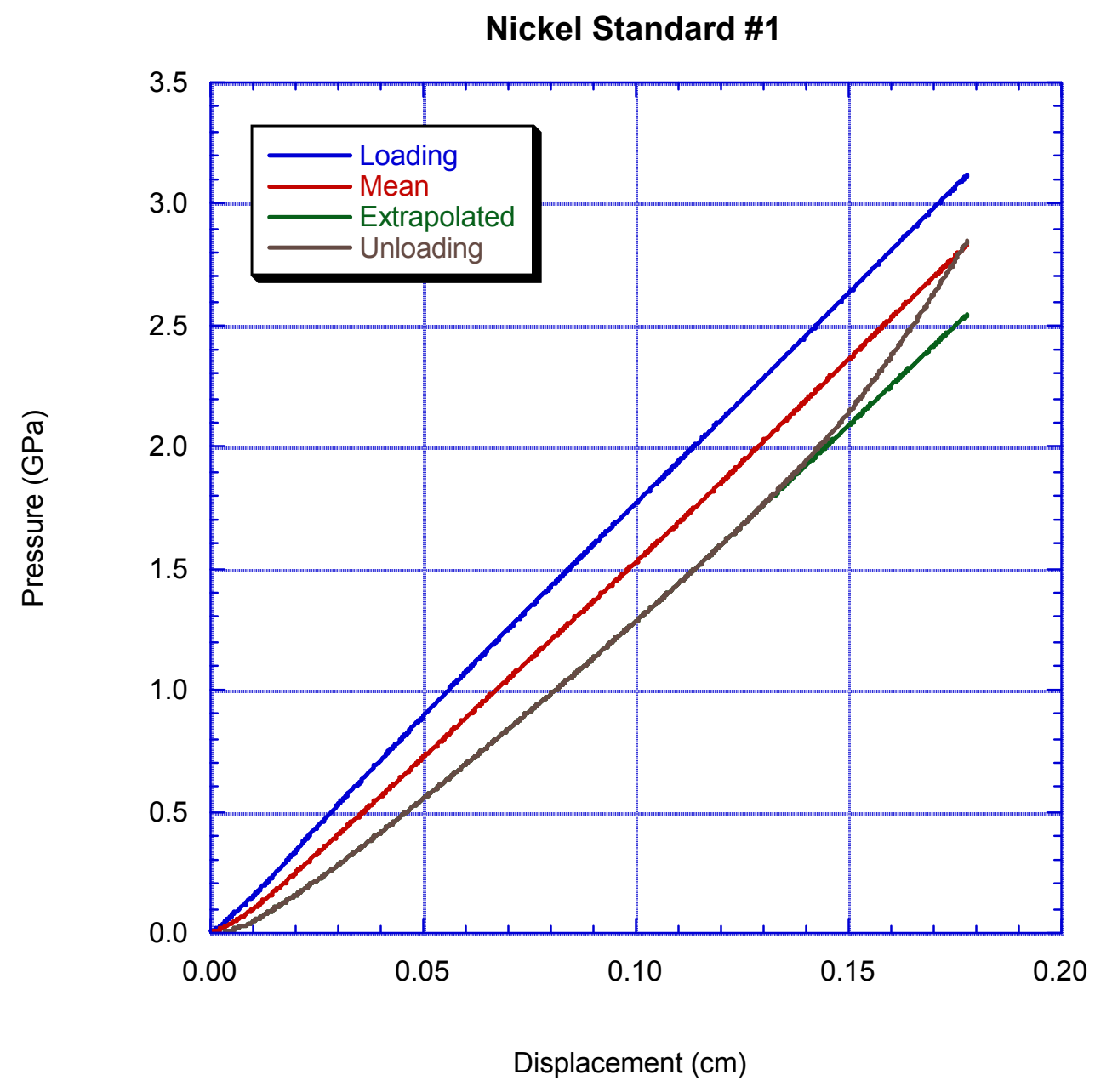

Fig. 15. Pressure versus displacement for Nickel Standard \#1. The loading data are shown in blue and the unloading data in brown. The green line has been obtained by extrapolation from the unloading data to remove the backlash effect. The red line shows the mean pressure at each displacement. 


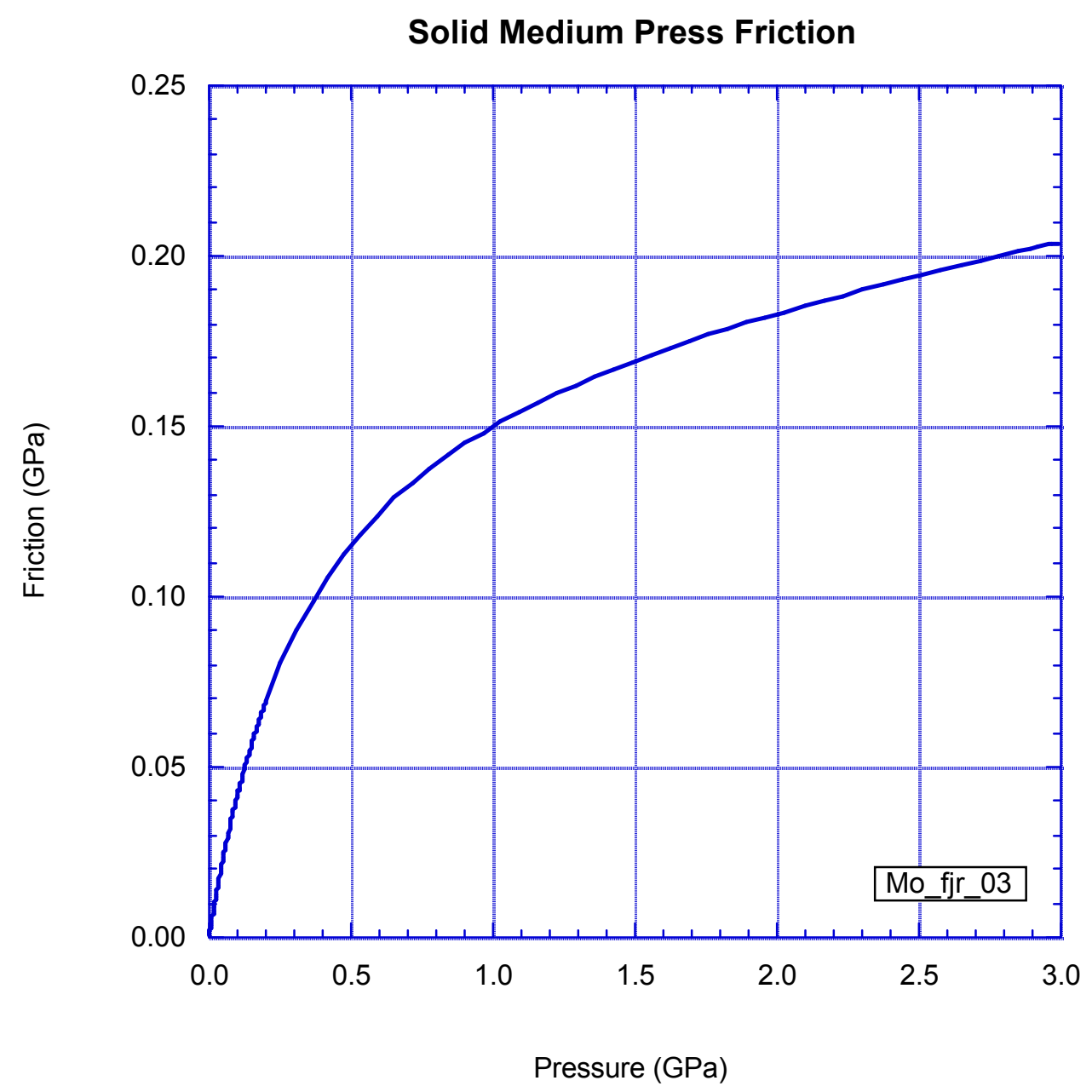

Fig. 16. Friction correction for the solid medium press. The friction correction was calculated from displacement data for molybdenum powder specimen Mo_fjr_03. 


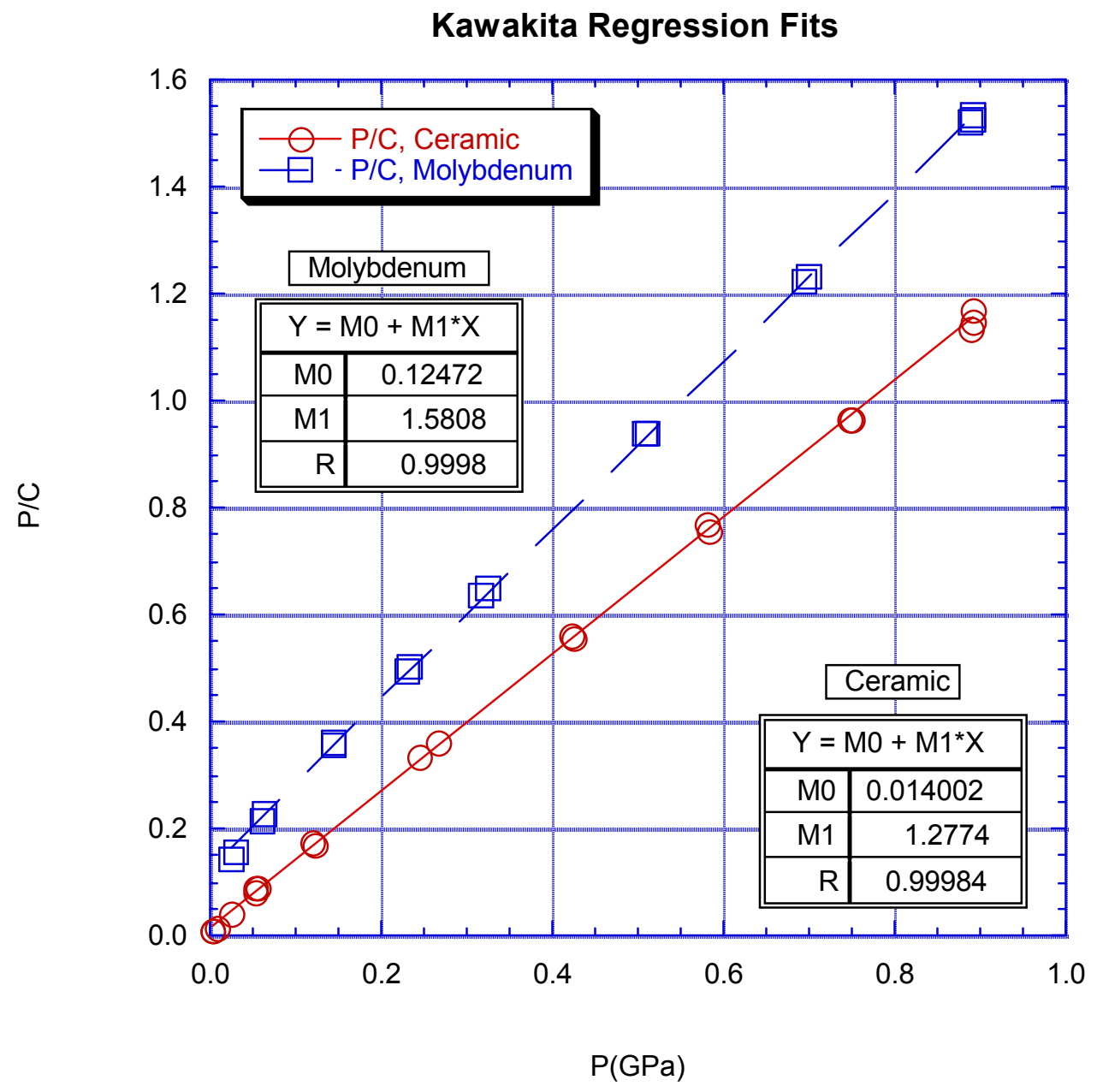

Fig. 17. Kawakita model regression fits for ceramic microspheres and molybdenum powder. 


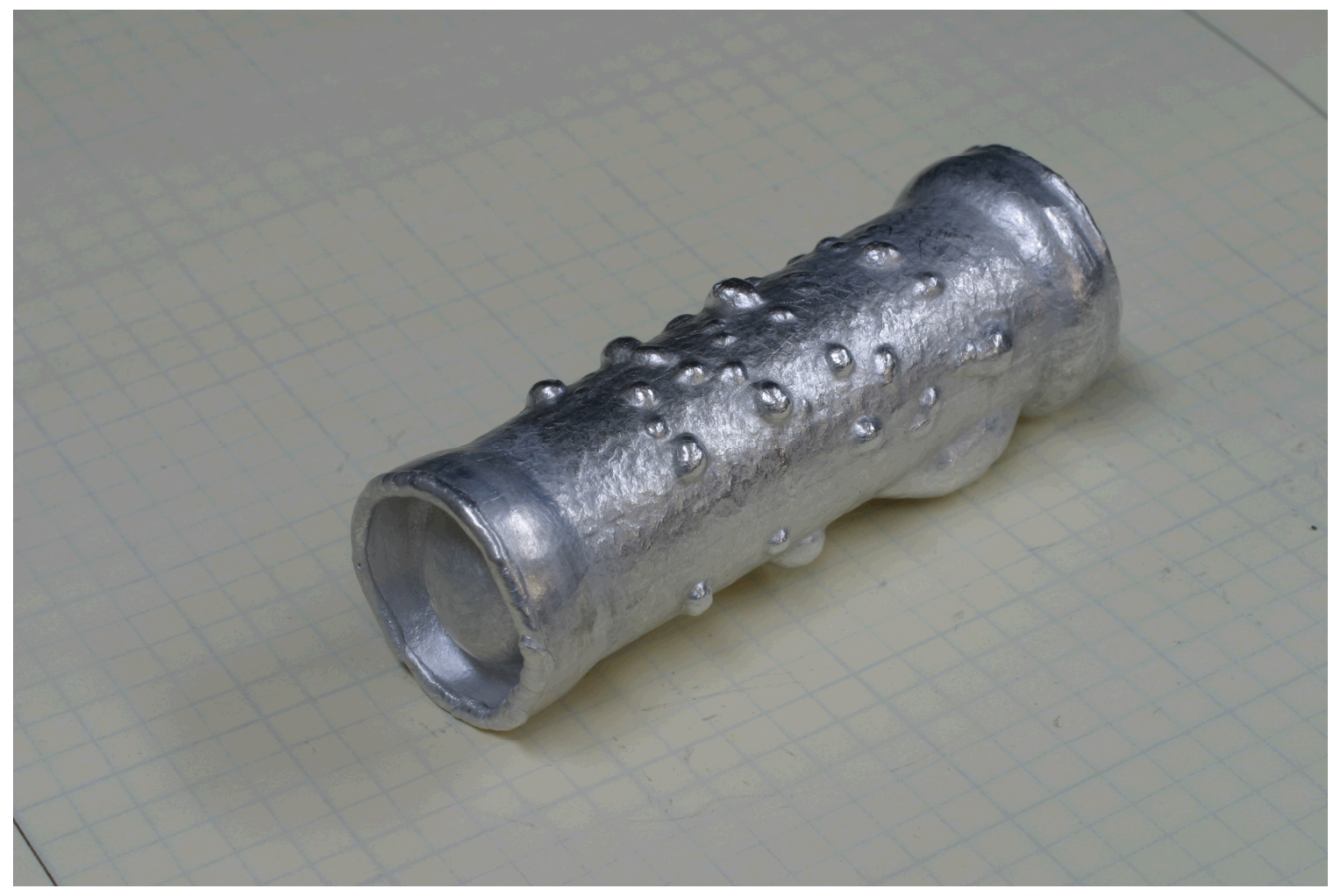

Fig. 18. Aluminum \#3 after compression to $0.9 \mathrm{GPa}$ in the liquid medium press. The bumps are pockets of trapped air that formed on decompression. The background grid size is five boxes per inch. 


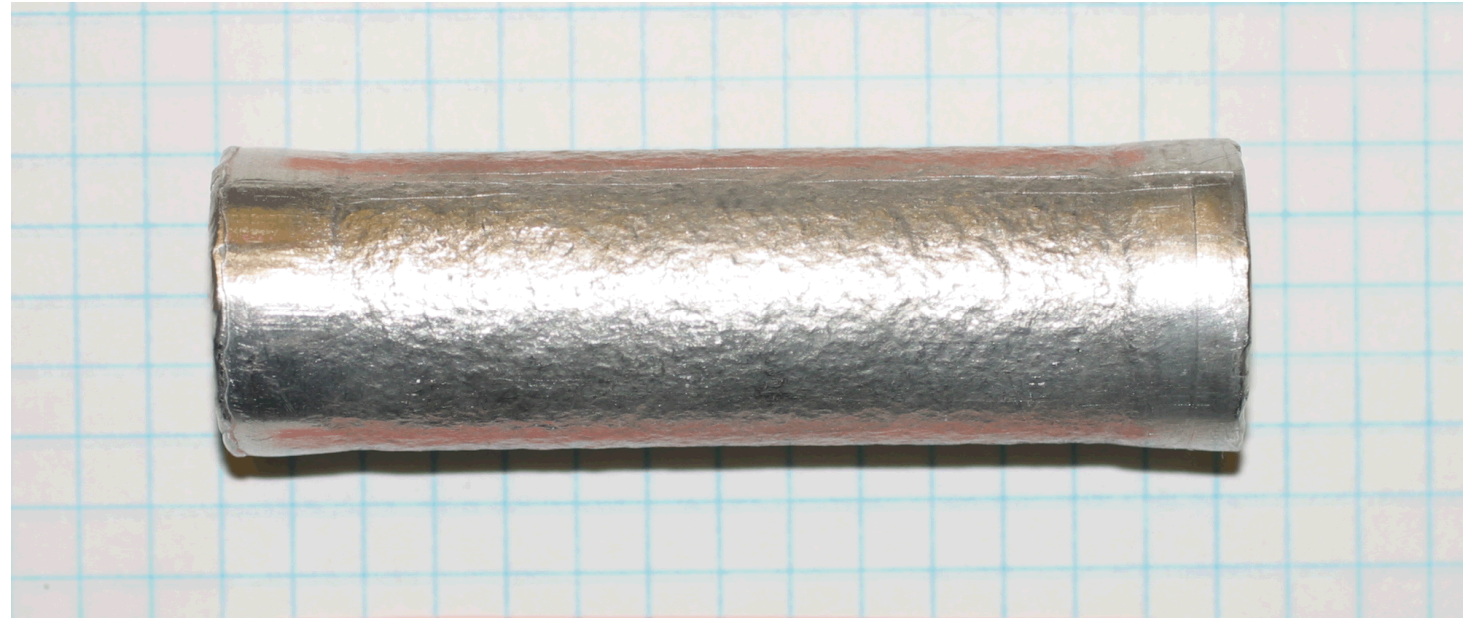

Fig. 19. Carbon \#3 after compression to $0.9 \mathrm{GPa}$ in the liquid medium press. The background grid size is four boxes per inch. 


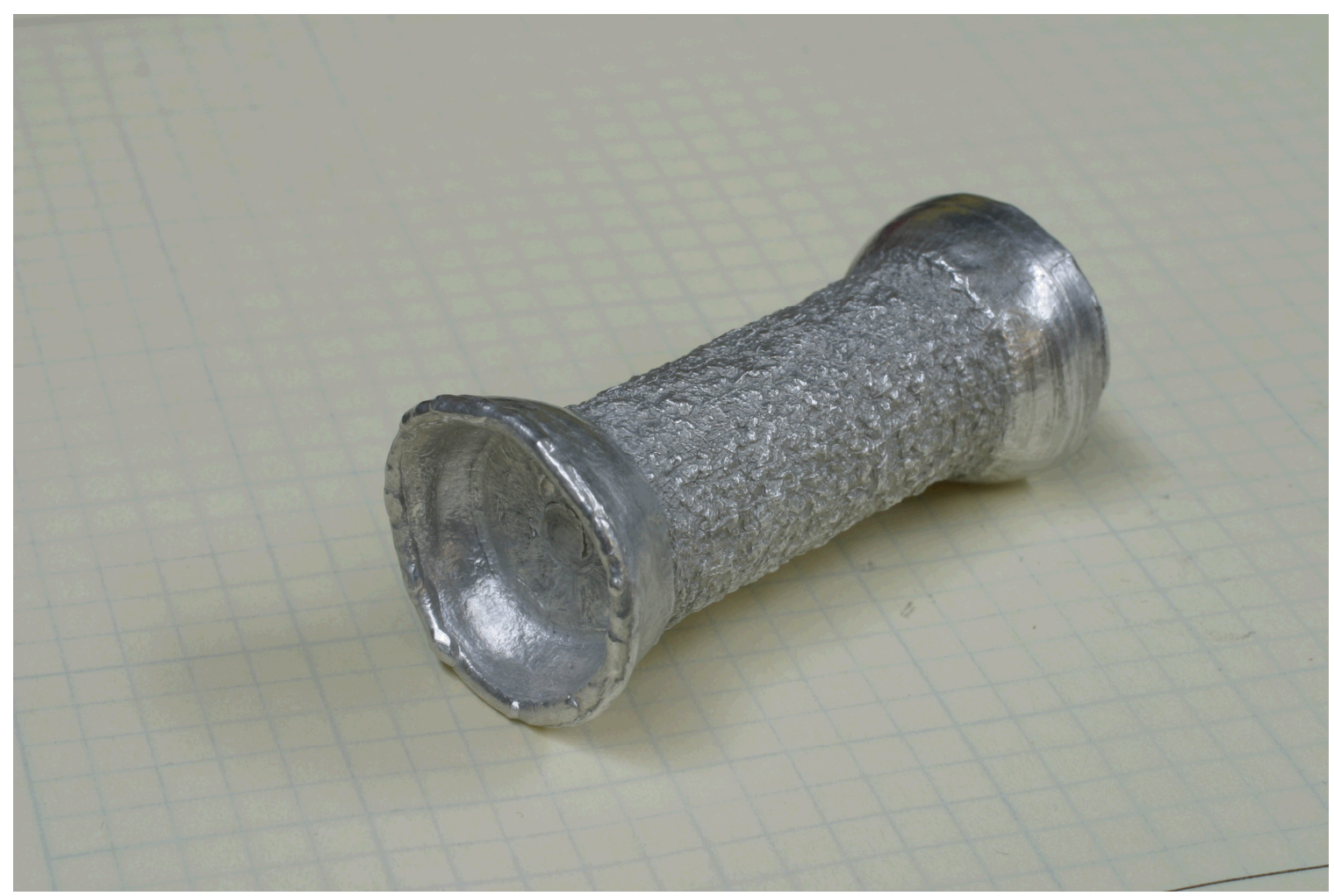

Fig. 20. Ceramic \#3 after compression to $0.9 \mathrm{GPa}$ in the liquid medium press. The background grid size is five boxes per inch. 


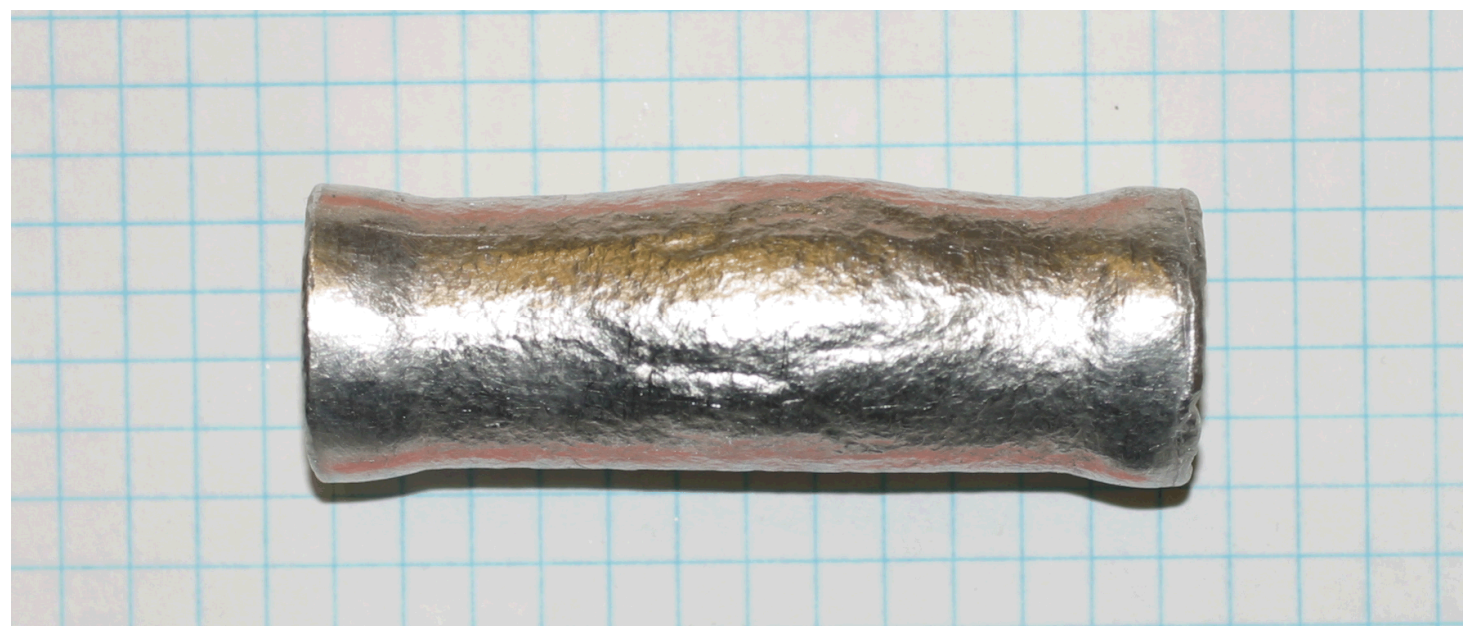

Fig. 21. Copper \#3 after compression to $0.9 \mathrm{GPa}$ in the liquid medium press. The background grid size is four boxes per inch. 


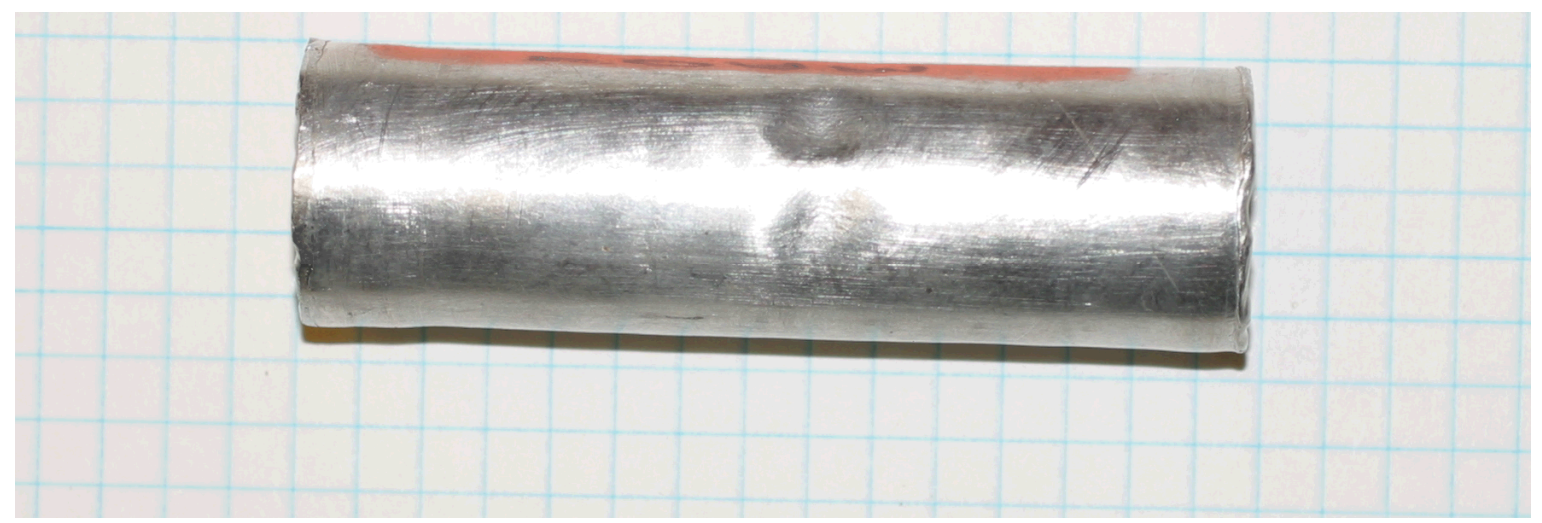

a.

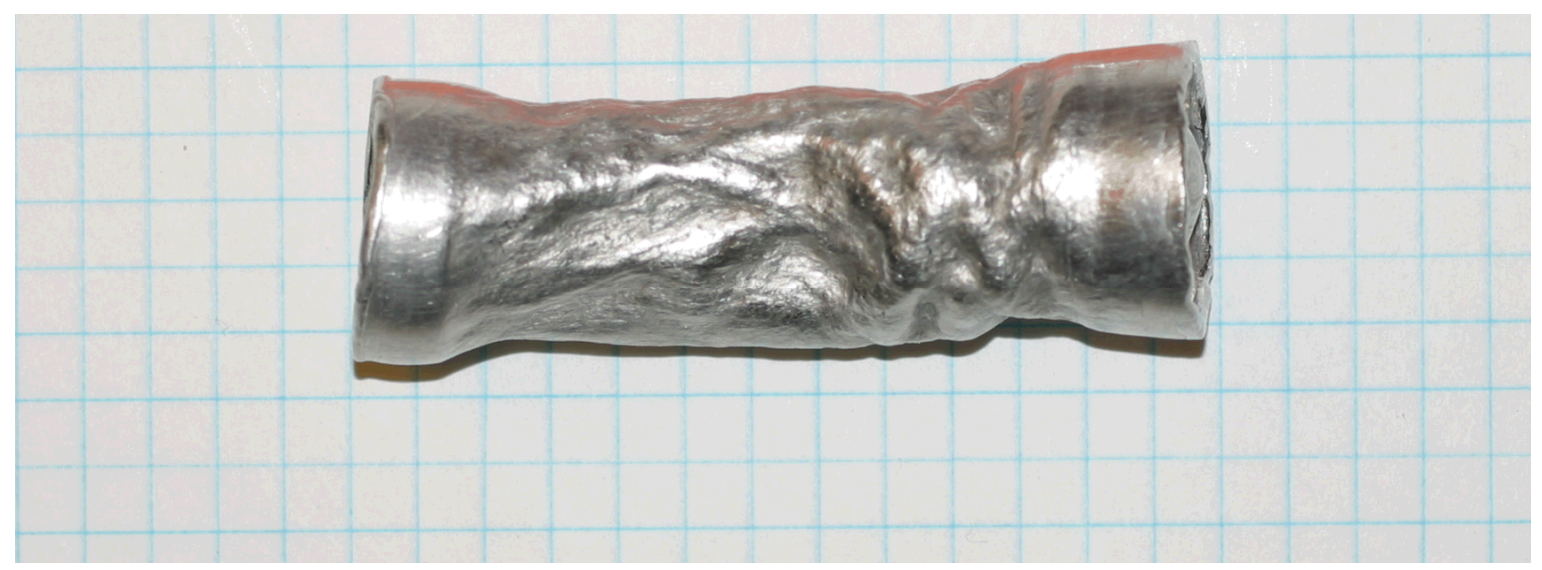

b.

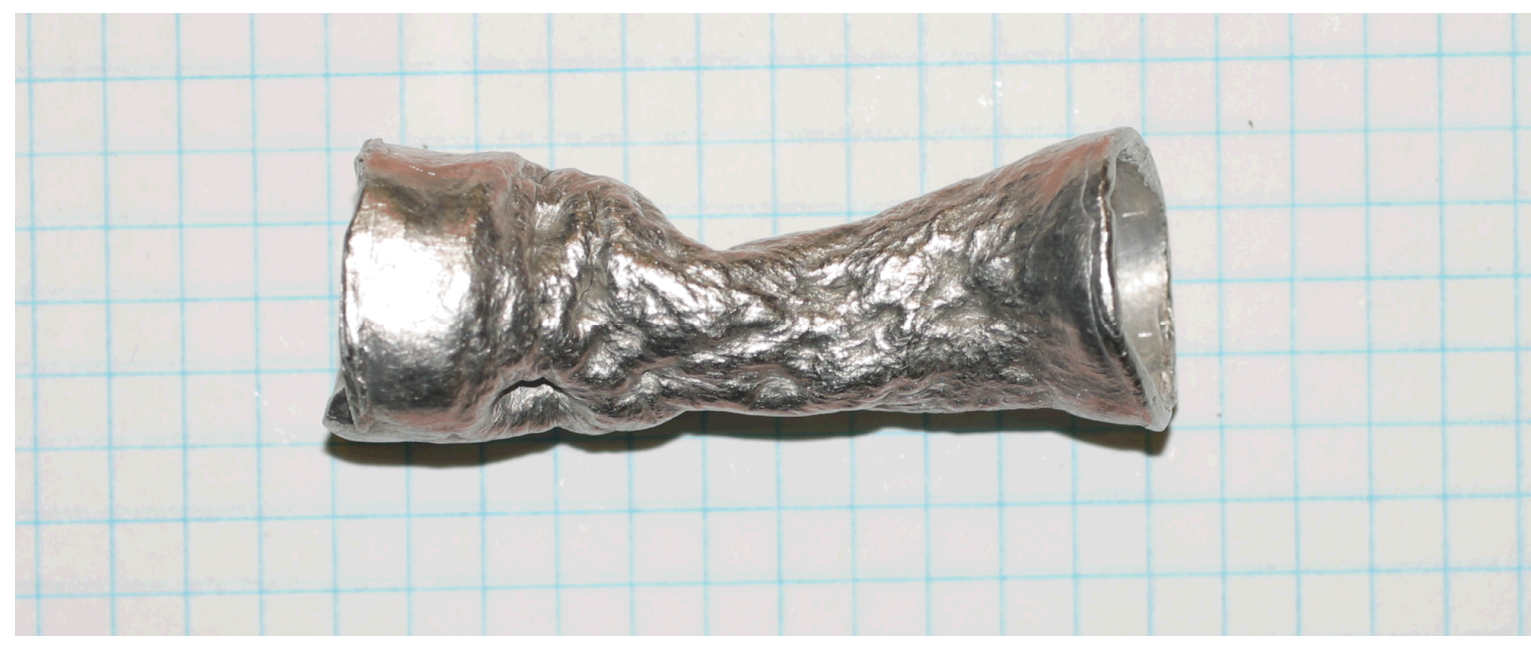

c.

Fig. 22. Foam specimen after hydrostatic compression to a) $5 \mathrm{MPa}$. b) $8 \mathrm{MPa}$. c) $30 \mathrm{MPa}$. 


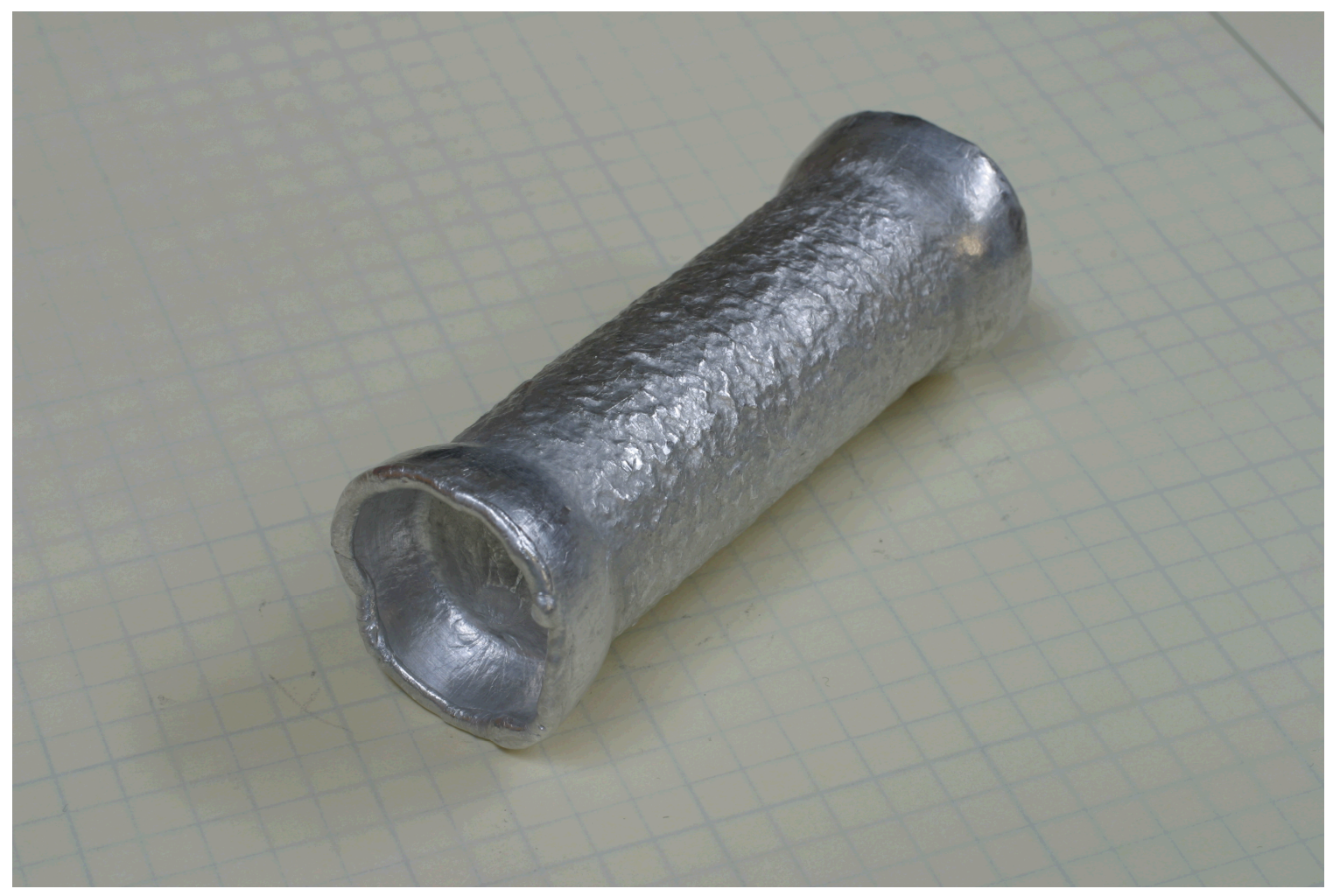

Fig. 23. Molybdenum \#3 after compression to $0.9 \mathrm{GPa}$ in the liquid medium press. The background grid size is five boxes per inch. 


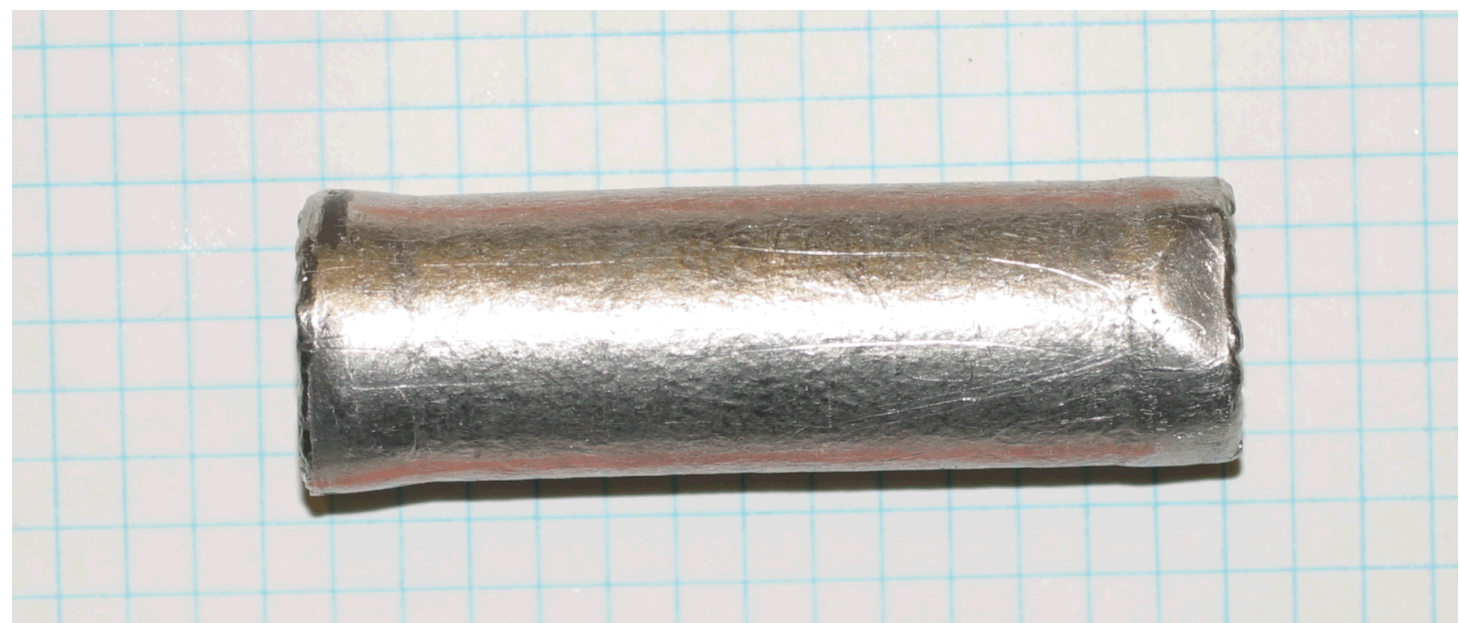

Fig. 24. Ottawa Sand \#2 after compression to $0.9 \mathrm{GPa}$ in the liquid medium press. The background grid size is four boxes per inch. 


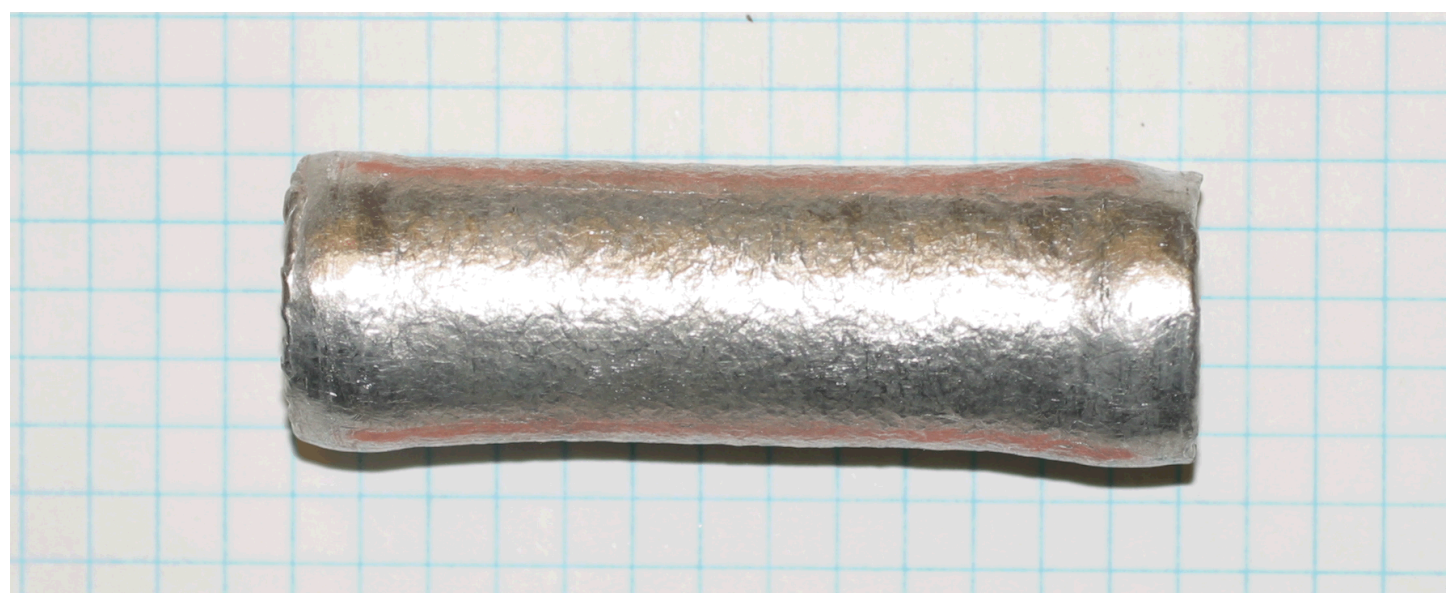

Fig. 25. Silicon Carbide \#5 after compression to $0.9 \mathrm{GPa}$ in the liquid medium press. The background grid size is four boxes per inch. 


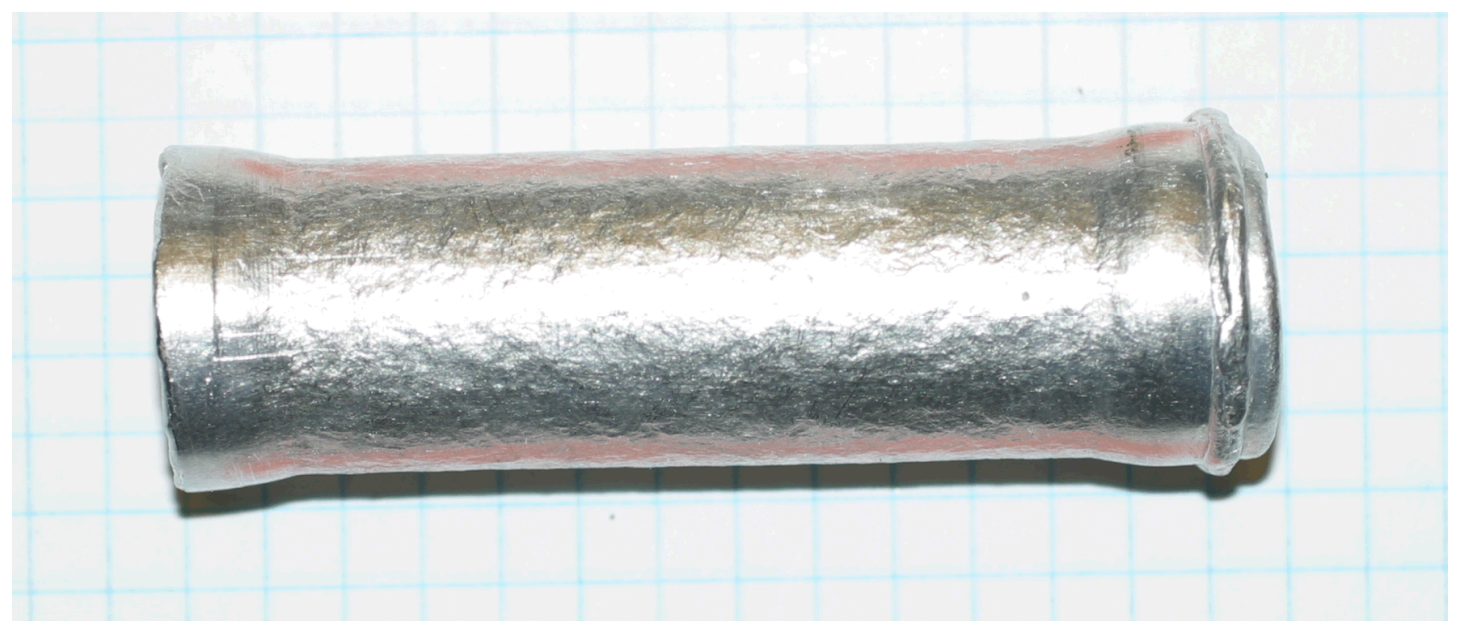

Fig. 26. Titanium \#3 after compression to $0.9 \mathrm{GPa}$ in the liquid medium press. The background grid size is four boxes per inch. 


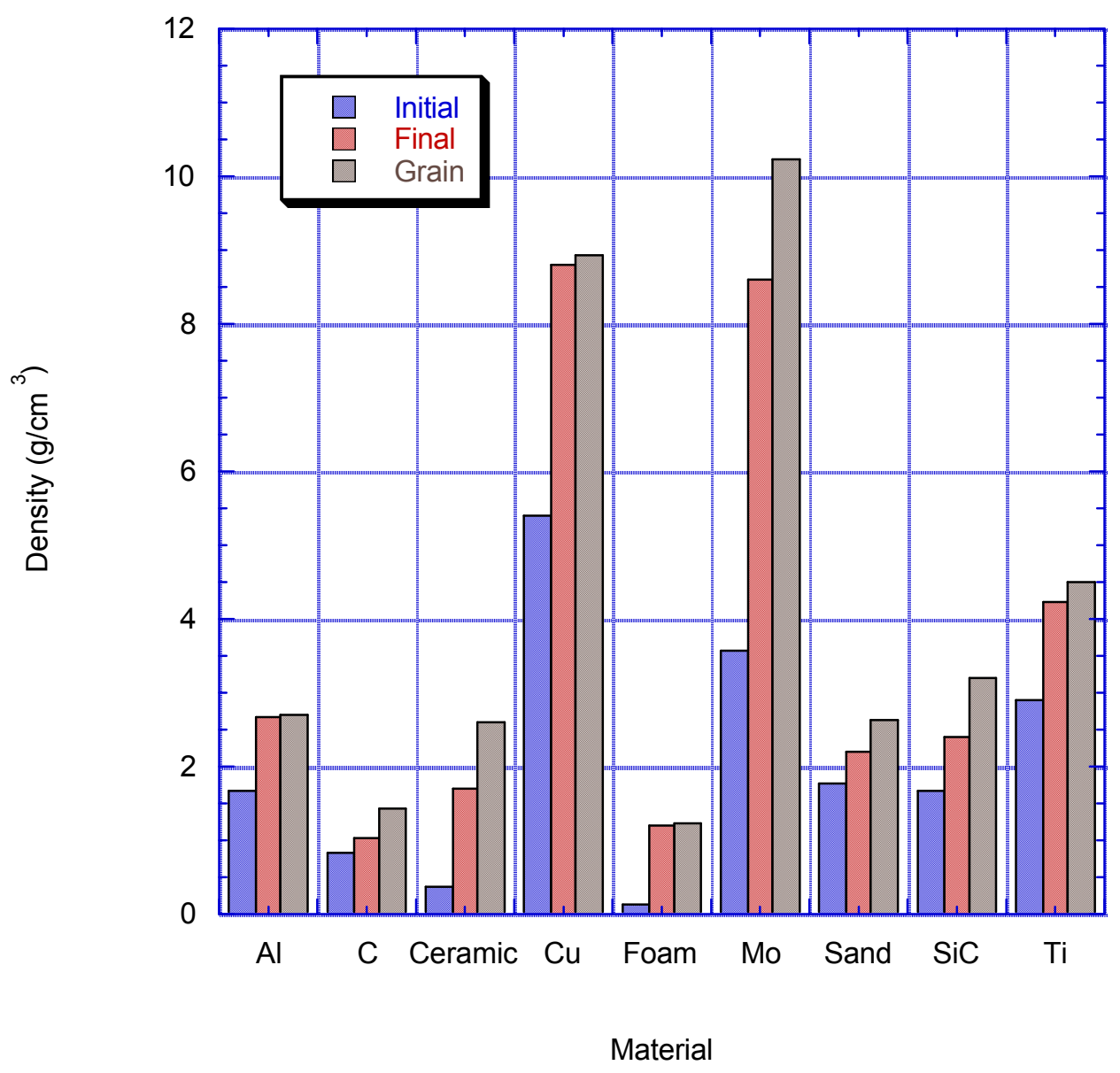

Fig. 27. Grain densities and initial and final bulk densities for the test materials after compaction to $0.9 \mathrm{GPa}$. 


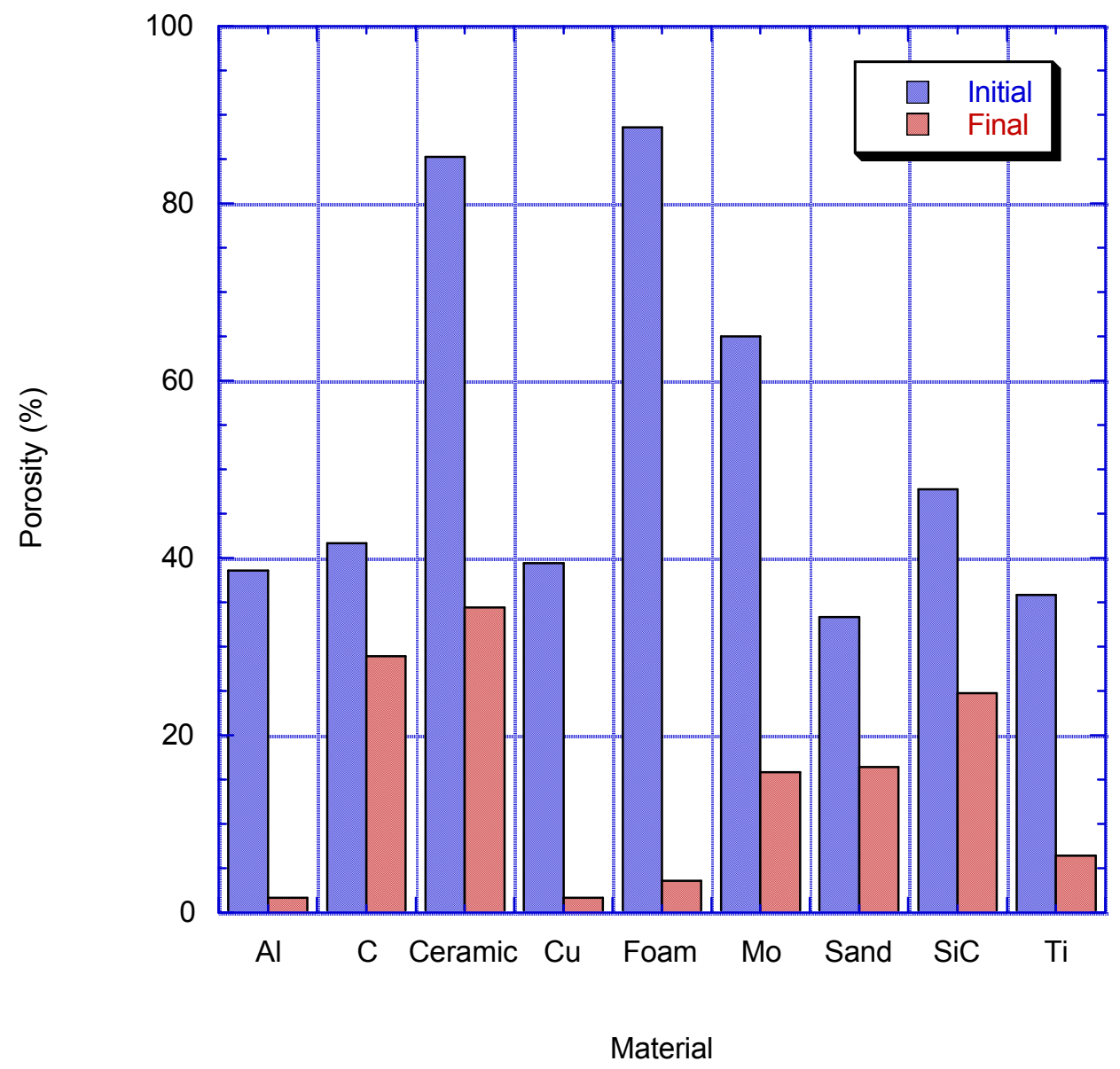

Fig. 28. Initial and final porosities for test materials after compaction to $0.9 \mathrm{GPa}$. 


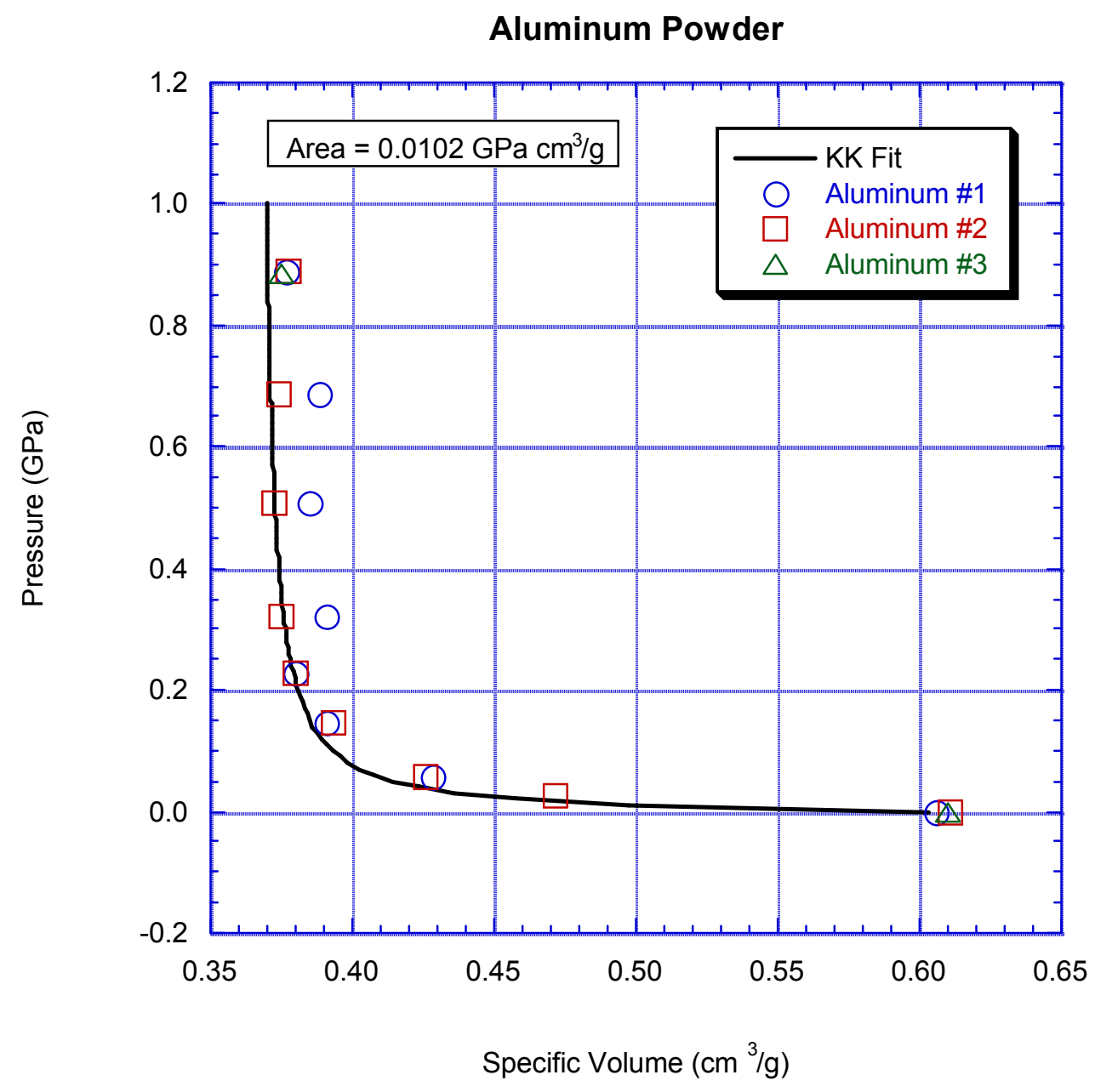

Fig. 29. Hydrostatic pressure versus specific volume for aluminum powder to $1 \mathrm{GPa}$. Pressures are corrected for friction. Volumes were measured in the helium pycnometer. Scatter is probably due to trapped air bubbles. Curve fit is from the Kawakita model. 


\section{Carbon Powder}

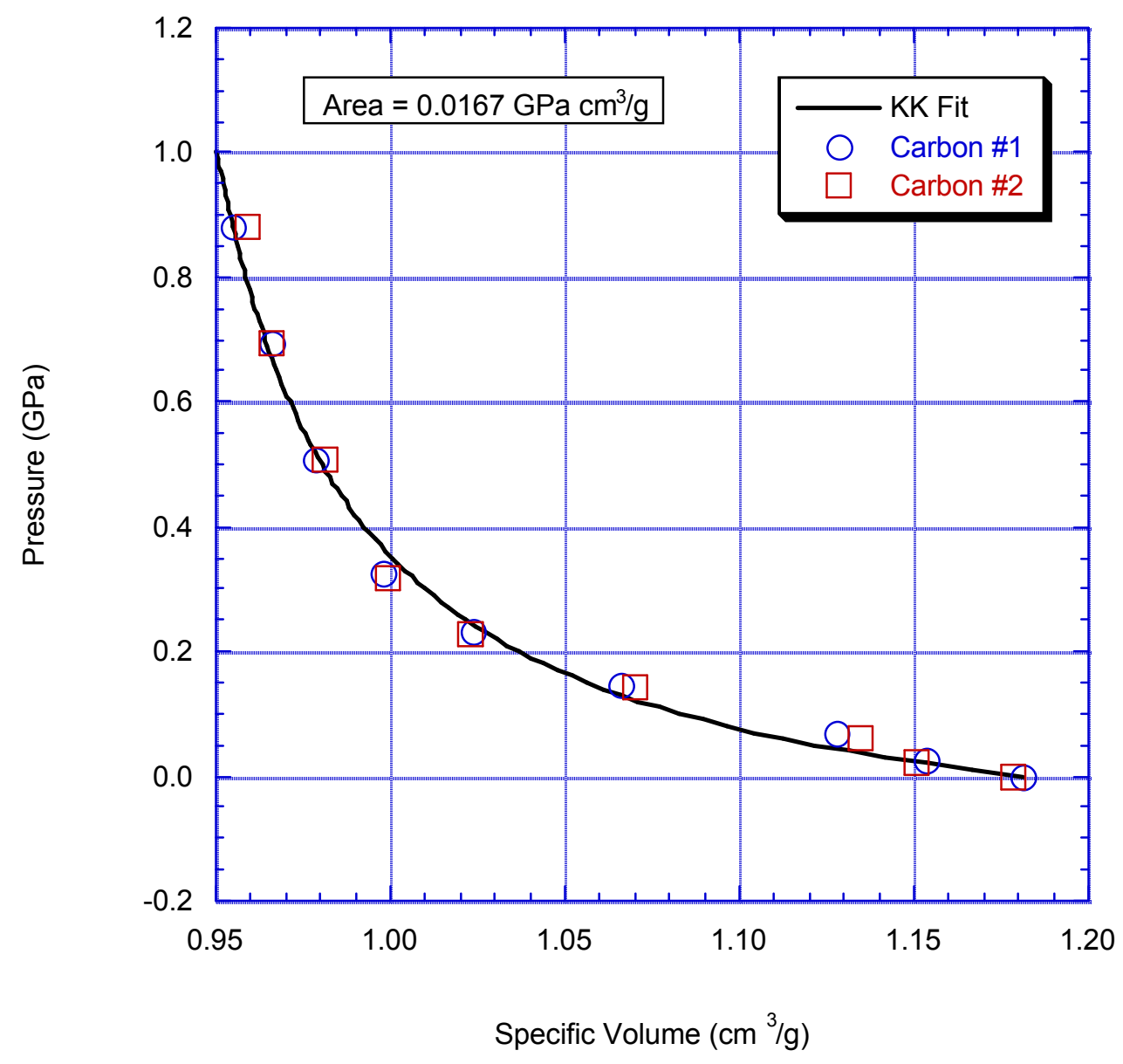

Fig. 30. Hydrostatic pressure versus specific volume for glassy carbon spheres to $1 \mathrm{GPa}$. Pressures are corrected for friction. Volumes were measured in the helium pycnometer. Curve fit is from the Kawakita model. 


\section{Ceramic Microspheres}

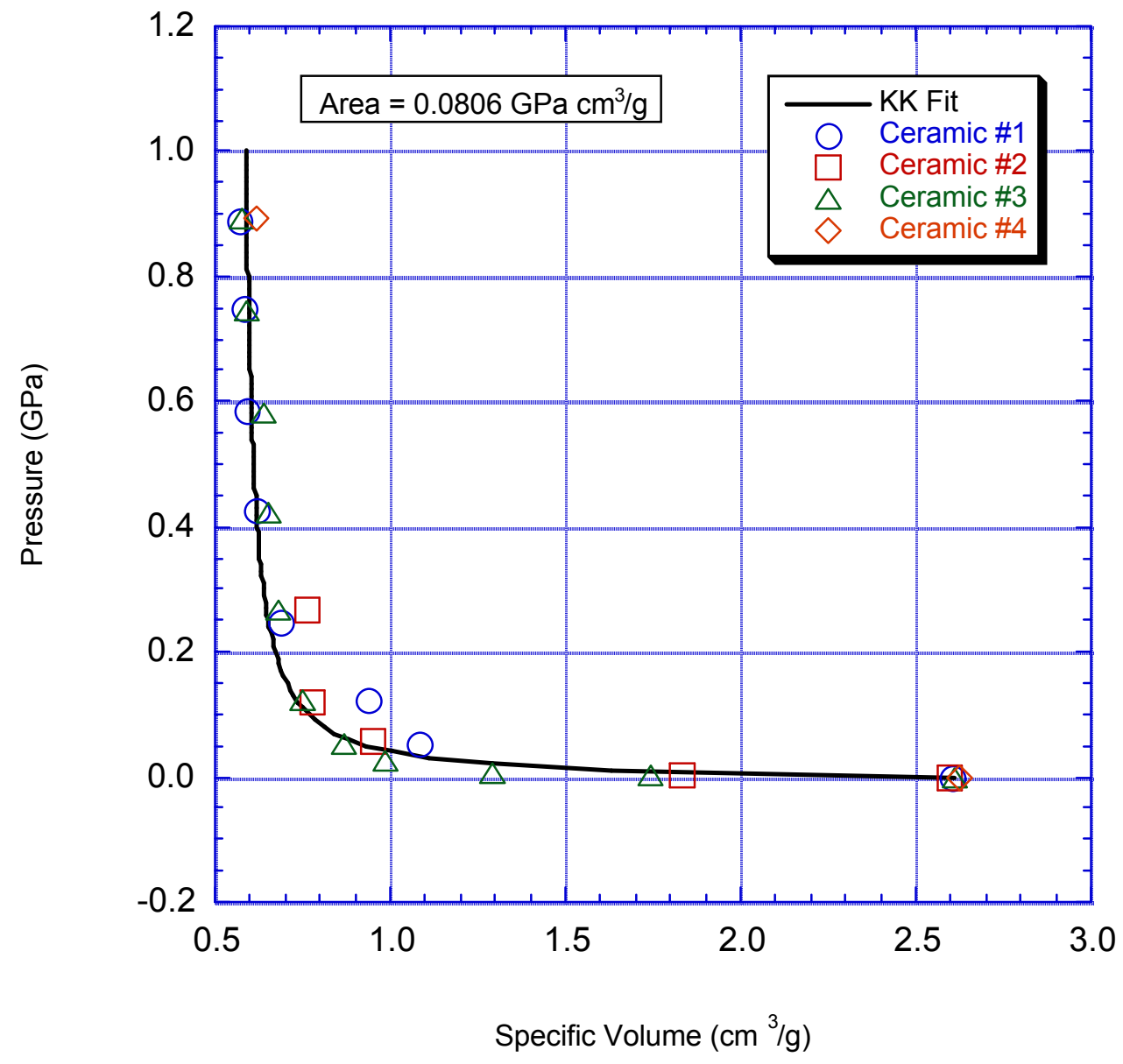

Fig. 31. Hydrostatic pressure versus specific volume for ceramic microspheres to $1 \mathrm{GPa}$. Pressures are corrected for friction. Volumes were measured in the helium pycnometer. Curve fit is from the Kawakita model. 


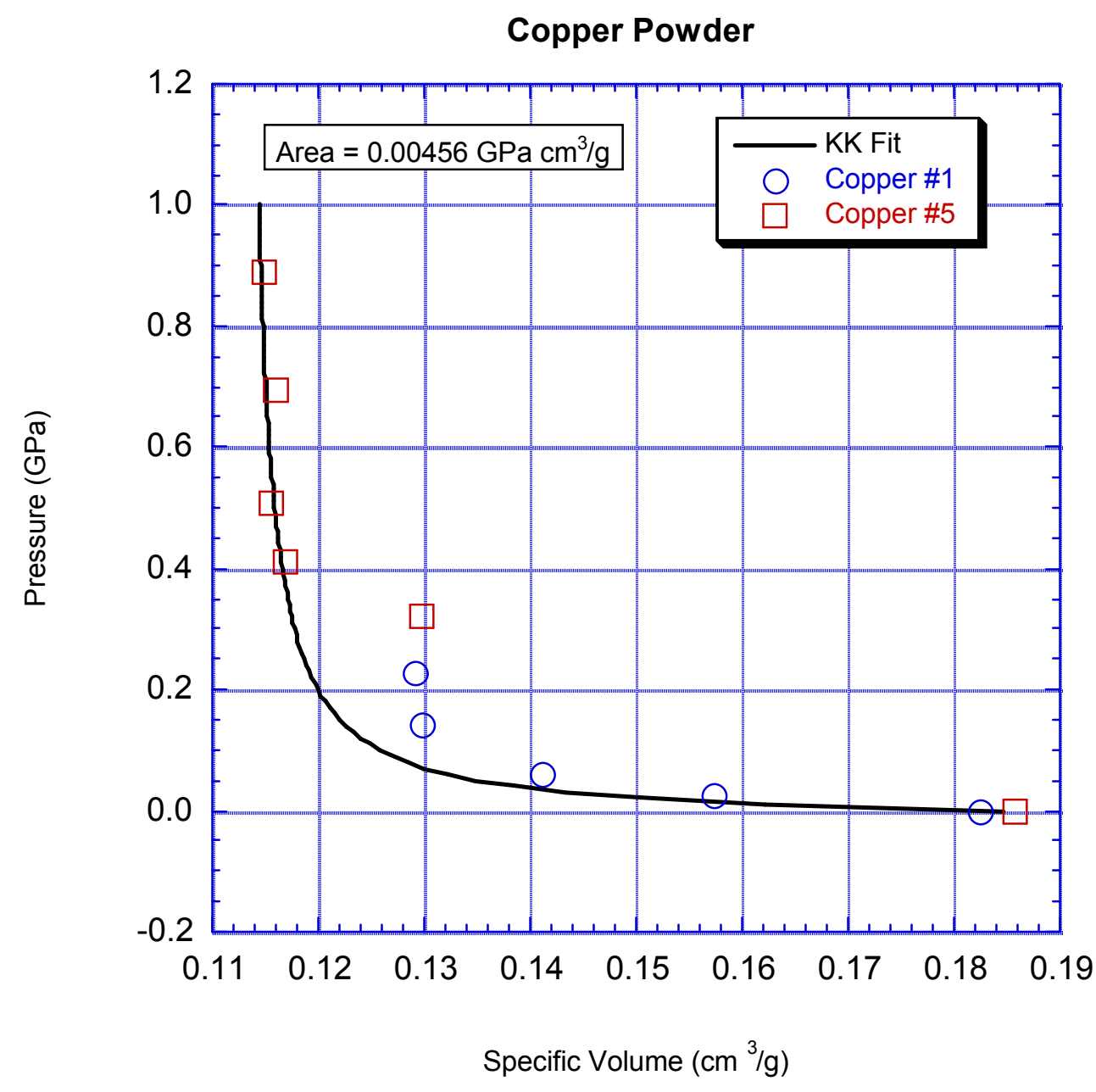

Fig. 32. Hydrostatic pressure versus specific volume for copper powder to $1 \mathrm{GPa}$. Pressures are corrected for friction. Volumes were measured in the helium pycnometer. Curve fit is from the Kawakita model. 


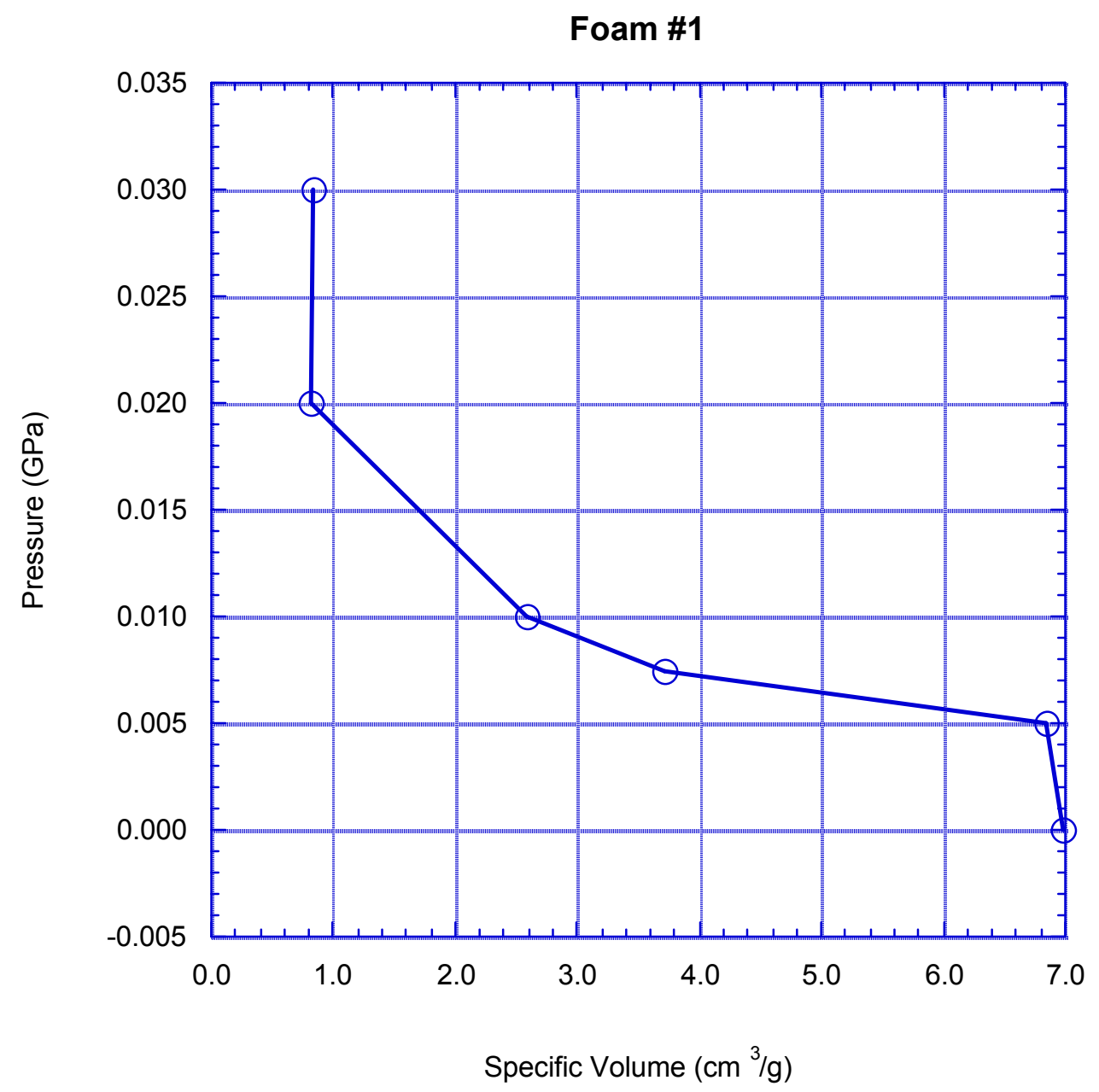

Fig. 33. Hydrostatic pressure versus specific volume for epoxy foam to $30 \mathrm{MPa}$. Very large volume reduction was observed between 5 and $20 \mathrm{MPa}$. Volumes were measured in the helium pycnometer. 


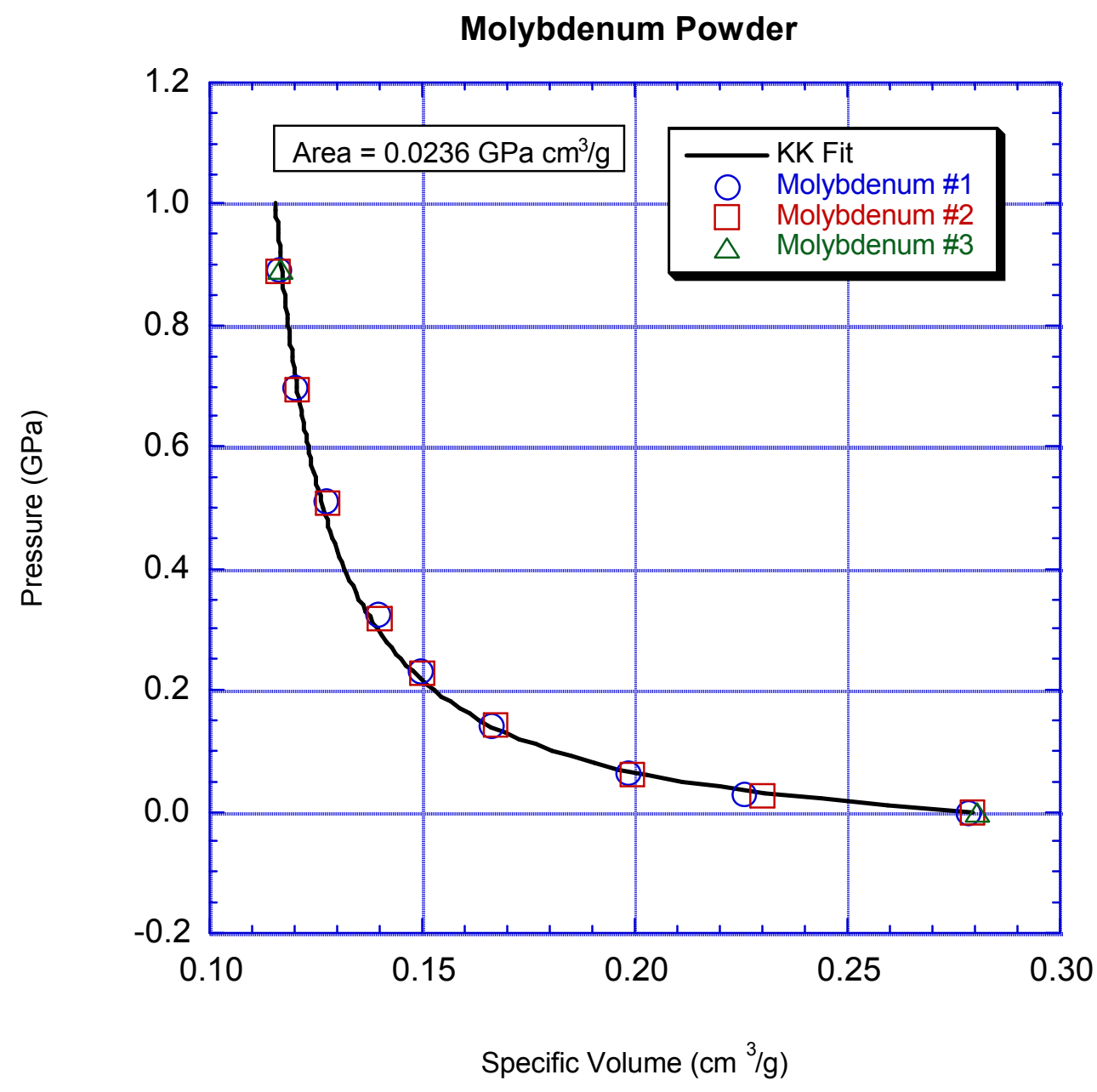

Fig. 34. Hydrostatic pressure versus specific volume for molybdenum powder to $1 \mathrm{GPa}$. Pressures are corrected for friction. Volumes were measured in the helium pycnometer. Curve fit is from the Kawakita model. 


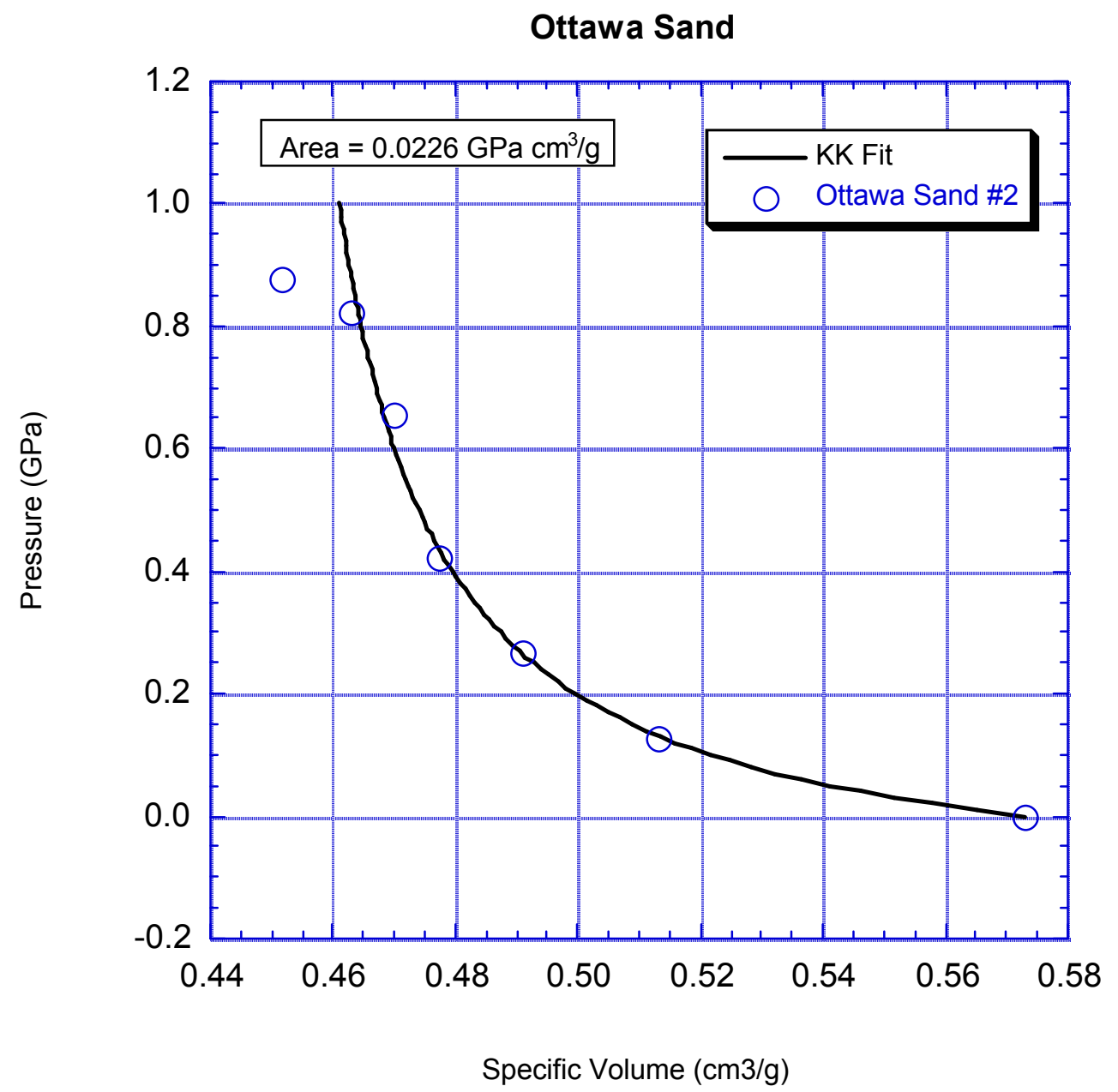

Fig. 35. Hydrostatic pressure versus specific volume for Ottawa sand to $1 \mathrm{GPa}$. Pressures are corrected for friction. Volumes were measured in the helium pycnometer. Curve fit is from the Kawakita model. 
Silicon Carbide Powder

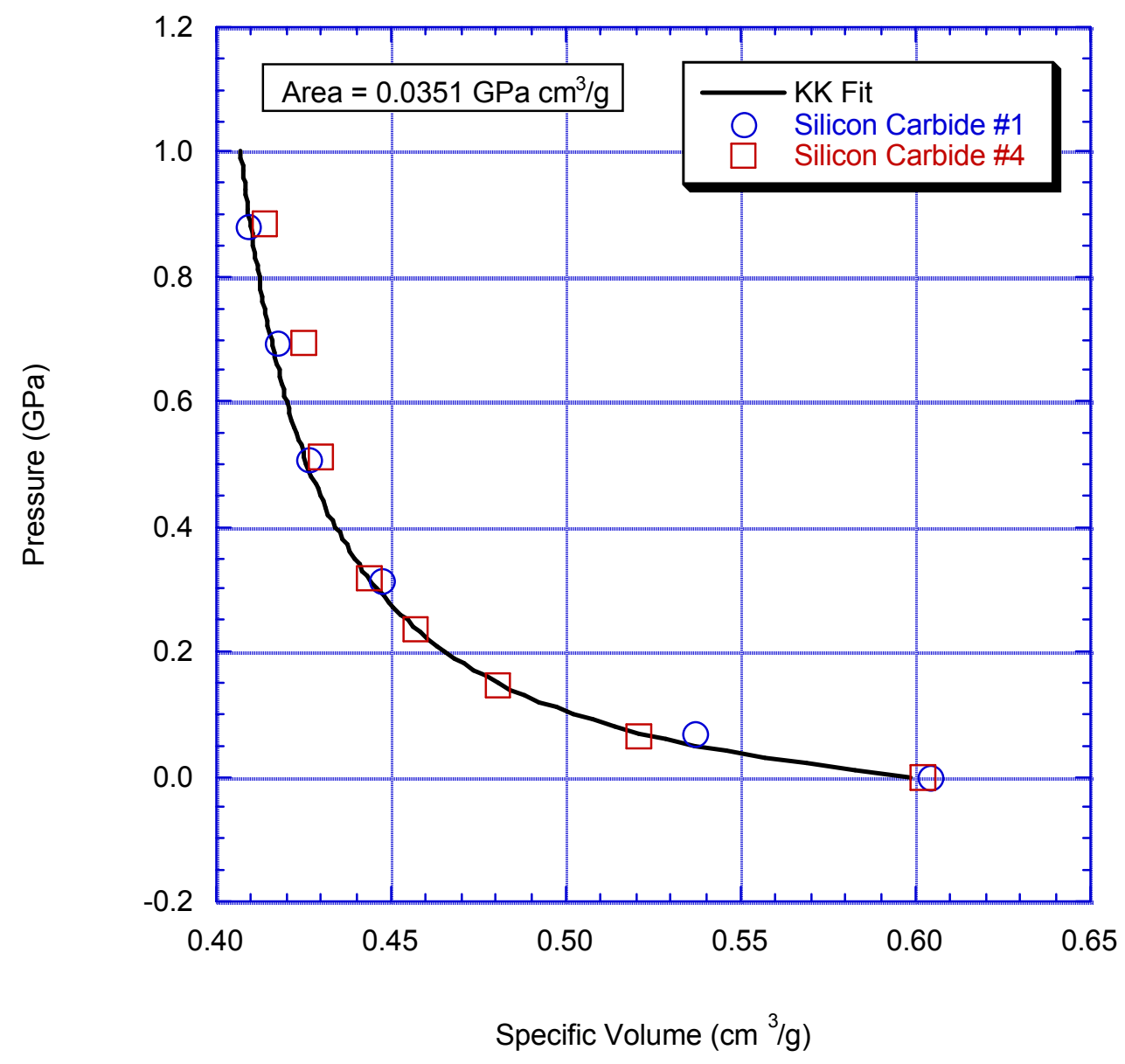

Fig. 36. Hydrostatic pressure versus specific volume for silicon carbide powder to $1 \mathrm{GPa}$. Pressures are corrected for friction. Volumes were measured in the helium pycnometer. Curve fit is from the Kawakita model. 
Titanium Powder

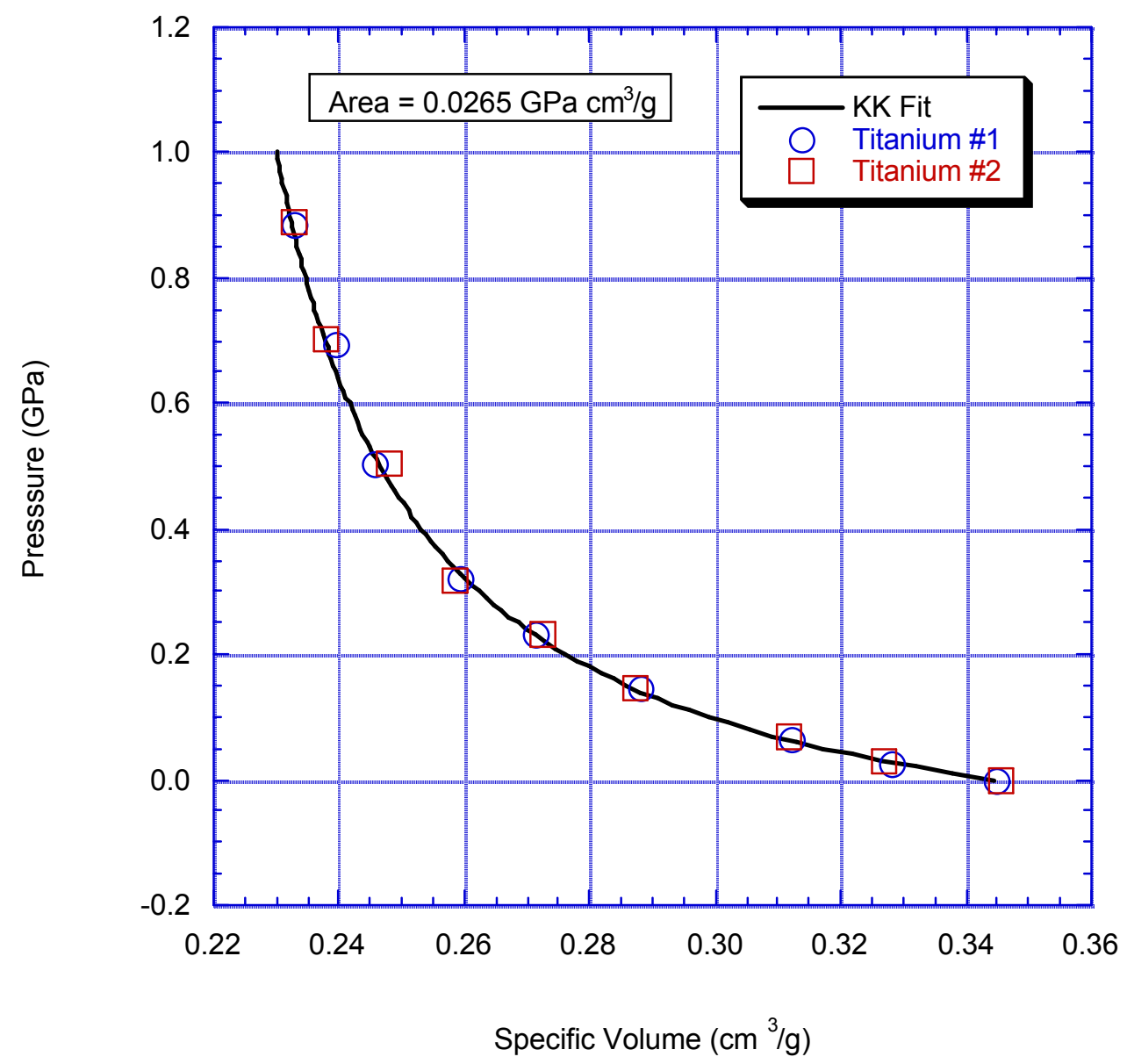

Fig. 37. Hydrostatic pressure versus specific volume for titanium powder to $1 \mathrm{GPa}$. Pressures are corrected for friction. Volumes were measured in the helium pycnometer. Curve fit is from the Kawakita model. 


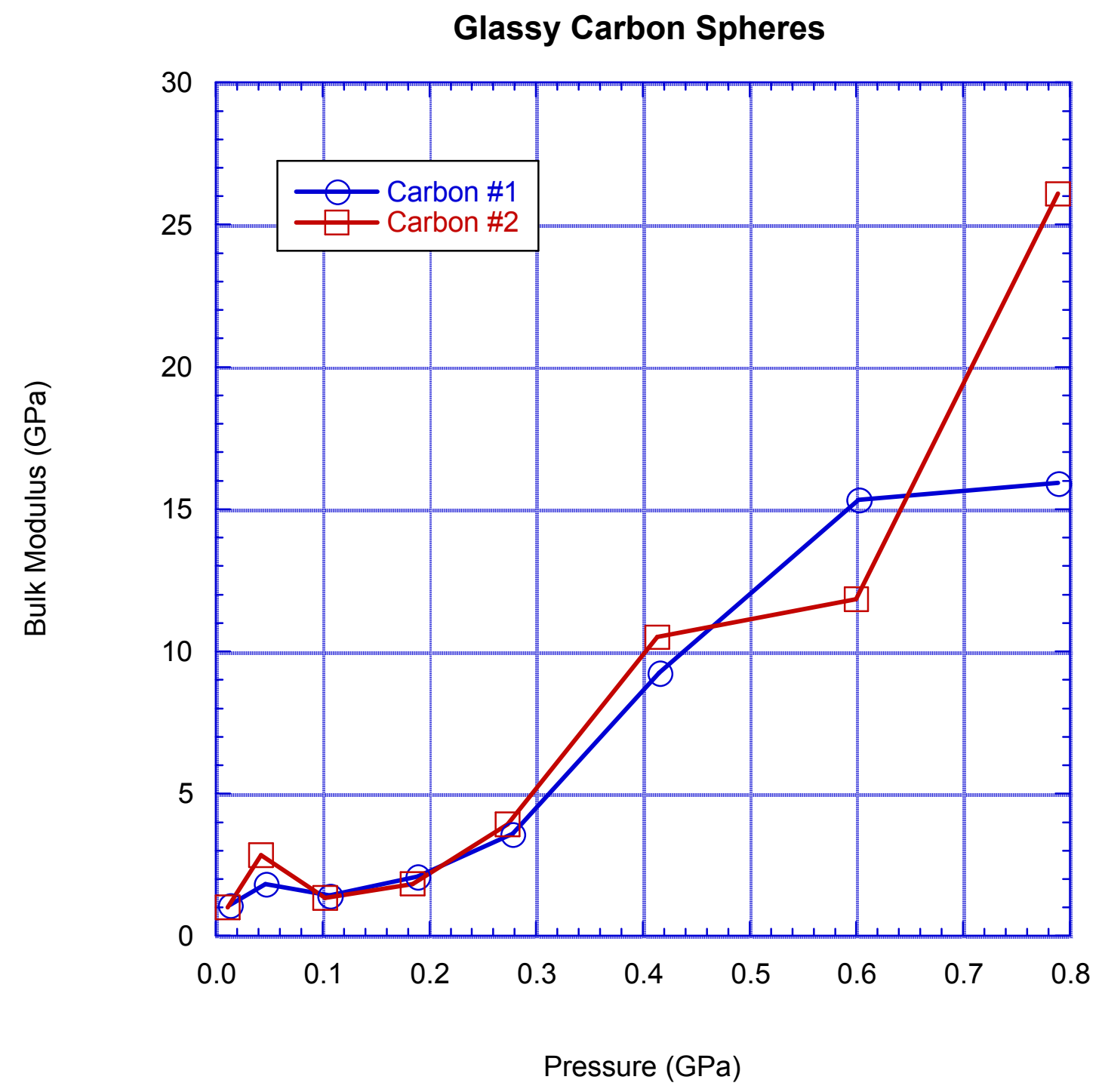

Fig 38. Bulk modulus for hydrostatically compressed glassy carbon spheres. 


\section{Ceramic Microspheres}

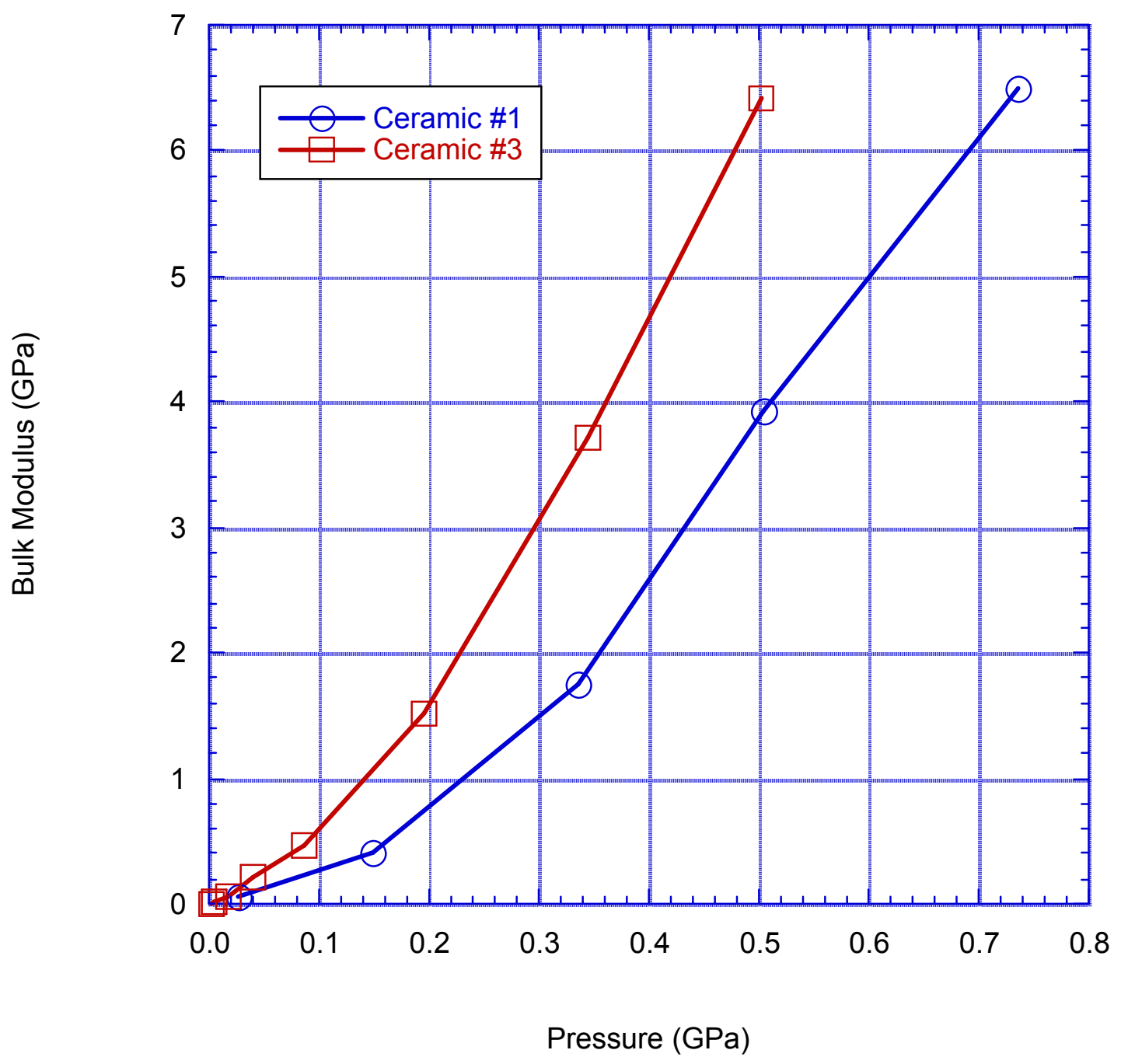

Fig. 39. Bulk modulus for hydrostatically compressed ceramic microsphere specimens. 


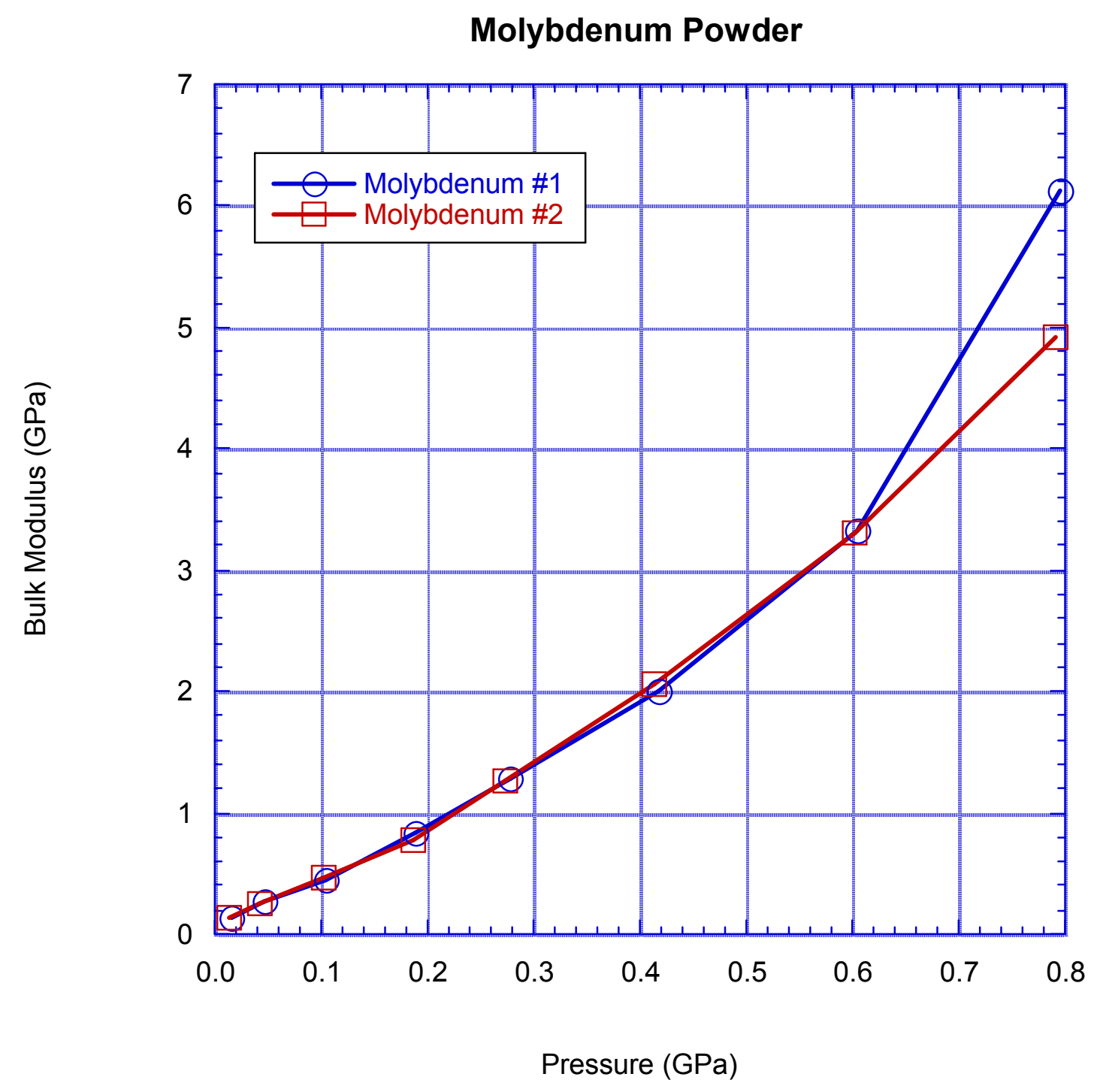

Fig. 40. Bulk modulus for hydrostatically compressed molybdenum powder. 


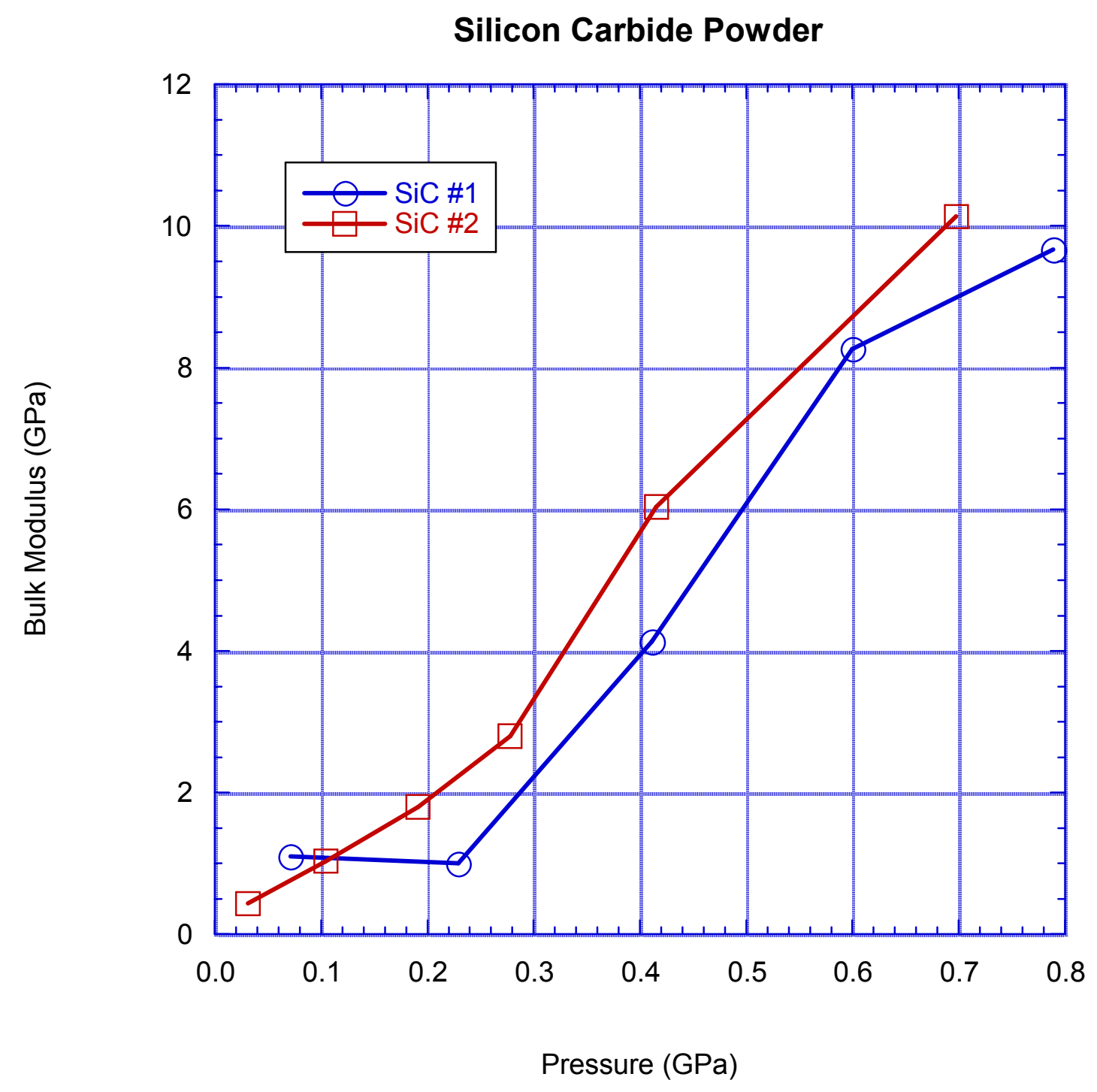

Fig. 41. Bulk modulus for hydrostatically compressed silicon carbide powder. 


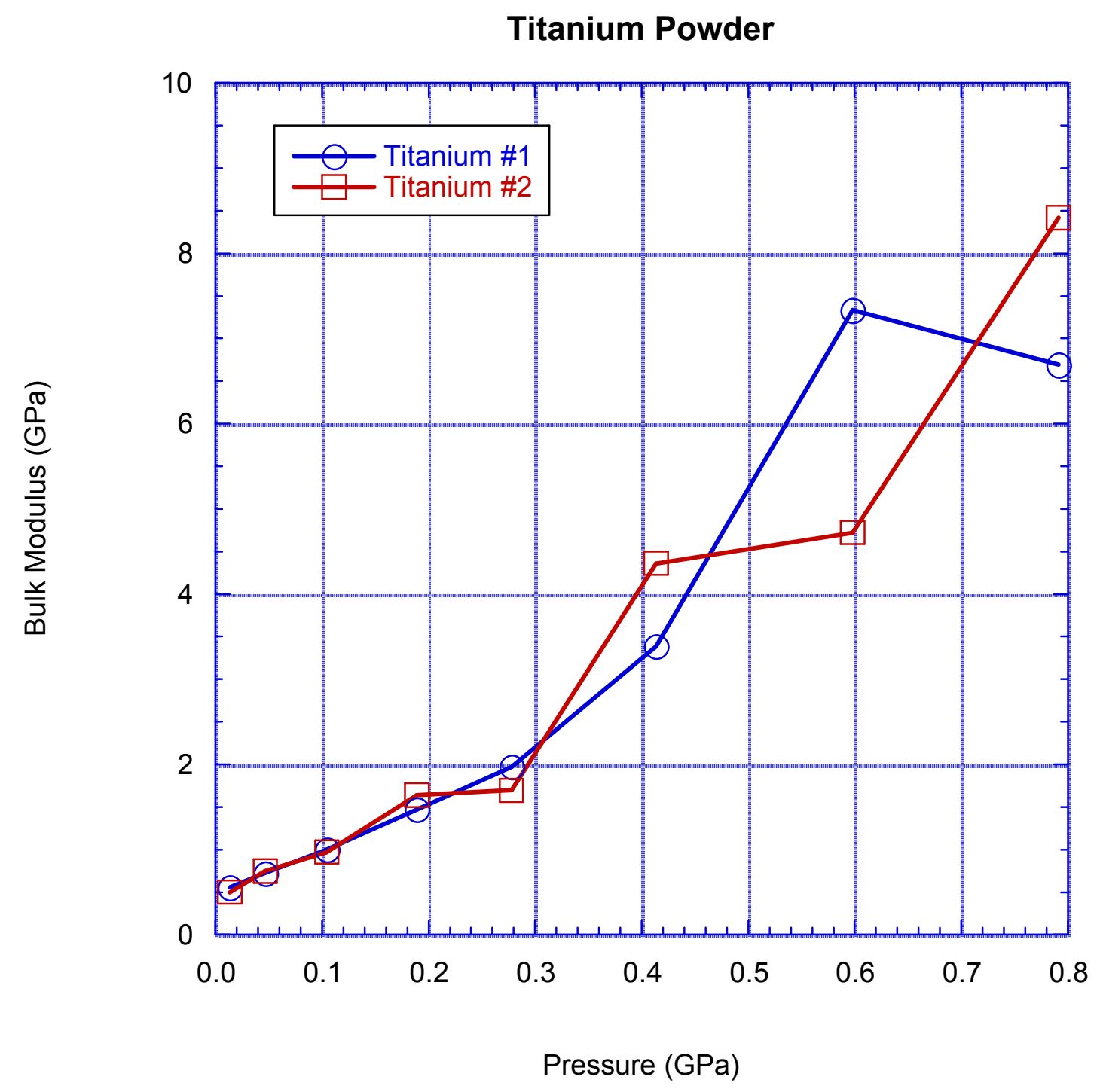

Fig. 42. Bulk modulus for hydrostatically compressed titanium powder. 


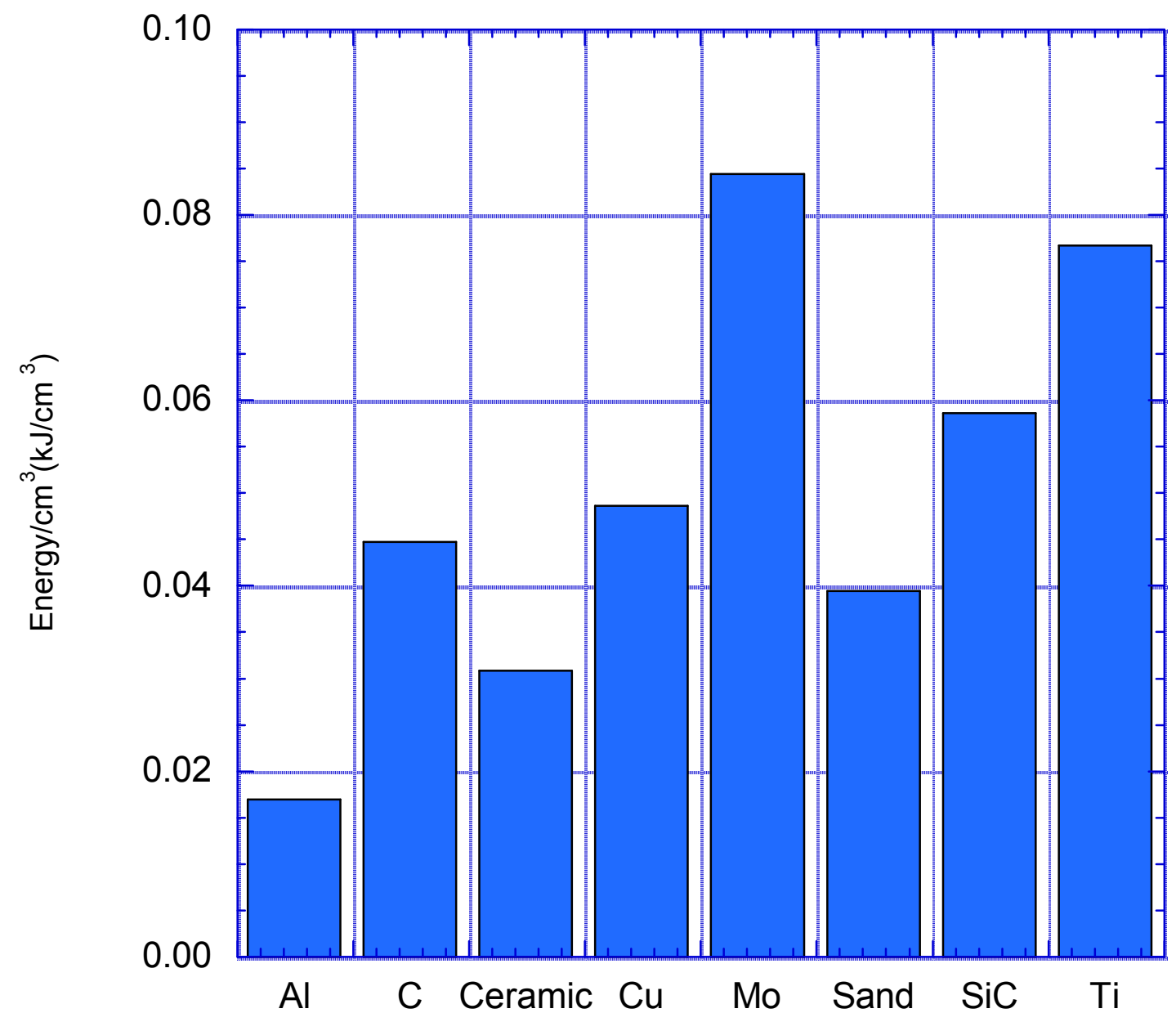

Material

Fig. 43. Energy expended per unit volume of material in hydrostatic compression to 1 GPa. 


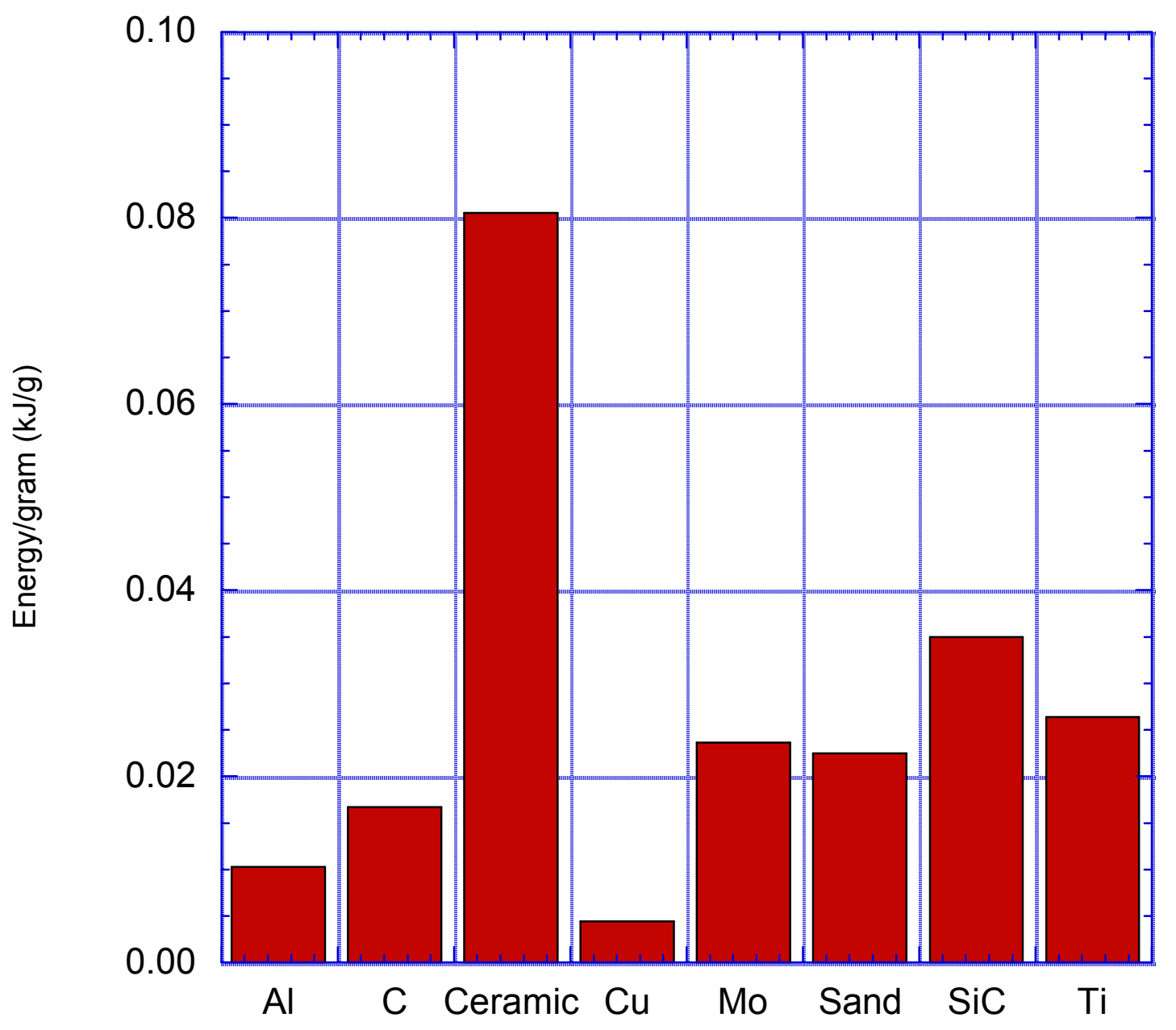

Material

Fig. 44. Energy expended per gram of material in hydrostatic compression to $1 \mathrm{GPa}$. 


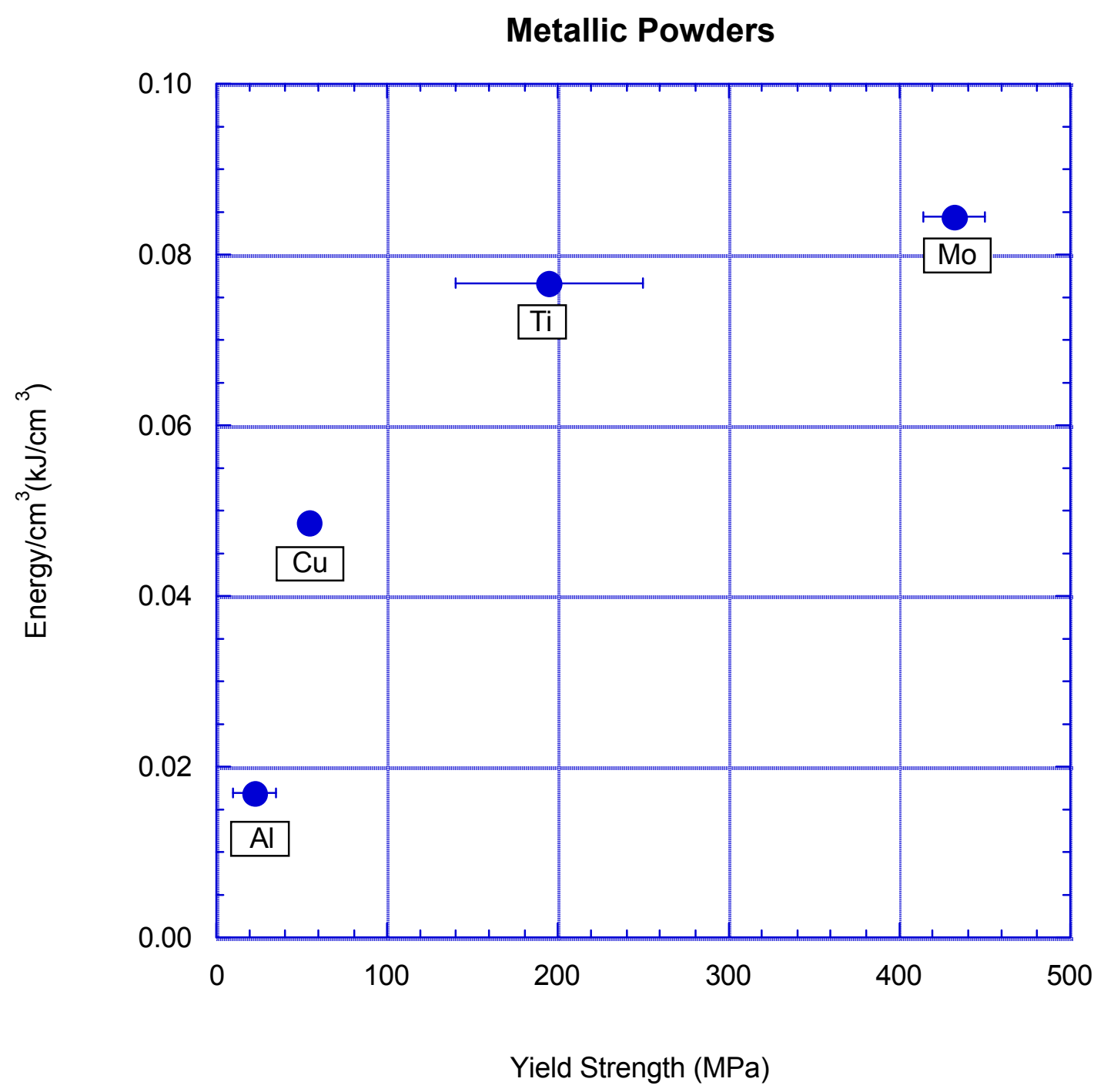

Fig. 45. Energy expended per unit volume in compression to $1 \mathrm{GPa}$ versus yield strength for metallic powders. Error bars show range of yield strengths for each material given by goodfellow.com. 


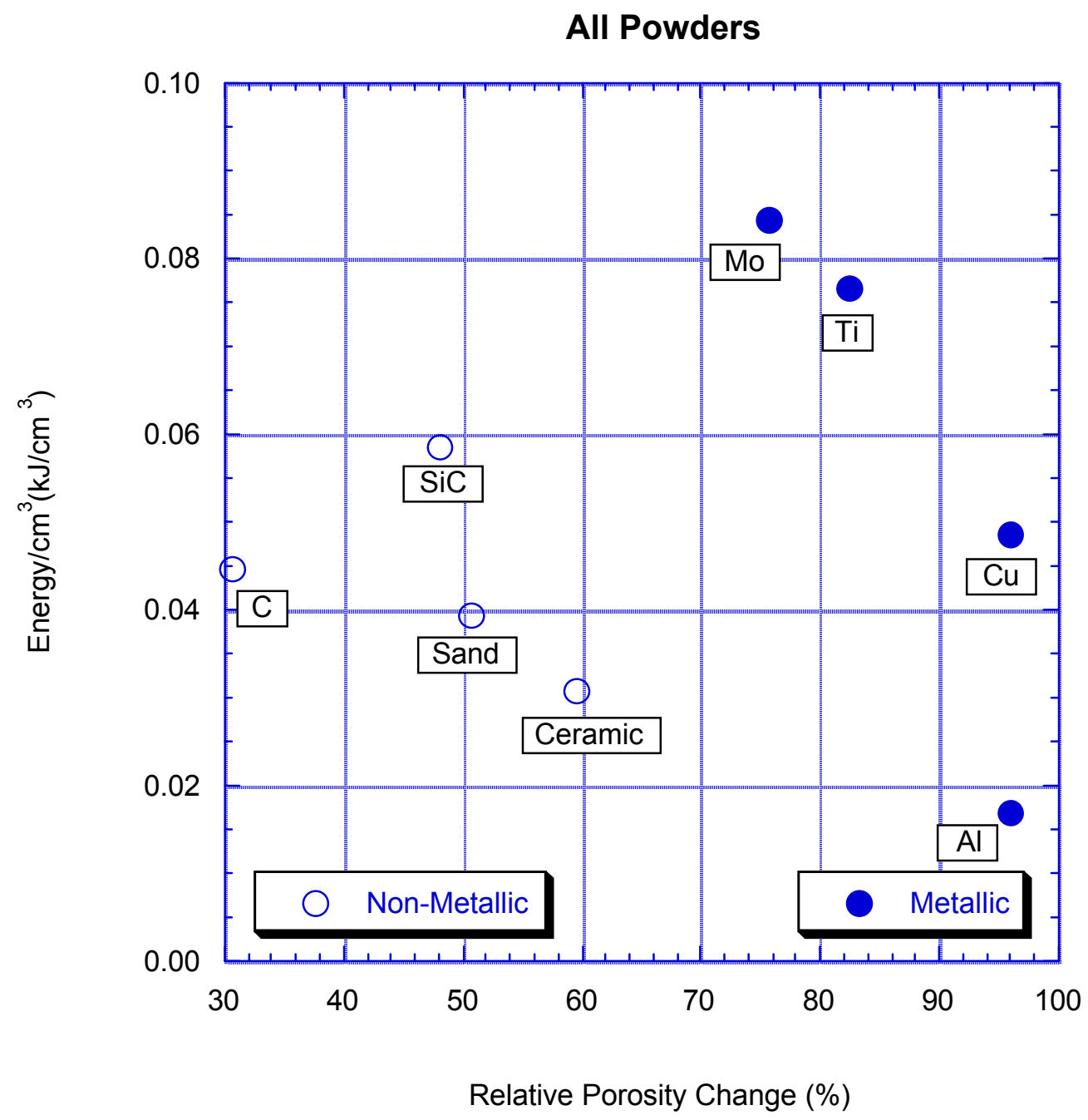

Fig. 46. Energy expended per unit volume and relative porosity change in hydrostatic compression to $1 \mathrm{GPa}$ for metallic and non-metallic test materials. 


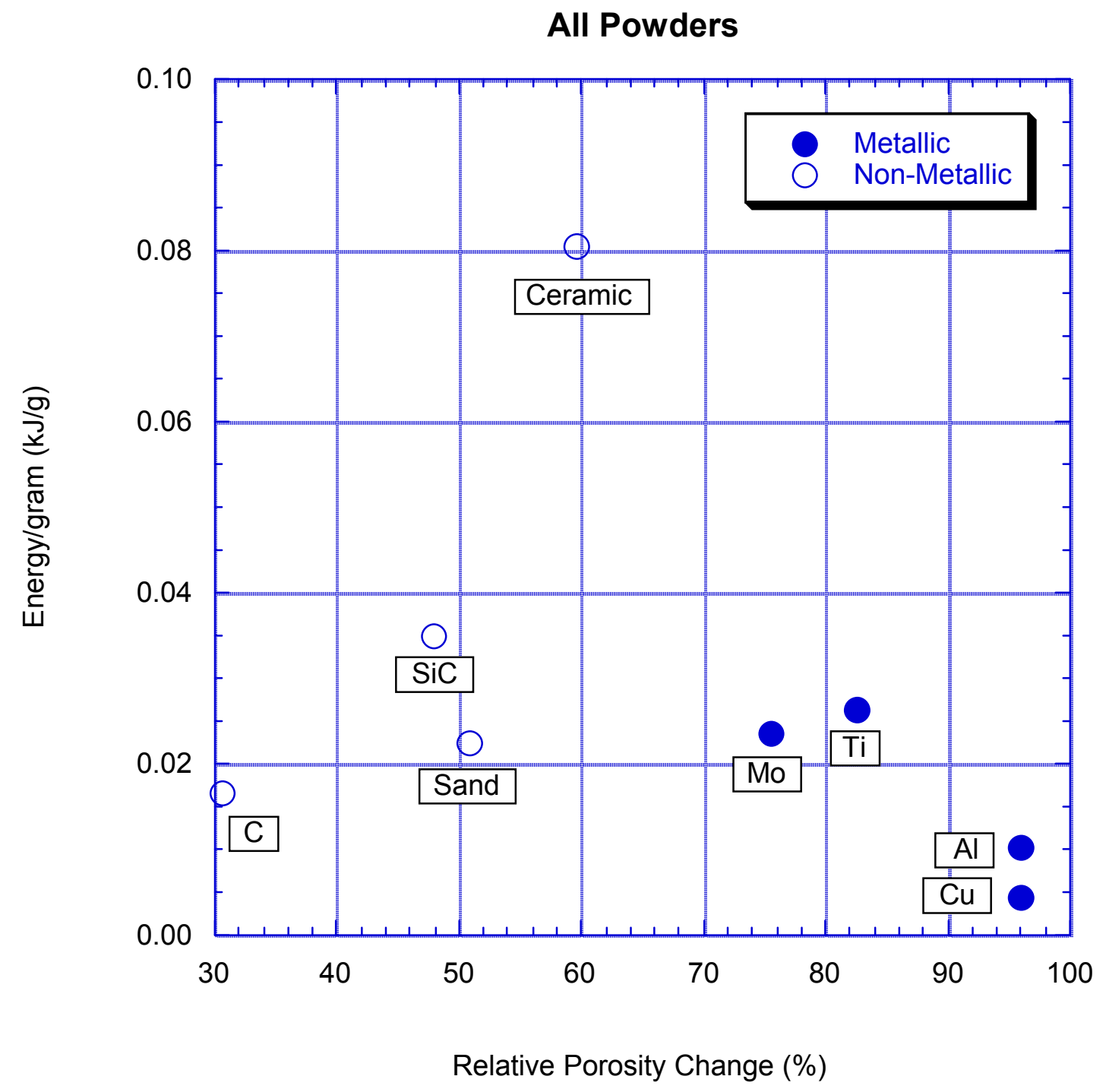

Fig. 47. Energy expended per gram and relative porosity change in hydrostatic compression to $1 \mathrm{GPa}$ for metallic and non-metallic test materials. 

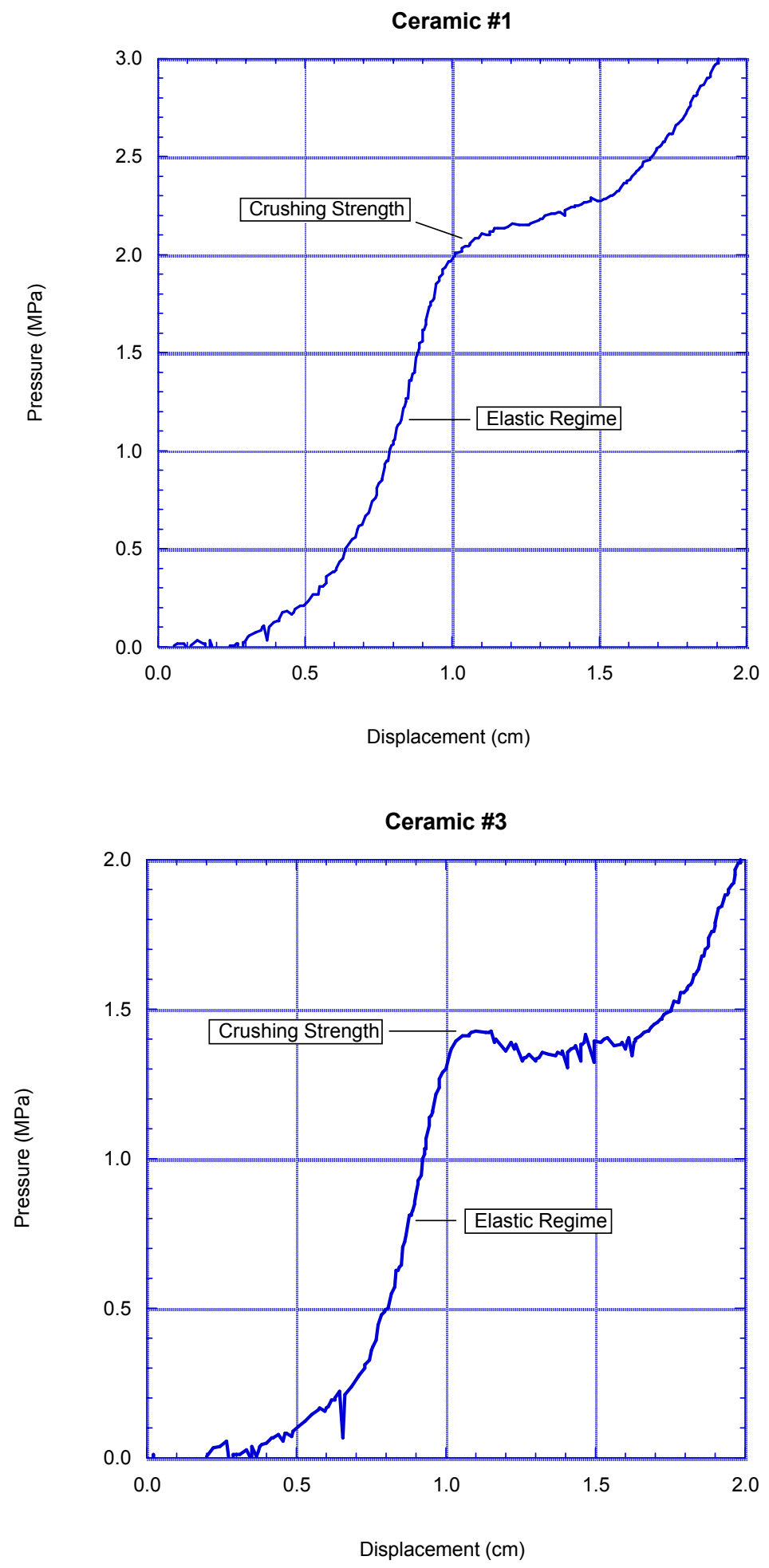

Fig. 48. Crushing strength of hollow ceramic microspheres. 


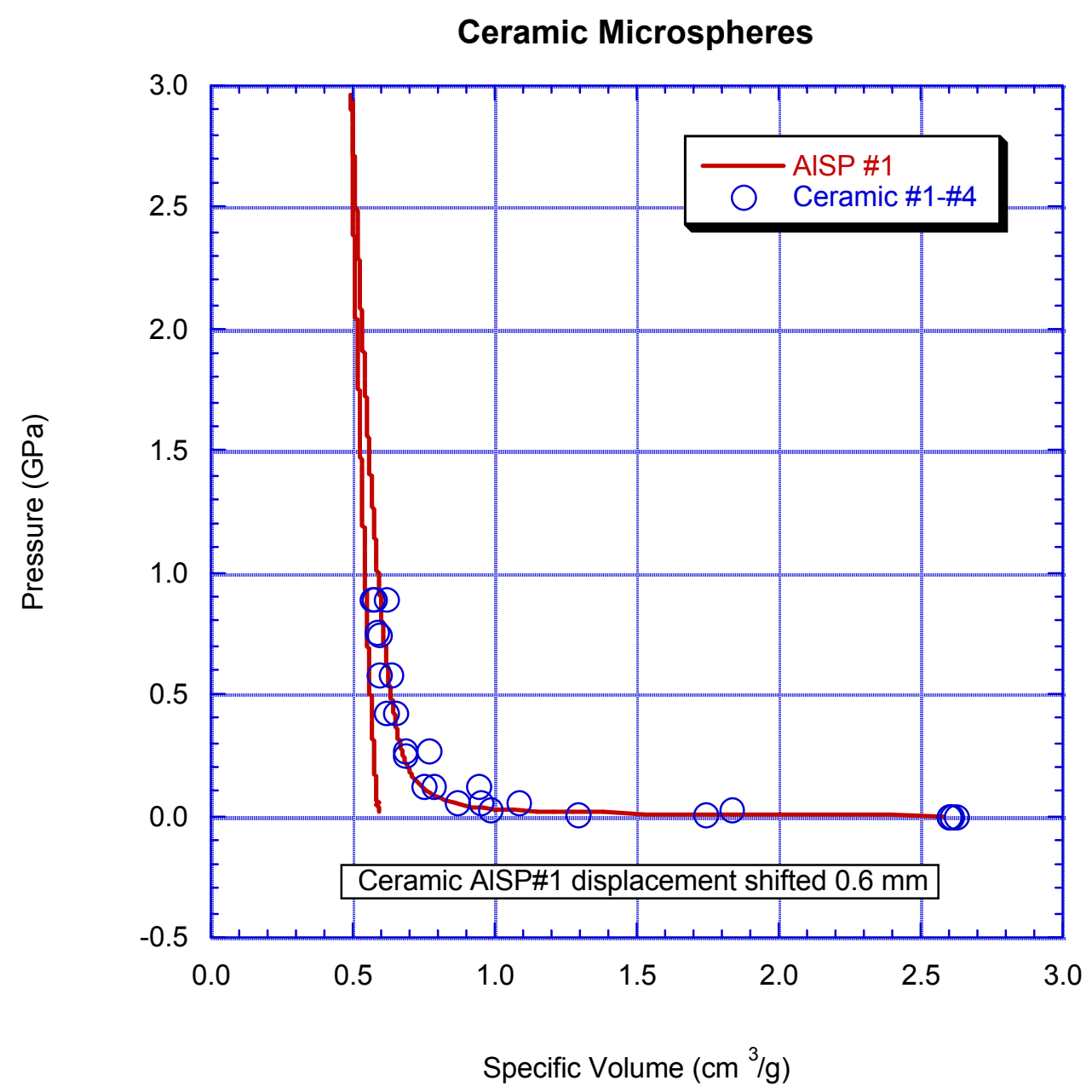

Fig. 49. Pressure versus specific volume for ceramic microspheres compressed to $3 \mathrm{GPa}$ in the solid medium press (solid line). Open circles are pressure-volume data from the liquid medium press. An error of $0.6 \mathrm{~mm}$ in picking the piston/specimen contact point has been inferred from micrometer measurements of the post-test specimen length. 
Molybdenum \#6

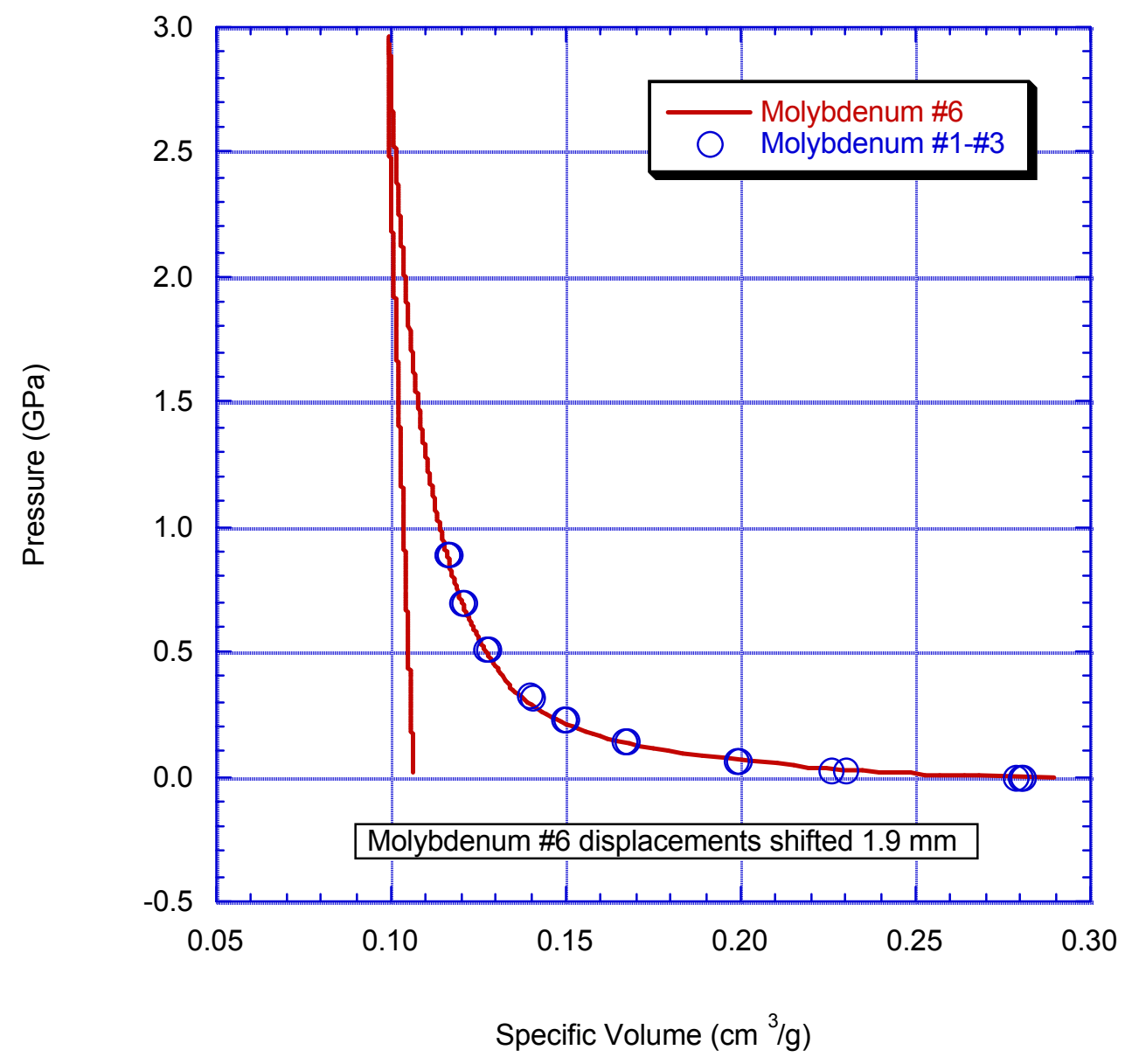

Fig. 50. Pressure versus specific volume for molybdenum powder compressed to $3 \mathrm{GPa}$ in the solid medium press (solid line). Open circles are pressure-volume data from the liquid medium press. A1.9 mm error in picking the piston/specimen contact point has been inferred from micrometer measurements of the post-test specimen length. 


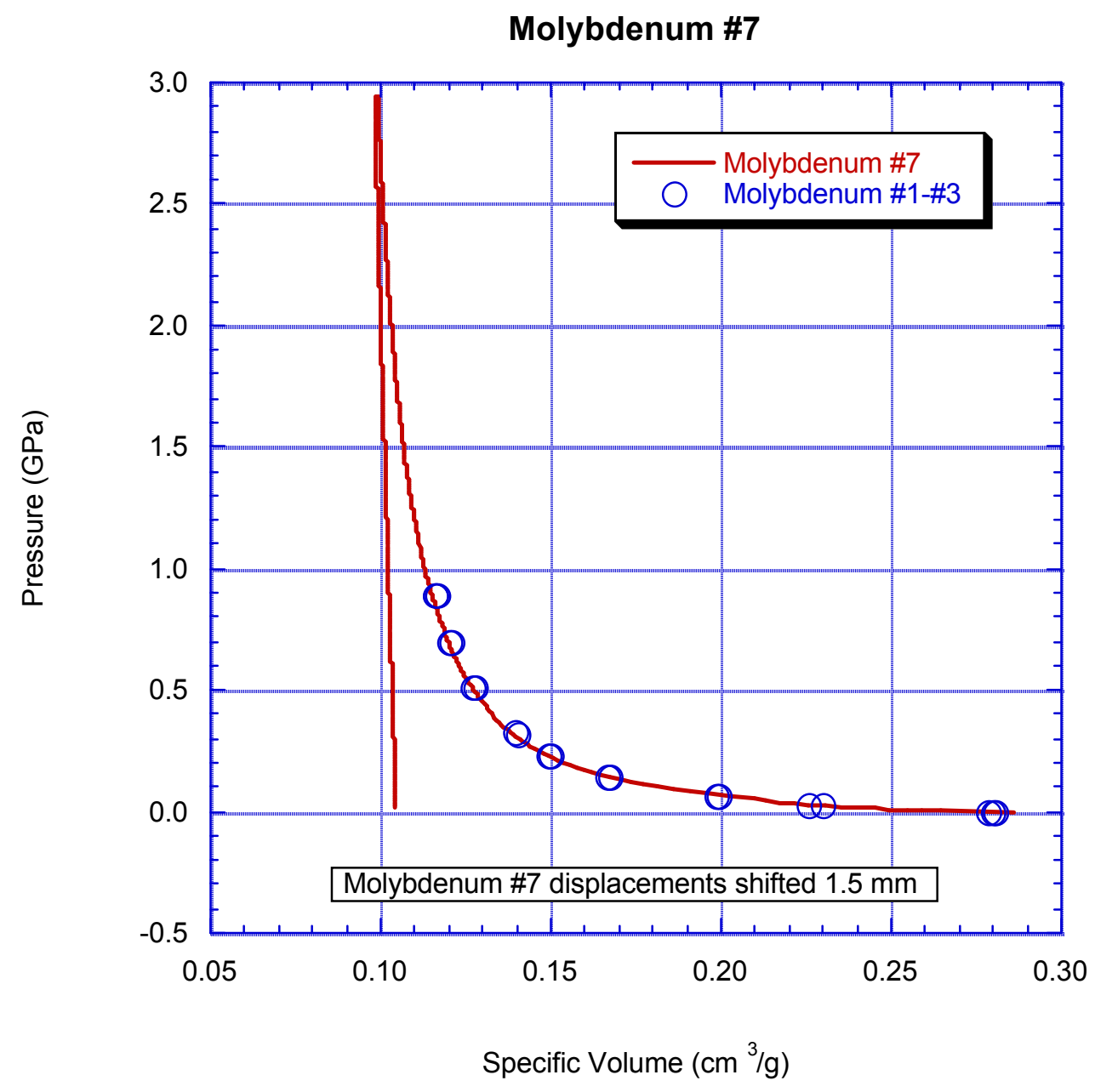

Fig. 51. Pressure versus specific volume for molybdenum powder compressed to $3 \mathrm{GPa}$ in the solid medium press (solid line). Open circles are pressure-volume data from the liquid medium press. A1.5 mm error in picking the piston/specimen contact point has been inferred from micrometer measurements of the post-test specimen length. 


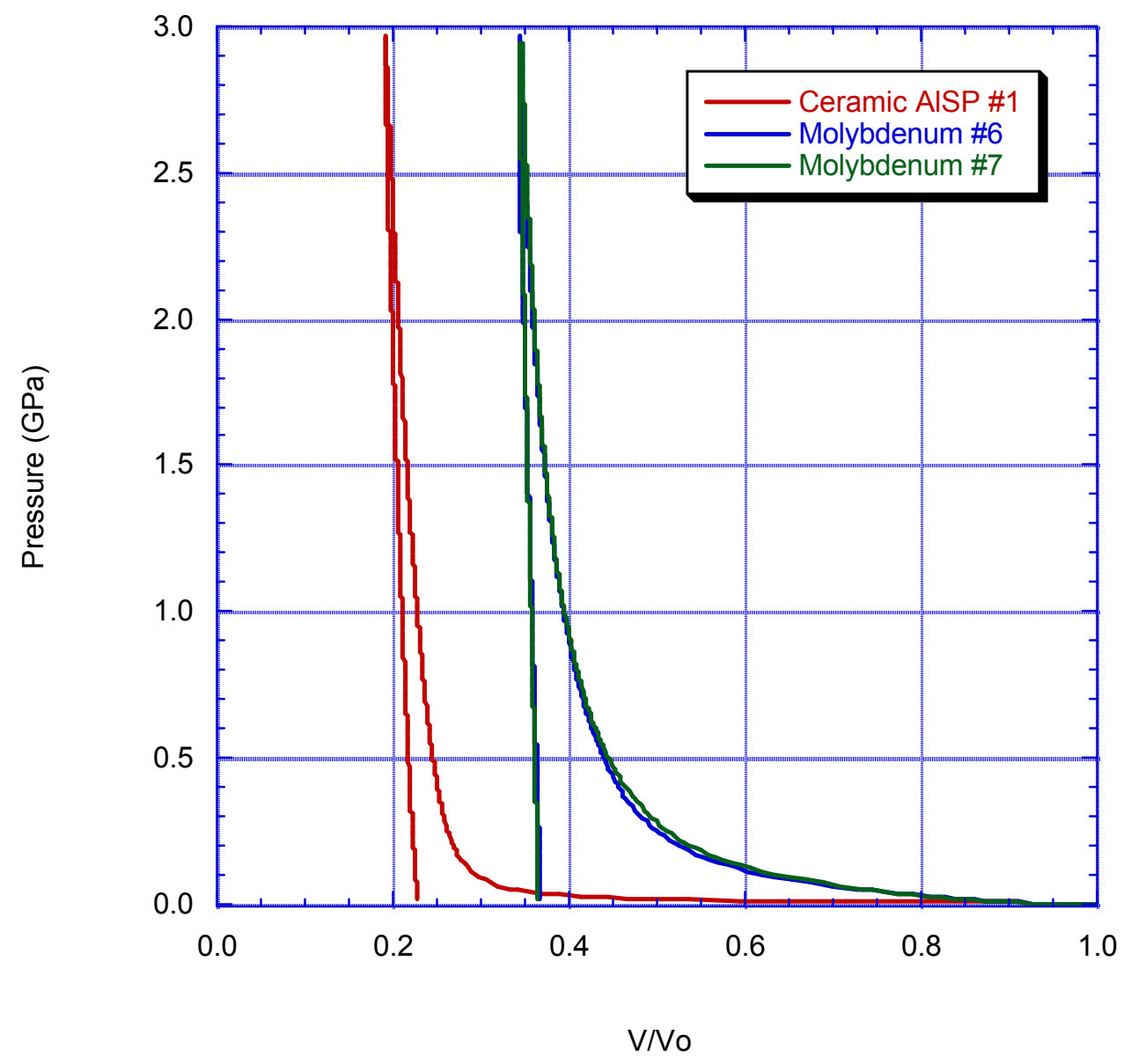

Fig. 52. Pressure versus relative volume for ceramic microspheres and molybdenum powder. 


\section{Ceramic Microspheres}

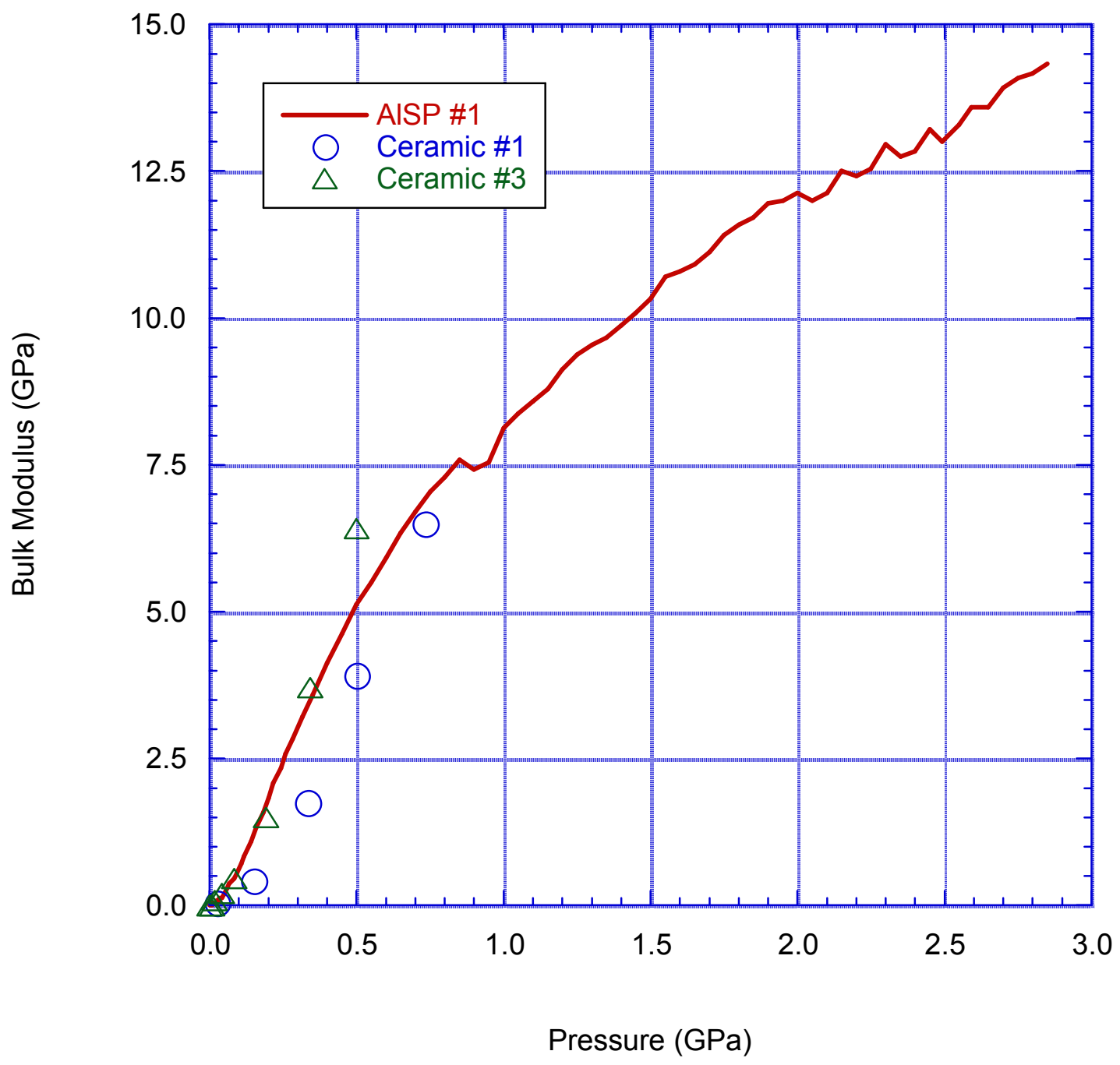

Fig. 53. Bulk modulus versus pressure for ceramic microsphere specimen AlSP\#1. Bulk moduli from hydrostatically compressed ceramic microsphere specimens (open symbols) are included for comparison. 


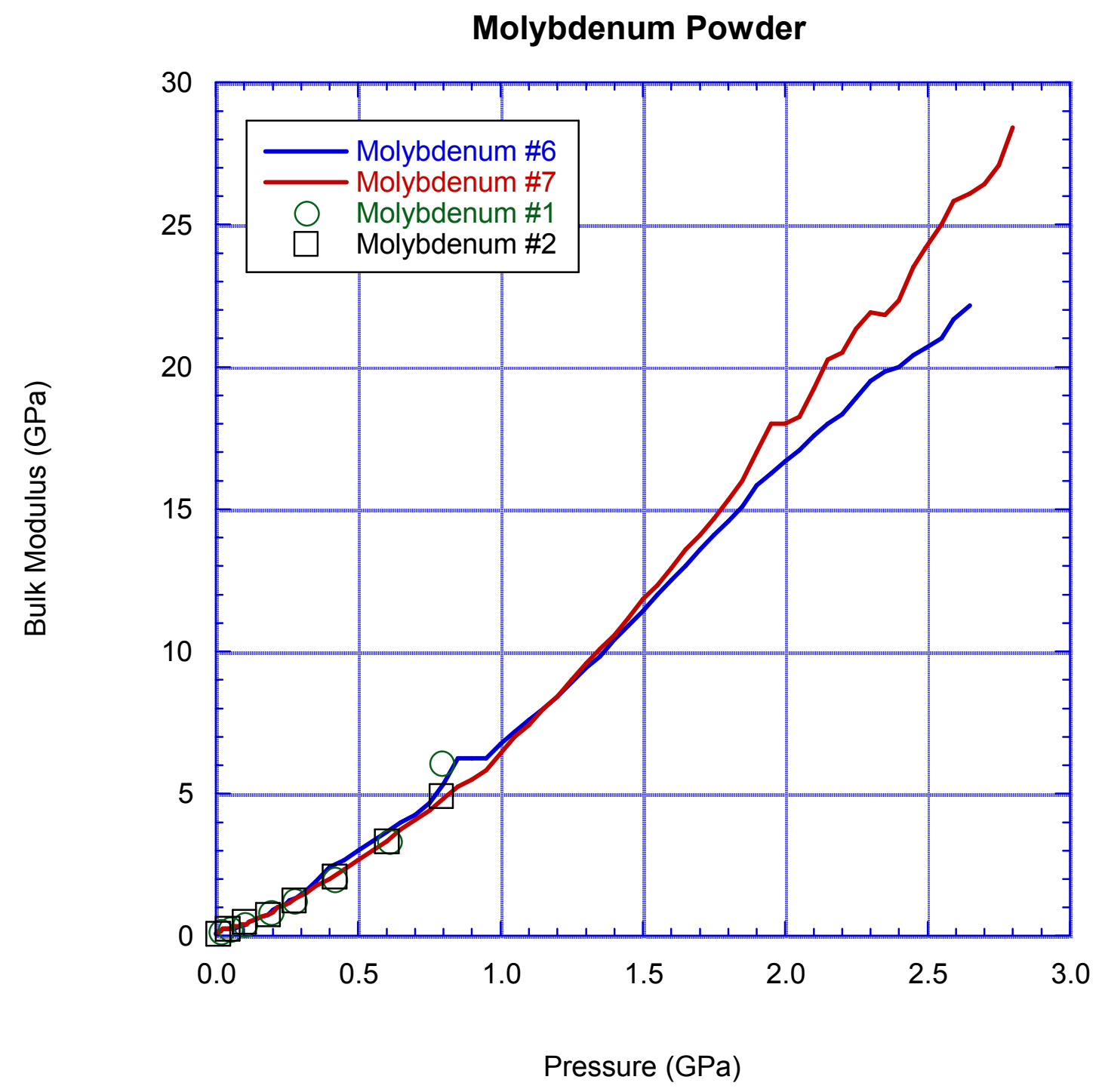

Fig. 54. Bulk modulus versus pressure for molybdenum powder. Bulk moduli from hydrostatically compressed molybdenum (open symbols) are included for comparison. 


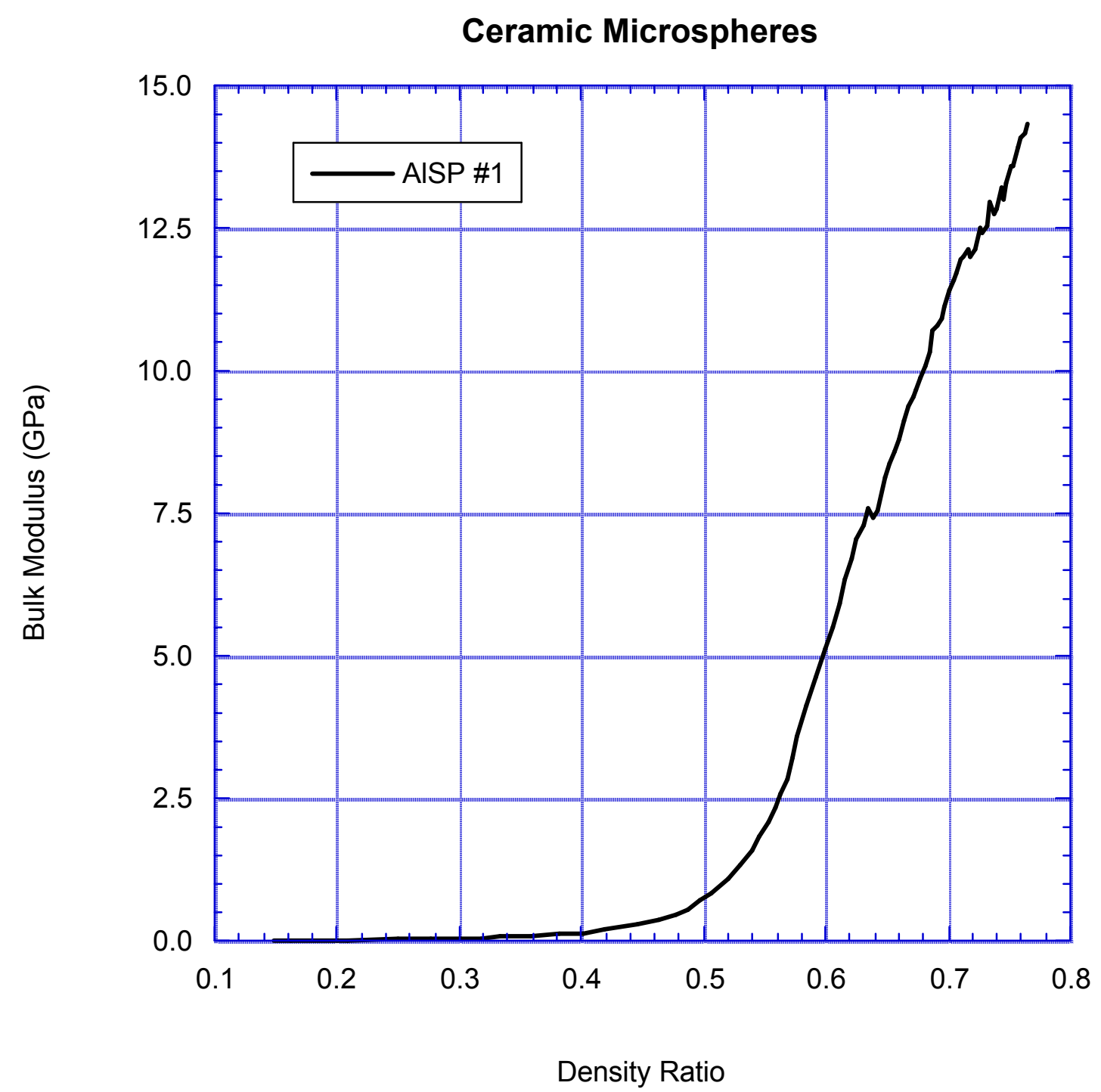

Fig. 55. Bulk modulus versus relative density for ceramic microsphere specimen AlSP\#1. A density ratio of 1.0 represents full densification at room pressure. 


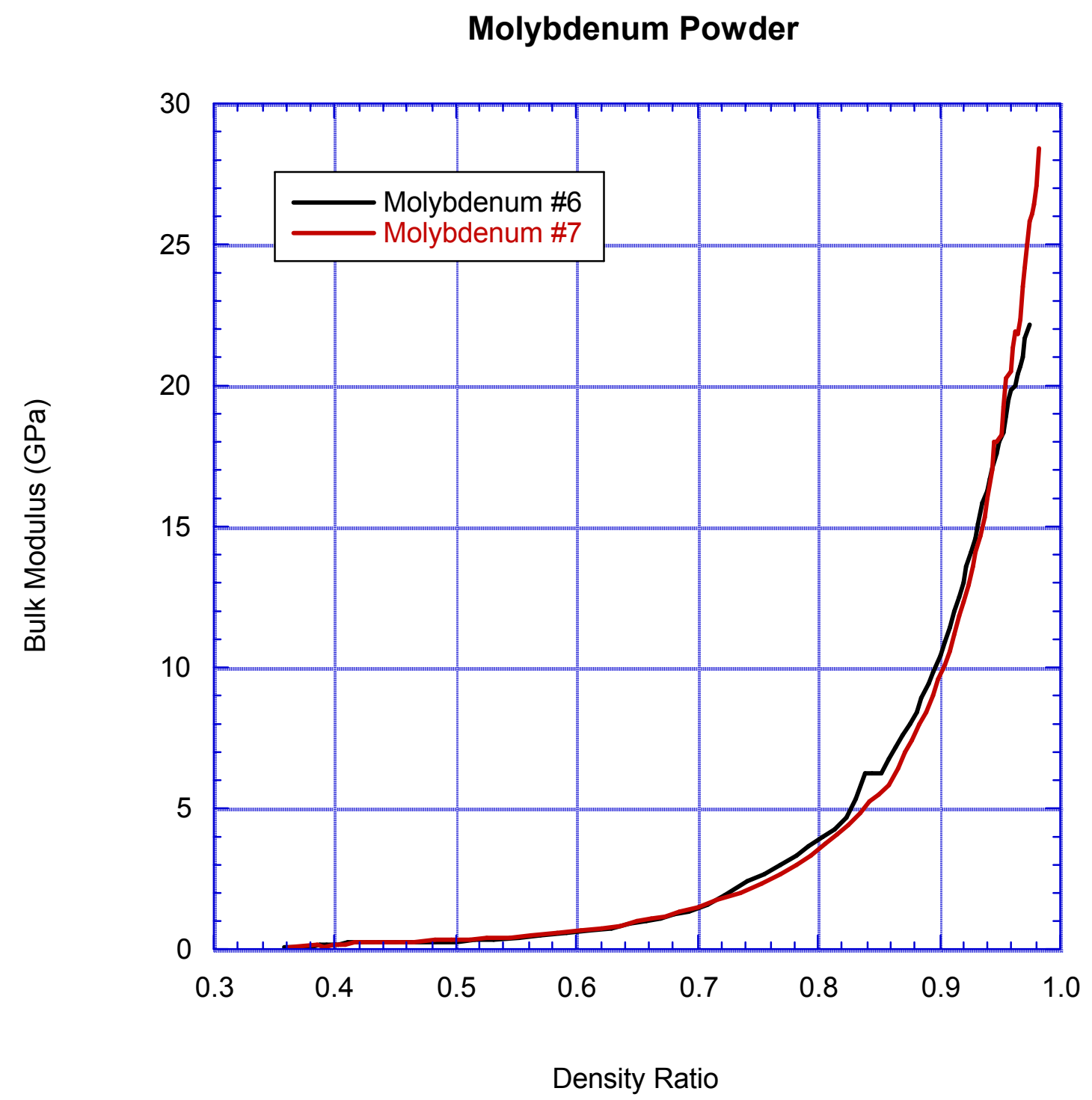

Fig. 56. Bulk modulus versus relative density for molybdenum powder. A density ratio of 1.0 represents full densification at room pressure. 


\section{Aluminum Powder}

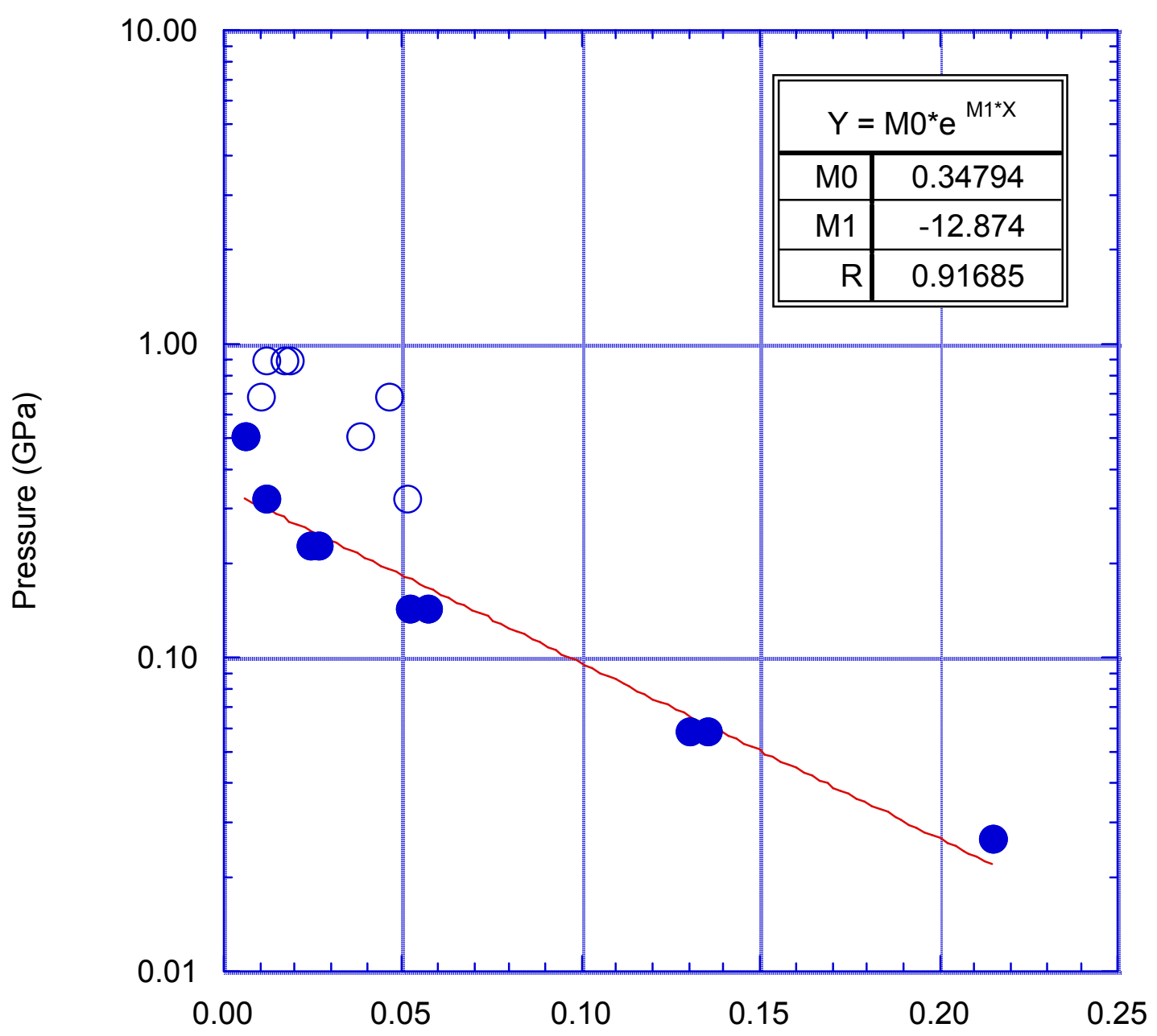

Void Ratio

Fig. 57. Porosity, expressed as void ratio, versus pressure for aluminum powder. Data shown as solid symbols were used in the regression fit. The open circles were omitted. Nearly all porosity was removed below $1 \mathrm{GPa}$. Scatter at low porosity may be due to trapped air pockets. 


\section{Carbon Powder}

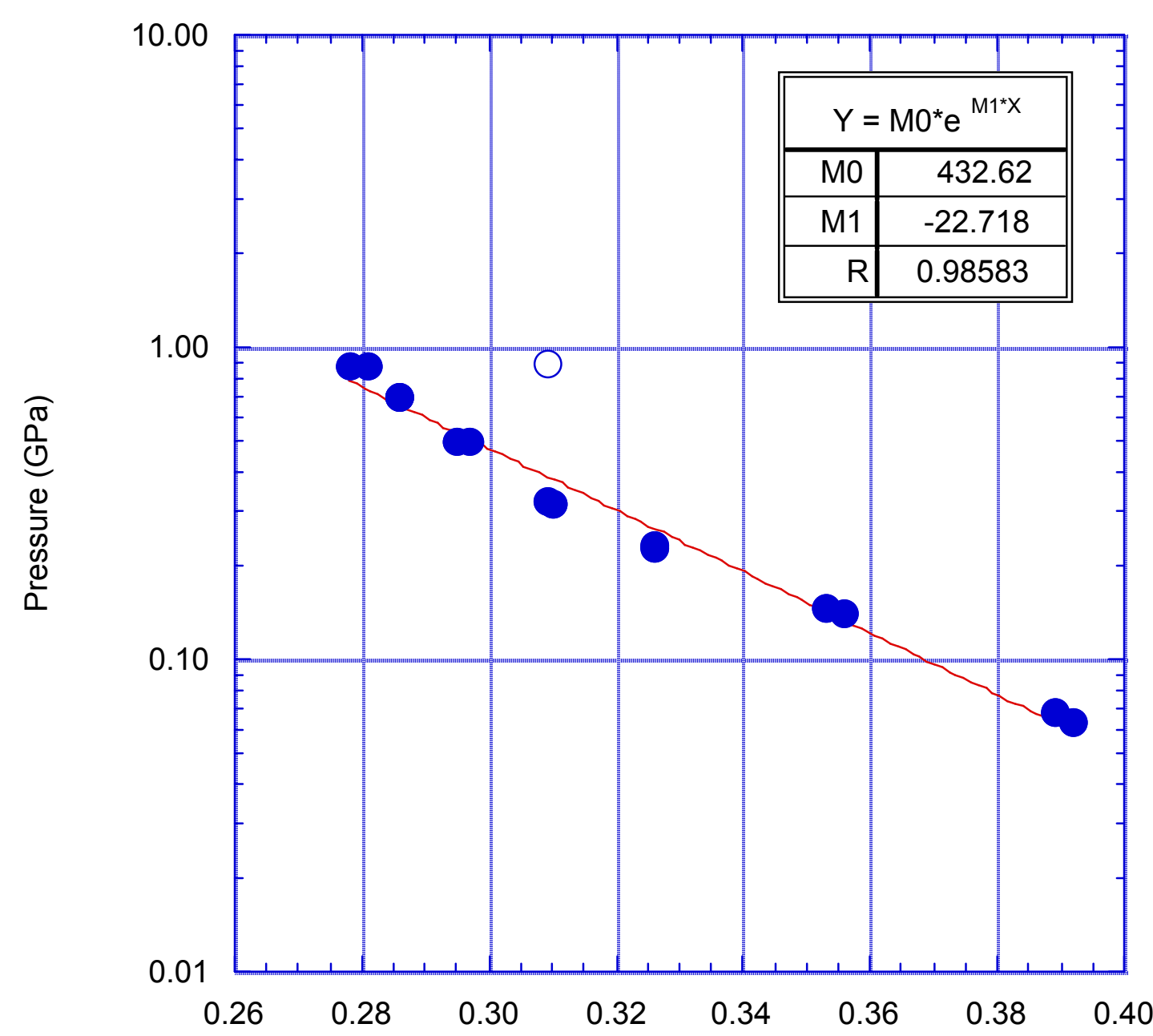

Void Ratio

Fig. 58. Porosity, expressed as void ratio, versus pressure for glassy carbon spheres. Data shown as solid symbols were used in the regression fit. The open circle was omitted. Much porosity remains at $0.9 \mathrm{GPa}$. The estimated merge pressure, found from the zero-porosity intercept, is over $430 \mathrm{GPa}$. 


\section{Ceramic Microspheres}

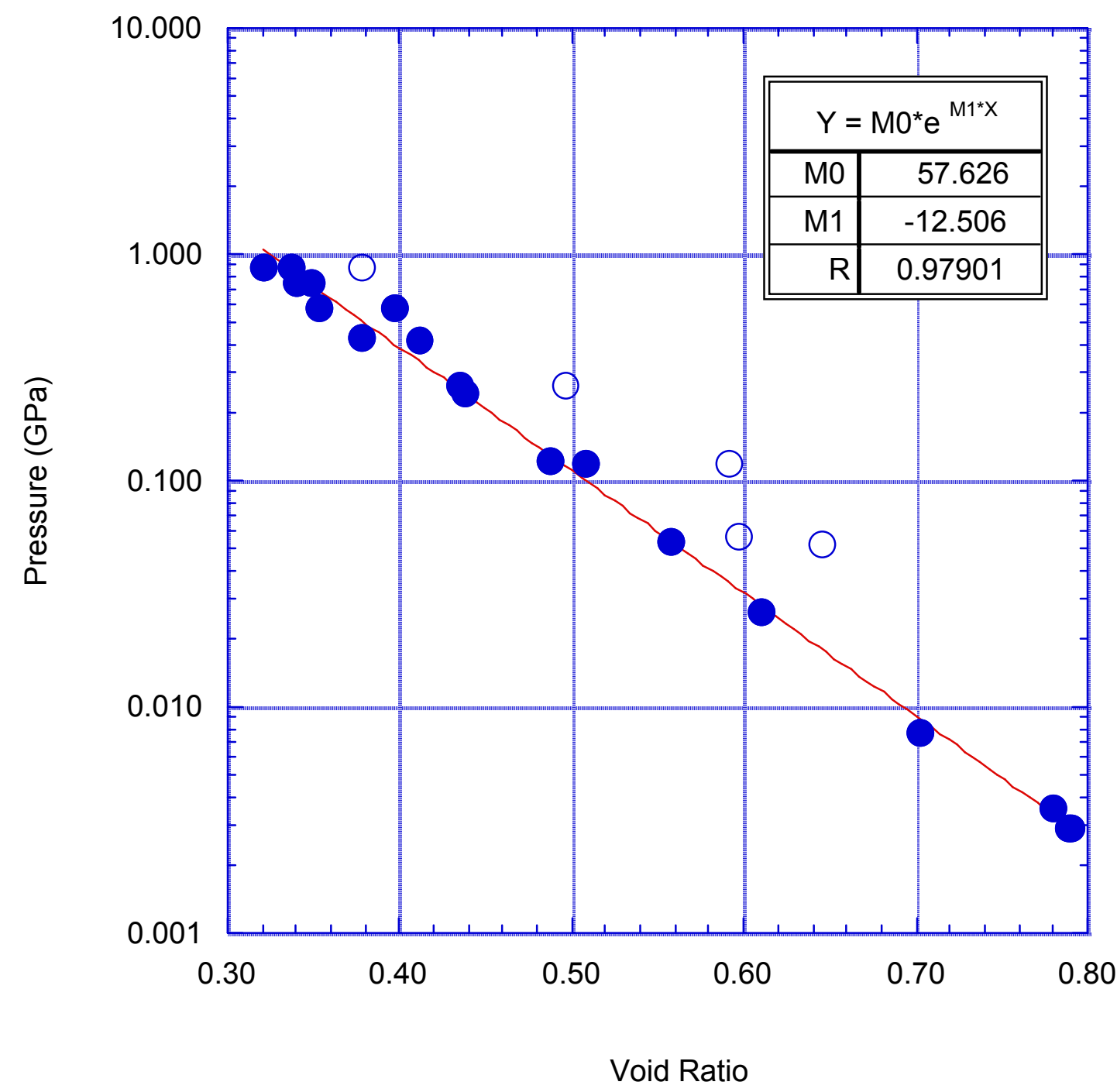

Fig. 59. Porosity, expressed as void ratio, versus pressure for ceramic microspheres. Data shown as solid symbols were used in the regression fit. The open circles were omitted. The predicted merge pressure is about $58 \mathrm{GPa}$. 
Copper Powder

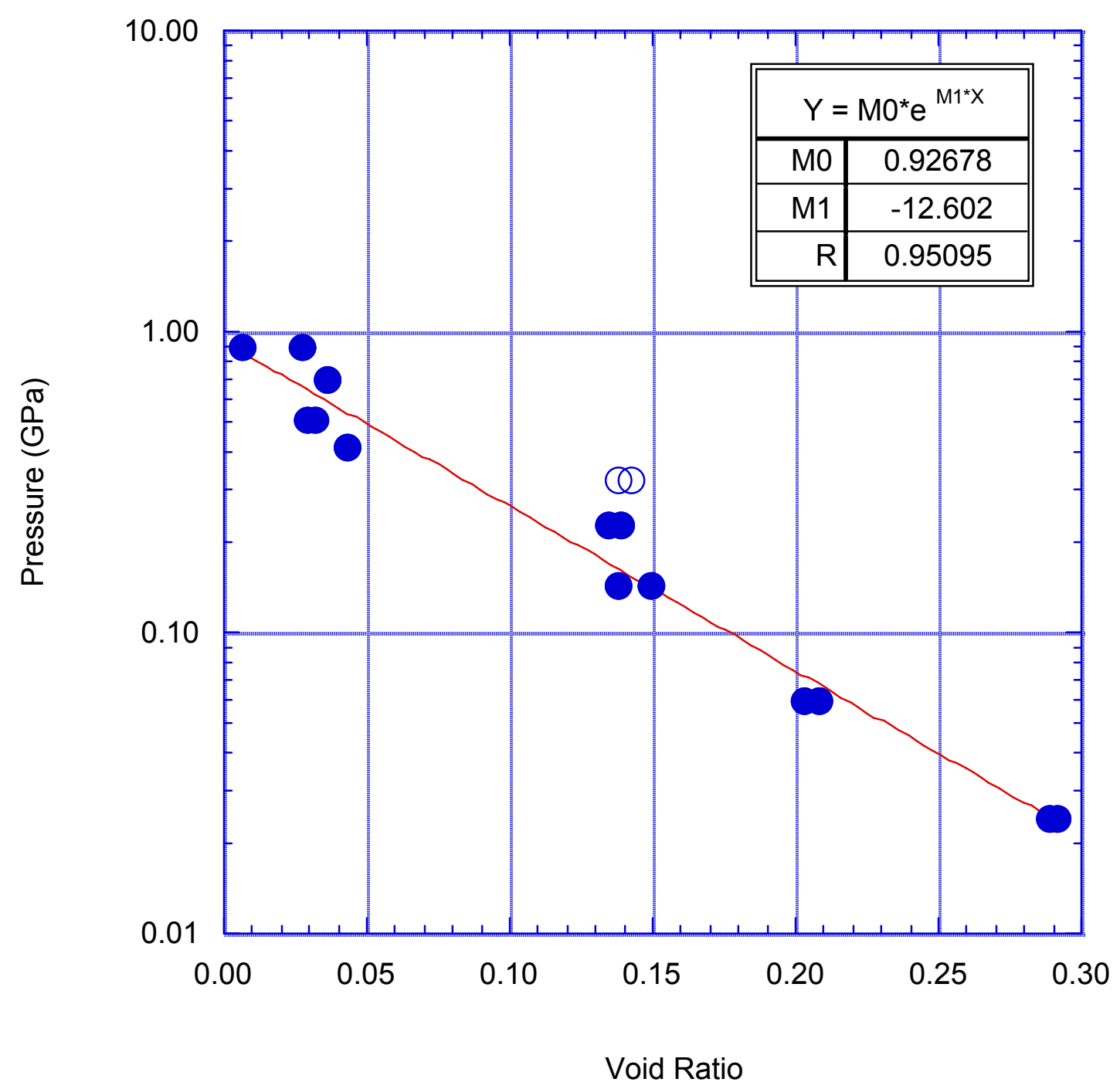

Fig. 60. Porosity, expressed as void ratio, versus pressure for copper powder. Data shown as solid symbols were used in the regression fit. The open circles were omitted. The predicted merge pressure of $0.93 \mathrm{GPa}$ is about the same as that reached in the hydrostatic tests. 
Molybdenum Powder

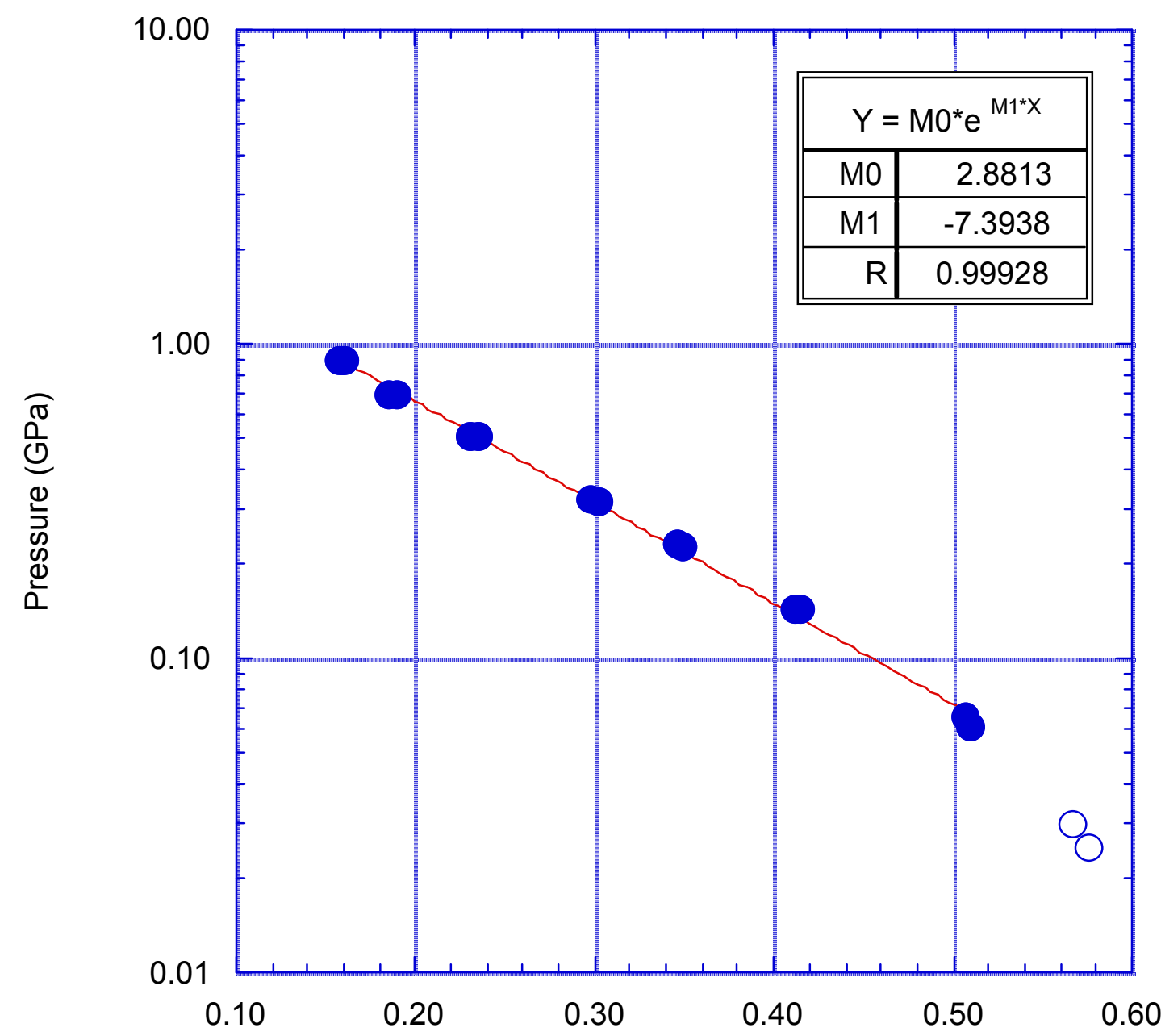

Void Ratio

Fig. 61. Porosity, expressed as void ratio, versus pressure for molybdenum powder. Data shown as solid symbols were used in the regression fit. The open circles were omitted. The data from the hydrostatic tests suggest that the pressure reached in the solid medium tests should be sufficient to remove all porosity. 


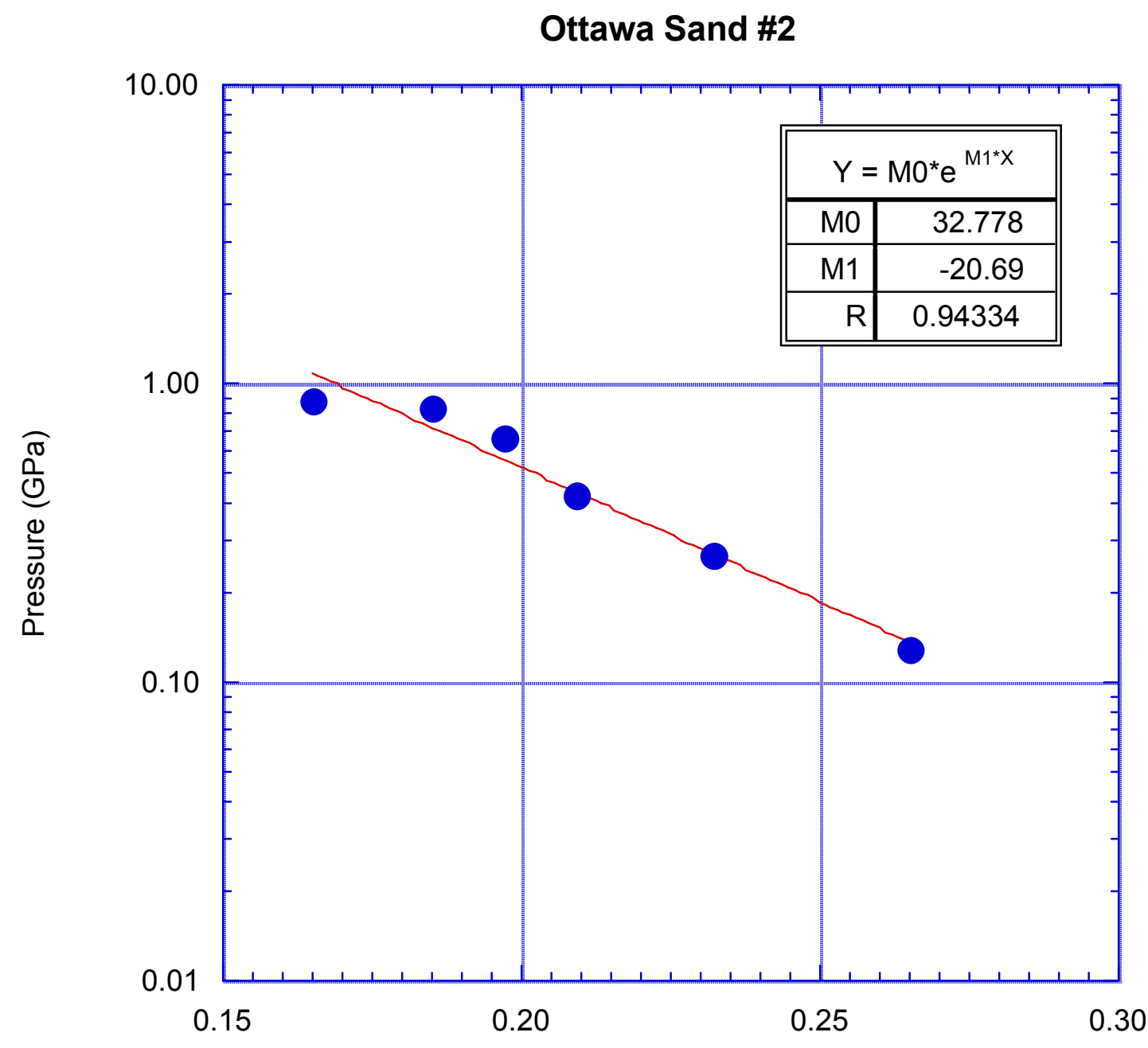

Void Ratio

Fig. 62. Porosity, expressed as void ratio, versus pressure for Ottawa sand. The predicted merge pressure is about $33 \mathrm{GPa}$. 


\section{Silicon Carbide Powder}

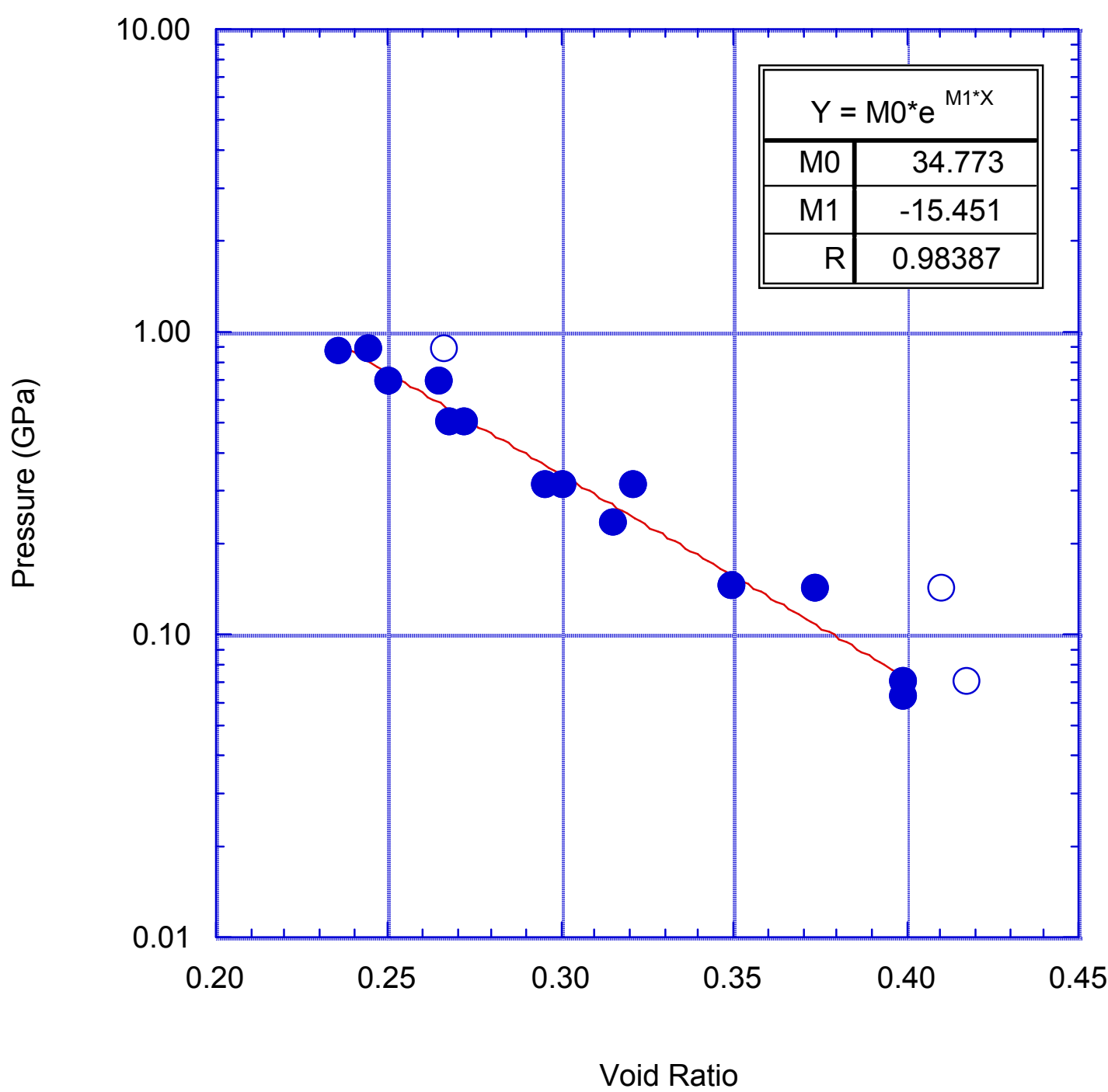

Fig. 63. Porosity, expressed as void ratio, versus pressure for silicon carbide powder. Data shown as solid symbols were used in the regression fit. The open circles were omitted. The predicted merge pressure is about $35 \mathrm{GPa}$. 
Titanium Powder

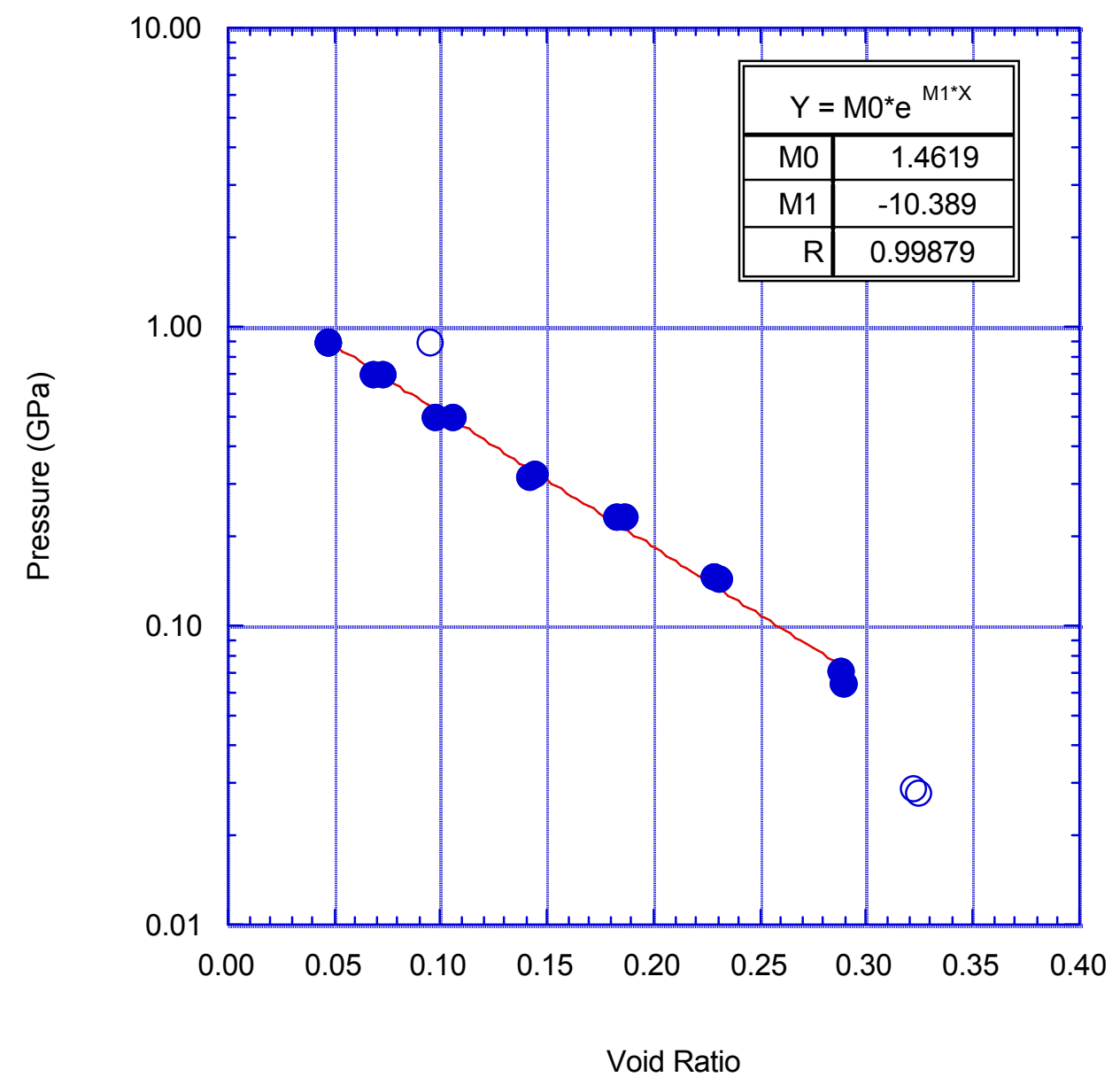

Fig. 64. Porosity, expressed as void ratio, versus pressure for titanium powder. Data shown as solid symbols were used in the regression fit. The open circles were omitted. The predicted merge pressure is about $1.5 \mathrm{GPa}$. 


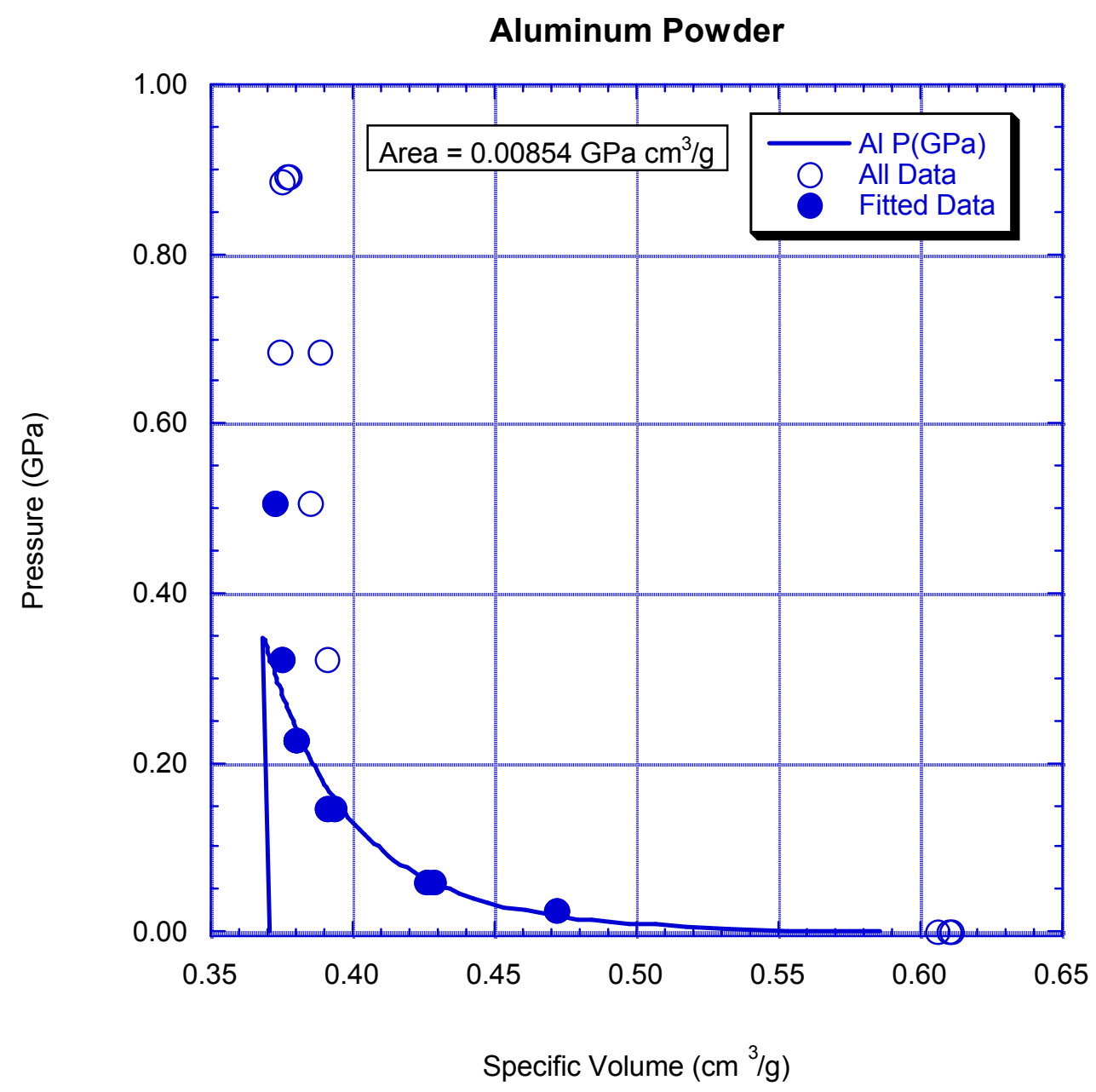

Fig. 65. Pressure-volume curve calculated from the exponential curve fit for aluminum powder. Data used in the curve fit are shown as solid circles. 


\section{Carbon Powder}

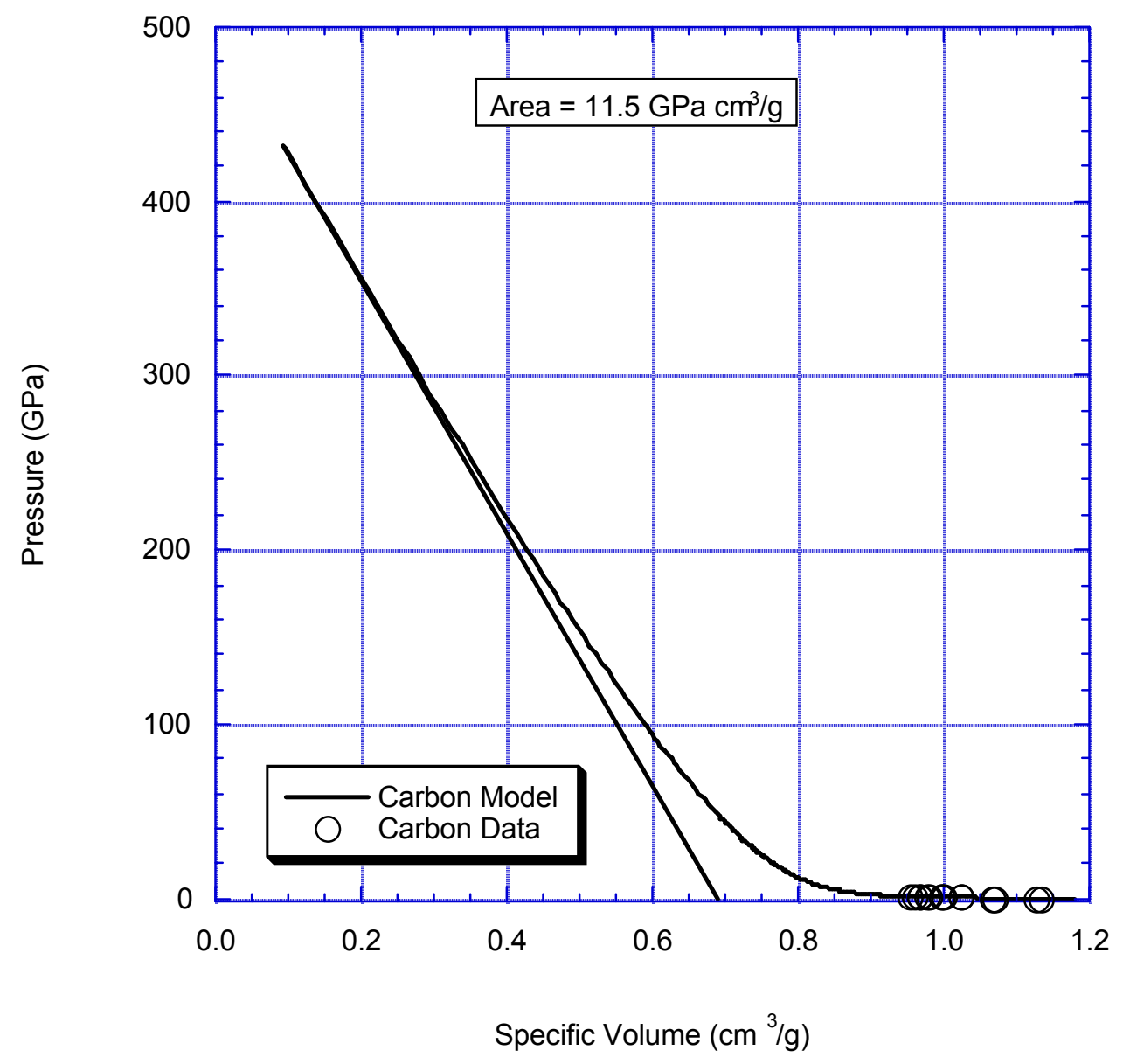

Fig. 66. Pressure-volume curve calculated from the exponential curve fit for glassy carbon spheres. The unloading portion of the curve assumes a constant bulk modulus. Data from the hydrostatic pressure tests are shown as open circles. 


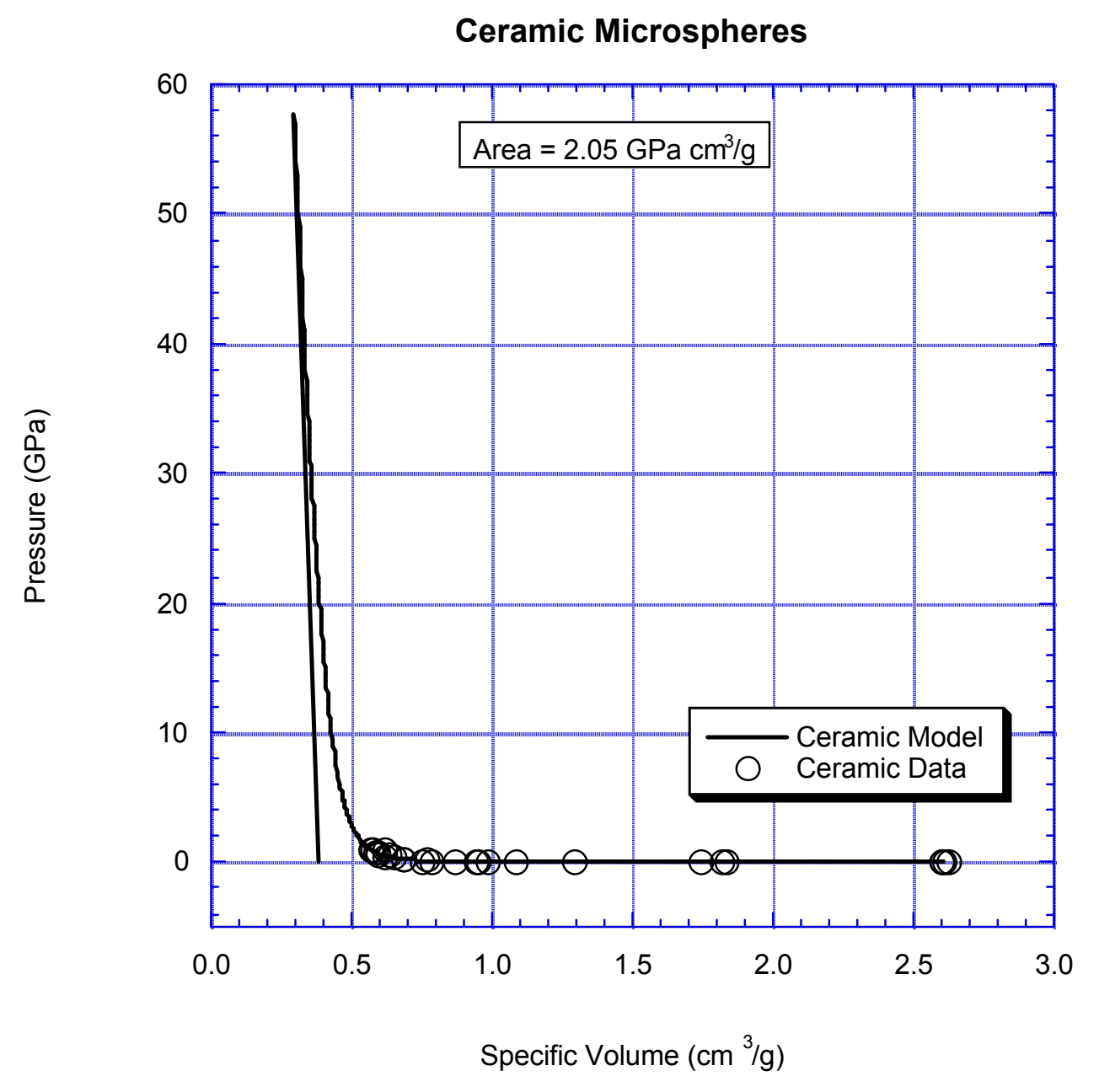

Fig. 67. Pressure-volume curve calculated from the exponential curve fit for ceramic microspheres. The unloading portion of the curve assumes a constant bulk modulus. Data from the hydrostatic pressure tests are shown as open circles. 


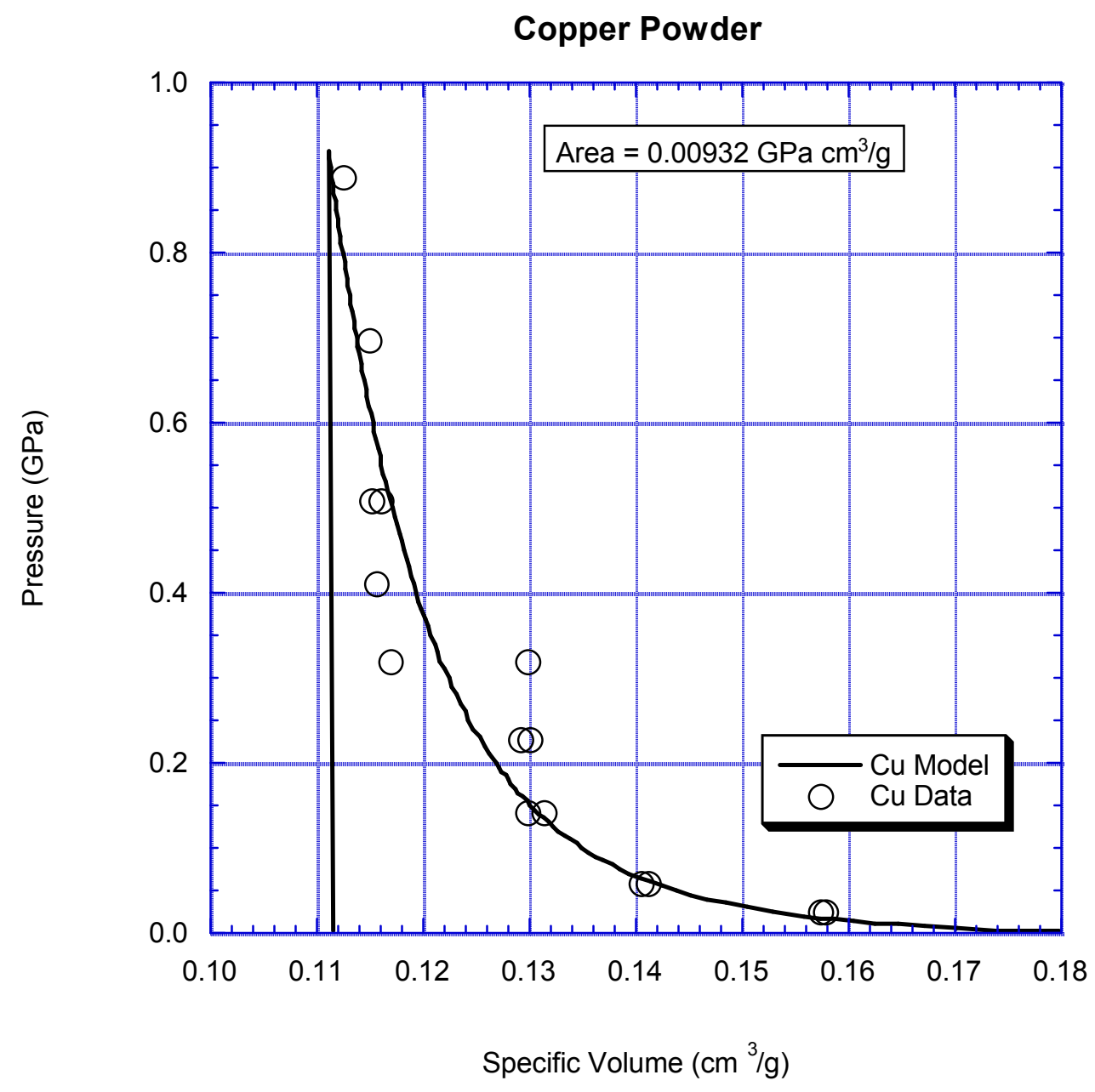

Fig. 68. Pressure-volume curve calculated from the exponential curve fit for copper powder. The unloading portion of the curve assumes a constant bulk modulus. Data from the hydrostatic pressure tests are shown as open circles. 


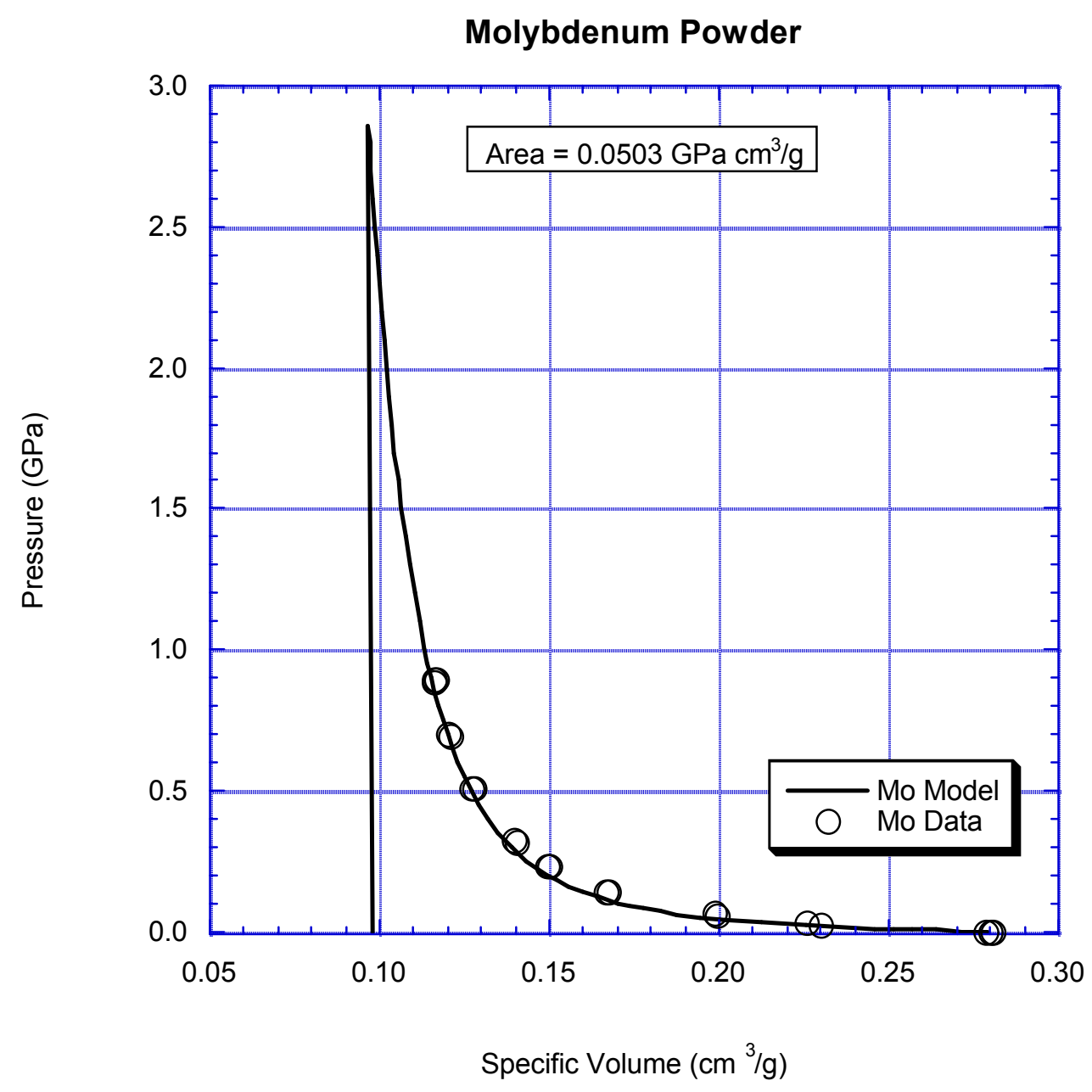

Fig. 69. Pressure-volume curve calculated from the exponential curve fit for molybdenum powder. The unloading portion of the curve assumes a constant bulk modulus. Data from the hydrostatic pressure tests are shown as open circles. 


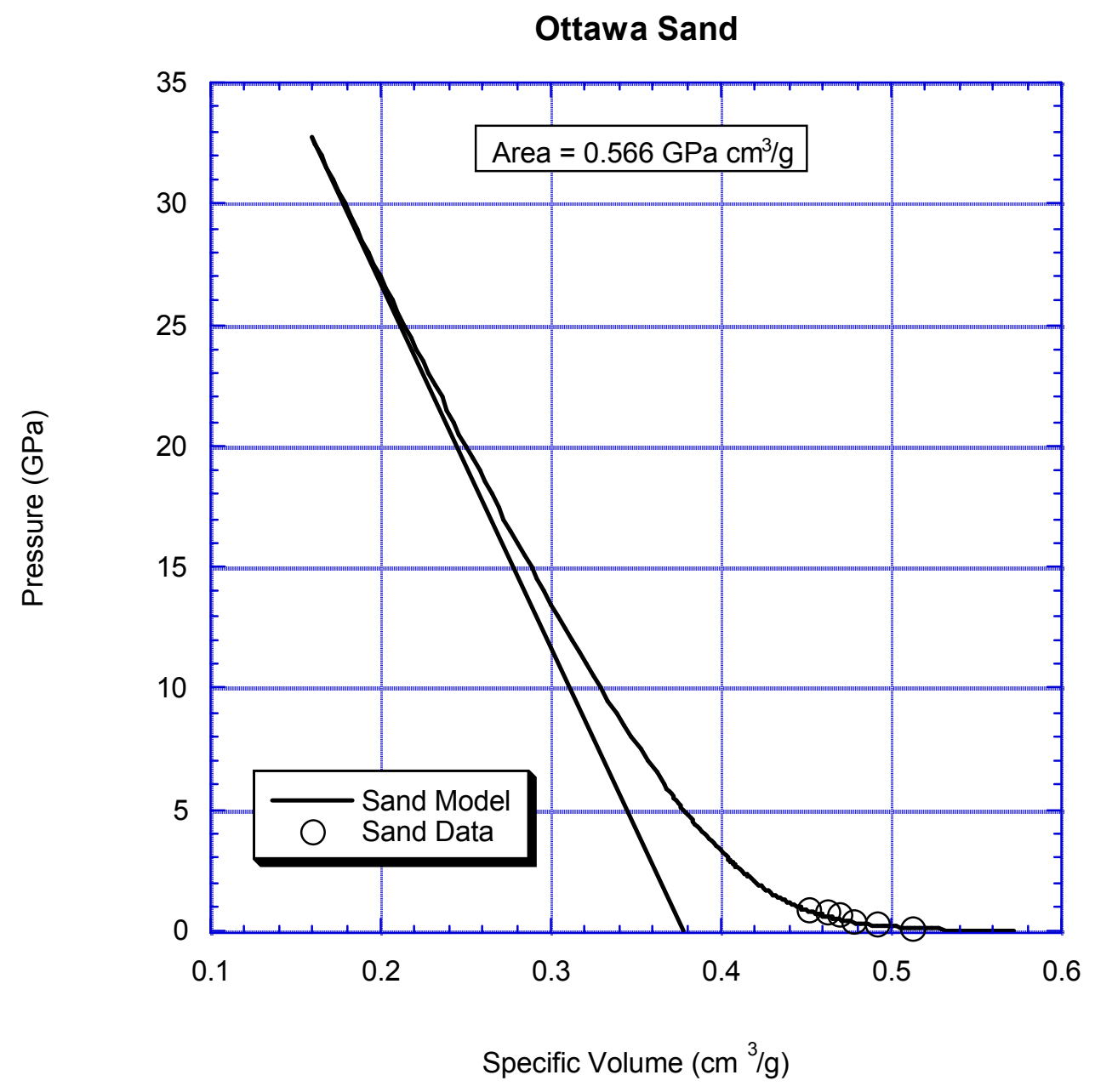

Fig. 70. Pressure-volume curve calculated from the exponential curve fit for Ottawa sand. The unloading portion of the curve assumes a constant bulk modulus. Data from the hydrostatic pressure tests are shown as open circles. 


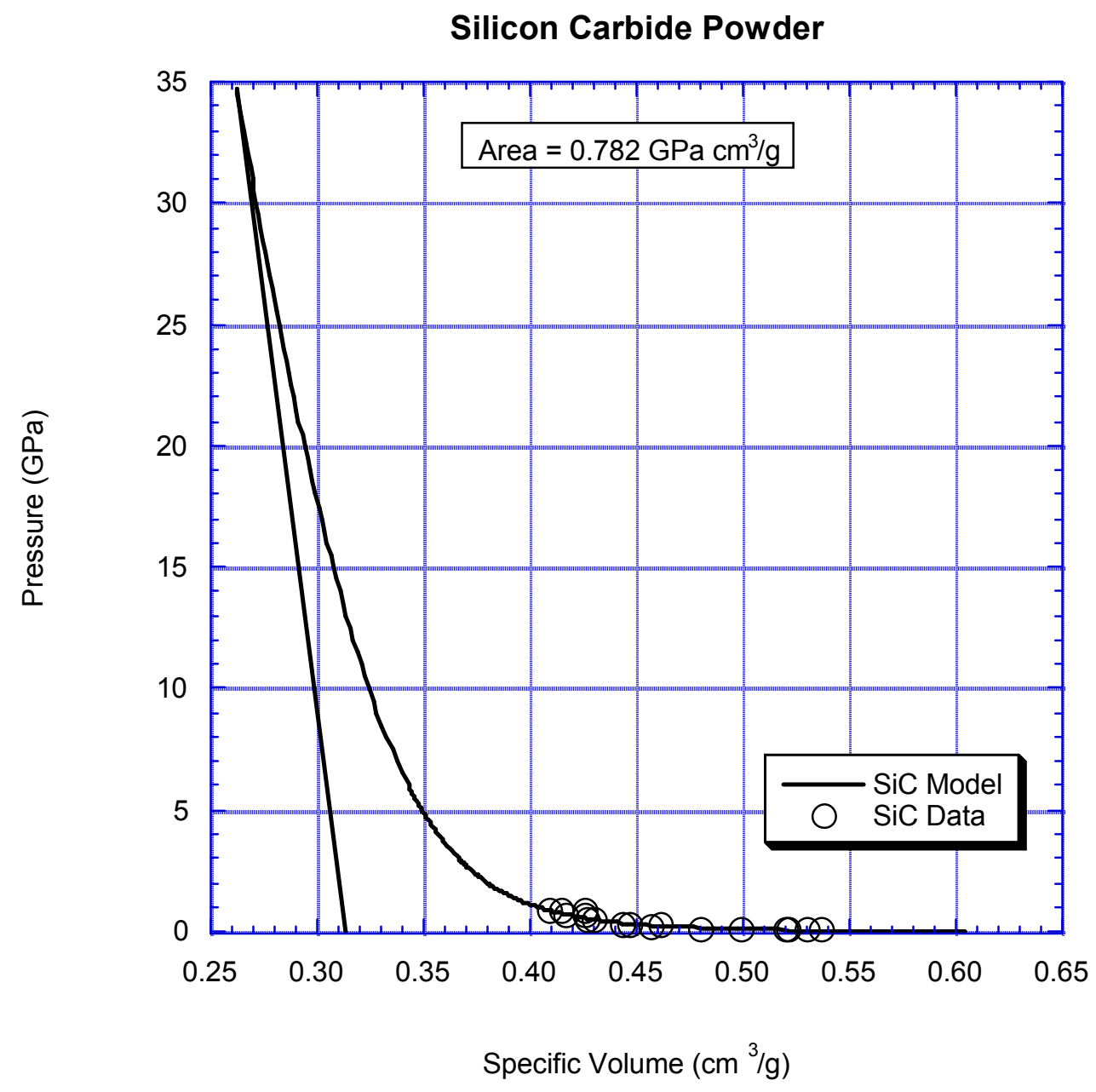

Fig. 71. Pressure-volume curve calculated from the exponential curve fit for silicon carbide powder. The unloading portion of the curve assumes a constant bulk modulus. Data from the hydrostatic pressure tests are shown as open circles. 
Titanium Powder

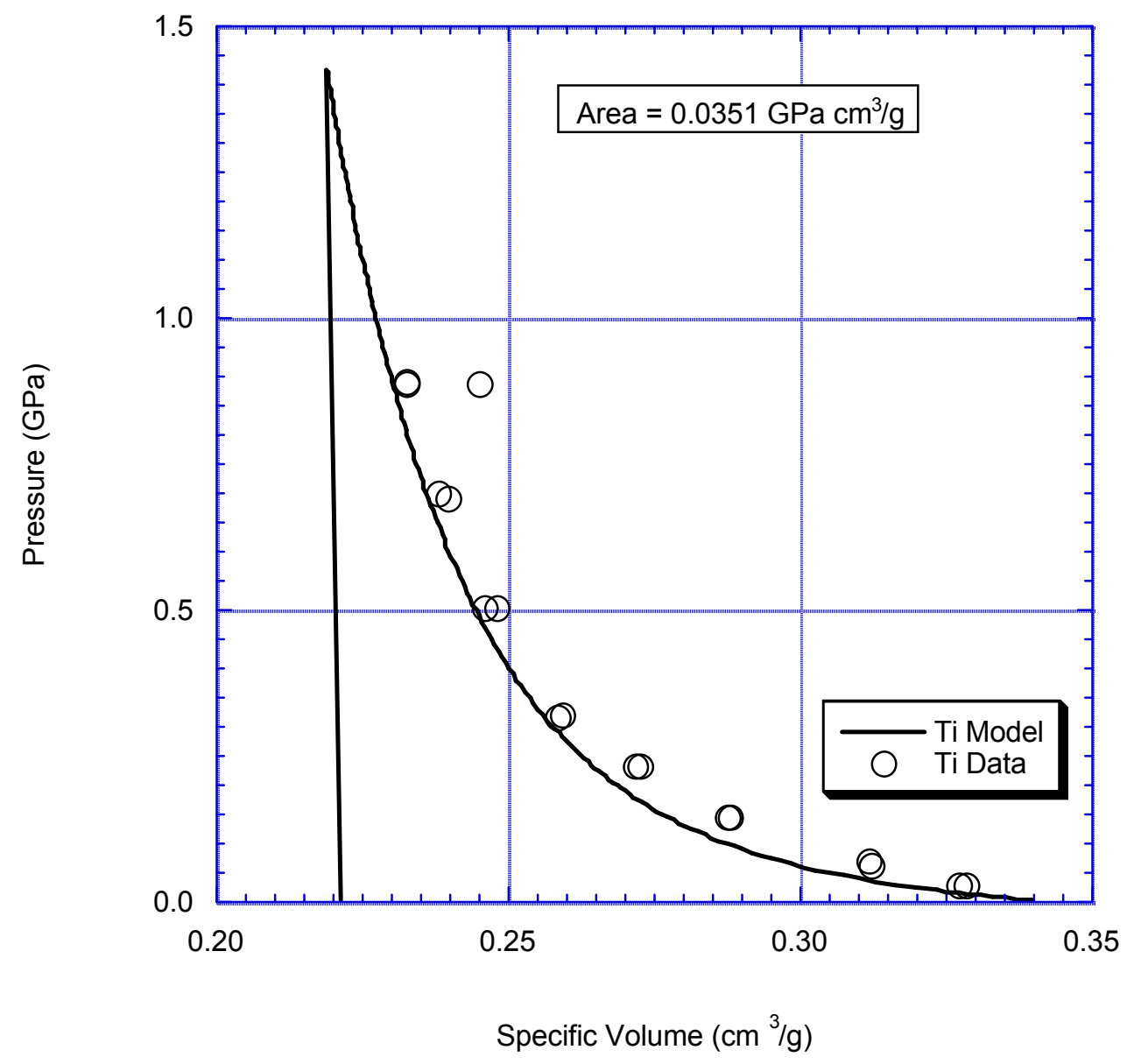

Fig. 72. Pressure-volume curve calculated from the exponential curve fit for titanium powder. The unloading portion of the curve assumes a constant bulk modulus. Data from the hydrostatic pressure tests are shown as open circles. 


\section{Exponential Model}

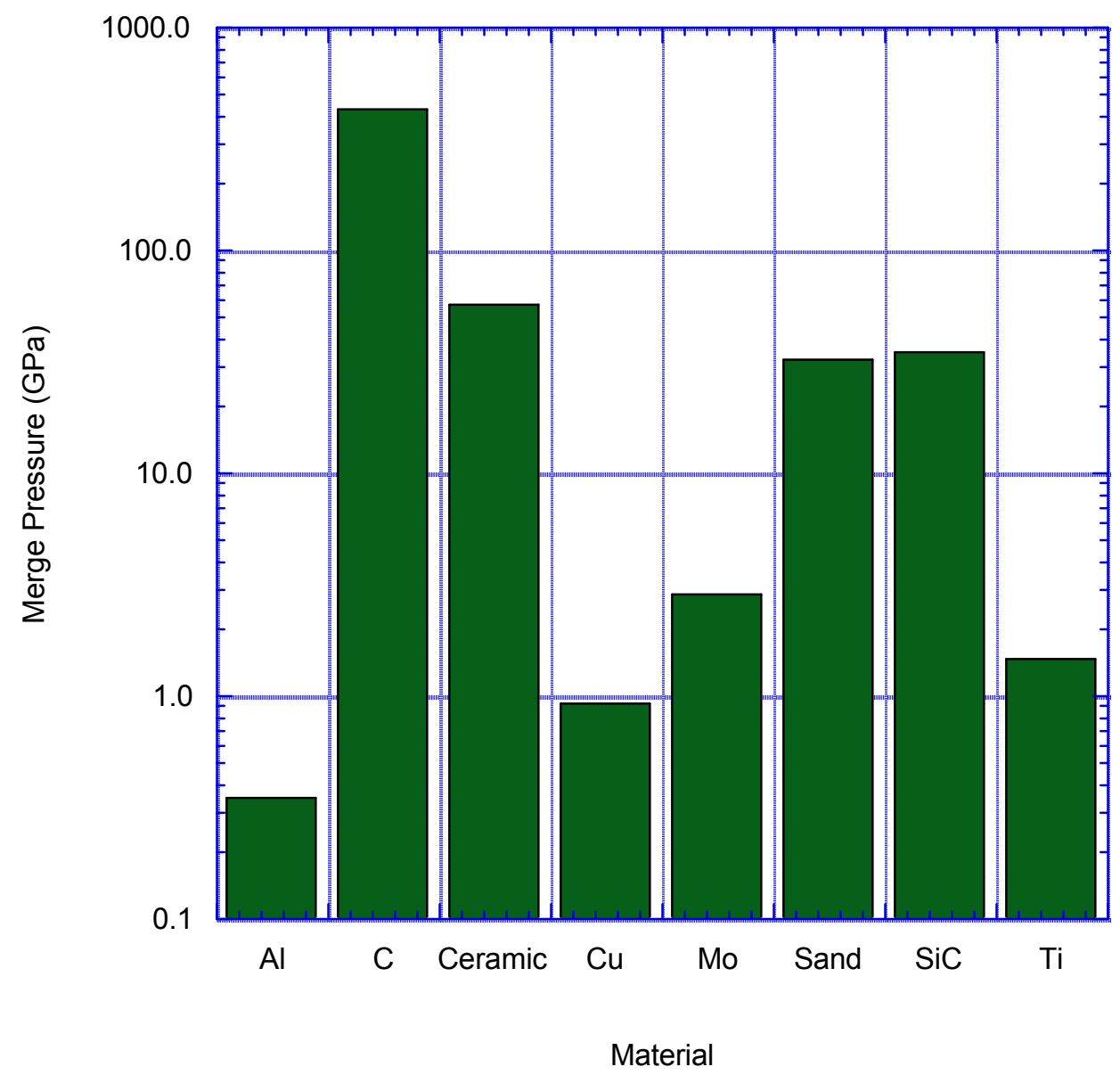

Fig 73. Merge pressures predicted by the exponential model fit for each material. 


\section{Exponential Model}

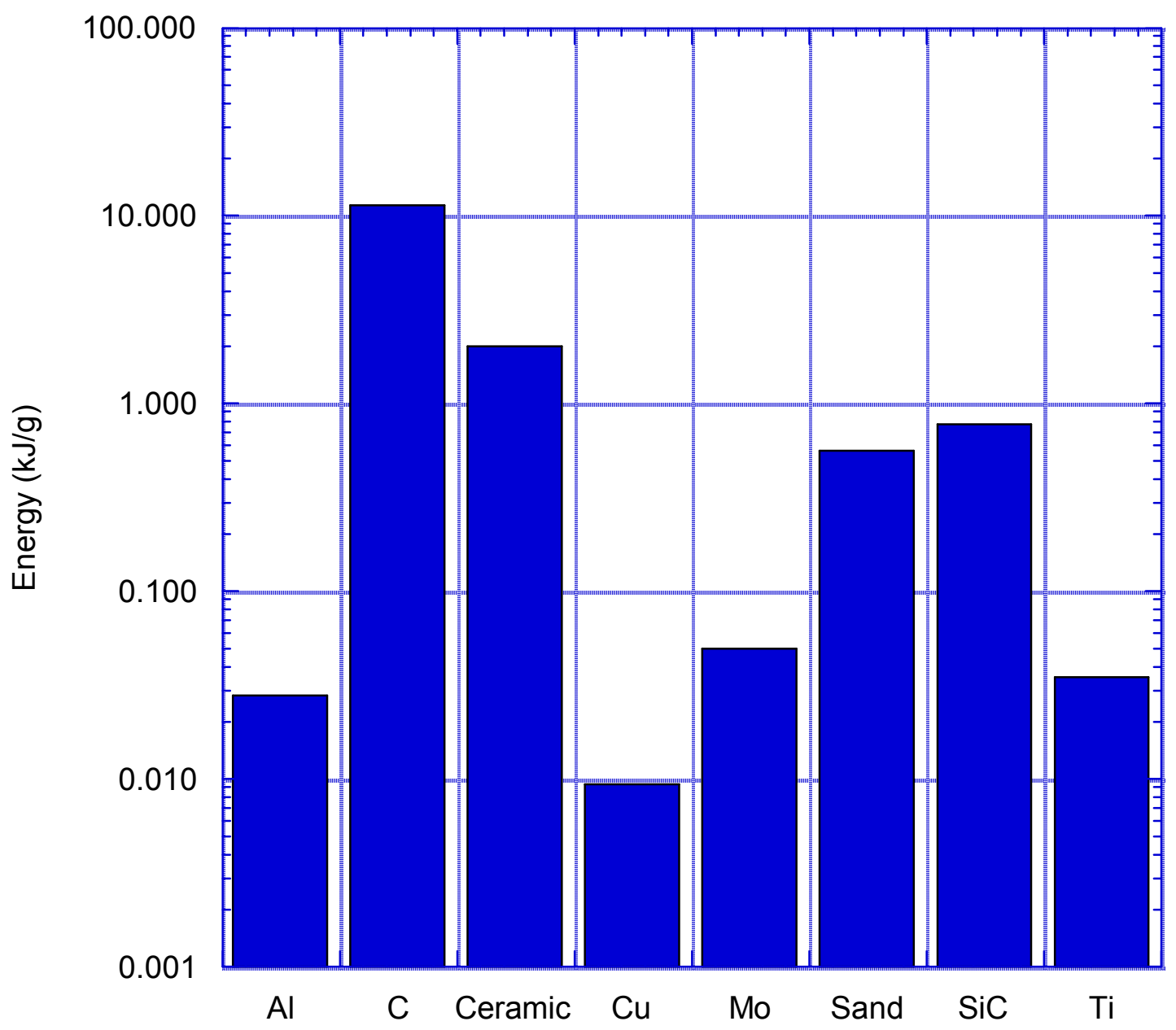

Material

Fig. 74. Total energy expended per gram of material predicted by the exponential model. 
First Order Model Fit

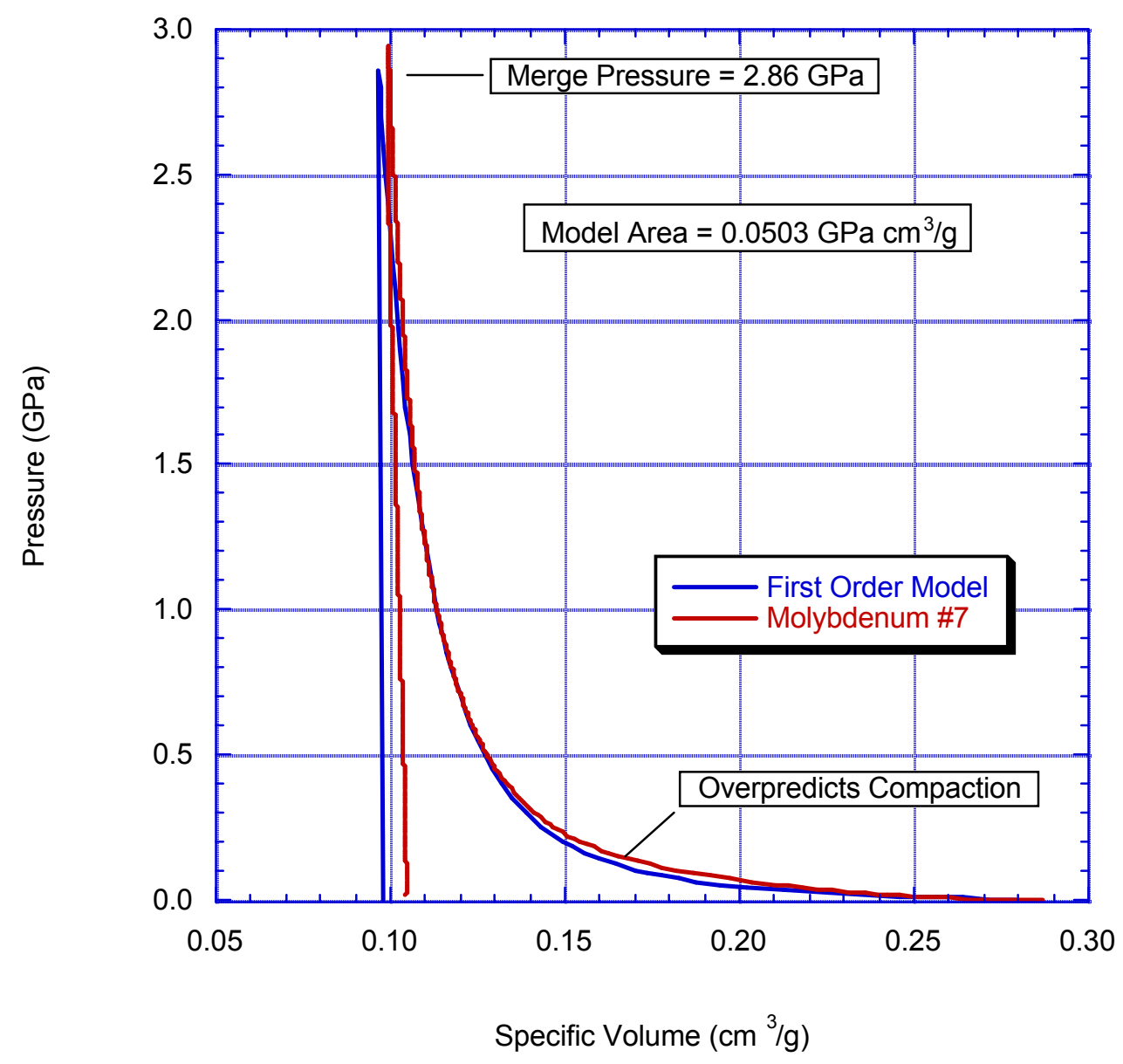

Fig. 75. Pressure-volume curve predicted by the exponential model (blue line) and solid medium data. The model slightly over-predicts compaction at low pressures and underpredicts merge pressure in comparison with the solid medium data. 


\section{c: Ipowder complorig moly 7 loading.xls}

Rank 1 Eqn 8149 [Decay1+2] y=a+bexp(-cx)+d/(1+dex)

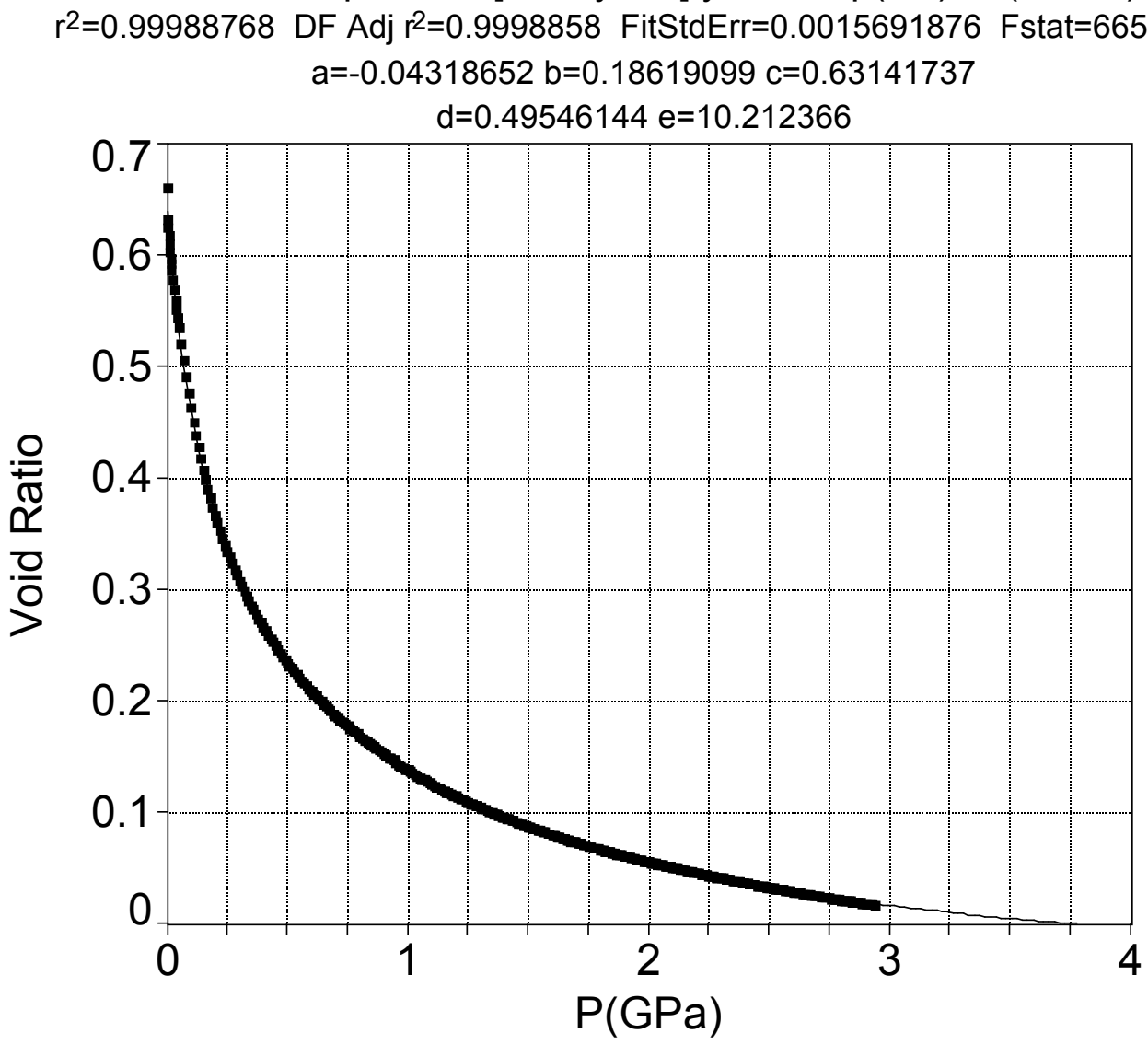

Fig. 76. Numerical curve fit through porosity data for solid medium molybdenum specimen Mo_fjr_7. The fitting parameters were used to calculate the pressure-volume curve shown in the following figure. 


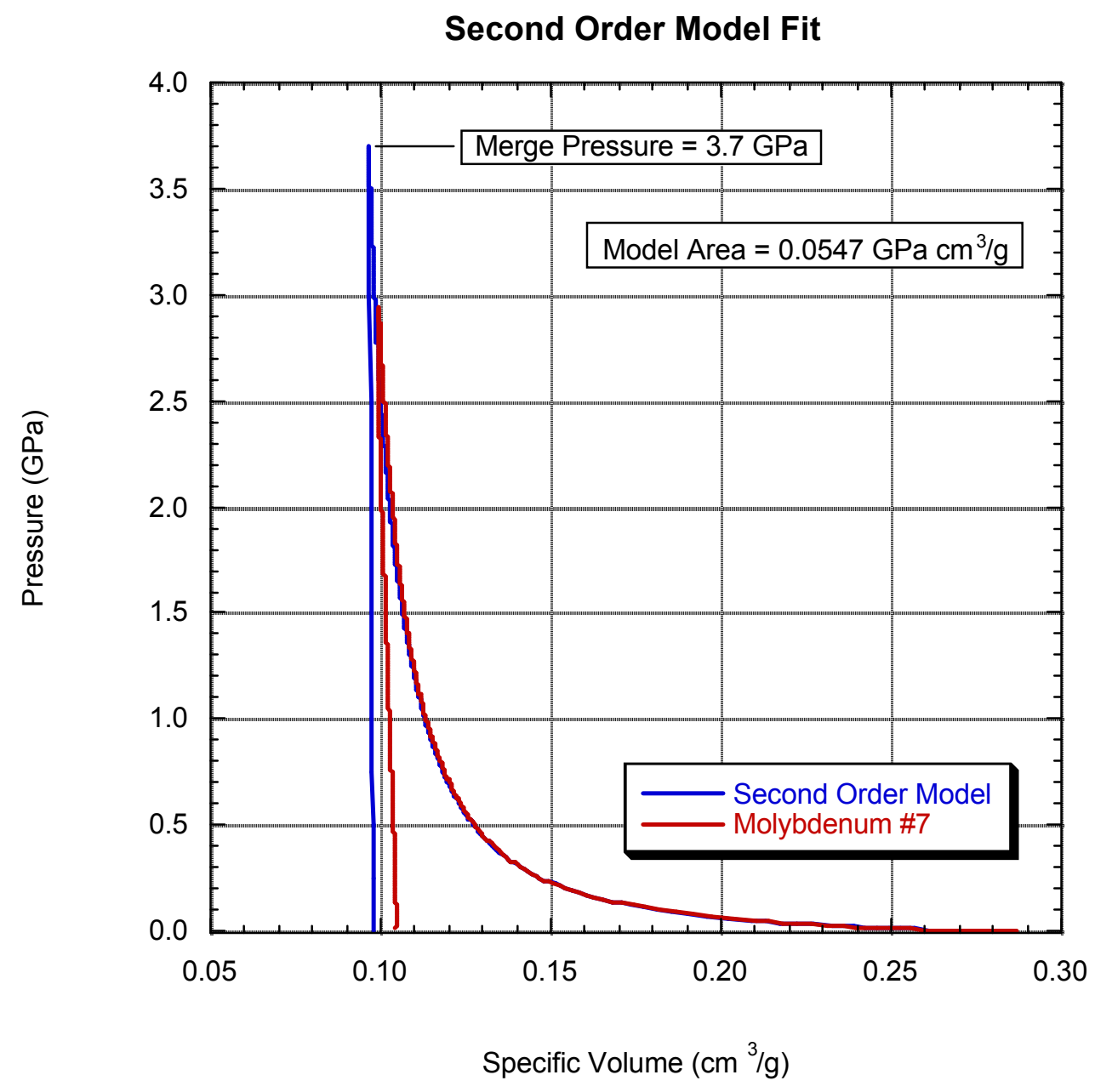

Fig. 77. Pressure-volume curve predicted by the second order model (blue line) and solid medium data. The predicted merge pressure of $3.7 \mathrm{GPa}$ is more consistent with the solid medium data than the merge pressure of under $3 \mathrm{GPa}$ predicted by the exponential model. 


\section{C:IPowder ComplAISP\#1 Loading.xls}

\section{Rank 1 Eqn 8153 [Decay2+2] $y=a+b /(1+b c x))+d /(1+d e x))$}

$r^{2}=0.99915273$ DF Adj $r^{2}=0.99913865$ FitStdErr $=0.0031173944$ Fstat $=89033.915$ $a=-0.3415914 b=0.47215491 c=89.04524$

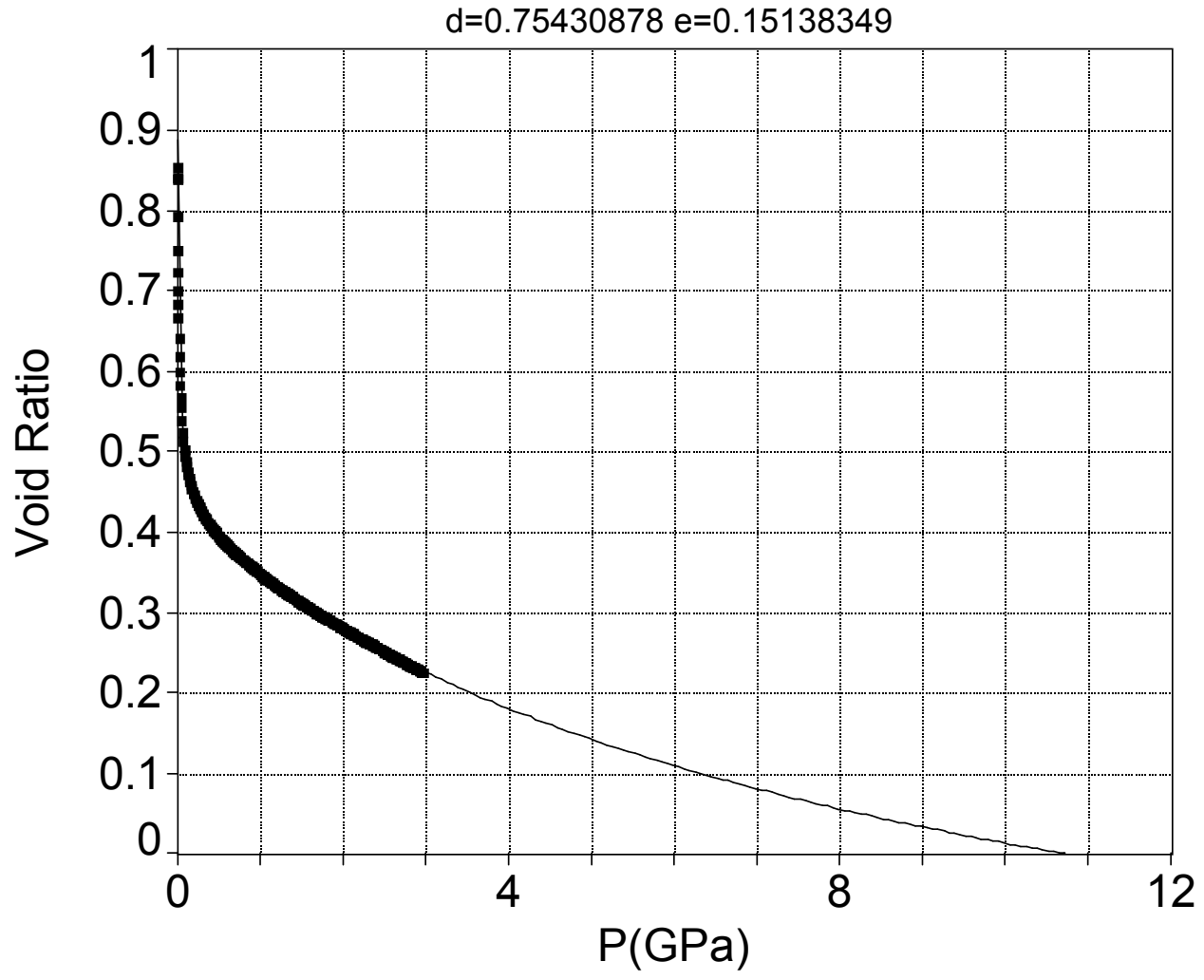

Fig. 78. Numerical curve fit through porosity data for solid medium ceramic specimen AlSP\#1. The fitting parameters were used to calculate the pressure-volume curve shown in the following figure. 


\section{Second Order Model Fit}

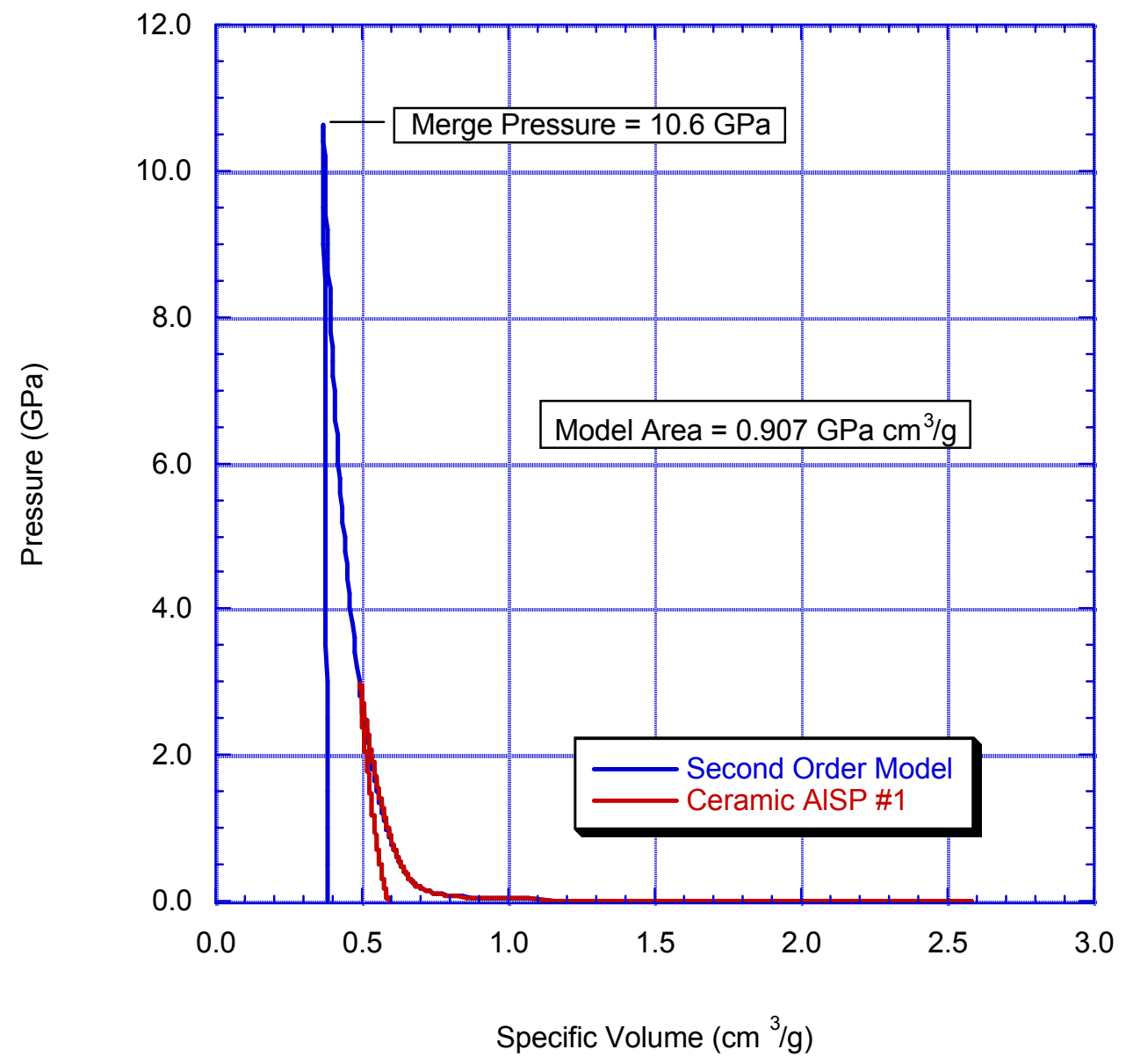

Fig. 79. Pressure-volume curve predicted by the second order model (blue line) and solid medium data (red line). The second order model predicts a much lower merge pressure $(10.6 \mathrm{GPa})$ than the exponential model $(57.6 \mathrm{GPa})$. 


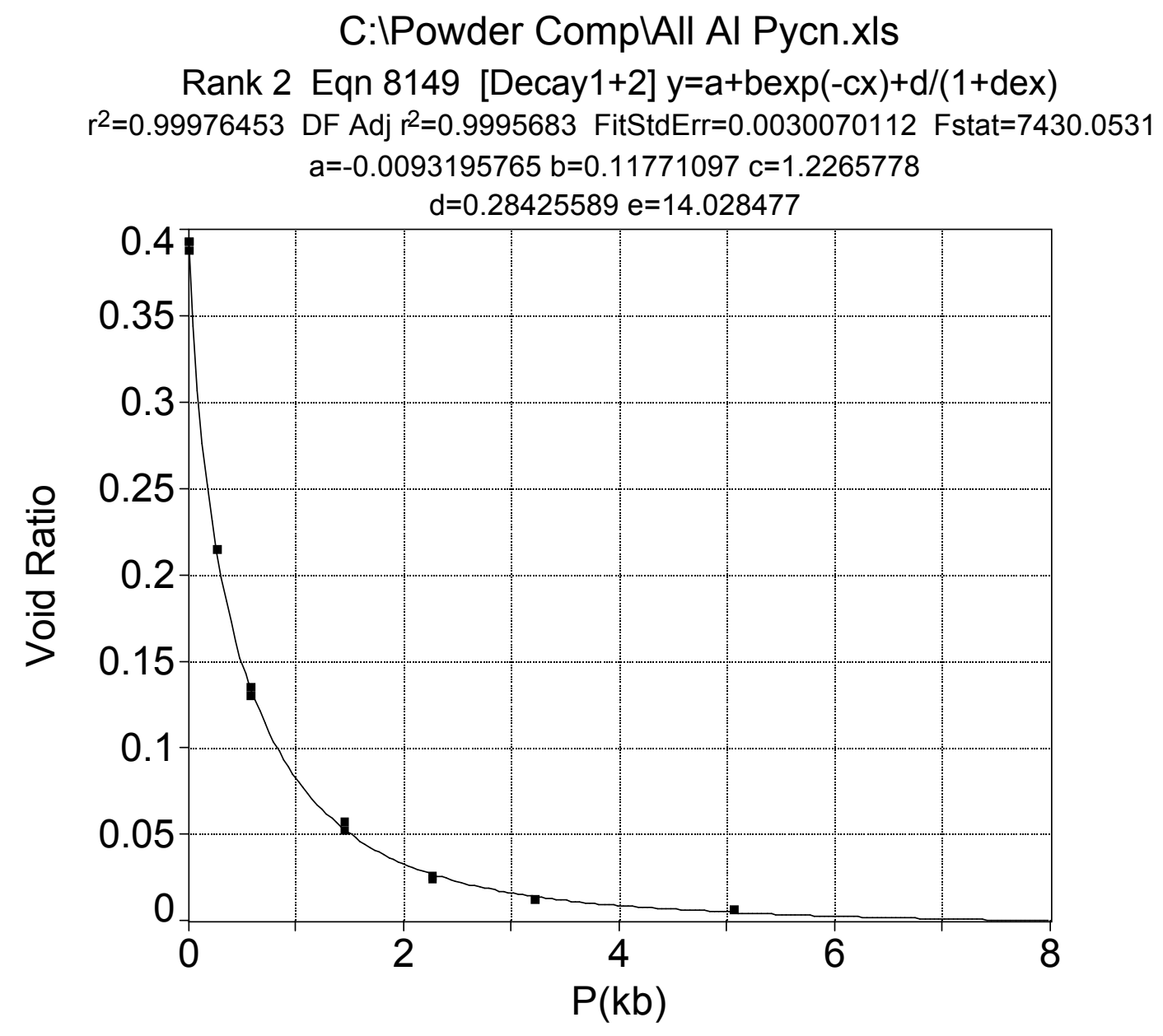

Fig. 80. Numerical curve fit through selected aluminum powder porosity data. The fitting parameters were used to calculate the pressure-volume curve shown in the following figure. 


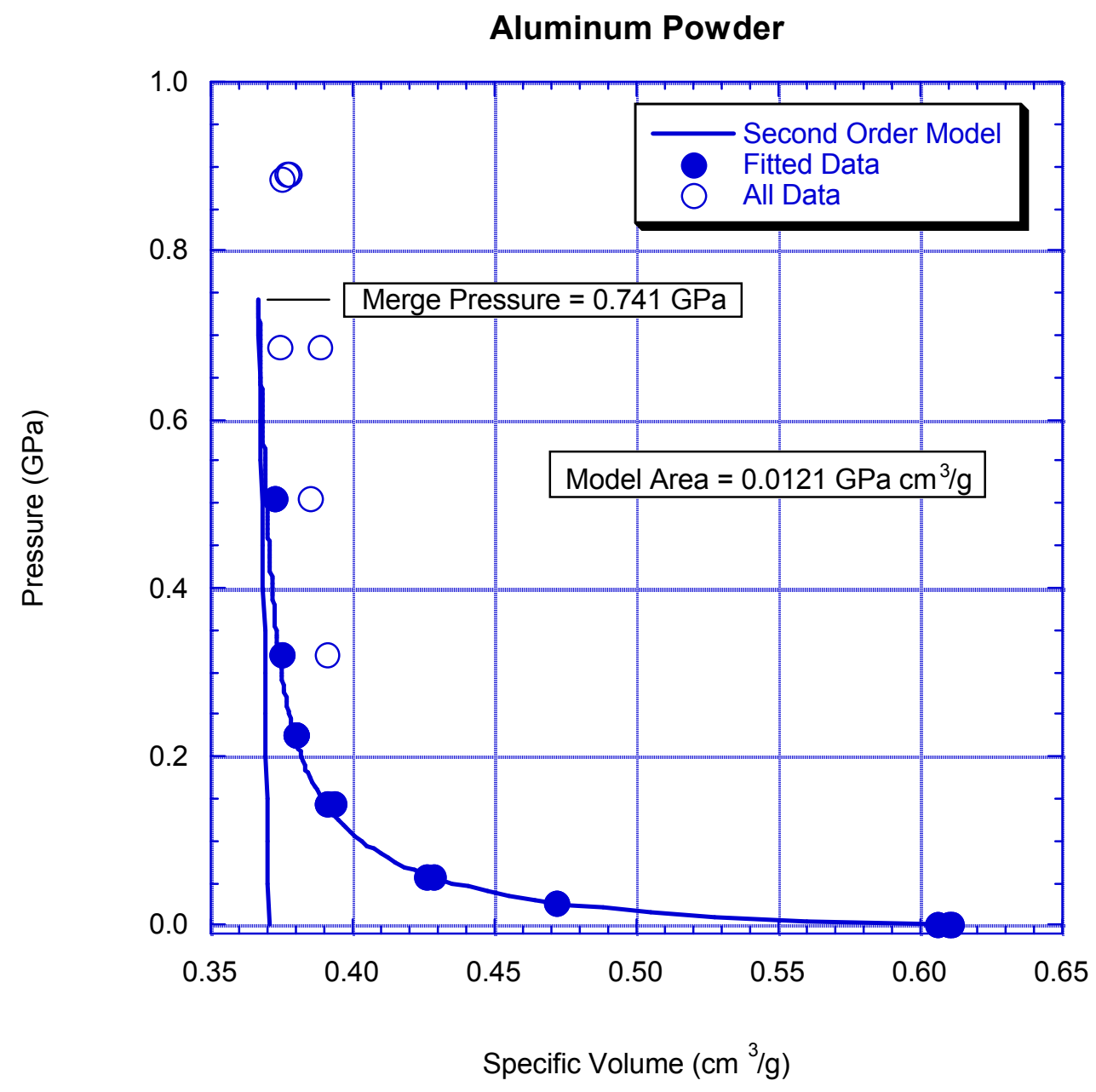

Fig. 81. Pressure-volume curve predicted by the second order model (blue line) and aluminum powder data. The predicted merge pressure of $0.74 \mathrm{GPa}$ is more consistent with the data than the merge pressure of $0.35 \mathrm{GPa}$ predicted by the exponential model. 


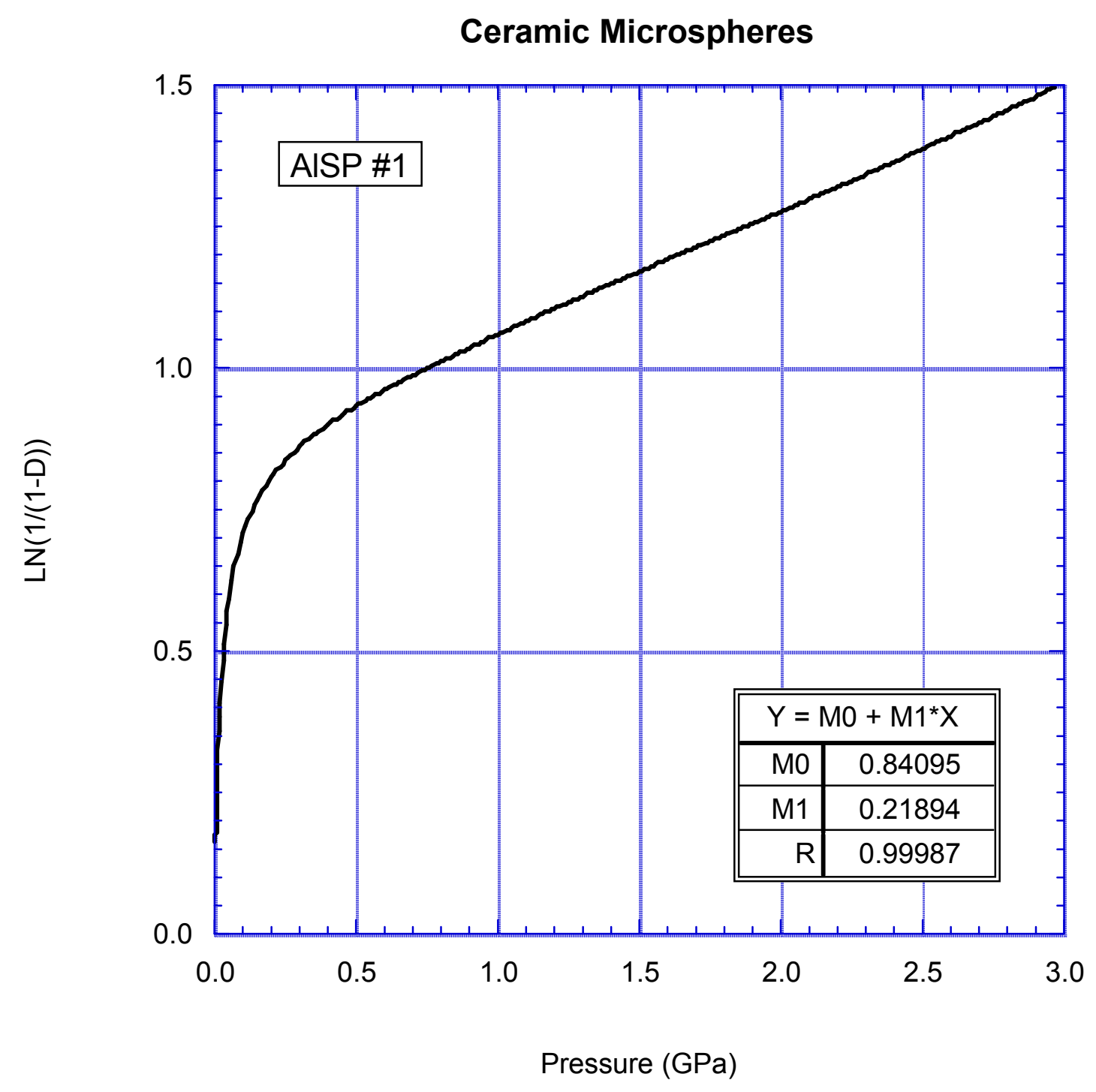

Fig. 82. Heckel plot for ceramic microsphere specimen AlSP \#1. Parameter D is relative density. The regression coefficients are for a linear fit to the data above $1.0 \mathrm{GPa}$. 


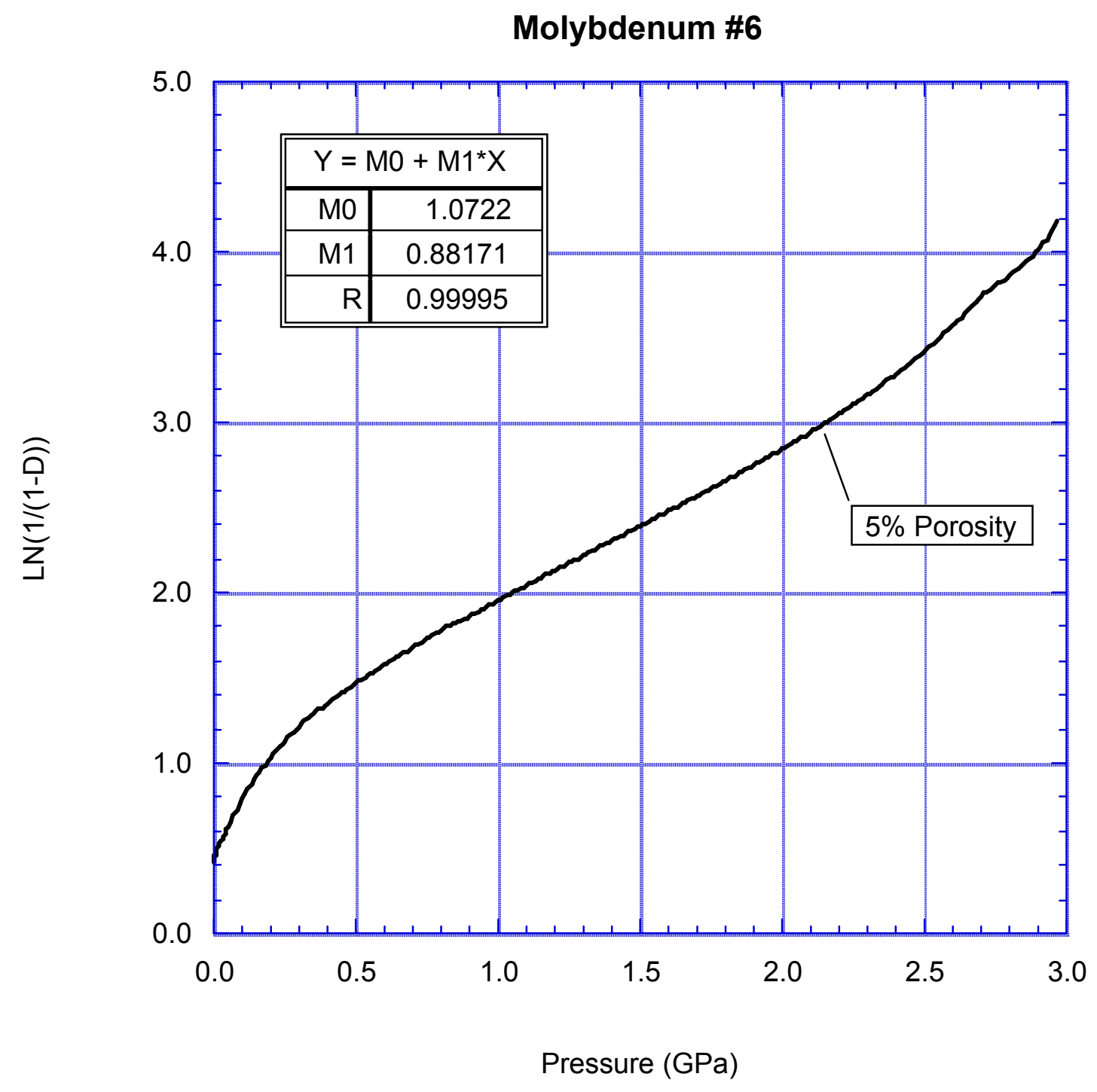

Fig. 83. Heckel plot for Molybdenum \#6. Parameter D is relative density. The regression coefficients are for a linear fit to the data between 1.0 and $2.0 \mathrm{GPa}$. 


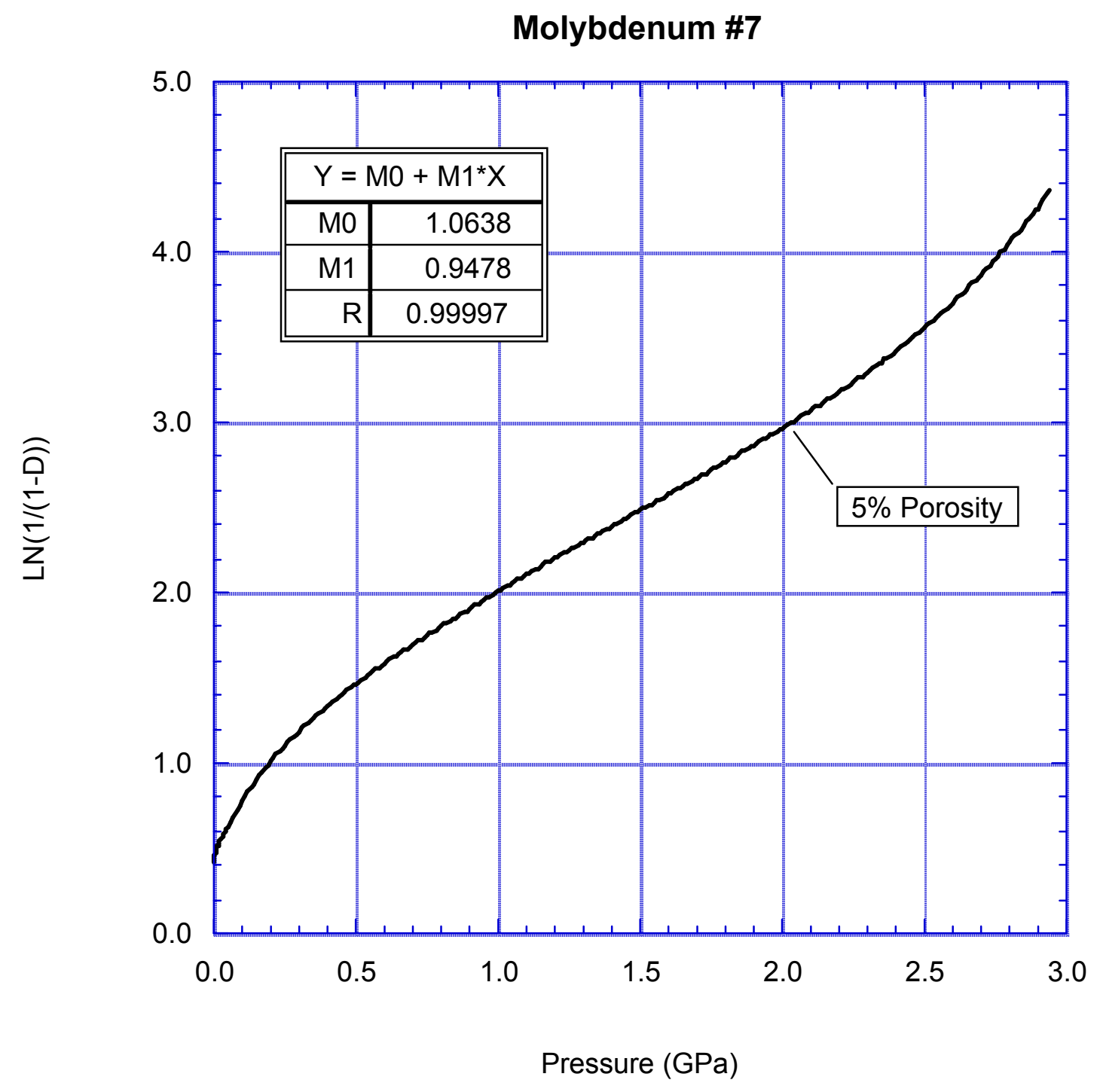

Fig. 84. Heckel plot for Molybdenum \#7. Parameter D is relative density. The regression coefficients are for a linear fit to the data between 1.0 and $2.0 \mathrm{GPa}$. 


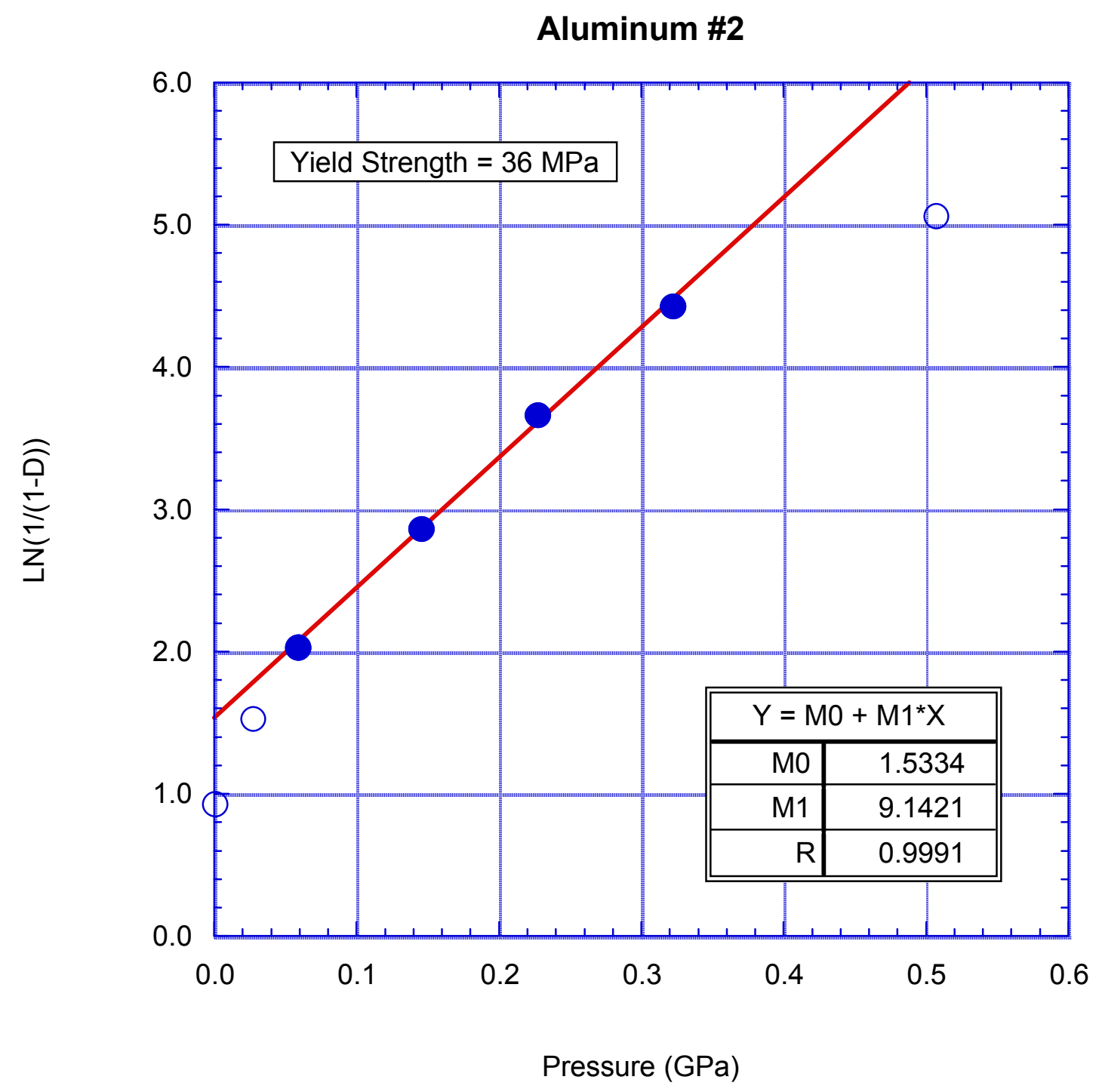

Fig. 85. Heckel plot for Aluminun \#2. Solid circles were used in the regression fit. A yield strength of $36 \mathrm{MPa}$ is obtained from the slope of the regression line. 
Glassy Carbon Spheres

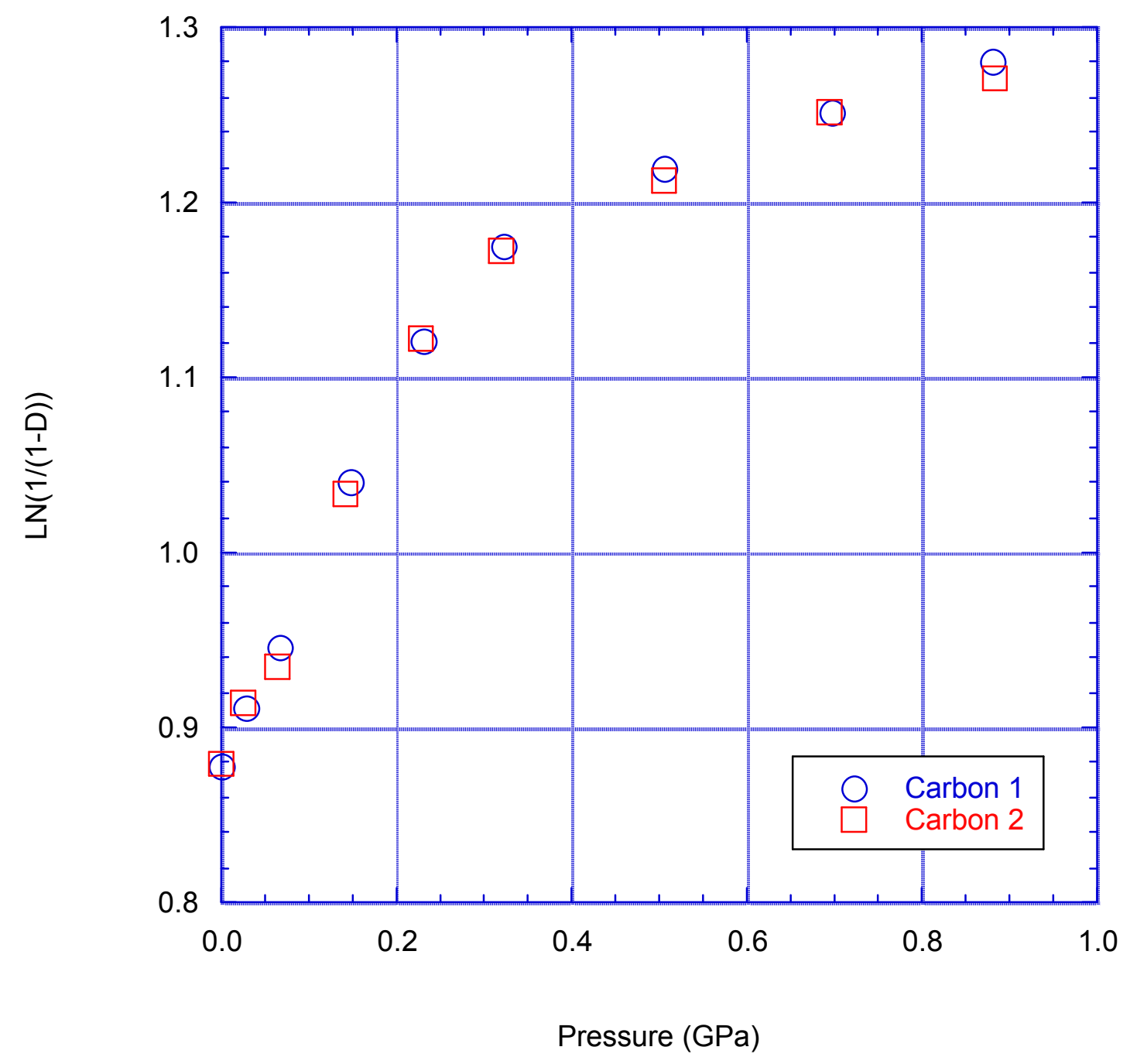

Fig. 86. Heckel plot for glassy carbon spheres. 


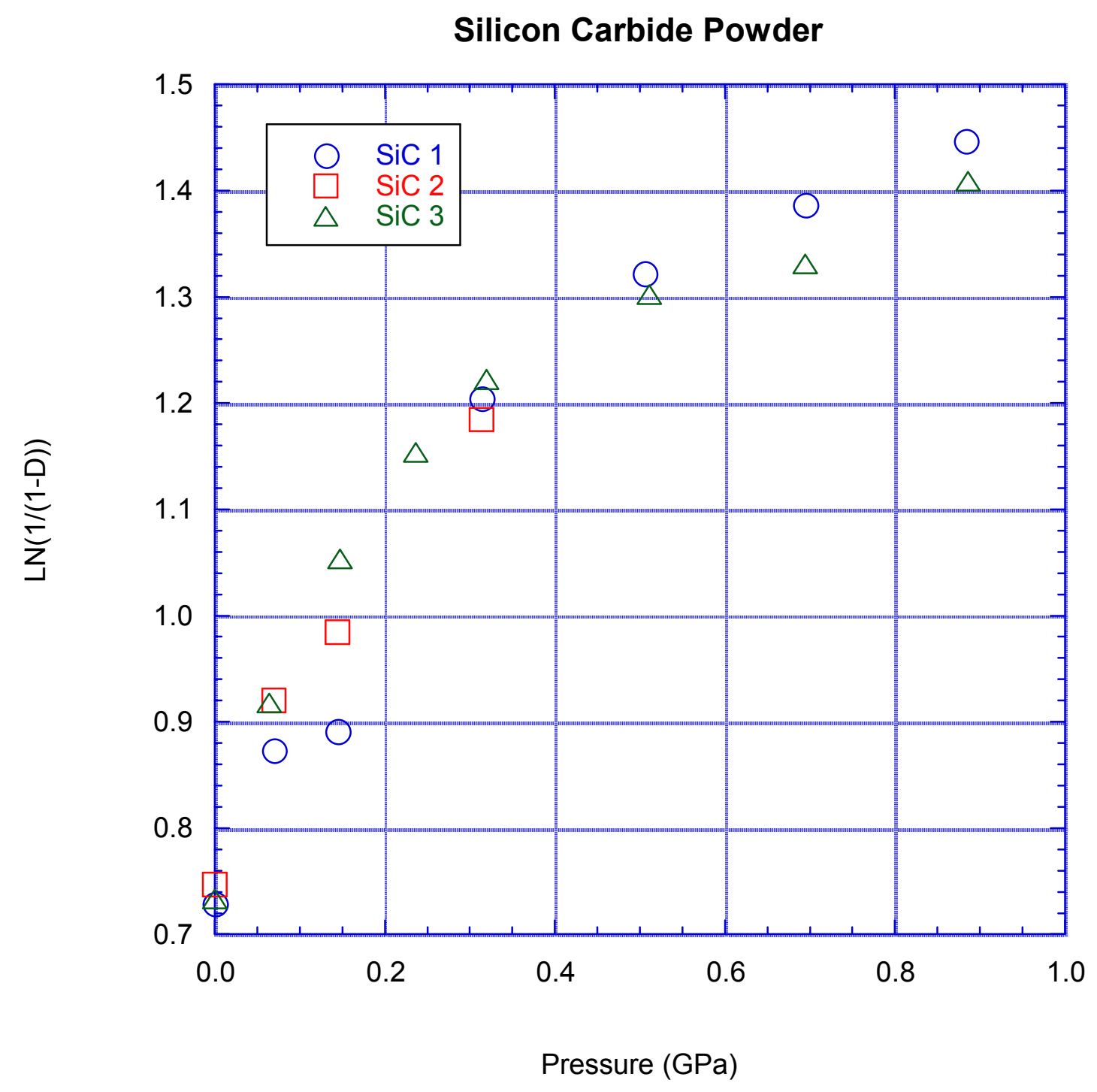

Fig. 87. Heckel plot for silicon carbide powder. 
Titanium Powder

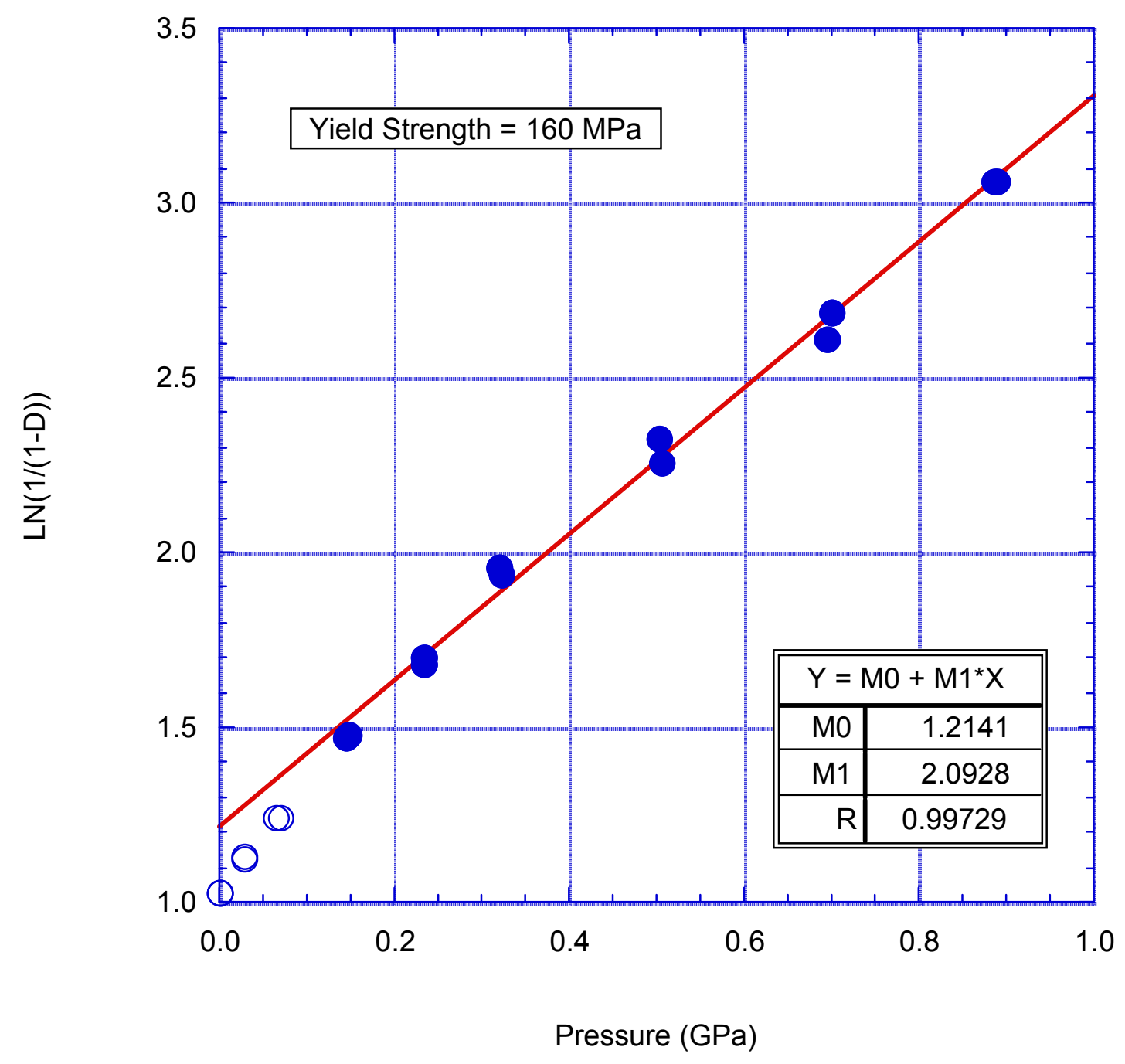

Fig. 88. Heckel plot for titanium. Solid circles were used in the regression fit. A yield strength of $160 \mathrm{MPa}$ is obtained from the slope of the regression line. 


\section{Appendix}

Table A1. Mass of solid medium specimen assembly components

\begin{tabular}{|l|r|r|r|r|r|}
\hline \multicolumn{1}{|c|}{ Specimen } & Container $(\mathrm{g})$ & Indium disk $(\mathrm{g})$ & \multicolumn{1}{c|}{ Tin Lid $(\mathrm{g})$} & \multicolumn{1}{c|}{ Powder $(\mathrm{g})$} & \multicolumn{1}{c|}{ Total $(\mathrm{g})$} \\
\hline AlSP_fjr_1 & 5.5308 & 1.2291 & 1.2282 & 1.0503 & 9.0378 \\
\hline Mo_fjr_1 & 5.1488 & 0.0000 & 1.2354 & 10.2974 & 16.6816 \\
\hline Mo_fjr_2 & 5.4392 & 0.0000 & 1.2353 & 10.3168 & 16.9913 \\
\hline Mo_fjr_3 & 5.2710 & 0.0000 & 1.2321 & 10.3415 & 16.8446 \\
\hline Mo_fjr_4 & 5.5858 & 1.2134 & 1.2301 & 9.7447 & 17.7741 \\
\hline Mo_fjr_5 & 5.5277 & 1.2257 & 1.2310 & 9.7520 & 17.7365 \\
\hline Mo_fjr_6 & 5.4486 & 1.2251 & 1.2282 & 9.7494 & 17.6511 \\
\hline Mo_fjr_7 & 5.6062 & 1.2185 & 1.2181 & 9.7500 & 17.7925 \\
\hline Nistd_fjr_1 & 5.0730 & 1.2281 & 1.2186 & 24.1567 & 31.6763 \\
\hline Nistd_fjr_2 & 5.4960 & 1.2274 & 1.2168 & 24.1796 & 32.1200 \\
\hline
\end{tabular}

Table A2. Curve-fitting parameters for the liquid medium press friction correction

\begin{tabular}{|c|c|r|}
\hline Parameter & Value & Standard Error \\
\hline a & $7.844867 \mathrm{E}-02$ & $3.033272 \mathrm{E}-03$ \\
\hline $\mathrm{b}$ & $4.123243 \mathrm{E}-01$ & $2.414624 \mathrm{E}-02$ \\
\hline $\mathrm{c}$ & $1.095429 \mathrm{E}+00$ & $1.578431 \mathrm{E}-02$ \\
\hline $\mathrm{d}$ & $-1.772550 \mathrm{E}-01$ & $5.848932 \mathrm{E}-03$ \\
\hline e & $-3.152367 \mathrm{E}-01$ & $1.173389 \mathrm{E}-02$ \\
\hline f & $3.062117 \mathrm{E}-02$ & $1.486933 \mathrm{E}-03$ \\
\hline $\mathrm{g}$ & $4.779694 \mathrm{E}-02$ & $2.077552 \mathrm{E}-03$ \\
\hline
\end{tabular}

$\mathrm{y}=\left(\mathrm{a}+\mathrm{cx}+\mathrm{ex}^{\wedge} 2+\mathrm{gx}^{\wedge} 3\right) /\left(1+b \mathrm{x}+\mathrm{dx} \wedge 2+f \mathrm{x}^{\wedge} 3\right)$

Table A3. Curve-fitting parameters for the solid medium press friction correction

\begin{tabular}{|c|c|r|}
\hline Parameter & Value & Standard Error \\
\hline $\mathrm{a}$ & $2.477645 \mathrm{E}-03$ & $3.087680 \mathrm{E}-03$ \\
\hline $\mathrm{b}$ & $2.639882 \mathrm{E}-01$ & $1.815612 \mathrm{E}-03$ \\
\hline $\mathrm{c}$ & $1.051913 \mathrm{E}+00$ & $4.783260 \mathrm{E}-03$ \\
\hline $\mathrm{d}$ & $-1.326210 \mathrm{E}-03$ & $3.133506 \mathrm{E}-05$ \\
\hline
\end{tabular}

$\mathrm{y}=(\mathrm{a}+\mathrm{cx}) /\left(1+\mathrm{bx}+\mathrm{dx} \mathrm{x}^{\wedge}\right)$

Table A4. Kawakita Regression Fit Coefficients and Model Parameters

\begin{tabular}{|l|r|r|r|r|r|}
\hline \multicolumn{1}{|c|}{ Material } & Intercept $(\mathrm{GPa})$ & \multicolumn{1}{c|}{ Slope } & Correlation & \multicolumn{1}{c|}{$\mathrm{a}$} & \multicolumn{1}{c|}{$\mathrm{b}$} \\
\hline Aluminum & 0.0320 & 2.5526 & 0.9997 & 0.3918 & 79.8536 \\
\hline Carbon & 0.8463 & 4.2698 & 0.9972 & 0.2342 & 5.0451 \\
\hline Ceramic & 0.0140 & 1.2774 & 0.9998 & 0.7828 & 91.2298 \\
\hline Copper & 0.1544 & 2.4488 & 0.9965 & 0.4084 & 15.8642 \\
\hline Molybdenum & 0.1247 & 1.5808 & 0.9998 & 0.6326 & 12.6748 \\
\hline Ottawa Sand & 0.6718 & 4.4455 & 0.9994 & 0.2249 & 6.6170 \\
\hline Silicon Carbide & 0.3430 & 2.7801 & 0.9982 & 0.3597 & 8.1064 \\
\hline Titanium & 0.5067 & 2.5106 & 0.9999 & 0.3983 & 4.9553 \\
\hline
\end{tabular}


Table A5a. Aluminum \#1, powder mass $=59.921 \mathrm{~g}$

\begin{tabular}{|l|l|l|l|l|l|l|}
\hline $\begin{array}{c}\text { Pressure } \\
(\mathrm{GPa})\end{array}$ & $\begin{array}{c}\text { Powder } \\
\text { Volume } \\
\left(\mathrm{cm}^{3}\right)\end{array}$ & $\begin{array}{c}\text { Bulk } \\
\text { Density } \\
\left(\mathrm{g} / \mathrm{cm}^{3}\right)\end{array}$ & $\begin{array}{c}\text { Porosity } \\
(\%)\end{array}$ & \multicolumn{1}{|c|}{ V/Vo } & $\begin{array}{c}\text { Specific } \\
\text { Volume, } \\
\left(\mathrm{cm}^{3} / \mathrm{g}\right)\end{array}$ & $\mathrm{Mu}$ \\
\hline $1.00 \mathrm{e}-04$ & 36.305 & 1.650 & 38.8 & 1.000 & 0.6059 & 0.0000 \\
\hline 0.0583 & 25.671 & 2.334 & 13.5 & 0.7071 & 0.4284 & 0.4146 \\
\hline 0.145 & 23.428 & 2.558 & 5.20 & 0.6453 & 0.3910 & 0.5503 \\
\hline 0.227 & 22.750 & 2.634 & 2.40 & 0.6266 & 0.3797 & 0.5964 \\
\hline 0.322 & 23.398 & 2.561 & 5.10 & 0.6445 & 0.3905 & 0.5521 \\
\hline 0.507 & 23.081 & 2.596 & 3.80 & 0.6358 & 0.3852 & 0.5733 \\
\hline 0.685 & 23.279 & 2.574 & 4.60 & 0.6412 & 0.3885 & 0.5600 \\
\hline 0.890 & 22.585 & 2.653 & 1.70 & 0.6221 & 0.3769 & 0.6079 \\
\hline
\end{tabular}

Table A5b. Aluminum $\# 2$, powder mass $=60.979 \mathrm{~g}$

\begin{tabular}{|l|l|l|l|l|l|l|}
\hline $\begin{array}{c}\text { Pressure } \\
(\mathrm{GPa})\end{array}$ & $\begin{array}{c}\text { Powder } \\
\text { Volume } \\
\left(\mathrm{cm}^{3}\right)\end{array}$ & $\begin{array}{c}\text { Bulk } \\
\text { Density } \\
\left(\mathrm{g} / \mathrm{cm}^{3}\right)\end{array}$ & $\begin{array}{c}\text { Porosity } \\
(\%)\end{array}$ & \multicolumn{1}{|l}{ V/Vo } & $\begin{array}{c}\text { Specific } \\
\text { Volume, } \\
\left(\mathrm{cm}^{3} / \mathrm{g}\right)\end{array}$ & $\mathrm{Mu}$ \\
\hline 0.00 & 37.227 & 1.638 & 39.3 & 1.000 & 0.6105 & 0.0000 \\
\hline 0.0266 & 28.768 & 2.120 & 21.5 & 0.7728 & 0.4718 & 0.29426 \\
\hline 0.0583 & 25.973 & 2.348 & 13.0 & 0.6977 & 0.4259 & 0.43346 \\
\hline 0.145 & 23.963 & 2.545 & 5.7 & 0.6437 & 0.3930 & 0.55372 \\
\hline 0.227 & 23.186 & 2.630 & 2.6 & 0.6228 & 0.3802 & 0.60562 \\
\hline 0.322 & 22.863 & 2.667 & 1.2 & 0.6141 & 0.3749 & 0.62821 \\
\hline 0.507 & 22.734 & 2.682 & 0.6 & 0.6107 & 0.3728 & 0.63736 \\
\hline 0.685 & 22.833 & 2.671 & 1.0 & 0.6133 & 0.3744 & 0.63065 \\
\hline 0.890 & 23.017 & 2.649 & 1.8 & 0.6183 & 0.3775 & 0.61722 \\
\hline
\end{tabular}

Table A5c. Aluminum \#3, powder mass $=59.229 \mathrm{~g}$

\begin{tabular}{|l|l|l|l|l|l|l|}
\hline $\begin{array}{c}\text { Pressure } \\
(\mathrm{GPa})\end{array}$ & $\begin{array}{c}\text { Powder } \\
\text { Volume } \\
\left(\mathrm{cm}^{3}\right)\end{array}$ & $\begin{array}{c}\text { Bulk } \\
\text { Density } \\
\left(\mathrm{g} / \mathrm{cm}^{3}\right)\end{array}$ & $\begin{array}{c}\text { Porosity } \\
(\%)\end{array}$ & \multicolumn{1}{|c|}{ V/Vo } & $\begin{array}{c}\text { Specific } \\
\text { Volume, } \\
\left(\mathrm{cm}^{3} / \mathrm{g}\right)\end{array}$ & $\mathrm{Mu}$ \\
\hline 0.00 & 36.128 & 1.639 & 39.3 & 1.000 & 0.6100 & 0.0000 \\
\hline 0.886 & 22.205 & 2.667 & 1.2 & 0.6146 & 0.3749 & 0.6272 \\
\hline
\end{tabular}


Table A6a. Carbon \#1, powder mass $=30.947 \mathrm{~g}$

\begin{tabular}{|l|l|l|l|l|l|l|}
\hline $\begin{array}{c}\text { Pressure } \\
(\mathrm{GPa})\end{array}$ & $\begin{array}{c}\text { Powder } \\
\text { Volume } \\
\left(\mathrm{cm}^{3}\right)\end{array}$ & $\begin{array}{c}\text { Bulk } \\
\text { Density } \\
\left(\mathrm{g} / \mathrm{cm}^{3}\right)\end{array}$ & $\begin{array}{c}\text { Porosity } \\
(\%)\end{array}$ & \multicolumn{1}{|l|}{ V/Vo } & $\begin{array}{c}\text { Specific } \\
\text { Volume, } \\
\left(\mathrm{cm}^{3} / \mathrm{g}\right)\end{array}$ & $\mathrm{Mu}$ \\
\hline 0.00 & 36.558 & 0.847 & 41.6 & 1.0000 & 1.181 & 0.0000 \\
\hline 0.0267 & 35.698 & 0.867 & 40.2 & 0.9765 & 1.153 & 0.0236 \\
\hline 0.0677 & 34.903 & 0.887 & 38.9 & 0.9547 & 1.128 & 0.0472 \\
\hline 0.147 & 32.981 & 0.938 & 35.3 & 0.9022 & 1.066 & 0.1074 \\
\hline 0.232 & 31.667 & 0.977 & 32.6 & 0.8662 & 1.023 & 0.1535 \\
\hline 0.323 & 30.876 & 1.002 & 30.9 & 0.8446 & 0.9977 & 0.1830 \\
\hline 0.506 & 30.272 & 1.022 & 29.5 & 0.8281 & 0.9782 & 0.2066 \\
\hline 0.696 & 29.900 & 1.035 & 28.6 & 0.8179 & 0.9662 & 0.2220 \\
\hline 0.881 & 29.559 & 1.047 & 27.8 & 0.8086 & 0.9551 & 0.2361 \\
\hline
\end{tabular}

Table A6b. Carbon \#2, powder mass $=30.867 \mathrm{~g}$

\begin{tabular}{|l|l|l|l|l|l|l|}
\hline $\begin{array}{c}\text { Pressure } \\
(\mathrm{GPa})\end{array}$ & $\begin{array}{c}\text { Powder } \\
\text { Volume } \\
\left(\mathrm{cm}^{3}\right)\end{array}$ & $\begin{array}{c}\text { Bulk } \\
\text { Density } \\
\left(\mathrm{g} / \mathrm{cm}^{3}\right)\end{array}$ & $\begin{array}{c}\text { Porosity } \\
(\%)\end{array}$ & \multicolumn{1}{|l|}{ V/Vo } & $\begin{array}{c}\text { Specific } \\
\text { Volume, } \\
\left(\mathrm{cm}^{3} / \mathrm{g}\right)\end{array}$ & $\mathrm{Mu}$ \\
\hline 0.00 & 36.387 & 0.848 & 41.5 & 1.0000 & 1.179 & 0.0000 \\
\hline 0.0238 & 35.526 & 0.869 & 40.1 & 0.9763 & 1.151 & 0.0248 \\
\hline 0.0627 & 35.038 & 0.881 & 39.2 & 0.9629 & 1.135 & 0.0389 \\
\hline 0.142 & 33.042 & 0.934 & 35.6 & 0.9081 & 1.071 & 0.1014 \\
\hline 0.227 & 31.576 & 0.978 & 32.6 & 0.8678 & 1.023 & 0.1533 \\
\hline 0.319 & 30.844 & 1.001 & 31.0 & 0.8477 & 0.9992 & 0.1804 \\
\hline 0.506 & 30.297 & 1.019 & 29.7 & 0.8326 & 0.9815 & 0.2017 \\
\hline 0.694 & 29.822 & 1.035 & 28.6 & 0.8196 & 0.9661 & 0.2205 \\
\hline 0.883 & 29.604 & 1.043 & 28.1 & 0.8136 & 0.9591 & 0.2300 \\
\hline
\end{tabular}

Table A6c. Carbon \#3, powder mass $=31.173 \mathrm{~g}$

\begin{tabular}{|l|l|l|l|l|l|l|}
\hline $\begin{array}{c}\text { Pressure } \\
(\mathrm{GPa})\end{array}$ & $\begin{array}{c}\text { Powder } \\
\text { Volume } \\
\left(\mathrm{cm}^{3}\right)\end{array}$ & $\begin{array}{c}\text { Bulk } \\
\text { Density } \\
\left(\mathrm{g} / \mathrm{cm}^{3}\right)\end{array}$ & $\begin{array}{c}\text { Porosity } \\
(\%)\end{array}$ & \multicolumn{1}{|l|}{$/ \mathrm{Mo}$} & $\begin{array}{c}\text { Specific } \\
\text { Volume, } \\
\left(\mathrm{cm}^{3} / \mathrm{g}\right)\end{array}$ & $\mathrm{Mu}$ \\
\hline 0.0 & 36.945 & 0.844 & 41.8 & 1.000 & 1.185 & 0.0000 \\
\hline 0.892 & 31.104 & 1.002 & 30.9 & 0.8419 & 0.9978 & 0.1872 \\
\hline
\end{tabular}


Table A7a. Ceramic \#1, powder mass $=13.939 \mathrm{~g}$

\begin{tabular}{|l|l|l|l|l|l|l|}
\hline $\begin{array}{c}\text { Pressure } \\
(\mathrm{GPa})\end{array}$ & $\begin{array}{c}\text { Powder } \\
\text { Volume } \\
\left(\mathrm{cm}^{3}\right)\end{array}$ & $\begin{array}{c}\text { Bulk } \\
\text { Density } \\
\left(\mathrm{g} / \mathrm{cm}^{3}\right)\end{array}$ & $\begin{array}{c}\text { Porosity } \\
(\%)\end{array}$ & \multicolumn{1}{|l|}{ V/Vo } & $\begin{array}{c}\text { Specific } \\
\text { Volume, } \\
\left(\mathrm{cm}^{3} / \mathrm{g}\right)\end{array}$ & $\mathrm{Mu}$ \\
\hline 0.00 & 36.292 & 0.3840 & 85.2 & 1.000 & 2.604 & 0.0000 \\
\hline 0.0529 & 15.108 & 0.9230 & 64.5 & 0.4163 & 1.084 & 1.4036 \\
\hline 0.121 & 13.107 & 1.064 & 59.1 & 0.3611 & 0.9403 & 1.7708 \\
\hline 0.246 & 9.5407 & 1.461 & 43.8 & 0.2629 & 0.6845 & 2.8047 \\
\hline 0.425 & 8.6167 & 1.618 & 37.8 & 0.2374 & 0.6182 & 3.2135 \\
\hline 0.584 & 8.2757 & 1.684 & 35.2 & 0.2280 & 0.5937 & 3.3854 \\
\hline 0.750 & 8.1147 & 1.718 & 33.9 & 0.2236 & 0.5822 & 3.4740 \\
\hline 0.888 & 7.8967 & 1.765 & 32.1 & 0.2176 & 0.5665 & 3.5964 \\
\hline
\end{tabular}

Table A7b. Ceramic \#2, powder mass $=14.082 \mathrm{~g}$

\begin{tabular}{|l|l|l|l|l|l|l|}
\hline $\begin{array}{c}\text { Pressure } \\
(\mathrm{GPa})\end{array}$ & $\begin{array}{c}\text { Powder } \\
\text { Volume } \\
\left(\mathrm{cm}^{3}\right)\end{array}$ & $\begin{array}{c}\text { Bulk } \\
\text { Density } \\
\left(\mathrm{g} / \mathrm{cm}^{3}\right)\end{array}$ & $\begin{array}{c}\text { Porosity } \\
(\%)\end{array}$ & \multicolumn{1}{|l|}{ V/Vo } & $\begin{array}{c}\text { Specific } \\
\text { Volume, } \\
\left(\mathrm{cm}^{3} / \mathrm{g}\right)\end{array}$ & $\mathrm{Mu}$ \\
\hline 0.00 & 36.617 & 0.385 & 85.2 & 1.000 & 2.600 & 0.000 \\
\hline 0.00292 & 25.836 & 0.545 & 79.0 & 0.7056 & 1.835 & 0.4156 \\
\hline 0.00292 & 25.619 & 0.550 & 78.9 & 0.6996 & 1.819 & 0.4286 \\
\hline 0.0569 & 13.442 & 1.048 & 59.7 & 0.3671 & 0.9545 & 1.722 \\
\hline 0.120 & 10.994 & 1.281 & 50.7 & 0.3002 & 0.7807 & 2.327 \\
\hline 0.267 & 10.754 & 1.310 & 49.6 & 0.2937 & 0.7636 & 2.403 \\
\hline
\end{tabular}

Table A7c. Ceramic \#3, powder mass $=14.206 \mathrm{~g}$

\begin{tabular}{|l|l|l|l|l|l|l|}
\hline $\begin{array}{c}\text { Pressure } \\
(\mathrm{GPa})\end{array}$ & $\begin{array}{c}\text { Powder } \\
\text { Volume } \\
\left(\mathrm{cm}^{3}\right)\end{array}$ & $\begin{array}{c}\text { Bulk } \\
\text { Density } \\
\left(\mathrm{g} / \mathrm{cm}^{3}\right)\end{array}$ & $\begin{array}{c}\text { Porosity } \\
(\%)\end{array}$ & \multicolumn{1}{|l|}{$/ \mathrm{Vo}$} & $\begin{array}{c}\text { Specific } \\
\text { Volume, } \\
\left(\mathrm{cm}^{3} / \mathrm{g}\right)\end{array}$ & $\mathrm{Mu}$ \\
\hline 0.00 & 37.113 & 0.3830 & 85.3 & 1.0000 & 2.612 & 0.0000 \\
\hline 0.00358 & 24.800 & 0.5730 & 78.0 & 0.6682 & 1.746 & 0.49608 \\
\hline 0.00769 & 18.306 & 0.7760 & 70.2 & 0.4933 & 1.289 & 1.0261 \\
\hline 0.0263 & 14.002 & 1.015 & 61.0 & 0.3773 & 0.9856 & 1.6501 \\
\hline 0.0537 & 12.333 & 1.152 & 55.7 & 0.3323 & 0.8682 & 2.0078 \\
\hline 0.121 & 10.656 & 1.333 & 48.7 & 0.2871 & 0.7501 & 2.4804 \\
\hline 0.268 & 9.6724 & 1.469 & 43.5 & 0.2606 & 0.6809 & 2.8355 \\
\hline 0.422 & 9.2814 & 1.531 & 41.1 & 0.2501 & 0.6533 & 2.9974 \\
\hline 0.581 & 9.0534 & 1.569 & 39.6 & 0.2439 & 0.6373 & 3.0966 \\
\hline 0.747 & 8.3984 & 1.692 & 34.9 & 0.2263 & 0.5912 & 3.4178 \\
\hline 0.892 & 8.2254 & 1.727 & 33.6 & 0.2216 & 0.5790 & 3.5091 \\
\hline
\end{tabular}


Table A7d. Ceramic \#4, powder mass $=13.901 \mathrm{~g}$

\begin{tabular}{|l|l|l|l|l|l|l|}
\hline $\begin{array}{c}\text { Pressure } \\
(\mathrm{GPa})\end{array}$ & $\begin{array}{c}\text { Powder } \\
\text { Volume } \\
\left(\mathrm{cm}^{3}\right)\end{array}$ & $\begin{array}{c}\text { Bulk } \\
\text { Density } \\
\left(\mathrm{g} / \mathrm{cm}^{3}\right)\end{array}$ & $\begin{array}{c}\text { Porosity } \\
(\%)\end{array}$ & \multicolumn{1}{|l|}{ V/Vo } & $\begin{array}{c}\text { Specific } \\
\text { Volume, } \\
\left(\mathrm{cm}^{3} / \mathrm{g}\right)\end{array}$ & $\mathrm{Mu}$ \\
\hline 0.00 & 36.458 & 0.3810 & 85.3 & 1.0000 & 2.623 & 0.0000 \\
\hline 0.892 & 8.5875 & 1.619 & 37.7 & 0.2355 & 0.6178 & 3.2493 \\
\hline
\end{tabular}

Table A8a. Copper \#1, powder mass $=200.78 \mathrm{~g}$

\begin{tabular}{|l|l|l|l|l|l|l|}
\hline $\begin{array}{c}\text { Pressure } \\
(\mathrm{GPa})\end{array}$ & $\begin{array}{c}\text { Powder } \\
\text { Volume } \\
\left(\mathrm{cm}^{3}\right)\end{array}$ & $\begin{array}{c}\text { Bulk } \\
\text { Density } \\
\left(\mathrm{g} / \mathrm{cm}^{3}\right)\end{array}$ & $\begin{array}{c}\text { Porosity } \\
(\%)\end{array}$ & \multicolumn{1}{|l|}{$/ \mathrm{Mo}$} & $\begin{array}{c}\text { Specific } \\
\text { Volume, } \\
\left(\mathrm{cm}^{3} / \mathrm{g}\right)\end{array}$ & $\mathrm{Mu}$ \\
\hline 0.00 & 36.620 & 5.483 & 38.7 & 1.0000 & 0.1824 & 0.0000 \\
\hline 0.0243 & 31.578 & 6.358 & 28.9 & 0.8623 & 0.1573 & 0.1596 \\
\hline 0.0592 & 28.343 & 7.084 & 20.8 & 0.7740 & 0.1412 & 0.2920 \\
\hline 0.143 & 26.065 & 7.703 & 13.8 & 0.7118 & 0.1298 & 0.4049 \\
\hline 0.227 & 25.942 & 7.740 & 13.4 & 0.7084 & 0.1292 & 0.4116 \\
\hline
\end{tabular}

Table A8b. Copper \#2, powder mass $=201.65 \mathrm{~g}$

\begin{tabular}{|l|l|l|l|l|l|l|}
\hline $\begin{array}{c}\text { Pressure } \\
(\mathrm{GPa})\end{array}$ & $\begin{array}{c}\text { Powder } \\
\text { Volume } \\
\left(\mathrm{cm}^{3}\right)\end{array}$ & $\begin{array}{c}\text { Bulk } \\
\text { Density } \\
\left(\mathrm{g} / \mathrm{cm}^{3}\right)\end{array}$ & $\begin{array}{c}\text { Porosity } \\
(\%)\end{array}$ & \multicolumn{1}{|l|}{ V/Vo } & $\begin{array}{c}\text { Specific } \\
\text { Volume, } \\
\left(\mathrm{cm}^{3} / \mathrm{g}\right)\end{array}$ & $\mathrm{Mu}$ \\
\hline 0.0 & 37.377 & 5.395 & 39.7 & 1.0000 & 0.1854 & 0.000 \\
\hline 0.0243 & 31.815 & 6.338 & 29.1 & 0.8512 & 0.1578 & 0.1748 \\
\hline 0.0592 & 28.310 & 7.123 & 20.3 & 0.7574 & 0.1404 & 0.3203 \\
\hline 0.143 & 26.499 & 7.610 & 14.9 & 0.7090 & 0.1314 & 0.4106 \\
\hline 0.227 & 26.202 & 7.696 & 13.9 & 0.7010 & 0.1299 & 0.4265 \\
\hline
\end{tabular}

Table A8c. Copper \#3, powder mass $=193.63 \mathrm{~g}$

\begin{tabular}{|l|l|l|l|l|l|l|}
\hline $\begin{array}{c}\text { Pressure } \\
(\mathrm{GPa})\end{array}$ & $\begin{array}{c}\text { Powder } \\
\text { Volume } \\
\left(\mathrm{cm}^{3}\right)\end{array}$ & $\begin{array}{c}\text { Bulk } \\
\text { Density } \\
\left(\mathrm{g} / \mathrm{cm}^{3}\right)\end{array}$ & $\begin{array}{c}\text { Porosity } \\
(\%)\end{array}$ & \multicolumn{1}{|l|}{ V/Vo } & $\begin{array}{c}\text { Specific } \\
\text { Volume, } \\
\left(\mathrm{cm}^{3} / \mathrm{g}\right)\end{array}$ & \multicolumn{1}{|c|}{} \\
\hline 0.0 & 35.793 & 5.410 & 39.5 & 1.0000 & 0.1849 & 0.0000 \\
\hline 0.888 & 21.782 & 8.889 & 0.6 & 0.6086 & 0.1125 & 0.64307 \\
\hline
\end{tabular}

Table A8d. Copper \#4, powder mass $=195.44 \mathrm{~g}$

\begin{tabular}{|l|l|l|l|l|l|l|}
\hline $\begin{array}{c}\text { Pressure } \\
(\mathrm{GPa})\end{array}$ & $\begin{array}{c}\text { Powder } \\
\text { Volume } \\
\left(\mathrm{cm}^{3}\right)\end{array}$ & $\begin{array}{c}\text { Bulk } \\
\text { Density } \\
\left(\mathrm{g} / \mathrm{cm}^{3}\right)\end{array}$ & $\begin{array}{c}\text { Porosity } \\
(\%)\end{array}$ & \multicolumn{1}{|l|}{ V/Vo } & $\begin{array}{c}\text { Specific } \\
\text { Volume, } \\
\left(\mathrm{cm}^{3} / \mathrm{g}\right)\end{array}$ & $\mathrm{Mu}$ \\
\hline 0.0 & 36.082 & 5.416 & 39.4 & 1.0000 & 0.1846 & 0.0000 \\
\hline 0.508 & 22.516 & 8.680 & 2.9 & 0.6240 & 0.1152 & 0.6027 \\
\hline
\end{tabular}


Table A8e. Copper \#5, powder mass $=195.32 \mathrm{~g}$

\begin{tabular}{|l|l|l|l|l|l|l|}
\hline $\begin{array}{c}\text { Pressure } \\
(\mathrm{GPa})\end{array}$ & $\begin{array}{c}\text { Powder } \\
\text { Volume } \\
\left(\mathrm{cm}^{3}\right)\end{array}$ & $\begin{array}{c}\text { Bulk } \\
\text { Density } \\
\left(\mathrm{g} / \mathrm{cm}^{3}\right)\end{array}$ & $\begin{array}{c}\text { Porosity } \\
(\%)\end{array}$ & \multicolumn{1}{|c|}{ V/Vo } & $\begin{array}{c}\text { Specific } \\
\text { Volume, } \\
\left(\mathrm{cm}^{3} / \mathrm{g}\right)\end{array}$ & $\mathrm{Mu}$ \\
\hline 0.0 & 36.276 & 5.384 & 39.8 & 1.0000 & 0.1857 & 0.0000 \\
\hline 0.321 & 25.475 & 7.667 & 14.2 & 0.7023 & 0.1304 & 0.4240 \\
\hline 0.321 & 25.349 & 7.705 & 13.8 & 0.6988 & 0.1298 & 0.4311 \\
\hline 0.411 & 22.823 & 8.558 & 4.3 & 0.6291 & 0.1168 & 0.5895 \\
\hline 0.508 & 22.564 & 8.656 & 3.2 & 0.6220 & 0.1155 & 0.6077 \\
\hline 0.696 & 22.665 & 8.618 & 3.6 & 0.6248 & 0.1160 & 0.6007 \\
\hline 0.888 & 22.446 & 8.702 & 2.7 & 0.6188 & 0.1149 & 0.6163 \\
\hline
\end{tabular}

Table A9. Foam \#1, mass $=5.3873 \mathrm{~g}$

\begin{tabular}{|l|l|l|l|l|l|l|}
\hline $\begin{array}{c}\text { Nominal } \\
\text { Pressure } \\
(\mathrm{GPa})\end{array}$ & $\begin{array}{c}\text { Powder } \\
\text { Volume } \\
\left(\mathrm{cm}^{3}\right)\end{array}$ & $\begin{array}{c}\text { Bulk } \\
\text { Density } \\
\left(\mathrm{g} / \mathrm{cm}^{3}\right)\end{array}$ & $\begin{array}{c}\text { Porosity } \\
(\%)\end{array}$ & \multicolumn{1}{|l|}{ V/Vo } & $\begin{array}{c}\text { Specific } \\
\text { Volume, } \\
\left(\mathrm{cm}^{3} / \mathrm{g}\right)\end{array}$ & $\mathrm{Mu}$ \\
\hline 0.0 & 37.591 & 0.143 & 88.5 & 1.000 & 6.978 & $2.000 \mathrm{e}-05$ \\
\hline 0.0050 & 36.874 & 0.146 & 88.3 & 0.9809 & 6.845 & 0.01947 \\
\hline 0.0075 & 20.010 & 0.269 & 78.5 & 0.5323 & 3.714 & 0.8787 \\
\hline 0.0100 & 13.923 & 0.387 & 69.0 & 0.3704 & 2.584 & 1.700 \\
\hline 0.020 & 4.4360 & 1.214 & 2.8 & 0.1180 & 0.8234 & 7.474 \\
\hline 0.030 & 4.4700 & 1.205 & 3.6 & 0.1189 & 0.8297 & 7.410 \\
\hline
\end{tabular}

Table A10a. Molybdenum \#1, powder mass = 132.91g

\begin{tabular}{|l|l|l|l|l|l|l|}
\hline $\begin{array}{c}\text { Pressure } \\
(\mathrm{GPa})\end{array}$ & $\begin{array}{c}\text { Powder } \\
\text { Volume } \\
\left(\mathrm{cm}^{3}\right)\end{array}$ & $\begin{array}{c}\text { Bulk } \\
\text { Density } \\
\left(\mathrm{g} / \mathrm{cm}^{3}\right)\end{array}$ & $\begin{array}{c}\text { Porosity } \\
(\%)\end{array}$ & \multicolumn{1}{|c|}{ V/Vo } & $\begin{array}{c}\text { Specific } \\
\text { Volume, } \\
\left(\mathrm{cm}^{3} / \mathrm{g}\right)\end{array}$ & $\mathrm{Mu}$ \\
\hline 0.00 & 36.979 & 3.594 & 64.8 & 1.000 & 0.2782 & 0.000 \\
\hline 0.0298 & 29.981 & 4.433 & 56.6 & 0.8108 & 0.2256 & 0.2334 \\
\hline 0.0649 & 26.397 & 5.035 & 50.7 & 0.7138 & 0.1986 & 0.4009 \\
\hline 0.143 & 22.110 & 6.011 & 41.2 & 0.5979 & 0.1664 & 0.6725 \\
\hline 0.233 & 19.879 & 6.686 & 34.6 & 0.5376 & 0.1496 & 0.8603 \\
\hline 0.324 & 18.523 & 7.176 & 29.8 & 0.5009 & 0.1394 & 0.9967 \\
\hline 0.510 & 16.883 & 7.873 & 23.0 & 0.4566 & 0.1270 & 1.191 \\
\hline 0.700 & 15.948 & 8.334 & 18.5 & 0.4313 & 0.1200 & 1.319 \\
\hline 0.891 & 15.457 & 8.599 & 15.9 & 0.4180 & 0.1163 & 1.393 \\
\hline
\end{tabular}


Table A10b. Molybdenum \#2, powder mass $=130.01 \mathrm{~g}$

\begin{tabular}{|l|l|l|l|l|l|l|}
\hline $\begin{array}{c}\text { Pressure } \\
(\mathrm{GPa})\end{array}$ & $\begin{array}{c}\text { Powder } \\
\text { Volume } \\
\left(\mathrm{cm}^{3}\right)\end{array}$ & $\begin{array}{c}\text { Bulk } \\
\text { Density } \\
\left(\mathrm{g} / \mathrm{cm}^{3}\right)\end{array}$ & $\begin{array}{c}\text { Porosity } \\
(\%)\end{array}$ & \multicolumn{1}{|l|}{ V/Vo } & $\begin{array}{c}\text { Specific } \\
\text { Volume, } \\
\left(\mathrm{cm}^{3} / \mathrm{g}\right)\end{array}$ & \multicolumn{1}{|c|}{$\mathrm{Mu}$} \\
\hline 0.00 & 36.343 & 3.577 & 65.0 & 1.000 & 0.2795 & 0.000 \\
\hline 0.0251 & 29.915 & 4.346 & 57.5 & 0.8231 & 0.2301 & 0.2150 \\
\hline 0.0606 & 25.926 & 5.015 & 50.9 & 0.7134 & 0.1994 & 0.4020 \\
\hline 0.144 & 21.762 & 5.974 & 41.5 & 0.5988 & 0.1674 & 0.6701 \\
\hline 0.229 & 19.525 & 6.659 & 34.8 & 0.5372 & 0.1502 & 0.8616 \\
\hline 0.317 & 18.224 & 7.134 & 30.2 & 0.5015 & 0.1402 & 0.9944 \\
\hline 0.509 & 16.603 & 7.830 & 23.4 & 0.4568 & 0.1277 & 1.189 \\
\hline 0.695 & 15.693 & 8.284 & 18.9 & 0.4318 & 0.1207 & 1.316 \\
\hline 0.889 & 15.087 & 8.617 & 15.7 & 0.4151 & 0.1160 & 1.409 \\
\hline
\end{tabular}

Table A10c. Molybdenum \#3, powder mass = 130.11g

\begin{tabular}{|l|l|l|l|l|l|c|}
\hline $\begin{array}{c}\text { Pressure } \\
(\mathrm{GPa})\end{array}$ & $\begin{array}{c}\text { Powder } \\
\text { Volume } \\
\left(\mathrm{cm}^{3}\right)\end{array}$ & $\begin{array}{c}\text { Bulk } \\
\text { Density } \\
\left(\mathrm{g} / \mathrm{cm}^{3}\right)\end{array}$ & $\begin{array}{c}\text { Porosity } \\
(\%)\end{array}$ & \multicolumn{1}{|c|}{ V/Vo } & $\begin{array}{c}\text { Specific } \\
\text { Volume, } \\
\left(\mathrm{cm}^{3} / \mathrm{g}\right)\end{array}$ & $\mathrm{Mu}$ \\
\hline 0.00 & 36.500 & 3.565 & 65.1 & 1.000 & 0.2805 & 0.0000 \\
\hline 0.892 & 15.161 & 8.582 & 16.0 & 0.4154 & 0.1165 & 1.4073 \\
\hline
\end{tabular}

Table A11. Ottawa Sand \#2, powder mass $=62.117 \mathrm{~g}$

\begin{tabular}{|l|l|l|l|l|l|l|}
\hline $\begin{array}{c}\text { Pressure } \\
(\mathrm{GPa})\end{array}$ & $\begin{array}{c}\text { Powder } \\
\text { Volume } \\
\left(\mathrm{cm}^{3}\right)\end{array}$ & $\begin{array}{c}\text { Bulk } \\
\text { Density } \\
\left(\mathrm{g} / \mathrm{cm}^{3}\right)\end{array}$ & $\begin{array}{c}\text { Porosity } \\
(\%)\end{array}$ & \multicolumn{1}{|l|}{ V/Vo } & $\begin{array}{c}\text { Specific } \\
\text { Volume, } \\
\left(\mathrm{cm}^{3} / \mathrm{g}\right)\end{array}$ & $\mathrm{Mu}$ \\
\hline 0.00 & 35.589 & 1.745 & 34.1 & 1.0000 & 0.5729 & 0.0000 \\
\hline 0.128 & 31.880 & 1.948 & 26.5 & 0.8958 & 0.5132 & 0.1163 \\
\hline 0.268 & 30.508 & 2.036 & 23.2 & 0.8572 & 0.4911 & 0.1668 \\
\hline 0.422 & 29.642 & 2.096 & 20.9 & 0.8329 & 0.4772 & 0.2011 \\
\hline 0.657 & 29.199 & 2.127 & 19.7 & 0.8205 & 0.4701 & 0.2189 \\
\hline 0.822 & 28.757 & 2.160 & 18.5 & 0.8080 & 0.4630 & 0.2378 \\
\hline 0.876 & 28.061 & 2.214 & 16.5 & 0.7885 & 0.4517 & 0.2688 \\
\hline
\end{tabular}


Table A12a. Silicon Carbide \#1, powder mass $=61.041 \mathrm{~g}$

\begin{tabular}{|l|l|l|l|l|l|l|}
\hline $\begin{array}{c}\text { Pressure } \\
(\mathrm{GPa})\end{array}$ & $\begin{array}{c}\text { Powder } \\
\text { Volume } \\
\left(\mathrm{cm}^{3}\right)\end{array}$ & $\begin{array}{c}\text { Bulk } \\
\text { Density } \\
\left(\mathrm{g} / \mathrm{cm}^{3}\right)\end{array}$ & $\begin{array}{c}\text { Porosity } \\
(\%)\end{array}$ & \multicolumn{1}{|c|}{ V/Vo } & $\begin{array}{c}\text { Specific } \\
\text { Volume, } \\
\left(\mathrm{cm}^{3} / \mathrm{g}\right)\end{array}$ & $\mathrm{Mu}$ \\
\hline 0.00 & 36.873 & 1.655 & 48.2 & 1.0000 & 0.6041 & 0.0000 \\
\hline 0.0704 & 32.773 & 1.863 & 41.7 & 0.8888 & 0.5369 & 0.1257 \\
\hline 0.145 & 32.389 & 1.885 & 41.0 & 0.8784 & 0.5306 & 0.1390 \\
\hline 0.315 & 27.286 & 2.237 & 30.0 & 0.7400 & 0.4470 & 0.3517 \\
\hline 0.315 & 27.443 & 2.224 & 30.4 & 0.7443 & 0.4496 & 0.3438 \\
\hline 0.507 & 26.045 & 2.344 & 26.7 & 0.7063 & 0.4267 & 0.4163 \\
\hline 0.695 & 25.459 & 2.398 & 25.0 & 0.6904 & 0.4171 & 0.4489 \\
\hline 0.882 & 24.972 & 2.444 & 23.5 & 0.6772 & 0.4091 & 0.4767 \\
\hline
\end{tabular}

Table A12b. Silicon Carbide \#3, powder mass $=60.577 \mathrm{~g}$

\begin{tabular}{|l|l|l|l|l|l|l|}
\hline $\begin{array}{c}\text { Pressure } \\
(\mathrm{GPa})\end{array}$ & $\begin{array}{c}\text { Powder } \\
\text { Volume } \\
\left(\mathrm{cm}^{3}\right)\end{array}$ & $\begin{array}{c}\text { Bulk } \\
\text { Density } \\
\left(\mathrm{g} / \mathrm{cm}^{3}\right)\end{array}$ & $\begin{array}{c}\text { Porosity } \\
(\%)\end{array}$ & \multicolumn{1}{|l|}{ V/Vo } & $\begin{array}{c}\text { Specific } \\
\text { Volume, } \\
\left(\mathrm{cm}^{3} / \mathrm{g}\right)\end{array}$ & $\mathrm{Mu}$ \\
\hline 0.00 & 36.007 & 1.682 & 47.4 & 1.0000 & 0.5944 & 0.0000 \\
\hline 0.0704 & 31.523 & 1.922 & 39.9 & 0.8755 & 0.5204 & 0.14269 \\
\hline 0.145 & 30.244 & 2.003 & 37.3 & 0.8399 & 0.4993 & 0.19084 \\
\hline 0.237 & 27.926 & 2.169 & 32.1 & 0.7756 & 0.4610 & 0.28954 \\
\hline 0.315 & 27.316 & 2.218 & 30.6 & 0.7586 & 0.4509 & 0.31867 \\
\hline
\end{tabular}

Table A12c. Silicon Carbide \#4, powder mass $=60.177 \mathrm{~g}$

\begin{tabular}{|l|l|l|l|l|l|l|}
\hline $\begin{array}{c}\text { Pressure } \\
(\mathrm{GPa})\end{array}$ & $\begin{array}{c}\text { Powder } \\
\text { Volume } \\
\left(\mathrm{cm}^{3}\right)\end{array}$ & $\begin{array}{c}\text { Bulk } \\
\text { Density } \\
\left(\mathrm{g} / \mathrm{cm}^{3}\right)\end{array}$ & $\begin{array}{c}\text { Porosity } \\
(\%)\end{array}$ & \multicolumn{1}{|l|}{ V/Vo } & $\begin{array}{c}\text { Specific } \\
\text { Volume, } \\
\left(\mathrm{cm}^{3} / \mathrm{g}\right)\end{array}$ & $\mathrm{Mu}$ \\
\hline 0.00 & 36.227 & 1.661 & 48.0 & 1.0000 & 0.6020 & 0.0000 \\
\hline 0.0629 & 31.334 & 1.920 & 39.9 & 0.8650 & 0.5207 & 0.1559 \\
\hline 0.147 & 28.912 & 2.081 & 34.9 & 0.7981 & 0.4804 & 0.2529 \\
\hline 0.237 & 27.499 & 2.188 & 31.5 & 0.7591 & 0.4570 & 0.3173 \\
\hline 0.319 & 26.694 & 2.254 & 29.5 & 0.7369 & 0.4436 & 0.3570 \\
\hline 0.511 & 25.858 & 2.327 & 27.2 & 0.7138 & 0.4297 & 0.4010 \\
\hline 0.694 & 25.580 & 2.352 & 26.4 & 0.7061 & 0.4251 & 0.4160 \\
\hline 0.886 & 24.919 & 2.415 & 24.4 & 0.6879 & 0.4141 & 0.4539 \\
\hline
\end{tabular}

Table A12d. Silicon Carbide \#5, powder mass $=60.525 \mathrm{~g}$

\begin{tabular}{|l|l|l|l|l|l|l|}
\hline $\begin{array}{c}\text { Pressure } \\
(\mathrm{GPa})\end{array}$ & $\begin{array}{c}\text { Powder } \\
\text { Volume } \\
\left(\mathrm{cm}^{3}\right)\end{array}$ & $\begin{array}{c}\text { Bulk } \\
\text { Density } \\
\left(\mathrm{g} / \mathrm{cm}^{3}\right)\end{array}$ & $\begin{array}{c}\text { Porosity } \\
(\%)\end{array}$ & \multicolumn{1}{|c|}{ V/Vo } & $\begin{array}{c}\text { Specific } \\
\text { Volume, } \\
\left(\mathrm{cm}^{3} / \mathrm{g}\right)\end{array}$ & $\mathrm{Mu}$ \\
\hline 0.0 & 36.238 & 1.670 & 47.7 & 1.000 & 0.5987 & 0.0000 \\
\hline 0.885 & 25.783 & 2.347 & 26.6 & 0.7115 & 0.4260 & 0.4054 \\
\hline
\end{tabular}


Table A13a. Titanium \#1, powder mass $=105.56 \mathrm{~g}$

\begin{tabular}{|l|l|l|l|l|l|l|}
\hline $\begin{array}{c}\text { Pressure } \\
(\mathrm{GPa})\end{array}$ & $\begin{array}{c}\text { Powder } \\
\text { Volume } \\
\left(\mathrm{cm}^{3}\right)\end{array}$ & $\begin{array}{c}\text { Bulk } \\
\text { Density } \\
\left(\mathrm{g} / \mathrm{cm}^{3}\right)\end{array}$ & $\begin{array}{c}\text { Porosity } \\
(\%)\end{array}$ & \multicolumn{1}{|c|}{ V/Vo } & $\begin{array}{c}\text { Specific } \\
\text { Volume, } \\
\left(\mathrm{cm}^{3} / \mathrm{g}\right)\end{array}$ & \multicolumn{1}{|c|}{$\mathrm{Mu}$} \\
\hline $1.00 \mathrm{e}-04$ & 36.399 & 2.900 & 35.7 & 1.0000 & 0.3448 & 0.0000 \\
\hline 0.0276 & 34.642 & 3.047 & 32.4 & 0.9517 & 0.3282 & 0.05069 \\
\hline 0.0642 & 32.945 & 3.204 & 28.9 & 0.9051 & 0.3121 & 0.1048 \\
\hline 0.144 & 30.407 & 3.472 & 23.0 & 0.8354 & 0.2880 & 0.1972 \\
\hline 0.232 & 28.662 & 3.683 & 18.3 & 0.7874 & 0.2715 & 0.2700 \\
\hline 0.323 & 27.371 & 3.857 & 14.4 & 0.7520 & 0.2593 & 0.3300 \\
\hline 0.504 & 25.952 & 4.068 & 9.7 & 0.7130 & 0.2458 & 0.4028 \\
\hline 0.694 & 25.278 & 4.176 & 7.3 & 0.6945 & 0.2395 & 0.4400 \\
\hline 0.887 & 24.565 & 4.297 & 4.7 & 0.6749 & 0.2327 & 0.4817 \\
\hline
\end{tabular}

Table A13b. Titanium \#2, powder mass $=105.30 \mathrm{~g}$

\begin{tabular}{|l|l|l|l|l|l|l|}
\hline $\begin{array}{c}\text { Pressure } \\
(\mathrm{GPa})\end{array}$ & $\begin{array}{c}\text { Powder } \\
\text { Volume } \\
\left(\mathrm{cm}^{3}\right)\end{array}$ & $\begin{array}{c}\text { Bulk } \\
\text { Density } \\
\left(\mathrm{g} / \mathrm{cm}^{3}\right)\end{array}$ & $\begin{array}{c}\text { Porosity } \\
(\%)\end{array}$ & \multicolumn{1}{|l|}{ V/Vo } & $\begin{array}{c}\text { Specific } \\
\text { Volume, } \\
\left(\mathrm{cm}^{3} / \mathrm{g}\right)\end{array}$ & $\mathrm{Mu}$ \\
\hline $1.00 \mathrm{e}-04$ & 36.375 & 2.895 & 35.8 & 1.0000 & 0.3455 & 0.0000 \\
\hline 0.0289 & 34.447 & 3.057 & 32.2 & 0.9470 & 0.3271 & 0.05596 \\
\hline 0.0702 & 32.826 & 3.208 & 28.8 & 0.9024 & 0.3117 & 0.1081 \\
\hline 0.148 & 30.263 & 3.480 & 22.8 & 0.8319 & 0.2874 & 0.2021 \\
\hline 0.232 & 28.691 & 3.670 & 18.6 & 0.7887 & 0.2725 & 0.2677 \\
\hline 0.318 & 27.212 & 3.870 & 14.1 & 0.7481 & 0.2584 & 0.3368 \\
\hline 0.505 & 26.104 & 4.034 & 10.5 & 0.7176 & 0.2479 & 0.3934 \\
\hline 0.701 & 25.067 & 4.201 & 6.8 & 0.6891 & 0.2381 & 0.4511 \\
\hline 0.890 & 24.504 & 4.297 & 4.7 & 0.6737 & 0.2327 & 0.4843 \\
\hline
\end{tabular}

Table A13c. Titanium \#3, powder mass $=105.17 \mathrm{~g}$

\begin{tabular}{|l|l|l|l|l|l|l|}
\hline $\begin{array}{c}\text { Pressure } \\
(\mathrm{GPa})\end{array}$ & $\begin{array}{c}\text { Powder } \\
\text { Volume } \\
\left(\mathrm{cm}^{3}\right)\end{array}$ & $\begin{array}{c}\text { Bulk } \\
\text { Density } \\
\left(\mathrm{g} / \mathrm{cm}^{3}\right)\end{array}$ & $\begin{array}{c}\text { Porosity } \\
(\%)\end{array}$ & \multicolumn{1}{|l|}{ V/Vo } & $\begin{array}{c}\text { Specific } \\
\text { Volume, } \\
\left(\mathrm{cm}^{3} / \mathrm{g}\right)\end{array}$ & $\mathrm{Mu}$ \\
\hline 0.00 & 36.419 & 2.888 & 35.9 & 1.000 & 0.3463 & 0.0000 \\
\hline 0.889 & 25.792 & 4.078 & 9.5 & 0.7082 & 0.2452 & 0.4121 \\
\hline
\end{tabular}

